\title{
WORKING PAPERS IN LITERACY, CULTURE, AND LANGUAGE EDUCATION (WPLCLE) VOLUME 1, 2012
}

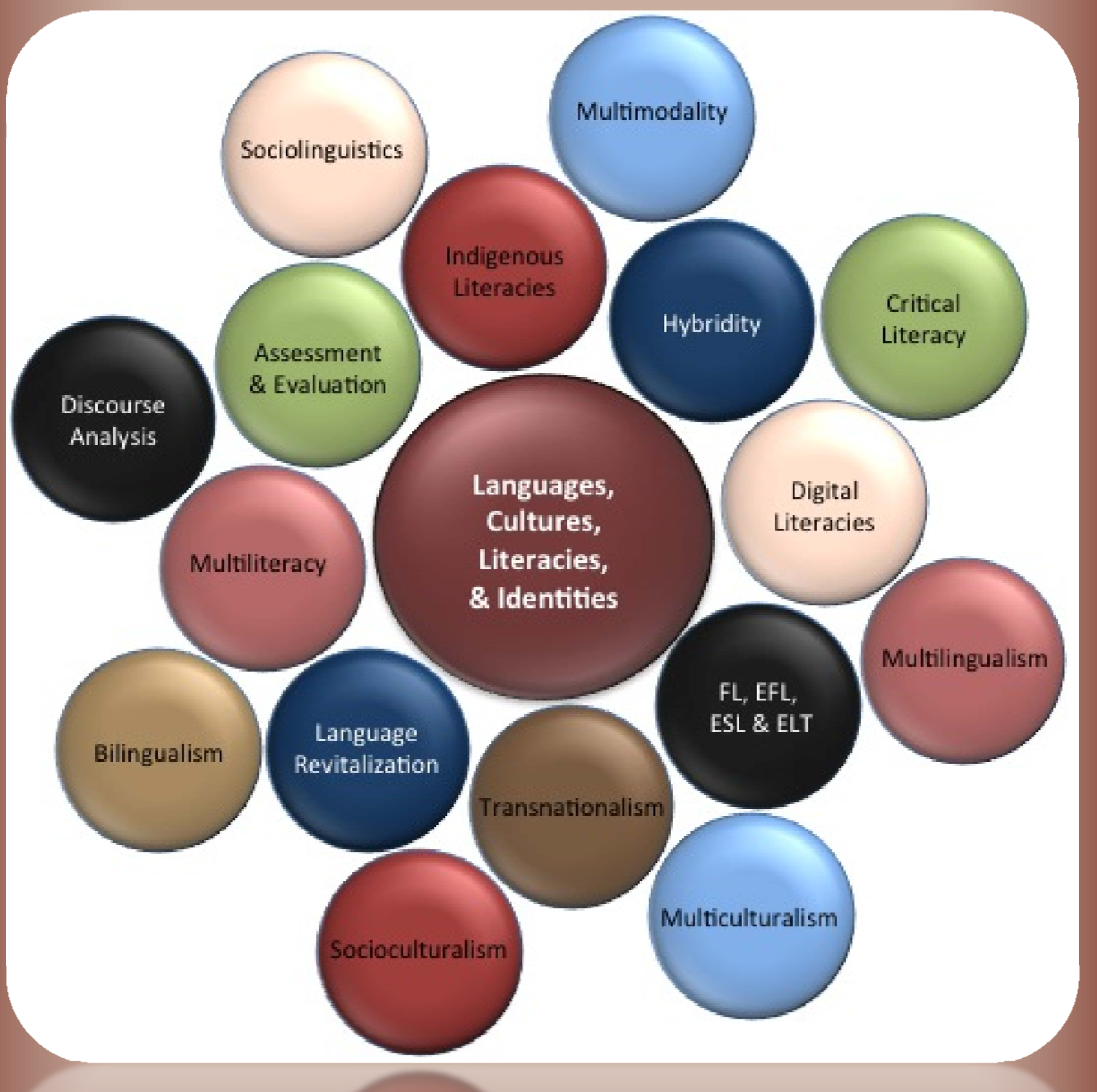

Department of Literacy, Culture, and Language Education School of Education Indiana University Bloomington 


\title{
EDITORIAL BOARD
}

\author{
Founder \& Editor-in-Chief \\ Serafín M. Coronel-Molina \\ Managing Editor \\ Bita H. Zakeri
}

\section{Assistants to the Editors}

Beth Buchholz

Alfreda Clegg

Ying-Sin Chen

Sang Jai Choi

Valerie Cross

Ophelia Hsiang-ling Huang

Hsiao-Chun Sandra Huang

Yi Chin Hsieh

Sheri Jordan

James Kigamwa

Hye-Kyung Kim
Hsiao-Chin Kuo

Yi -Ching Lee

Erin Lemrow

Jaehan Park

Stacy Penalva

Julie Rust

Bryce Smedley

Christy Wessel-Powell

Chi-Chuan Yang

Jae-Seok Yang

\section{ADVISORY BOARD}

Donna Sayers Adomat

Stephanie Carter James Damico

D. Ted Hall

Mary Beth Hines

Mitzi Lewison

Carmen Medina
Larry Mikulecky

Martha Nyikos

Faridah Pawan

Beth Lewis Samuelson

Raymond Smith

Karen Wohlwend

\section{WEBMASTERS}

Serafín M. Coronel-Molina Jaehan Park 
Copyright (C) 2012 Working Papers in Literacy, Culture, and Language Education (WPLCLE), and the respective authors.

All rights reserved. No part of this work may be reproduced in any form by any means, including photocopying and recording, or by any information storage or retrieval system (except for brief quotations in critical articles or reviews) without written permission from WPLCLE or the respective authors.

Working Papers in Literacy, Culture, and Language Education (WPLCLE)

School of Education, Indiana University

W.W. Wright Education Building

201 N. Rose Ave., Room \#3044

Bloomington, IN 47405-1006

Phone: (812) 856-8270

Fax: (812) 856-8287

E-mail: wplcle@indiana.edu

Website: http://education.indiana.edu/Home/tabid/13967/Default.aspx 


\section{Acknowledgements}

The Working Papers in Literacy, Culture, and Language Education (WPLCLE) is a project very near and dear to my heart. Despite the immense amount of time and effort I have spent in developing the concept, and formatting and editing this first volume, I could not have brought it to publication alone. Both the creation of the WPLCLE and the editorial process of the present volume are the result of the continued support, hard work, and dedication of many people. First of all, my profound gratitude goes to Mary Beth Hines, the former Chair, and Larry J. Mikulecky, the current Chair of the Department of Literacy, Culture, and Language Education (LCLE) for their kind support. They helped me present this case before the Executive Associate Deans of the School of Education at that time, Don Hossler and Jack Cummings, who graciously provided vital resources for the operations of the WPLCLE.

After I finished developing the content, Pratima Dutta and Jon Lawrence helped me design the website, and upload the initial content. Subsequently, I publicized this new publication venue widely, and recruited graduate student volunteers to fill key positions such as Managing Editor, Assistants to the Editors, and Webmasters. I was fortunate to find wonderful people who fulfilled their respective roles in WPLCLE exceptionally. My heartfelt thanks go to all of them for their dedicated collaboration. I am also deeply grateful to my colleagues in LCLE for agreeing to serve on the Advisory Board, and for their encouragement and moral support to make this initiative happen.

My special thanks go to Bita H. Zakeri, who provided me invaluable assistance in her role as Managing Editor, designed the cover of the present volume, and drafted the Introduction. I also owe a debt of gratitude to institutions, friends, colleagues, and social media venues from Indiana University and from around the world for their help in publicizing the WPLCLE Call for Papers locally and globally.

Last but not least, I am profoundly grateful to all the contributors to this volume for choosing WPLCE to publish their work. My deepest gratitude also goes to the Department of Literacy, Culture, and Language Education in the School of Education for hosting the WPLCE website and for supporting this new publication venue. Without the generous assistance of all these fine people and institutions, WPLCLE would never have become a reality, and this volume would never have seen light of day.

Bloomington, Indiana, March 5, 2012

Serafín M. Coronel-Molina 


\section{TABLE OF CONTENTS}

Contributors .vi

\section{Introduction}

Serafín M. Coronel-Molina \& Bita H. Zakeri 1

LANGUAGE, CULTURE, IDENTITY, AND BILINGUALISM 6

Inga Language and Culture Revitalization in Putumayo, Colombia

Valerie Cross \& Serafín M. Coronel-Molina

Background and Motivation of Students Studying a Native American Language at the University Level

Juliet L. Morgan

Complexities of Immigrant Identity: Issues of Literacy, Language, and Culture in the Formation of Identity

Bita H. Zakeri. 50

Students Writing across Cultures: Teaching Awareness of Audience in a Co-curricular Service Learning Project

Beth Lewis Samuelson \& James Chamwada Kigamwa.

The Curriculum as Cultures in Conflict: Exploring Monocultural and Multicultural Ideologies through the Case of Bilingual Education

Juanjuan Zhu \& Steven P. Camicia . 88

LITERACY STUDIES

One Story, Many Perspectives: Reading and Writing Graphic Novels in the Elementary Social Studies Classroom

Erica Christie.

Standard Written Academic English: A Critical Appraisal

Laura (Violeta) Colombo

A Skype-Buddy Model for Blended Learning Carmen E. Macharaschwili \& Linda Skidmore Coggin ....

Looking for Children Left Behind: American Language Policies in a Multilingual World Suparna Bose.. 
Literacy Programs for Incarcerated Youth in the United States

Diana Brace

ENGLISH AS A SECOND AND FOREIGN LANGUAGE

Strategy-Based Reading Instruction Utilizing the CALLA Model in an ESL/EFL Context Young-Mee Suh

The Challenges of Teaching and Learning English Literature in L2 Context: The Case of Junior Secondary Schools in Botswana

Deborah Adeninhun Adeyemi

The Effectiveness of Correcting Grammatical Errors in Writing Classes: An EFL Teacher's Perspective Hye-Kyung Kim

Undocumented Mexican Immigrants in Adult ESL Classrooms: Some Issues to Consider Sheri Jordan

\section{Book Review}

Language Learning and Teacher Education: A Sociocultural Approach, edited by Margaret Hawkings, Clevedon, UK: Multilingual Matters, 2004

Craig D. Howard. 


\section{Contributors}

Deborah Adeninhun Adeyemi holds a Doctor of Education degree from the University of South Africa (UNISA) in English Language Education. She is presently a senior lecturer in the Department of Languages and Social Sciences Education at the University of Botswana. Her Master of Education degree is from the University of Botswana in English Language Education, and she earned her BS in English Education from Indiana University, Bloomington, USA. She specializes in Language in Education issues and pedagogy. Her publications have appeared in the Journal of the International Society for Teacher Education (JISTE), Journal of Educational Enquiry, New Horizons in Education, and Academic Exchange Quarterly, to mention a few.

Suparna Bose is currently a graduate student working on a Master's degree in Literacy, Culture, and Language Education in the School of Education at Indiana University, Bloomington. She is interested in English as a Second Language, multilingualism, multiculturalism, and race relations in the contemporary world. She is originally from India and holds a Master's degree in English Literature, specializing in the Renaissance. She has taught English literature and ESL in India, Singapore and Japan. She speaks English, Bengali and Hindi.

Diana Brace is a graduate student in the Literacy, Culture, and Language Education department. She holds a Bachelor's degree in Journalism and Mass Communication from the University of Iowa, as well as certification in secondary English and Journalism education from the same institution. Her research interests include adolescent literacies, critical literacy, literacy identities, social justice education, criminal justice reform, and how these interests intersect with education in the criminal justice system.

Steven P. Camicia is an Assistant Professor in the School of Teacher Education and Leadership at Utah State University. His research focuses on curriculum and instruction in the areas of perspective consciousness, social justice, global education, and democratic decision making processes.

Linda Skidmore Coggin is a doctoral student in Literacy, Culture, and Language at Indiana University, Bloomington. Her research interests include literacy learning through multiple modalities and children as producers of multimodal texts.

Laura (Violeta) Colombo holds a Master's in Intercultural Communication and she holds a doctorate in Language, Literacy and Culture from the University of Maryland, Baltimore County. Her research interests are academic writing in foreign languages, especially at the university level, and second language education. 
Serafín M. Coronel-Molina is an Assistant Professor in the Department of Literacy, Culture, and Language Education at Indiana University, Bloomington. He is an educational linguist and sociolinguist. Dr. Coronel-Molina received his Bachelor's degree from Ricardo Palma University in Peru; his Master's degree from The Ohio State University, and his Ph.D. from the University of Pennsylvania. He has published articles in Quechua, English and Spanish, and has presented papers nationally and internationally. His research is of an interdisciplinary nature, drawing on fields as diverse as sociolinguistics, linguistic anthropology, literacy studies, policies and politics of language, pragmatics, and history of the Andes.

Erica M. Christie is a doctoral candidate in Curriculum and Instruction at Indiana University with a minor in Social Foundations of Education. The title of her dissertation is "Reorienting Service Learning: Teaching and Learning for Social Justice in an Elementary Classroom." She holds a Master of Science in Elementary Education from Indiana University and a Bachelor of Arts in Sociology from Bowdoin College. Erica previously worked as an elementary teacher in Indianapolis, Indiana. Her research interests include social studies education, service learning, curriculum integration, and critical literacy.

Valerie Cross is a Ph.D. student in the department of Literacy, Culture, and Language Education at Indiana University. She received her Bachelor's degree from Furman University in Spanish and Psychology, and her Master's in Teaching English to Speakers of Other Languages from Indiana University in 2007. Valerie has taught ESL at Indiana University and the Universidad de Oriente in Yucatan, Mexico. Her research interests include indigenous language maintenance, bilingual education, and language teacher development.

Craig D. Howard is a Ph.D. candidate at Indiana University in Instructional Systems Technology and the assistant editor of the International Journal of Designs for Learning. He holds a Master of Arts from Teachers College, Columbia University in TESOL, and has taught ESL at the City University of New York and EFL at Kanda University of International Studies in Chiba, Japan. His research focuses on developing methods for teaching discourse skills to both native and non-native speakers.

Sheri Jordan has taught adult ESL for over 15 years, mainly in adult education and university programs on the West Coast of the United States. She is currently finishing her coursework in the Literacy, Culture, and Language Education Ph.D. program at Indiana University. At IU, she has also taught Multicultural Education, Critical Literacy in the Content Areas, and other undergraduate and graduate courses in the School of Education.

James Chamwada Kigamwa is a Ph.D. Candidate in the Literacy, Culture, and Language Education Department at Indiana University. Prior to starting the doctoral program at IU, he was involved in regional literacy efforts in eastern Africa.

Hye-Kyung Kim is a doctoral candidate in the Department of Literacy, Culture, and Language Education at Indiana University. Before pursuing her doctoral degree in the US, she taught for almost ten years at the college level in South Korea. At IU, she has taught Socio/Psycholinguistic Applications to Reading Instruction and Instructional Issues in Language Learning for English Teachers. Her research interests include teacher education 
for non-native EFL/ESL teachers, bilingual education for EFL/ESL children, EFL/ESL teacher and learner identity, and issues of World Englishes.

Carmen E. Macharaschwili is a doctoral student in Literacy, Culture, and Language Education at Indiana University, Bloomington. Carmen teaches in the Education Department at Holy Cross College and for the Alliance for Catholic Education English as a New Language Program at the University of Notre Dame. Her research interests include technology in the classroom, bilingual education, family literacy, and cross-cultural literacy.

Juliet L. Morgan is currently pursuing a Master of Arts in Applied Linguistic Anthropology at the University of Oklahoma. She received a Bachelor's degree in Spanish and French from the University of Arkansas in 2009. In addition to researching the Native American language classes in higher education in Oklahoma, she is writing her thesis on the classificatory verb system in Plains Apache. She intends to graduate in Spring of 2012.

Beth Lewis Samuelson is an Assistant Professor of Literacy, Culture, and Language Education at the Indiana University School of Education, where she teaches classes in literacy theory and in the English as a Second Language and World Languages teacher education programs. She is an educational linguist with a strong background in language learning and cross-cultural experience in non-Western contexts. She was a 2006 Spencer/National Academy of Education Postdoctoral Fellow and a finalist in the 2006 National Council of Teachers of English Promising Researcher competition. Her research interests include language awareness and the flows of English literacy practices across global boundaries. She has particular interests in understanding the nature of metaknowledge about language and the role that it plays in literacy learning and communication. Dr. Samuelson received a 2012 Margot Stern Strom Teaching Award from Facing History and Ourselves.

Young-Mee Suh teaches undergraduate and graduate students in Korea, including theory and practice in secondary school English for pre-service and in-service teachers, general English reading for freshmen and sophomores, and vocabulary training for English major students. Her research interests include strategy-based language teaching and learning in an EFL context, material development for EFL classes, and training teachers for professional development.

Bita H. Zakeri is a doctoral student in Literacy, Culture, and Language Education at Indiana University. Her research interests include ESL/EFL research and literacy development in various cultures, with particular focus on immigrant identity, especially the ways in which immigrants negotiate identities in various social, political, and personal spaces. She is especially concerned with issues of equity, equality, and social justice. Her previous research backgrounds include $18^{\text {th }}$ - and19 th-century British Literature and early Eastern literature, as well as African-American literature. Her interest in literature partnered with her experiences as an ESL student and immigrant, interest in various cultures, and passion for teaching, are the driving forces behind her research in literacy studies.

Juanjuan Zhu is a doctoral student in Curriculum and Instruction at Utah State University. Her research interests are foreign/second language education, human rights education, and comparative analysis of citizenship education through language classrooms between China and the US. 


\section{Introduction}

\section{Serafín M. Coronel-Molina \\ Bita H. Zakeri}

The Working Papers in Literacy, Culture, and Language Education (WPLCLE) is an annual peer-reviewed online publication that provides a forum for faculty and students to publish research papers within a conceptual framework that values the integration of theory and practice in the field of Literacy, Culture, and Language Education. The mission of this journal is twofold: (1) to promote the exchange of ideas and dissemination of research, and (2) to facilitate academic exchange between students, faculty, and scholars from around the world.

Publications in WPLCLE are full-length articles dealing with the following areas of research: first- and second-language acquisition, macro- and micro-sociolinguistics in education, linguistic anthropology in education, language policy and planning from local and global perspectives, language revitalization, pragmatics in language teaching and learning, literacy, biliteracy and multiliteracy, hybrid literacies, bilingual education, multilingual and multicultural education, classroom research on language and literacy, discourse analysis, technology in language teaching and learning, language and gender, language teaching professional development, quantitative and qualitative research on language and literacy education, language related to curriculum design, assessment and evaluation, English as a foreign or second language, multimodal literacies, new literacies or electronic/media/digital literacies. Among other areas of publication interest of the WPLCLE are the New Literacy Studies, home and workplace literacy, indigenous literacies of the Americas, sociocultural approaches to language and literacy education, secondlanguage instruction and second-language teacher education, literacy as social practice, critical literacy, early literacy, practitioner inquiry/teacher research, children's literacy, African-American literacies, Latino/Hispanic literacies, cross-linguistic and cross-cultural literacy practices, heritage language and culture maintenance and loss, and local and global (transnational) literacies.

This volume marks the first collection of fourteen essays and one book review chosen from an array of submissions for our inaugural 2012 publication. The papers are organized thematically as follows: (1) Language, Culture, Identity, and Bilingualism; (2) Literacy Studies; and (3) English as a Second and Foreign Language. Within these thematic units, the articles are organized according to related topics.

The first thematic unit, Language, Culture, Identity, and Bilingualism, is comprised of five articles that together cover topics ranging transnationally from the Americas to Europe, the Middle East, and Africa. The first article of this section, entitled "Inga Language and Culture Revitalization in Putumayo, Colombia," is a collaborative work written by 
Valerie Cross and Serafín M. Coronel-Molina. This essay discusses the rise of and concern with Quechua language maintenance due to an increase in Quechua-Spanish bilingualism and the use of Spanish within indigenous communities and classrooms. Based on research in second language acquisition (SLA), language revitalization, and intercultural bilingual education, this work highlights suggestions to improve recent efforts to overcome the many overt and covert challenges to bilingual education implementation in Putumayo, Colombia. This article attempts to bring such forms of resistance to the surface and provide suggestions for overcoming them, in hopes of facilitating the grassroots-initiated language policy and planning goals of cultural revitalization and language shift reversal that are already in place.

The second article, "Background and Motivation of Students Studying a Native American Language at the University Level," by Juliet Morgan, follows first- through fourthsemester university-level Native American language learners at the University of Oklahoma. The data for this study was collected through a survey designed to discover who is enrolling in Cherokee, Cheyenne, Choctaw, Muscogee Creek, and Kiowa at the University of Oklahoma, and why these individuals choose to study these languages. The study works toward an understanding of whether these students are motivated by integrative or instrumental factors and how understanding these students' backgrounds and motivations can inform teaching methods.

The third article, "Complexities of Immigrant Identity: Issues of Literacy, Language, and Culture in the Formation of Identity" by Bita H. Zakeri, is primarily concerned with the social struggles of immigrant and ESL students with language, identity, and culture. This work discusses some of the major hurdles faced by immigrants in English-speaking societies and in academic institutions as they struggle to adapt to a new social sphere, and change, lose, and gain new identities. Using autoethnographical data and literature in this area, Zakeri discusses issues of immigrant identity and literacy from a twofold perspective: (a) a lack of attention to immigration and acculturation phenomena; and (b) the importance of understanding immigrant students' experiences and the need for diversification of teachers and teaching methods.

The fourth article, "Students Writing across Cultures: Teaching Awareness of Audience in a Co-curricular Service Learning Project" by Beth Lewis Samuelson and James Chamwada Kigamwa, examines a model for out-of-school literacy instruction using available linguistic and cultural models for teaching audience awareness across cultures. The literacy model described engages undergraduate and secondary students in a crosscultural story-telling exchange and calls for anticipating the needs of young readers who do not share linguistic or cultural backgrounds. Samuelson and Kigamwa outline the process of helping the writers to understand their Rwandan audience, and highlight some of the linguistic and cultural issues that arose in the early drafts and persisted throughout the editing process despite direct feedback. Through workshops they discussed available linguistic and cultural designs; in their research, they track some of the responses of the writers. The paper closes with examination of a story from the third volume for evidence that the writers had addressed the needs of the Rwandan readers in their stories.

The fifth article, "The Curriculum as Cultures in Conflict: Exploring Monocultural and Multicultural Ideologies through the Case of Bilingual Education" by Juanjuan Zhu and 
Steven P. Camicia, argues that curriculum contentions are cultural struggles. To illustrate this issue, they examine contention surrounding which and how languages are taught in the curriculum. Zhu and Camicia locate this struggle within their positionalities, as a departure point for their analysis of competing ideologies surrounding language and curriculum. Using a dialogical methodology to examine tensions between monocultural and multicultural ideologies, the authors provide an illustration through an imaginary dialogue between them, Eric D. Hirsch, and Mikhael Bakhtin. Based on the struggles located in the bodies of the authors and the imaginary dialogue of two cultural theorists, they conclude that a monological curriculum represents the domination of one cultural group over others, rather than confirming the pedagogical and social rationales provided by opponents of multilingual education.

The second thematic unit of this volume, called Literacy Studies, is composed of six articles that cover a spectrum of issues in this area. The first of the articles in this section (effectively the sixth of the issue), entitled "One Story, Many Perspectives: Reading and Writing Graphic Novels in the Elementary Social Studies Classroom," by Erica Christie, examines the ways elementary students understand and retell a complex social studies story using multiple textual formats. Third-grade students were exposed to a picture book and graphic novel version of the true story of Alia Muhammad Baker, a courageous Iraqi librarian. After reflecting on the texts, students re-narrated the story; many chose to write graphic novels. Students expressed high levels of interest in graphic novels, exhibited new perspectives on the Iraq War and active citizenship, and utilized key features of graphic novels to tell complex and multilayered social stories.

The seventh article is entitled "Standard Written Academic English: A Critical Appraisal," by Laura (Violeta) Colombo. In this essay, Colombo applies the postulates of Gramsci, Bourdieu and Canagarajah to show how dominant structures are reproduced in scientific communication worldwide. Colombo argues that these structures do not allow nondominant epistemologies and ways of producing and communicating science to participate in the international arena. She proposes that a critical appraisal of each of the terms present in SWAE is the first step towards a more democratic conceptualization of science communication, where the standards are seen not only as innocuous means of communication but also as ideologically charged fictitious universals.

The eighth article, "A Skype-Buddy Model for Blended Learning," coauthored by Carmen E. Macharaschwili and Linda Skidmore Coggin, explores the benefits of online learning. The authors discuss online learning in higher education and some of the challenges universities face in providing students with quality education experiences through distance learning, and meeting the students' needs for engagement and challenge within a collaborative framework. They propose ways that Voice over Internet Protocol (VoIP) could be used to provide face-to-face participation in a traditional classroom using a unique "Skype buddy" system. The authors examine experiences related to the satisfaction, benefits, challenges, and surprises of each of the participants (Skype buddies, professors, and other students in the class) in two doctoral seminars. 
The ninth essay, "Looking for Children Left Behind: American Language Policies in a Multilingual World" by Suparna Bose, discusses ramifications of the 2010 Census reports, a substantial increase in language-minority populations, and the atmosphere of distrust towards bilingual and bidialectal people felt by mainstream American society. The author examines the process of assimilation, immersion, and silencing of immigrant/minority cultures, resulting in the loss of their identity. Bose argues that the negative effects of this loss can be observed in lower self-esteem, lower grades, and rising school dropout rates of language-minority children today. She then recommends ways to increase the marketability of future American citizens, both monolingual and bilingual, in an era of globalization and the plurality of the English language.

The last article of the second thematic unit is "Literacy Programs for Incarcerated Youth in the US." This article, written by Diana Brace, collects and analyzes research on literacy programs in juvenile correctional facilities. Her research uncovers a troubled institution lacking resources and clear solutions. Brace suggests that this reveals the need for new approaches to research on incarcerated youths' literacy learning, and calls for research that investigates how the literacy identities of incarcerated youth can be utilized to increase literacy learning both within and outside the correctional facility. The author further suggests that this goal could best be achieved under a theoretical framework informed by the theories of Bakhtin, Freire, and Peck, Flower, and Higgins.

The third and final thematic unit, entitled English as a Second and Foreign Language, is composed of four articles. The first of these, article number eleven in the issue, is entitled "Strategy-Based Reading Instruction Utilizing the CALLA Model in an ESL/EFL Context," by Young-Mee Suh. It explores four English reading instructional approaches that are primarily used in ESL/EFL reading classes: Experience-Text-Relationship, Reciprocal Teaching Approach, Transactional Strategy Instruction, and the Cognitive Academic Language Learning Approach. Each reading approach is based on reading strategy instruction, and students are considered active learners in these paradigms. Targeting postsecondary school students whose English reading proficiency levels are between intermediate and high-intermediate, the author illustrates each stage of the CALLA instructional model and provides a sample lesson plan. ESL/EFL teachers may utilize the demonstration or the lesson plan in a real teaching situation to help learners be successful ESL/EFL readers while increasing their content knowledge and language proficiency.

The twelfth article, "The Challenges of Teaching and Learning English Literature in the L2 Context: The Case of Junior Secondary Schools in Botswana" by Deborah Adeninhun Adeyemi, discusses the ways various Motswana policy documents have advocated for an enlightened and well-informed society and the provision of a ten-year basic education as a fundamental human right of the country's citizens. It is against this background that the paper discusses the importance of English literature in the Junior Secondary School (JSS) curriculum and examines the challenges faced by teachers and students in the teaching/learning process that can hamper the achievement of the country's educational and social goals.

The thirteenth article, "The Effectiveness of Correcting Grammatical Errors in Writing Classes: An EFL Teacher's Perspective” by Hye-Kyung Kim, reveals that the role of grammar instruction to help students reduce errors in L2 writing is under debate: Truscott 
claims that error correction is largely ineffective and harmful, whereas Ferris argues that students need feedback on their grammatical errors. Kim emphasizes that grammar correction is considered to be one of the most important forms of feedback. This chapter examines the role of grammar correction in L2 writing on the basis of these controversies and discusses some pedagogical implications of error correction for teaching writing, with particular reference to her own experience of teaching EFL writing classes in South Korea.

The final article, "Undocumented Mexican Immigrants in Adult ESL Classrooms: Some Issues to Consider" by Sheri Jordan, argues that with anti-immigrant sentiments permeating the media, policy, and public discourse throughout the United States, little room seems to exist for understanding what drives Mexican migrants northward. Jordan frames her argument within a discussion of the historical conditions leading to US immigration policy, negative discourses and stereotypes in the American media and public, and continuing Mexican migration in spite of great sacrifice, and the choices of individuals to migrate to the US. Educators of adult ESL students need a framework, which the author outlines, as they encounter these students in the classroom. This framework combines Freire's "pedagogy of the oppressed" with a transformative pedagogy that relinquishes deficit models and invites student knowledge into the classroom.

This first volume of WPLCLE ends with a book review by Craig Howard on the book entitled Language Learning and Teacher Education: A Sociocultural Approach, edited by Margaret Hawkins. Howard provides an in-depth review of the articles in this collection, highlighting the book's value for researchers and practitioners of language teaching. 


\section{LANGUAGE, CULTURE, IDENTITY, AND BILINGUALISM}




\title{
Inga Language and Culture Revitalization in Putumayo, Colombia
}

\author{
Valerie Cross \\ Serafín M. Coronel-Molina
}

\begin{abstract}
Increasing levels of Quechua-Spanish bilingualism and increased use of Spanish within indigenous communities and classrooms have given rise to concern about Quechua language maintenance (Hornberger, 1988, 1998, 1999; Hornberger \& Coronel-Molina, 2004). The present investigation is preliminary and explores the possibility of bilingual intercultural education to promote Quechua (Inga) language revitalization in the Putumayo region of Colombia. Because of the large role that schooling has played in the language shift process, Inga language revitalization efforts have focused on implementing use of the Inga language in schools. This paper offers suggestions based on research in second language acquisition (SLA), language revitalization, and bilingual intercultural education to improve recent efforts and overcome the many overt and covert challenges that exist to bilingual education implementation in Putumayo, Colombia. This article attempts to bring such forms of resistance to the surface and provide suggestions for overcoming them, in hopes of facilitating the grassroots-initiated language planning goals of culture revitalization and reversing language shift that are already in place.
\end{abstract}

\section{Introduction}

In the present context of cultural, economic, and political globalization, world languages with international status continue to gain perceived value, while local languages correspondingly lose value or "currency" in the global language market (McCarty, 2003). Increasing levels of Quechua-Spanish bilingualism and increased use of Spanish within indigenous communities and classrooms have given rise to concern about Quechua language maintenance (Hornberger, 1988, 1998, 1999; Hornberger \& Coronel-Molina, 2004). The present investigation is preliminary, as the authors have not yet conducted field work in the Putumayo region of Colombia. The authors draw on other Andean and bilingual research to explore the possibility of bilingual intercultural education to promote Quechua language revitalization in the Putumayo region of Colombia. More specifically, the paper is an attempt to portray the present linguistic and educational situation of Colombian Ingas, as well as to outline forms of resistance and possibility of bilingual Inga-Spanish education in Putumayo.

Following a brief overview of Quechua language shift, this paper focuses on the Inga context in Colombia. The historical role of schools in Inga communities, including their influence on language shift from Inga to Spanish, will then be addressed. Because of the 
large role that schooling has played in the language shift process, Inga language revitalization efforts have focused on implementing the use of the Inga language as a medium (versus as a school subject) in schools. The present paper focuses on the resulting bilingual education efforts in Putumayo, Colombia, highlighting some potential impediments in the present program and curricular design as well as various other forms of resistance to the efforts. Suggestions are made to improve the present bilingual education situation based on second language acquisition (SLA), language revitalization, and bilingual intercultural education research. While we acknowledge that there exist many overt and covert challenges to bilingual education implementation in Putumayo, this paper attempts to bring such forms of resistance to the surface and provide suggestions for overcoming them in hopes of facilitating the grassroots-initiated language planning goal of reversing language shift.

\section{Quechua Language Shift}

In the midst of comparable histories that include resisting years of European colonization attempts, similar experiences and challenges have emerged across diverse Quechuaspeaking communities. One such challenge has been the function of Spanish as a significant tool of colonization and its status as the national language of many of the countries where indigenous communities reside (Coronel-Molina, 1999, 2007; Hornberger, 1987). Language has served as an important means of preservation of Quechua culture and civilization as well as resistance against colonizing forces (Carlosama Gaviria, 2001). In the context of increased contact with the Spanish language in the last five centuries, trends of language shift toward use of Spanish and bilingualism have become increasingly prevalent (for a comprehensive definition and literature review of language shift, see Coronel-Molina, 2009).

Within many Quechua communities, Spanish is commonly learned at a young age, resulting in high levels of 'bilingualism,' understood here as native-like productive and receptive command of two languages. Generational differences in the occurrence of bilingualism among indigenous persons are vast and increasing in the context of recent escalation of contact with nonindigenous national populations, due to immigration as well as other factors (Coronel-Molina, 1999; Harvey, 1994; Hornberger, 2000). Quechua language maintenance has become an issue of concern in light of the recently increasing rates of language shift away from Quechua (Hornberger, 1988, 1998, 1999; Hornberger \& Coronel-Molina, 2004).

\section{Colombian Inga Context \\ Present Linguistic Reality}

According to Colombia's 2005 census (DANE, 2005), of Colombia's 41,468,384 total population, about $3.4 \%$ or $1,392,623$ are considered ethnically indigenous and represent a vast diversity of indigenous groups. According to DANE (2007), 64 American Indian languages are spoken in Colombia, representing 13 language families. Inga is one such language, and is spoken by Ingano populations found mostly in rural areas in and around the Putumayo department of southwest Colombia as well as in urban areas such as Bogotá. The ethnic population of Ingas is approximately 17,860, and the Inga language is one of 
many dialects of Quechua (Ethnologue, 2005). Inga, also known as Highland Inga, is spoken by approximately 16,000 people, 12,000 of whom reside in Colombia, mostly in and around the department of Putumayo in Colombia (Ethnologue, 2005). Ingas and other indigenous groups represent $21 \%$ of the total population in the department of Putumayo (DANE, 2005). Despite the laws that have been passed to protect the rights of indigenous languages, Spanish continues to be the official language in the state institutions of Colombia (Education Project, 2003).

\section{Inga Language Shift in the Putumayo Region}

Soler Castillo (2003) investigated degrees of bilingualism and indigenous (Inga) attitudes toward Spanish and the Inga dialect of Quechua in the rural Inga town of Santiago in the department of Putumayo, Colombia and in the urban area of Santafé in the department of Bogotá, Colombia. The comparison of these two locations resulted from hypotheses that the Ingas in Bogotá, most of whom migrated from Santiago, are losing their language and culture at an accelerated rate compared to their rural counterparts due to the increased contact with the city culture. In her research, Soler Castillo found similar generational trends in command of the Inga language in both locations. The adults (older than 26) are fully bilingual Inga-Spanish, and the youth (15-25 years) and children (9-14 years) are not considered fully bilingual because though they have good comprehension of Inga, they speak it infrequently. Adults have proficiency in both languages but prefer to speak Inga in the majority of contexts, and younger members prefer to use Spanish in almost all contexts. Despite the stark generational division in bilingualism and language use found among Inga Quechua speakers of these communities, Soler Castillo describes the general linguistic attitudes toward both Inga and Spanish as very positive across ages.

The recent shift toward use of Spanish over Inga in various contexts reflects political and cultural pressures and may be cause for concern in terms of Inga language preservation. Social dynamics and language choice are complicated even further for the many Ingas that migrate to urban areas in search of work (Soler Castillo, 2003). Due to greater contact with Spanish speakers, Inga families living in urban areas communicate mostly in Spanish or a form of Inga laced with Spanish loan words and syntax, whereas those in rural areas have a tendency to communicate in Inga (Education Project, 2003). Within families with higher education levels, as well as in families with one nonindigenous parent, Spanish tends to be the primary language spoken. Inga children raised in a household in which they have extensive contact with the grandparents or elders of the family have the highest probability of growing up bilingual (Education Project, 2003).

\section{Role of Schooling in Inga Language Shift}

The shift in language use from Quechua to Spanish is especially evident upon examination of the use of the two languages within indigenous classrooms. Schooling in colonial contexts is one specific domain where the dominant language is often instantiated at the expense of the indigenous languages present in the society (Coronel-Molina, 1999, 2007). Schools run by members of the colonizing society have historically served as a tool of colonization and have played an important role in promoting language shift toward the language of colonization (Carlosama Gaviria, 2001; Hornberger, 1987). Carlosama Gaviria (2001) describes the instantiation of schooling by members of the dominant, colonizing 
population as a tool of submission and integration of indigenous groups into the majority society. He claims that this colonizing attempt is realized through methods and strategies aimed at ridding indigenous pupils of their cultural identities in favor of adoption of the national majority culture, which is thought or claimed to be more civilized.

In light of the sociohistorical context of many indigenous populations, one can understand more completely the role that schools have historically had, and the embedded ideologies and expectations of the role of schools within communities. As most schools in these particular Quechua communities were founded for the sole purpose of teaching community members Spanish and were to be maintained as separate entities from the rest of the community, it is not surprising that all teaching has historically been conducted in Spanish and the school is ideologically and physically positioned on the periphery of the community. As has been observed in other Andean and non-Andean language revitalization contexts, such positioning can negatively affect student learning and deter indigenous community member involvement in education and curriculum planning affecting indigenous children (García, 2005; Harvey, 1994).

Schools in Inga communities in the Putumayo Valley of Colombia are no different from those highlighted above, having long been associated with colonization. Educational institutions have contributed to the hegemony of the Spanish language within the indigenous communities of Colombia. In the case of the Inga communities in the Putumayo region, the mission of assimilation has been enacted through boarding schools in which teaching is exclusively in Spanish, children are separated from their families and culture, and use of traditional Inga dress and the Inga language have been prohibited and replaced by mainstream Spanish language and culture (Education Project, 2003). As outlined by Fishman (1991), attempts to distance indigenous students from their culture can be a powerful tool in reducing symbolic power and agency, especially coupled with banning use of the native language (Bourdieu 1991). Schooling historically based on colonization and taught by nonindigenous outsiders had and continues to have many important implications for language medium and classroom curricula. As Carlosama Gaviria (2001) asserts, teaching in Colombia has been based on one model with the objective of "civilizing" and instructing the "Indian" about how to integrate into the national society.

Within the context of varying levels of bilingualism, both indigenous and nonindigenous teachers in Inga schools use Spanish as the mode of instruction. The Inga students from rural communities who do not know Spanish are at an early disadvantage in the Spanish-dominated educational system. As Hornberger (2006) points out based on research with Quechua communities in Puno, Peru, attribution of a naturally shy and reserved personality to Quechua children discounts and veils the possibility that these children may be quiet in the classroom due to the language barrier that many experience. The early disadvantage is evident in the frequent obligation of Inga-speaking students to repeat primary grades, especially the first year of school (Education Project, 2003). While some of these students do learn Spanish as a second language eventually (at least oral communication skills), the early schooling experiences in a language they do not understand coupled with the demand that they repeat grades are likely to contribute to negative school attitudes and a high drop-out rate. The frequent occurrence of early dropout among Inga schoolchildren may be reflected in the drastically higher population of 
students in the first grade (more than 100) and relatively few students enrolled in the sixth grade or beyond (less than 20) (Education Project, 2003).

\section{Language Revitalization}

Language policy and planning (LPP) efforts have been explored and theorized by many scholars in a variety of contexts (Canagarajah, 2005; Cooper, 1989; Fishman, 1991; Hinton \& Hale, 2001; Kaplan, 1994; Kaplan \& Baldauf, 1997; McCarty, 2011; Ricento, 2006, among others). Concern about language shift and death, and the possibility of reversing language shift and of revitalization of endangered languages have become a major focus in LPP research (Crystal, 2000; Fishman, 1991; Grenoble and Whaley, 2006; Hinton and Hale, 2001). Following Coronel-Molina's $(1999,2007)$ framework of language shift in particular social domains, language revitalization is defined by King (2001) as "the attempt to add new linguistic forms or social functions to an embattled minority language with the aim of increasing its uses or users" (p. 23). This notion of revitalization of languages that have been threatened or partially lost implies a situated context of multiple languages assigned unequal degrees of power or status. For these reasons, indigenous language planning must also incorporate planning for the other, often "dominant" language(s) present in the context (Hornberger, 2006; Karam, 1974). In contrast to the notion of language maintenance, which focuses more on maintaining and strengthening immigrant and indigenous languages, language revitalization requires deliberate efforts by the speakers of the language and tends to originate within the speech communities (Fishman, 1991; Hornberger, 2006). Hornberger and King (1996) also emphasize the necessity of involvement of present and future speakers of a language in the process of indigenous language revitalization, an involvement that must also be present in the implementation of multilingual education in indigenous contexts (see also Hornberger, 2006).

\section{Inga Language Revitalization}

Inga language revitalization efforts have emerged largely from the grassroots level, and the community-level concerns about reversing language shift and revitalizing the Inga language have been inextricably linked to cultural revitalization concerns. Also, language revitalization efforts in the Putumayo have centered around the incorporation of Inga in the community schools. For that reason, it is logical to examine the history of the efforts to change the schooling context along with the accompanying national policies that have supported these efforts. Cultural revitalization efforts will also be briefly addressed, followed by a section including a more critical examination of the bilingual education efforts in the Putumayo.

In the 1970s and 1980s, grassroots movements involved people within the Inga community voicing a need to establish their own educational system, one that is culturally relevant for indigenous students and which incorporates the Inga language in the curriculum. Musu Runakuna ("New People") is among the indigenous organizations that have called for research and support for improving education within their communities, and specifically for the incorporation of Inga in community schools (Tandioy Jansasoy, personal communication, November 3, 2008). This is often referred to as "etnoeducación" (ethno-education) in Colombia, and as Educación Intercultural Bilingüe ("Intercultural Bilingual Education") in other Spanish-speaking countries (Carlosama Gaviria, 2001). 
Addressing the lack of native Inga teachers and consequently the need for preparation of indigenous teachers followed.

Following the grassroots demands for educational policy change, the national government of Colombia passed numerous laws supporting indigenous education. The General Law of Education (Law 115 in 1994) in Colombia, which followed the Constitutional Reform of 1991, and Decree 804 (1995) provided an impetus for supporting improved education in the indigenous communities of Colombia (Ministerio de Educación Nacional, República de Colombia). The need and desire for educational improvements in indigenous communities, particularly in the Inga communities of the Sibundoy Valley, are clearly evident, but actual change and development is still in the beginning stages.

\section{Inga Culture Revitalization}

Underlying the possibility of language revitalization must be a unified community consciousness of the endangered status of the language, and efforts to revitalize must be initiated at the grassroots level (Coronel-Molina 1999, 2005, 2007; Hornberger \& King 1996, 1998, 2001). Grassroots support seems to be dependent upon a valuing of not only the indigenous language but also of the group's cultural practices. Fishman (1991) describes cultural dislocation as a disruption of traditional cultural practices often resulting in a decrease in collective control in communities. As previously mentioned, Fishman (1991) asserts that along with social and physical/demographic dislocations, cultural dislocations can contribute to a complicated language shift process resulting in the reduction of power and agency (Bourdieu, 1991). Because of the intricate link between indigenous language and cultural identity (Coronel-Molina \& Quintero, 2010; Hornberger, 1988; Hornberger \& Coronel-Molina, 2004; Howard, 2007; King, 2000), inherent in language revitalization (and multilingual education) efforts must be the promotion of valuing indigenous cultural practices and identity.

As mentioned above, Inga language revitalization concern and efforts are linked to cultural revitalization, with their success possibly interdependent. In this way, a precursor for success of bilingual programs which promote the teaching of Inga language and culture is promotion of Inga cultural revitalization. While national laws that promote and celebrate the ethnic diversity of Colombia abound, indigenous groups still experience much discrimination. Soler Castillo (2003) discusses the discrimination that Ingas experience in schools and communities in urban areas like Bogotá. On the grassroots level in both urban and rural communities, appreciation of the Inga culture must be shared in the face of globalization and the presence of national culture, before unified community support of bilingual education can flourish. This Inga cultural renaissance or revitalization has been promoted by various indigenous leaders and groups. The Musu Runakuna group has been instrumental in promoting the rights of Ingas and in renewing Inga cultural traditions within communities in the Putumayo since the 1980s (Tandioy Jansasoy, personal communication, November 3, 2008). In addition to petitioning the government and working for political rights, the Musu Runakuna has consulted elders of the community about cultural traditions which they have worked to restore. Along with cultural revitalization efforts, pockets of grassroots language planning efforts have emerged to promote Inga language education. 


\section{Bilingual Intercultural Education}

As schooling is one important domain which has been instrumental in promoting language shift away from indigenous language use in societies, the possible role of schools in promoting indigenous language revitalization must be considered (Hornberger, 2008; Hornberger \& King, 1996). With the prevalence of Spanish in the broader community and perception of a higher market value of the language, it is not surprising that the belief in the importance of Inga children learning Spanish is widespread. It has been observed that most Ingas who do learn predominantly through Spanish in school use Spanish more than Inga, and are usually lacking in both Inga and Spanish academic literacy and skills. The need for Inga to be used in schools serving Inga children has been established also, and a push for Inga-Spanish bilingual education in the Putumayo has surfaced.

Thus far, one Inga-Spanish bilingual school has been established in the Putumayo region, in the town of Santiago. The school is situated in a town where there have historically been two schools, one for girls run by nuns and another for boys run by the Maristas (male Catholic headmasters), both of which are still in place and serve many nonindigenous as well as indigenous students. The bilingual school was implemented within the last five years and is called "Ingapa wasi Carlos Tamoabioy," translated as "The Carlos Tamoabioy Ingas' School." The school currently serves about 70 students, male and female, in grades one through five, with the goal of extending the school to provide education through grade nine in the near future. The curriculum follows a typical transition model including a gradual progression from total Inga instruction in grade one to nearly total Spanish instruction in grade five. Spanish is first introduced in grade two, and instruction is to be 50 percent in both Inga and Spanish in grade three, followed by a decrease in use of Inga in grades four and five (Tandioy Jansasoy, personal communication, November 5, 2008).

Still, bilingual education efforts in the Putumayo seem to fall short of producing students with high levels of bilingualism or academic skills in either or both languages, perhaps due to insufficient support of Inga literacy, among other factors. Arguments based on second language acquisition principles claim that the development of both languages, including academic proficiency in them, would be better supported with a bilingual education program that provides adequate Inga L1 support in the classroom throughout schooling. While Spanish may continue to be used more in some domains, the subsequent increases in Inga interpersonal and academic language skills that students would obtain through schooling would likely contribute to the maintenance of the language.

In the next section, program design considerations are presented. Challenges and some possible solutions to Inga-Spanish bilingual education components including program design, materials development, and teacher training will be addressed. Second language acquisition research supporting the need for L1 academic support throughout bilingual schooling efforts will be presented, followed by intercultural bilingual education program types. Suggested program improvements are aimed at increasing the possibility of bilingual education to reverse language shift and contribute to Inga language revitalization. 


\section{Program Design Considerations}

\section{Supporting L1 Academic Literacy in Bilingual Education}

The assumption that academic literacy, known as Cognitive Academic Language Proficiency (CALP), is distinct from general communicative language development or Basic Interpersonal Communication Skills (BICS) is important for understanding language development via schooling (Cummins, 1981). Unlike the language used in informal interpersonal communication, formal language in oral and written academic classroom tasks is thought to require the generation of more complex syntax, more cognitively demanding manipulation of language, and less contextual support (Chamot \& O'Malley, 1994; Cummins, 1982; 1996; Wright \& Kuehn, 1998). According to this distinction, a student can develop interpersonal communicative skills in a second language but not develop the academic skills in that language necessary for high academic achievement. Researchers also seem to agree that the ability to understand and use academic language in the classroom positively correlates with student academic achievement in both the L1 (first language) and L2 (second language) (Chamot \& O'Malley, 1994; Collier, 1989). In the Inga example, just because a student learns Spanish communicative skills through schooling does not necessarily mean that the student will develop academic skills in Spanish.

Much research attests the importance of developing academic language proficiency in the L1 before learning it in the L2, and also demonstrates that academic skills or language learned through the L1 easily transfers to the L2 (Eisterhold Carson et al., 1990; Holm \& Dodd, 1996; Jiang \& Kuehn, 2001). If this research is substantiated, it would imply that Inga students would benefit more from beginning their schooling in their native Inga language and continuing to develop academic skills through Inga even when Spanish is added later. Previous experiences with literacy and schooling in the L1 logically affect students' potential in the development of L2 academic literacy. From early literacy experiences (presumably in the L1), children develop attitudes toward literacy, beliefs about what literacy entails, and strategies for learning literacy skills (Carson, 1992; Carson et al., 1990). These early experiences can transfer to literacy development in the L2 (Holm \& Dodd, 1996), or at least equip students with tools and resources to draw on in the development of literacy in a new language. Cummins (1989) found correlations between L1 and L2 academic proficiency to range from .60 to .80 and demonstrated that students' ability to read in the first language predicted their L2 reading ability. Although this only demonstrates a correlation, the implications are supported in further research.

In a study of a bilingual program for Navajo speakers in the US, students learned to read first in Navajo in kindergarten through grade 2, were then introduced to reading in English, and continued thereafter to have instruction in both Navajo and English (Rosier \& Farella, 1976). When compared with Navajo students who had only received academic literacy instruction in English, the students who learned to read first in Navajo outperformed the others in academic achievement in the English L2 more in each successive grade level and approximated national norms in English academic achievement by sixth grade. The cognitive development and content knowledge students have developed and continue developing in the L1 benefit these students when they are learning academic literacy in the L2. In addition to previous L1 academic literacy experience, the amount of continued L1 academic literacy development while learning the L2 also directly affects 
ultimate L2 academic literacy attainment (Jiang \& Kuehn, 2001; Lewelling, 1991; Swain, 1981).

The benefit of continued cognitive development that usually occurs with L1 support in the L2 classroom accounts for much of the L1 to L2 academic literacy transfer that has been observed (Bialystok, 1991; Collier, 1987, 1989, 1992; Collier \& Thomas, 1989; Cummins, 1981, 1991; Thomas \& Collier, 1995). Saville-Troike (1998) describes transfer as "a preexisting knowledge base for making inferences and predictions" (p. 5). According to this definition, it is logical that previous and continued cognitive development in the L1 in second language learning contexts impacts the potential for highly proficient L2 development. The importance of the opportunity for students in second language learning contexts to continue cognitive development through the L1 while learning the L2 has been highlighted in previous research. Among this research are studies supporting the idea that students may experience cognitive deficiencies in the L2 if their L1 language and literacy does not reach a certain threshold (Collier, 1987; Collier \& Thomas, 1989; Cummins, 1981, 1991; Thomas \& Collier, 1997). This claim is supported by researchers who attest that cognitive and academic development in the L1 can transfer to second language development (Collier, 1989, 1992; Genesee, 1994; Thomas \& Collier, 1997). If opportunities for continued cognitive development through the L1 are few or nonexistent in L2 academic learning, the cognitive and academic development that transfers to the L2 will be significantly diminished.

Many also assert that L1 content and conceptual knowledge can translate easily to the L2 when enough proficiency is attained in the language-another reason for the observed academic literacy transfer effect from L1 to L2. These claims would logically predict that continuing the development of content knowledge in the L1 while L2 proficiency is still limited will aid students in understanding complex concepts in the L2 later. This idea is tied to the cognitive development argument because when students are discouraged from drawing on and continuing development of background subject knowledge in their L1 while their L2 proficiency is developing, as with cognitive strategies in their L1, development in this arena is essentially delayed until the student gains more L2 proficiency (Collier, 1995). Hakuta (1990) presents the example that a child learning about velocity in Spanish should be able to transfer this knowledge to English without having to relearn the concept when provided with the necessary English vocabulary.

L1 literacy effects on L2 development may be delayed in the sense that they are not observable until a certain level of L2 proficiency is attained. Collier (1995) emphasizes that the complex cognitive development, background subject knowledge, and academic literacy skills learners have developed in their L1 will not show immediately in the L2, but rather with time as their L2 proficiency and literacy skills develop. This would be an example of positive L1 transfer. The lack of such skill and literacy development in the L1 would logically be predicted to lead to negative transfer to the L2, which would also be expected to surface later. Indeed, Collier (1995) reports that L2ers with limited L1 academic and cognitive development being schooled in a second language for part or all of the school day often do well in early grades (K through 2 or 3 ) but have trouble keeping up academically as the cognitive demands increase with successive grades. The disadvantages of lack of L1 development may go largely unnoticed until students reach higher levels of schooling or 
more academically challenging tasks, at which time the prospect of gaining highly developed L1 literacy will have been dramatically reduced. A strong case for the theoretical benefits of continued L1 academic literacy development deriving from students receiving some or all of their schooling through their L1 has been made. Suggestions for carrying out this claim in Inga-Spanish bilingual education with regard to program types will now be addressed.

\section{Bilingual Education Program Types}

Based on Hornberger's (1991) description of bilingual education models and program types, King (2004) discusses the two main models of bilingual education that have been implemented in South America. Programs designed primarily for indigenous students are referred to as "transitional models" based on the notion of using instruction in the L1 prior to or along with Spanish to transition students to L2 Spanish development. Arguments in support of these programs which utilize L1 instruction are that they better engage students with the school curriculum and support biliteracy development, which in turn promotes equality in the wider national society. However, such programs have also been criticized for promoting a "subtractive form of bilingualism" due to their heavy orientation towards transitioning the students to the use of Spanish, perhaps at the expense of their indigenous L1. Often in this educational environment in which Quechua is the L1 and Spanish is the L2, teachers emphasize Spanish acquisition, which supports a shift toward the dominant language and national culture.

"Enrichment" models of bilingual education describe the programs typically provided for high status or "elite" nonindigenous Spanish speakers in which usually English as a Foreign Language (EFL) is taught as the L2, and sometimes even used as the mode of instruction. These programs have been primarily reserved for nonindigenous populations and are said to be additive, in the sense that students learn an L2 viewed as a high status language as a means to enrich the students' educational and social opportunities. King (2004) claims that the approaches of the transition and enrichment models leave indigenous students with fewer educational opportunities, and describes a new bilingual education initiative implemented by an Ecuadorian indigenous group which incorporates aspects of the enrichment model in schools for indigenous students. The educational changes that have taken place in this Ecuadorian community resulted from localized planning by members within the community where language shift toward Spanish has resulted in most children being monolingual Spanish speakers. The objective of the new educational system is for indigenous (Quechua) speakers to attain a form of additive bilingualism like that offered in the nonindigenous elite schools via instruction of their heritage Quechua language as a second language. King argues that the new approach to bilingual education, along with language planning at the local level, provide the highest possibility for endangered language survival in the context of globalization threats.

The present curriculum model in the bilingual school in the Putumayo more closely resembles the transitional model, proceeding gradually from $100 \%$ in Inga to $100 \%$ in Spanish (Education Project, 2003). Inga is proposed to be used as the predominant language of instruction in grade one, followed by the introduction of Spanish in grade 2, instruction half in Spanish and half in Inga in grade 3, then a gradual decrease in Inga until 
only Spanish is used in grade 5 instruction. The curriculum here does not support L1 literacy development throughout schooling as the research suggests, which may hinder students' ultimate academic literacy achievement in both the L1 and the L2, as has been suggested. Also, the promotion of Inga language maintenance by the present model is questionable at best, and more enrichment-type models may be both applicable and beneficial to bilingual education initiatives in the Putumayo.

\section{Proposed Changes to the Inga-Spanish Bilingual Program}

According to the research presented in the previous section, Inga students would benefit from a bilingual program in which they begin their schooling in Inga and continue to develop academic literacy in Inga throughout the schooling process. After two years of schooling in Inga only, students could benefit from adding part of their schooling through Spanish, at which time their prior Inga academic literacy will be able to translate to Spanish. When their Spanish interpersonal communication proficiency has reached a certain threshold after three or four years, students should demonstrate higher academic literacy and achievement in both languages. In this way, students are able to maintain their native Inga language while simultaneously developing academic proficiency in Spanish, a characteristic of an enrichment-type program model.

Another consideration in the Inga context is total years of schooling offered. The proposed program may be more attuned to a system of schooling through grade 9 or higher, another change that has been proposed by the Inga bilingual education activists. In similar contexts, for example in Peru, where children generally do not stay in school past grade 5, indigenous parents have resisted bilingual education efforts in which Spanish is not introduced until grade 2 or 3 because of the low ultimate achievement students reach in Spanish. For this reason, until Inga-Spanish bilingual schooling is extended through grade 9 it may be beneficial to offer some Spanish as a second language instruction beginning in grade 1. Development of Inga and Inga-Spanish materials would be necessary for the implementation of this type of program and has proven difficult thus far. Materials development is one of many challenges to be addressed in the Inga context of bilingual education efforts.

Situated within a sociohistorical context in which many indigenous and nonindigenous members alike had long maintained the language ideology of the inherent superiority of Spanish over Quechua for academic purposes, the local language planning initiatives have met with resistance common to language revitalization efforts in similar contexts (Coronel-Molina, 2007, 2008; King, 2004). King (2004) highlights three common challenges faced by efforts to implement enrichment heritage bilingual education in indigenous communities: methods and materials development, reaching consensus about the dialect to be used in instruction, and attaining unity in language ideology and support across community members. The challenges of bilingual materials development and unity in community support in the Putumayo will be addressed in the next two sections. Examples of bilingual education efforts in Ecuador and Bolivia will be highlighted as examples which may shed light on possible avenues for Inga education in the Putumayo. 


\section{Bilingual Materials Development}

The development of materials and implementation of pedagogical methodology that is culturally relevant for Inga students, as well as resources for teachers, are important for implementing a bilingual education curriculum. Having materials in Inga and bilingual Inga-Spanish is critical for carrying out the suggested program design. In addition to maintaining some teaching in the students' native Inga language, the integration where possible of aspects of students' native cultures can also aid L1 and L2 literacy development by allowing students to draw on background knowledge from their native language and culture. Incorporating Inga culture in the education materials will not only facilitate the learning of language and academic literacy skills, but will also promote the valuing of Inga culture, an important part of the language revitalization process. Many communities and curriculum designers serving language minority students or seeking to produce bilingual students have realized the importance of incorporating native cultural elements and forms of knowledge into language or general education.

Some Inga community members have recognized the need to incorporate the Inga culture into bilingual education materials. One such instance is the case of Francisco Tandioy's project at Indiana University of creating an Inga-Spanish book based on Inga oral narratives. The other principal materials that have been created at Indiana University with Tandioy's help are a collection of units to teach the Inga language primarily through grammatical points and dialogues. This set of language lessons, translated from Inga to English and from Inga to Spanish, and designed to teach Inga as a foreign language to university students in the US, may not adequately serve Inga students at the primary level in Colombia. While the teachers and parents of the community seemed to receive these pedagogical materials well, many also expressed the need for more pictures and less writing to make it more suitable for the children (Tandioy Jansasoy, personal communication, December 18, 2008). Tandioy agrees and hopes to amend these materials, as well as create more materials in both Inga and Spanish based on Inga mythology, stories, and narratives. Of course, such materials development necessitates time and financial support. Lack of financial backing for such efforts has remained a powerful form of resistance to the implementation of Inga-Spanish bilingual education.

The case of Maori immersion in New Zealand demonstrates an extreme example of basing education on heritage linguistic and cultural knowledge and respect. A critical element of the success of the Maori immersion program described by Harrison (2005) is the support and contributions of the local Maori community for the program. Despite the constraints placed on the curriculum standards by the national Ministry of Education, the Waikato-Tainui tribal leaders used their constrained power to create an alternative credit system and incorporate a tribal knowledge base in the curriculum. Students observed tribal ceremonies, took field trips to important historical and cultural sites, and became experts in a tribal knowledge base determined by tribal community leaders and parents of the students. Although the context varies greatly from that of the Ingano context in Colombia, the completely functional bilingual and bicultural individuals that have participated in the program demonstrate the potential benefits of providing both native language and native culture support in schools. 
In her study of a Quechua-Spanish bilingual rural school in the department of Cochabamba in Bolivia, Hornberger (2006) observed a then-relatively new biliteracy curriculum established under the Bolivian National Education Reform of 1994. Some of the books provided by the Reform for every primary classroom include six "Big Books" in Spanish (with large pages and colorful illustrations), three of which are based on indigenous (Quechua, Aymara, and Guarani) oral traditions (p. 285). These L2 materials that incorporate indigenous cultural content are an example of contextualized material design, which can promote biliteracy development of indigenous students. "Given that, in the Bakhtinian sense, an individual develops a sense of self through incorporating the languages, dialects, genres, and words of others to which she has been exposed, this biliterate practice offers a familiar voice for indigenous children to incorporate in their own voices" (p. 286). This example provides support for the possibility of incorporating culturally relevant materials and curricula in indigenous schools which promotes both Quechua and Spanish literacy and the Quechua language, and could be applied more directly to the Inga context. Not surprisingly, such a practice is a contentious one that may be resisted by both indigenous and nonindigenous members who reject the merging of indigenous content with the Spanish language (Hornberger, 2006). (For more information about indigenous education in Bolivia, see López, 2005; Albó, 1995, 1999; Albó \& Barrios Suvelza, 2007. For bilingual education in Latin America, see López, 2006; López \& Rojas, 2006; López \& Sichra, 2008).

Much resistance to bilingual education efforts emerges at the national level in explicit forms such as unsupportive policies, or in implicit forms such as lack of financial backing of policies. In the case of the Sibundoy Valley, for example, bilingual education endeavors, including bilingual materials development in particular, are greatly hindered by the scarcity of financial support which oftentimes has been promised but not provided, or not well distributed, by Colombia's national government (Tandioy Jansasoy, personal communication, October 9, 2008). Some national government funding has been provided for the bilingual education project, and presently supports the salaries of the three indigenous teachers. Funding is insufficient, however, to adequately support bilingual Inga-Spanish material design and production. Insufficient funding serves as a form of resistance against bilingual education efforts, but may be overcome by bottom-up indigenous efforts of language planning. Such language planning is taking place within a group of Inga teachers and leaders from the town of Santiago who are dedicated to the promotion of biliteracy development of Inga students and the revitalization of the Inga language.

With the collaborative goal of producing fully bilingual and bicultural individuals with high levels of L1 and L2 literacy, curriculum design and language of medium must be carefully planned in designing a program that adequately serves the bilingual needs of students. Incorporating knowledge from the minority cultural background of the students can make the curriculum more accessible and relevant to students' experience, and promote valuing of the native culture. Also, the programs most successful at producing biliterate individuals assume that bilingual education works best when students' L1 is developed first or simultaneously with the second language, as in the Maori immersion and Bolivian Quechua-Spanish bilingual education examples. In addition to program design and 
material development considerations, community support for bilingual education efforts and bilingual teacher training are critical elements to consider.

\section{Community Support and Teacher Preparation}

Individual and often community-wide resistance to the introduction of Quechua as a mode of classroom instruction also persists in the department of Putumayo, greatly diminishing the success of bilingual education initiatives within and across communities. Resistance to restructuring the traditional curriculum in favor of a new system created by and for Inga people has been evidenced to varying degrees within different towns of the community. This lack of unity in a desire to change the educational system among the Inga towns has helped to perpetuate the traditional colonial-based system in which Spanish dominates as the mode of instruction in classrooms. Resistance toward a system of education created by Inga members can be seen in the rejection of the Inga education project (2003) proposal which was written by a group of indigenous teachers and leaders from the towns of San Andrés and Santiago, and submitted to the MEN in 2003 (Tandioy Jansasoy, personal communication, October 9,2008 ). The MEN refused financial support of the project on the grounds of insufficient funds available for distribution. Teachers-both indigenous and nonindigenous - and leaders, including Spanish priests, in other Inga towns also rejected the proposal, which was designed to apply to all Inga towns. Opponents expressed the desire to be in control of their own educational system and reserve their right to maintain the "traditional" (i.e., Spanish-based) educational system in their communities (Tandioy Jansasoy, personal communication, October 9, 2008).

Nonindigenous teachers commonly believe that there is no need for the Inga students to learn their own language, and they have been able to enforce this belief through the power assigned to them via membership in local and national teachers' unions (Tandioy Jansasoy, personal communication, October 9, 2008). Some indigenous teachers often resist a shift toward teaching in Inga (and teaching the Inga language), citing as the main reason the paucity of teaching materials in Inga and the abundance and accessibility of materials in Spanish. The creation of new materials and an overhaul of the traditional system may be seen by many as unnecessary and difficult due to a lack of resources and training on curriculum and materials development within Inga communities. Perception of a need to change the current educational system as well as sufficient means for training and materials seem to be prerequisites for the possibility of enacting a restructured curriculum in the Inga community schools.

The program of education and preparation of indigenous teachers in the Putumayo region was initiated by the Ministry of Education of Colombia in 1992 to fulfill constitutional mandates to support and develop indigenous education (ethno-education). By 2001, however, there were still no published reports about the program (Carlosama Gaviria, 2001). Indigenous teacher training in the Putumayo is still very much in the beginning stages of development, but has been addressed in literature by Carlosama Gaviria (2001) and in a collaborative educational project proposal for the creation of a bilingual intercultural educational institute submitted (but not approved) in 2003. Carlosama Gaviria (2001) continued a project started in 1990 by the MEN in which he investigated education and teacher preparation within the Inga department of Santiago in 
the Putumayo region of Colombia. The Musu Runakuna and other indigenous leaders are still working on developing the initiative to provide opportunities for Inga community members to receive quality teacher training (Tandioy Jansasoy, personal communication 2008). In addition to the training that many teachers receive at the normal schools in Colombia and elsewhere, additional training with regard to language acquisition and bilingual materials development and use would also contribute to the proposed bilingual education program reforms.

\section{Conclusion and Future Directions}

Language shift from Inga to Spanish has been an increasing reality in the Putumayo in recent decades. The education of Inga children mostly in Spanish by typically nonindigenous teachers who do not speak Inga has undoubtedly contributed to the shift. The accompanying lack of schooling through the native Inga language has also likely deprived Inga students of the possibility of developing literacy and academic skills in Inga or Spanish. The present paper is an attempt to show the current educational situation of the Colombian Inga children, including recent grassroots efforts to implement IngaSpanish bilingual education.

Bilingual education is in the early stages of development in the Putumayo Valley, and its future will depend on many factors analogous to those that have been observed repeatedly in implementations of bilingual education in other indigenous contexts. Challenges associated with indigenous bilingual education initiatives in the Putumayo Valley of Colombia abound, and increased support at both the national and local level is a precursor for more unified bilingual education implementation. Provision and success of bilingual programs in the Putumayo will continue to be influenced by national governmental support as well as support from community members in towns where biliteracy practices are implemented. Beginning with increased consciousness of the importance of revitalization and promotion of Inga language and culture within and among Inga communities, overturning long-established colonial educational practices in favor of indigenous-driven biliteracy education can and hopefully will be made possible.

Drawing on research from language revitalization, bilingual intercultural education, and second language acquisition, suggestions for improving bilingual education program design, materials, and teacher training in the Inga Putumayo context have been presented. Along with sources of resistance and suggestions for overcoming them, acknowledgement of the importance of a unified grassroots support for intercultural bilingual education initiatives as a precursor for success has been made. For schools in the Putumayo to possibly reverse language shift, teachers, parents, and community members must be unified in their support for the educational initiatives, and should be well informed about program and materials designs with the best chance of producing bilingual, academically proficient students. Ethnographic research in the Inga context could present a more grounded examination of the complex situation concerning language shift, language policy and planning, and the planning and implementation of bilingual education in the Putumayo. Future planning and implementation efforts should be coordinated with the parents, elders, and teachers of the communities in the Putumayo who have already engaged in a 
great deal of dialog regarding Inga language and culture revitalization, largely through the implementation of bilingual education for Inga children.

\section{References}

Albó, X. (1995). Bolivia plurilingüe: guía para planificadores y educadores. La Paz: UNICEFCIPCA.

Albó, X. (1999). Iguales aunque diferentes: hacia unas políticas interculturales y lingüísticas para Bolivia. La Paz: Ministerio de Educación, UNICEF-CIPCA.

Albó, X., \& Barrios Suvelza, F. X. (2007). Por una Bolivia plurinacional e intercultural con autonomías. La Paz: Programa de las Naciones Unidas para el Desarrollo.

Bialystok, E. (1991). Letters, sounds, and symbols: Changes in children's understanding of written language. Applied Psycholinguistics , 12, 75-89.

Bourdieu, P. (1991). Language and symbolic power. Cambridge, MA: Harvard University Press.

Canagarajah, A. S. (Ed.). (2005). Reclaiming the local in language policy and practice. Mahwah, NJ: Lawrence Erlbaum.

Carlosama Gaviria, J. A. (2001). Formación y capitación de docentes Ingas en etnoeducación - Santiago, Putumayo, Colombia. (Doctoral dissertation, Universidad Mayor de San Simón). Retrieved from http://bvirtual.proeibandes.org/bvirtual/docs/tesis/ proeib/Tesis Jesus Carlosama.pdf

Carson, J. E., Carrell, P. L., Silberstein, S., Kroll, B., \& Kuehn, P. A. (1990). Reading-writing relationships in first and second language. TESOL Quarterly, 24(2), 245-266.

Carson, J. G. (1992). Becoming biliterate: First language influences. Journal of Second Language Writing, 1(1), 37-60.

Chamot, A. U., \& O’Malley, J. (1994). The CALLA handbook. Reading, MA: Addison-Wesley.

Collier, V. P. (1987). Age and rate of acquisition of second language for academic purposes. TESOL Quarterly, 21, 617-641.

Collier, V. P. (1989). How long? A synthesis of research on academic achievement in second language. TESOL Quarterly, 23, 509-531.

Collier, V. P. 1992. A synthesis of studies examining long-term language minority student data on academic achievement. Bilingual Research Journal, 16(1-2), 187-212.

Collier, V. P. (1995). Acquiring a second language for school. Directions in Language \& Education, 1(4). Washington, DC: National Clearinghouse for Bilingual Education.

Collier, V. P., \& Thomas, W.P. (1989). How quickly can immigrants become proficient in school English? Journal of Educational Issues of Language Minority Students, 5, 26-38.

Cooper, R. (1989). Language planning and social change. Cambridge, UK: Cambridge University Press. 
Coronel-Molina, S. M. (1999). Functional domains of the Quechua language in Peru: Issues of status planning. International Journal of Bilingual Education and Bilingualism, 2(3), 166-180.

Coronel-Molina, S. M. (2005). Lenguas orginarias cruzando el puente de la brecha digital: nuevas formas de revitalización del quechua y el aimara. In S. M. Coronel-Molina \& L. L. Grabner-Coronel (Eds.), Lenguas e identidades en los Andes: perspectivas ideológicas y culturales (pp. 31-82). Quito: Abya Yala.

Coronel-Molina, S. M. (2007). Language policy and planning, and language ideologies in Peru: The case of Cuzco's High Academy of the Quechua Language (Qheswa Simi Hamut'ana Kuraq Suntur). Unpublished doctoral dissertation, University of Pennsylvania, PA.

Coronel-Molina, S. M. (2008). Language ideologies of the high academy of the Quechua language in Cuzco, Peru. Latin American and Caribbean Ethnic Studies, 3(3), 319-340.

Coronel-Molina, S. M. (2009). Definitions and critical literature review of language attitude, language choice and language shift: Samples of language attitude surveys. Bloomington, IN: Indiana University Scholar Works. Retrieved from https://scholarworks.iu.edu/dspace/bitstream/handle/2022/3785/DefinitionsCritical-Review-of-Topics-in-Sociolinguistics.pdf?sequence $=1$

Coronel-Molina, S. M., \& Quintero, V. (2010). The sociolinguistics of indigenous languages in South America. In M. Ball (Ed.), The Routledge handbook of sociolinguistics around the world (pp. 42-51). Oxford: Routledge.

Crystal, D. (2000). Language death. Cambridge, UK: Cambridge University Press.

Cummins, J. (1981). Age on arrival and immigrant second language learning in Canada: A reassessment. Applied Linguistics II, 2, 132-149.

Cummins, J. (1982). Tests, achievement, and bilingual students. Focus No. 9. Washington, DC: National Clearinghouse for Bilingual Education.

Cummins, J. (1989). Language and literacy acquisition in bilingual contexts. Journal of Multilingual and Multicultural Development, 10(1), 17-31.

Cummins, J. (1991). Interdependence of first- and second-language proficiency in bilingual children. In E. Bialystok (Ed.), Language processing in bilingual children (pp. 70-89). Cambridge, UK: Cambridge University Press.

Cummins, J. (1996). Negotiating identities: Education for empowerment in a diverse society. Ontario: California Association for Bilingual Education.

DANE. Censo General de Colombia. (2005). Retrieved from http://www.dane.gov.co/

Education Project. (2003). Proyecto educativo: Creación de la Institución Educativa Intercultural Bilingüe Inga Carlos Tamoabioy. Unpublished manuscript.

Eisterhold Carson, J., Carrell, P. L., Silberstein, S., Kroll, B., \& Kuehn, P. A. (1990). Readingwriting relationships in first and second language. TESOL Quarterly, 24(2), 245-266. 
Ethnologue. (2008). Retrieved from

http://www.ethnologue.com/show country.asp?name=colombia

Fishman, J. (1991). Reversing language shift. Clevedon, UK: Multilingual Matters.

García, M. E. (2005). Making indigenous citizens: Identity development and multicultural activism in Peru. Palo Alto, CA: Stanford University Press.

Genesee, F. (1994). Educating second language children: The whole child, the whole curriculum, the whole community. Cambridge, UK: Cambridge University Press.

Grenoble, L. A., \& Whaley, L. J. (2006). Saving languages: An introduction to language revitalization. New York: Cambridge University Press.

Hakuta, K. (1990). Bilingualism and bilingual education: A research perspective. Focus No. 1. Washington, DC: National Clearinghouse for Bilingual Education.

Harrison, B. (2005). The development of an Indigenous knowledge program in a New Zealand Maori-language immersion school. Anthropology \& Education Quarterly, 36(1), 57-72.

Harvey, P. (1994). The presence and absence of speech in the communication of gender. In P. Burton et al. (Eds.), Bilingual women: Anthropological approaches to second language use (pp. 164-179). Oxford: Berg.

Hinton, L., \& Hale, K. (Eds.). (2001). The green book of language revitalization in practice. San Diego: Academic Press.

Holm, A., \& Dodd, B. (1996). The effect of first written language on the acquisition of English literacy. Cognition, 59, 119-147.

Hornberger, N. H. (1987). Schooltime, classtime, and academic learning time in rural Highland Puno, Peru. Anthropology \& Education Quarterly, 18(3), 207-221.

Hornberger, N. H. (1988). Bilingual education and language maintenance: A Southern Peruvian Quechua case. Berlin: Mouton de Gruyter.

Hornberger, N. H. (1991). Spanish in the community: Changing patterns of language use in highland Peru. In C. A. Klee and L. A. Ramos-García (Eds.), Sociolinguistics of the Spanish-speaking world: Iberia, Latin America, United States (pp. 141-162). Arizona: Bilingual Press.

Hornberger, N. H. (1998). Language policy, language education, language rights: Indigenous, immigrant, and international perspectives. Language in Society, 27, 439-458.

Hornberger, N. H. (1999). Maintaining and revitalizing indigenous languages in Latin America: State planning vs. grassroots initiatives. International Journal of Bilingual Education and Bilingualism, 2(3), 159-165.

Hornberger, N. H. (2000). Bilingual education policy and practice in the Andes: Ideological paradox and intercultural possibility. Anthropology \& Education Quarterly, 31(2), 173-201. 
Hornberger, N. H. (2006). Voice and biliteracy in indigenous language revitalization: Contentious educational practices in Quechua, Guarani, and Maori contexts. Journal of Language, Identity, and Education, 5(4), 277-292.

Hornberger, N. H. (Ed.). (2008). Can school save indigenous languages? Policy and practice on four continents. London: Palgrave.

Hornberger, N. H., \& Coronel-Molina, S. M. (2004). Quechua language shift, maintenance, and revitalization in the Andes: The case for language planning. International Journal of Society and Language, 167, 9-67.

Hornberger, N. H., \& King, K. A. (1996). Language revitalisation in the Andes: Can schools reverse language shift? Journal of Multilingual and Multicultural Development, 17(6), 427-441.

Hornberger, N. H., \& King, K. A. (1998). Authenticity and unification in Quechua language planning. Language, culture and curriculum, 11(3), pp. 390-410.

Hornberger, N. H., \& King, K. A. (2001). Reversing Quechua language shift in South America. In J, Fishman (Ed.), Can threatened languages be saved? (pp. 166-194). Clevedon, UK: Multilingual Matters.

Howard, R. (2007). Por los linderos de la lengua: ideologías lingüísticas en los Andes. Lima, Peru: Institut Français d'Études Andines-IFEA; Instituto de Estudios Peruanos-IEP; Pontificia Universidad Católica del Perú-PUCP.

Jiang, B., \& Kuehn, P. (2001). Transfer in the academic language development of postsecondary ESL students. Bilingual Research Journal, 25(4), 417-436.

Kaplan, R. B. (1994). Language policy and planning in New Zealand. Annual Review of Applied Linguistics, 14, 156-173.

Kaplan, R. B., \& Baldauf, R. B., Jr. (1997). Language planning: From practice to theory. Clevedon, UK: Multilingual Matters.

Karam, F. X. (1974). Toward a definition of language planning. In Joshua Fishman (Ed.), Advances in Language Planning (pp. 103-124). The Hague: Mouton.

King, K. A. (2000). Language ideologies and heritage language education. International Journal of Bilingual Education and Bilingualism, 3(3), 167-184.

King, K. A. (2001). Language revitalization processes and prospects: Quichua in the Ecuadorian Andes. Clevedon, UK: Multilingual Matters.

King, K. A. (2004). Language policy and local planning in South America: New directions for enrichment bilingual education in the Andes. International Journal of Bilingual Education and Bilingualism, 7(5), 334-347.

Lewelling, V. W. (1991). Academic achievement in a second language. Washington, DC: ERIC Clearinghouse on Languages and Linguistics.

López, L. E. (2005). De resquicios a boquerones: la educación intercultural bilingüe en Bolivia. La Paz: PROEIB Andes; Plural. 
López, L. E. (2006). Cultural diversity, multilingualism and indigenous education in Latin America. In O. García, T. Skutnabb-Kangas, and M. E. Torres-Guzmán (Eds.), Imagining multilingual schools: Languages in education and globalization (pp. 238261). Clevedon, UK: Multilingual Matters.

López, L. E., \& Rojas, C. (2006). La EIB en América Latina bajo examen. La Paz: Banco Mundial; GTZ; Plural.

López, L. E., \& Sichra, I. (2008). Intercultural bilingual education among indigenous peoples in Latin America. In N. H. Hornberger (Ed.), Encyclopedia of language and education (pp. 295-309). Berlin: Springer.

McCarty, T. L. (2003). Revitalizing indigenous languages in homogenizing times. Comparative Education, 39(2), 147-163.

McCarty, T. L. (Ed.). (2011). Ethnography and language policy. New York: Routledge.

Ministerio de Educación Nacional, República de Colombia. Retrieved from http://www.mineducacion.gov.co/1621/propertyvalue-34389.html

Ricento, T. (Ed.). (2006). An introduction to language policy: Theory and method. Malden, MA: Wiley-Blackwell.

Rosier, P., \& Farella, M. (1976). Bilingual education at Rock Point-some early results. TESOL Quarterly, 10, 379-388.

Saville-Troike, M. (1998). Teaching and testing for academic achievement: Perspectives on an ill-structured domain. Unpublished manuscript.

Soler Castillo, S. (2003). Bilingüismo y actitudes lingüísticas de la comunidad indígena Inga ante el español y el inga. In A. Torres Torres (Ed.), Confines culturales y mestizaje: perspectiva histórico-geográfica. Cultura e intercultura en la enseñanza del español como lengua extranjera, monográfico de Espéculo. Barcelona: Universitat de Barcelona, Facultat de Filologia. Retrieved from http://www.ub.edu/filhis/culturele/inga.html

Swain, M. (1981). Time and timing in bilingual education. Language Learning, 31(1), 1-15.

Thomas, W. P., \& Collier, V. P. (1997). School effectiveness for language minority students. Washington, DC: National Clearinghouse for Bilingual Education.

Wright, E., \& Kuehn, P. A. (1998). The effects of academic language instruction on collegebound at-risk secondary students. Journal of Educational Opportunity, 17(1), 9-22. 


\title{
Background and Motivation of Students Studying a Native American Language at the University Level
}

\author{
Juliet L. Morgan
}

\begin{abstract}
This study examines the background and motivations of first through fourth semester university-level Native American language learners at the University of Oklahoma. A survey of ten questions collected data concerning demographic information, students' home language background, their favored classroom activities, motivations for taking the course, and intended future study of the language. The survey was designed to discover who is enrolling in Cherokee, Cheyenne, Choctaw, Muscogee Creek, and Kiowa at the University of Oklahoma, and why these individuals choose to study these languages. The analysis distinguishes heritage language learners from second language learners. The results of the study work toward an understanding of whether these students are motivated by integrative or instrumental factors and how understanding these students' backgrounds and motivations can inform teaching methods.
\end{abstract}

\section{Background and Motivation of Students Studying a Native American Language at the University Level}

The University of Oklahoma (OU) teaches five Native American languages (NALs) that fulfill college foreign language credit. These languages are Cherokee, Cheyenne, Choctaw, Muscogee Creek, and Kiowa. In my first semester as a Master's student at OU, I enrolled in a Cherokee language class. Later, I became the teaching assistant to the Native American Language Program, responsible for helping the instructors create course materials. Curious to understand who the students studying NALs are, I designed a ten-question survey on student language backgrounds, language learning motivation, and future intentions of language study, which I gave out to the students during the fall of 2010. To my knowledge, there have been no other studies on the background and motivations of university-level NAL students, a group of learners who are overlooked in the study of university language learners and in the discussion of language revitalization. A more informed understanding of their backgrounds and motivations can contribute to a better understanding of their language learning needs.

\section{Background}

The five languages involved in this survey are all spoken in Oklahoma. There are a total of forty NALs historically or currently spoken in Oklahoma, representing eleven language families. The large number of languages is due to the removal of many tribes to Indian Territory during the nineteenth century. For example, Kiowa and Cheyenne were spoken in 
Oklahoma pre-removal period, but the Cherokee, Choctaw, and Muscogee Creek tribes (among others) were forcibly removed to the Indian Territory. It is impossible for OU to offer all of the indigenous languages of Oklahoma, and as with other areas of high linguistic diversity, finding enough funding and support to teach a large number of endangered languages is a huge challenge. Since 1991, the University of Oklahoma has offered sustained funding and support for five Oklahoman NALs through the Native American Language Program. This year marks the twentieth year of teaching Cherokee, Choctaw, and Kiowa, while Muscogee Creek has been taught for eighteen years and Cheyenne for ten years.

All Oklahoman NALs are critically endangered. Of the forty NALs spoken in Oklahoma in 1900, 53\% (or 21 languages) have no fluent first language speakers left today (Linn, 2011). The Cherokee language (Iroquoian) has an estimated 8,000 native speakers, but no sustainable speaker population under 45 (Linn, 2011). Choctaw (Muscogean), the second most populous tribe, has an estimated 1,000 fluent speakers still in Oklahoma (Linn, 2011). Cheyenne (Algonquian) is estimated to have only 20 fluent speakers in Oklahoma today and Muscogee Creek (Muscogean) has approximately 3,000 fluent speakers over the age of 64 (Linn, 2011; Martin \& Mauldin, 2001). Kiowa (Kiowa-Tanoan) currently has approximately sixty fluent speakers left (Linn, 2011). The five languages taught at OU exemplify the diverse distribution of current NAL situations in Oklahoma.

A variety of interrelated reasons are identified as having a role in the decline of NAL use in the United States, including contact, colonization, warfare, forced relocations, and intermarriages with speakers of other languages (Hinton, 2008; McCarty, 2008). In the late $19^{\text {th }}$ and early $20^{\text {th }}$ centuries, boarding schools actively sought to erase indigenous languages and this period is often cited as one of the most prominent causes of language loss among Native Americans (McCarty and Zepeda, 2010). Today, assimilation into American society and the overwhelming amount of contact with English has greatly increased the rate of loss in many NAL communities. The endangered status of NALs gives them a unique position in language learning, and programs like the one at OU are rare.

The Native American Language Program at OU was started in 1991 in the Department of Anthropology. Originally, the program involved an elder native speaker and a professionally trained linguist teaching together in the classroom. Each language team had to create their own teaching materials and curriculum, as at that time there were no available textbooks or teaching materials. Even today, only Cherokee, Choctaw, and Muscogee Creek have published textbooks. The classes were originally offered at night and not for foreign language credit, making them more similar to community classes than typical university-level language classes. One of the major challenges to the program was creating enough materials to teach the classes for two semesters. After one year, the classes passed the application to be taught for undergraduate foreign language credit and moved to daytime hours, changes which attracted a larger number of students. The program evolved to have native speakers with previous teaching experience (such as teaching any subject in a public school or teaching community classes in the language) taking full control of teaching the classes.

At the time the survey was administered in fall 2010, the program as a whole offered four semesters of Cheyenne and Muscogee Creek and three semesters of Cherokee, 
Choctaw, and Kiowa. The first and second semesters of Cherokee, Choctaw, and Muscogee Creek are five hours per week while all of the other classes (all levels of Kiowa and Cheyenne and all third and fourth semester levels of all the languages) are three hours per week. Today the program has twelve instructors: three Cherokee, one Cheyenne, three Choctaw, two Muscogee Creek, and three Kiowa. All but four of the instructors are native speakers. Since its inception, the program's instructors have shifted from a team of elder native speakers and linguists to native speakers with teaching experience, and now the most recently hired instructors are younger, competent second language speakers and two of them have a degree or are getting a degree in language education. As the elder instructors retire the trend of hiring second language speakers may continue, especially given the small numbers and elderly ages of most native speakers in Oklahoma.

The decision to teach Native languages is not simple. Nonimmersion classes offered to adult learners are not expected to be successful in creating new speakers of the language (Hinton, 2011). While the inclusion of NALs allows OU to better reflect the community in Oklahoma, the choice to teach entirely outside of the community comes with its own challenges. Like Ojibwe classes at Michigan State University, the placement of these classes at the university removes the classes, instructors, and resources from the community and takes the learning process out of community contexts (Morgan, 2005). However, teaching NALs at institutions of higher education is still important. These classes may not be producing new speakers, but they are producing teaching materials, which preserve and document the languages, and they raise awareness among young adults of the endangered status of NALs. Additionally, these classes recognize NALs as a part of university-level learning, bringing the NAL into a new domain and making it a part of the everyday life of these young adults. The classes show that NALs can be taught at universities and that young nonnative speakers can teach them there.

\section{NALs in Language Learning}

Before understanding the results of this research, the novelty of studying and teaching endangered NALs at the university level must first be emphasized. Partly due to this novelty, the position of these languages in the theory of language learning is still under debate. Arguments have been made to include them in second language learning, heritage language learning, or to create a new model of heritage mother tongue or ancestral language learning (Carreira, 2004; Hinton, 2011; McCarty, 2008; White, 2006). These languages have been put in such a variety of categories because of the diverse situations of the 175 NALs spoken in the United States. Each category is applicable and valuable for some communities. Consider, for example, the different resources available to Cherokee with 8,000 native speakers and Cheyenne with only 20. There are common issues that all Native American communities share, especially the tie to a Native American identity and the pressures of simultaneously preserving and passing on the language. Based on the information gathered through the survey, some of the participants' backgrounds and motivations in this study allow them to be grouped as heritage language learners.

Heritage language learners have a familial connection and/or previous linguistic background with the language, while second language learners (L2Ls) may be anyone learning a language which is not their mother tongue. The term heritage language learner 
(HLL) is just starting to develop a concrete definition, with the debate centering on whether the learner's level of linguistic proficiency or association with an ethnic identity/community is more important in determining his/her status as an HLL. For most language teachers, HLL refers to a student with a previously developed proficiency in the language via their home environment (Valdés, 2001). However, the term is also being applied to NAL learners, many of whom have never or rarely heard their language spoken, but who consider the language to be a deep part of their heritage and identity.

Carreira (2004) offers four categories of HLLs based on different levels of heritage language community involvement, familial background and ancestral connection with the heritage language community, and proficiency in the heritage language. Carreira's four categories describe learners who are defined by their membership in the heritage language community regardless of their linguistic proficiency (HLL1s); learners who are defined primarily by their familial or ancestral background, not by their present primary membership in the heritage language community (HLL2s); learners who are bilingual and defined only by their level of linguistic proficiency (HLL3s); and learners with some knowledge of the heritage language, but whose community membership is often questioned because of their lack of proficiency in the language (HLL4s).

Carreira's four subcategories of HLLs do not exactly line up with the results of this survey, but her three criteria for classifying HLLs based on community membership, familial background, and linguistic proficiency can be used to identify participants in the survey who may have needs more like those of HLLs. The results of the question about previous exposure to the language, in combination with student responses to the question on motivation, can identify a subgroup of students who are taking the course out of a desire to better connect with family or community members who speak the language, who are taking the course because they have Native American ancestry, and/or who have had previous exposure to the language in their home. Students who have any or all of these three traits may be HLLs and this particular subgroup of participants will be given special attention in examining the results of the survey.

The subgroup of HLLs can be further divided into a "narrowly" defined group (those with connections to the NAL community or NAL-speaking family members or previous exposure to the NAL in their home) and a "broadly" defined group (those with only Native American ancestry). These categories are very similar to the narrow and broad categories of HLLs used by Reynolds, Howard, and Deák (2009) in their study of HLLs. Based on their backgrounds and motivations, the narrow HLLs are more likely to be actively involved with the NAL community and are similar to Carreira's HLL1s. The broad HLLs are similar to Carreira's HLL2s and have also been called "learners with a heritage motivation" because they often enroll in language courses to find a connection with their ancestral identity, whereas the narrow HLLs are reinforcing a pre-existing identity (Carreira, 2004).

HLLs are difficult to define because the definition must include the large variety of learners who may be identified as HLLs, and at the same time differentiate HLLs from L2Ls by focusing on their unique needs. NAL learners are also difficult to situate in current language learning paradigms because their situations are so diverse. While they have needs that are similarly unique to HLLs, particularly identity/linguistic needs that stem from their family background (Carreira, 2004), they also have needs unique only to 
learners of endangered languages. NALs are learned by students who have a recent or remote heritage and existing or potential identity connected to the language, which may or may not be spoken in the home or community (or even at all) and which is currently facing endangerment. With this constant threat come certain responsibilities and pressures which only language teachers and learners of endangered languages experience. The following discussion of the results of the survey seeks to categorize NAL students in order to identify the types of learners present in NAL classrooms. Understanding the types of learners in the classroom, and what learning needs these types of learners have, is invaluable to instructors, and specific pedagogical implications are further discussed in detail at the end of this article.

\section{Motivation}

The importance of student motivation in language learning was originally introduced under L2 acquisition theory, but it is also studied in HLLs (see, for example, Reynolds et al., 2009). Motivation is usually described as a combination of effort and desire to achieve the goal or fulfill the need of learning the language, plus favorable perceptions or attitudes towards learning the language, plus a belief in the likely success of learning the language (Gardner, 1985; Saville-Troike, 2006). Most of the previous motivation studies in L2 acquisition and HL learning research have been concerned with commonly taught languages, such as Spanish (Hernández, 2008; Mandell, 2002). In one study with HLLs of nineteen different languages, the researcher found that the desire "to connect with my family" and "to understand my heritage" were key motivators for narrowly defined HLLs, but not for broadly defined HLLs or non-HLLs (Reynolds et al., 2009). Past research has found that L2Ls and HLLs typically have different orientations of motivation, and the results of this study suggest that NAL students similarly have different motivation orientations depending on if they are HLLs and whether they are broadly or narrowly defined HLLs.

In 1959, Gardner and Lambert introduced the integrative and instrumental orientation model of language learning motivation and these have remained important concepts in L2 motivation studies. Integrative motivation describes a student who has a positive opinion of the language and its culture, to the extent that the student may wish to integrate linguistically or culturally with the target language group (Ueno, 2005). Instrumental motivation describes a student who is focused on the practical usefulness of the language or another pragmatic benefit to be attained through studying the language, such as economic or social advancement (Ueno, 2005). Unlike integrative motivation, instrumental motivation does not involve interest or identification with the target language community (Ueno, 2005). The ten motivators included in this survey are divided into instrumental and integrative factors in Table 1 (see Appendix).

White (2006, p. 96) notes that traditional instrumental motivations (academic and economic advancements) do not apply to NAL learners, but I disagree. In order to be applicable to NAL learners, motivators have to be refocused to a more local context. For example, NAL learners may be motivated by local academic advancements such as fulfilling the foreign language requirement. Additionally, one student indicated that she was studying Choctaw because it would be "professionally advantageous," another traditionally 
instrumental motivator, and noted that she believed this to be in the context of seeking a job with the Chickasaw Nation (Choctaw and Chickasaw are closely related languages). Thus, NAL students can be instrumentally motivated in slightly different ways than traditional L2Ls, but still in terms of academic and economic advancements.

\section{Method}

The survey was approved by OU's Institutional Review Board and was distributed and collected by the researcher during the first few weeks of November 2010. Students were informed that participation in the study was voluntary and anonymous, and that participating or not had no effect on their grade. Due to university research restrictions, surveys completed by participants who were under 18 or over 55 were excluded from the results. Students completed the survey during a regular class meeting and typically finished within ten minutes. The full survey can be found at the end of the Appendix.

A total of 273 students enrolled in an NAL class at OU participated in the study. During the fall semester of 2010, Cherokee, Choctaw, and Kiowa classes of the first-, second-, and third-semester levels were offered, though the third-semester Cherokee classes did not participate in the study due to scheduling conflicts with the instructor. All four semester levels of Muscogee Creek were included in the study. Only one Cheyenne class was offered and so only the five students studying Cheyenne at the intermediate level are represented in this study. Table 2 (see Appendix) summarizes the participants by languages and semester levels. The total enrollment of all the NAL classes that participated in the survey was 466 , so $58.5 \%$ of the possible participant pool completed a survey. This is mainly due to the low attendance of students on days that the survey was given. Fifty-two percent of the participants were male, $46 \%$ female, and $2 \%$ chose not to provide a gender. On average, students of NALs are upper-class undergraduates between the ages of eighteen and twenty-two. The Cheyenne students' results are somewhat problematic to analyze because of the small sample size.

The survey consisted of 10 questions. The first three questions of the survey collected demographic information about the students. Questions 4-6 collected information about the students' previous experience with the language and whether the language is used in their home. Questions 7 and 8 were designed to gather information about which classroom activities (lectures, conversation activities, etc.) students feel are their favorites and which they feel they need more of. Question 9 required students to select and rank factors that motivated them to enroll in the NAL class. Finally, the last question of the survey gathered information about students' plans for future study of the language.

Not every survey that was filled out was included due to students not completing the survey or failing to follow the directions. Student responses for Questions 1-6 were tallied and totaled, and percentages for each category summed to $100 \%$. For Questions 7-9, students were allowed to check anywhere from zero to ten responses. The totals for Questions 7 and 8 are not examined in terms of percentages, as the number of responses selected by each student varied. Student responses for Question 9 were tallied according to how each motivator was ranked. Some of the totals for Questions 9 and 10 summed to more than $100 \%$ as some students gave equal ranking to two or more motivators on Question 9 or selected more than one response for Question 10. As students were not 
required to select and rank a minimum number of motivators on Question 9, the number of students who selected a first, second, or third choice varied from the overall number of participants. The majority of respondents only selected one motivator, though some students selected and ranked all ten. Due to the dwindling of the number of respondents as the rankings lowered, only the top three choices are compared in the results. In comparing students' top three highest ranked motivators, the raw scores (and not the percentages) were used to rank and list them as integrative or instrumental.

\section{Results}

The survey was designed to answer six research questions about NAL students. The results to each research question are examined by overall NAL students, by individual languages, and by narrow and broad HLLs. The total HLL population was 135 (49.5\% of the total population), with 72 students $(26 \%$ of the total population) having narrow HLL characteristics and 63 (23\%) having broad HLL characteristics. Given that only 7\% of OU students identified as American Indian or Alaskan Native for the Fall 2010 semester, the number of HLL students in these classes seems relatively high (University of Oklahoma Institutional Research and Reporting).

\section{(1) How much previous formal contact with the NAL do students typically have?}

The overwhelming majority of students studying a NAL have had absolutely no previous formal contact with the language. Only $13.5 \%$ of the total population had any previous formal contact with the language, while $20.8 \%$ of the narrow HLL population and $8 \%$ of the broad HLLs had taken a nonuniversity course in the language. There were only 27 students who reported previous informal contact (hearing the NAL in the home). At OU, only $12 \%$ (32 students) had high school classes in the NAL that they were studying. For the 20082009 school year, NAL classes made up 1.3\% of the total world language classes offered at the secondary level in Oklahoma (Oklahoma State Department of Education, 2009). While $12 \%$ at the university-level is a minority, they are a relatively larger group than the overall population of high school students in NAL classes in Oklahoma.

The Kiowa learners had the largest number of students (12) who had studied the language in high school, and the Cheyenne learners had absolutely no students with previous high school classes in the language. The Cherokee group had nine students, the Choctaw group six students, and the Muscogee Creek group five students who had taken a high school class. Unfortunately, the State Department of Education of Oklahoma does not currently record which languages are taught in the high school (rather, they are all collectively recorded as "NAL"), and so the differences between the individual language groups cannot be analyzed in terms of the popularity of particular NAL classes offered at the high school level with quantitative data from the state (Oklahoma State Department of Education, 2009). However, based on my experience volunteering at the Native American Youth Language Fair, there are more Oklahoman high school language classes in Choctaw than in the other four NALs offered at OU. Kiowa and Cheyenne have at least one high school level language course, so it is unsurprising that no students had high school Cheyenne classes, but it is interesting that so many students were continuing their study of 
Kiowa from high school. Of course, not every class necessarily participates in the language fair, and high school NAL students may be going on to other universities.

Not a single student had ever taken an online course in the language, but only Choctaw currently has an online language course. Only five students had taken a community class and all five of these students fall under the broad definition of HLLs. Four of these students also heard the language spoken at home, meaning they are classified under the narrow definition of HLL. The low numbers of community class students is consistent with Morgan (2005) who, in discussing the Ojibwe program at Michigan State University, noted that university-level NAL learners are typically students with "limited community involvement" (p. 98). Community language classes may attract more students who hear the language growing up (which is unsurprising, as these students are probably more involved in the community). The OU NAL classes do not appear to be attracting a large number of community class students.

\section{(2) Which classroom activities are favored by NAL learners and which do they feel they need more of?}

Collectively, students studying a NAL indicated that they favor classroom activities involving cultural and historical information, conversation, and grammar. The HLL subgroups have the same favorite activities as the total NAL population. Overall, students studying a NAL feel they need more classroom activities involving conversation, cultural and historical information, and grammar. Notice that these are the same activities that they favor, only in a different order. The HLL subgroups feel they need more of the same activities as the overall NAL student population, except they prioritize speaking over grammar. The top three most checked answers for both questions differ only slightly between the individual languages, as shown in Table 3 (see Appendix). That NAL students, and in particular the HLLs, prefer activities involving cultural and historical information could be interpreted as students wanting to connect with the community and learn more about their heritage.

In examining the results of these two questions, it is unclear if students understood the difference between them, as their responses are very similar. In future surveys, these questions will be reworded to make it clear that the first question refers to classroom activities that the student enjoys and feels are effective, while the second question is asking about classroom activities that need more attention, perhaps because they are missing completely or are not often used.

\section{(3) What are the most common factors motivating students to study a NAL at the university level?}

The overall highest ranked motivator of all of the students studying a NAL was "to fulfill the foreign language requirement" (Figure 1 in the Appendix). Over half of the students of all the languages, except for Cheyenne, selected this factor as their number one reason for taking the course, with all of the other factors ranking as the number one choice less than $30 \%$ of the time. The individual Cheyenne results are not discussed for this question, as there was little consensus among the small sampling. 
No clear single factor was the second choice across all of the languages. Rather, considerable variation exists between the languages, as shown in Figure 2 (see Appendix). Some of the individual languages did not even have a clear majority, with two factors gaining the same number of student responses. The Cherokee students selected both "because I have Native American ancestry" and because the language is "easier to learn than other languages" as the top rated second choice motivator. The Choctaw students selected the same motivator for their second choice as for their first choice (to fulfill the language requirement). The Muscogee Creek students selected "because I have Native American ancestry" and the Kiowa group selected because the "classes are easier than other language classes" as their overall second choice motivator. Considered as a collective group regardless of individual languages, the students chose because the "classes are easier than other language classes" as the second most chosen motivator.

As with the second choice, there is no clear overall third choice motivator across all of the languages (Figure 3 in the Appendix). Cherokee students chose because Cherokee "classes are easier than other language classes," while Choctaw and Kiowa both chose because the "language is easier to learn than other languages." Muscogee Creek students chose "to fulfill the foreign language requirement," the same factor as their most common first choice selection. As a collective group, the students chose because the language "is easier to learn than other languages taught at this university" as the most commonly selected third choice motivator.

For HLLs, both subgroups chose as the most commonly selected first choice motivator "to fulfill the foreign language requirement" and as their second choice "because I have Native American ancestry." For the third choice motivator, the groups had different selections. The narrow HLLs chose "to connect with NAL-speaking community members" while the broad HLLs chose because the "classes are easier than other language classes." These subgroups are partially determined by the students' choices of ancestry and speaking with community members as motivational factors, so while it is unsurprising to find these factors, it is interesting to find them so highly ranked (as the HLLs only had to select the factors, not highly rank them).

\section{(4) Are students studying NALs more integratively or instrumentally motivated?}

Grouping the factors as integrative or instrumental allows for the identification of overarching trends across the languages. As shown in Table 4 (see Appendix), the collective majority of the NAL students selected instrumental motivators as their top three choices. Table 5 (see Appendix) additionally shows that the individual languages continue this trend, where all five language groups selected as the top three highest ranked motivators an instrumental factor, though some also gave equal ranking to an integrative factor as well. Only the Muscogee Creek group selected "because I have Native American ancestry," an integrative motivator, as the second choice majority, without an instrumental factor receiving the same ranking. Of the integrative motivators, having Native American ancestry was the second most chosen motivator for three of the NAL groups (Cherokee, Cheyenne, and Muscogee Creek). Both HLL subgroups also chose fulfilling the language requirement as their first choice motivator and having Native American ancestry as their second choice. However, the narrow HLL group chose an integrative factor for their third 
choice and the broad group an instrumental factor. Thus, narrow HLLs may be more instrumentally motivated and broad HLLs more integratively motivated.

\section{(5) How many students have an interest in continuing their study of the language?}

The majority of Cherokee, Choctaw, and Kiowa students only intend to study the language until they fulfill their foreign language requirement (Table 6 in the Appendix). The results from students studying Muscogee Creek are unique, in that less than half of the students only intended to study the language until they had fulfilled the requirement (the lowest percentage of all the languages) and more than $20 \%$ of the students were interested in a minor (the highest of all the languages). Most of the Cheyenne students stated that the fourth semester intermediate Cheyenne class was the last Cheyenne class they would be taking, though the fourth semester may have been the last required course to meet the foreign language requirement. Only one student indicated that $\mathrm{s} / \mathrm{he}$ would pursue a minor in Cheyenne if a minor were available.

As a whole, and by individual languages (except for Muscogee Creek), the majority (over half) of the students studying a NAL at this university only intend to study the language up until the foreign language requirement is met. The narrow HLL subgroup had the highest percentage of students interested in a minor (33\%), though $36 \%$ still intended to only study the NAL until fulfilling the language requirement. The broad HLL group had very little interest in a minor $(9.5 \%)$ and a clear majority interest (65\%) in only studying the language until fulfilling the requirement. The responses provided for this question did not include community opportunities for future language study. Some students (especially HLLs) may have been interested in furthering their NAL study if there were opportunities in their community. Community language classes may be more attractive to some students, especially HLLs, as these classes are free and do not involve formal grading, but they also engage the student directly with the NAL community.

\section{(6) How do student motivations and their intentions or desires for future study interact?}

The majority of the students who chose "to fulfill the foreign language requirement" as their highest rated motivator indicated for their highest ranked future intentions of study that they would only study the target language as far as needed to fulfill the foreign language requirement or that the current course was the last class they would be taking in the language. Other studies, all done with non-NALs, found a similar correlation between students' motivation to study the language because of the university foreign language requirement and their lack of desire to continue their study of the language (Hernández, 2008; Thomas, 2010). The 67 out of 273 students who selected an integrative motivator as their first choice were more likely to indicate that they would be interested in a minor in the language, if one were offered. Thus, there is a correlation between integratively motivated NAL students and choosing to continue the study of the language beyond the basic foreign language requirement, as found with students studying other languages (Hernández, 2008; Thomas, 2010).

For both HLL subgroups, the majority of the students who chose to fulfill the requirement as their first choice motivator indicated that they also only plan to study the 
language until the requirement is fulfilled. However, for narrow HLLs who are primarily motivated by their Native American ancestry or their desire to speak with community members in the language, the majority indicated that they were interested in pursuing a minor in the language. There were no such trends in the broad HLL group, the majority of which intend to only fulfill the requirement regardless of primary motivation. For details about Cherokee, Choctaw, Muscogee Creek and Kiowa students' future studies by highest rated motivators, see Figures 4, 5, 6 and 7 in the Appendix.

\section{Further Discussion}

Overall, students studying a NAL have had relatively little formal contact with the language, and this may account for the surprisingly common misperception that these languages are "easier to learn than other languages." While it is possible that some of the students may have mistakenly identified the language as easy to learn when in fact the classes were easy, as another researcher using a similar survey with Spanish suspected (Mandell, 2002), this survey included an option to check that the classes, not the language, were easier. However, a surprising number of students $(132$, or $48 \%$ of the total participants) seemed to believe that the languages themselves were easier to learn. One student even wrote under the "other" option of Question 6 that "my main motivation for taking this class is that it is insultingly easy." Due to my experience as a teaching assistant in the program, I am not surprised to find this belief so prevalent among the students. This misperception may change as the newer instructors in the program come in with more formal teaching experience. Considering that most of the older instructors gained teaching experience through teaching community classes, where there is no formal grading, students may perceive the classes-and by association the languages-as easier due to the differences in teaching methods and classroom management styles.

The survey was not designed to investigate student attitudes or ideologies concerning NALs. However, as mentioned at the beginning of this article, motivation includes not only the desire to achieve a goal (such as fulfilling the foreign language requirement), but also favorable perceptions or attitudes towards learning the language, plus a belief in the relevance of learning the language. Based on their motivation and comments, some of the students who participated in this survey may have a negative attitude toward learning the NAL. While a few students' comments cannot be generalized to include all students studying a NAL, the attitude behind their comments may explain some of the trends identified in this study (such as the misperception that the languages are "easy"). Previous research has associated integrative motivation with a positive attitude in the classroom (Ueno, 2005), and NAL students overall are not integratively motivated. Additionally, in administering the survey, I observed more than one student make a laughing comment about Question 6, "Do your parents or family members speak at home?" One student even left a comment on the survey referring to the NAL as a "useless language." However, more research is required to investigate student attitudes and perceptions of NALs at OU.

Reynolds et al. (2009) found that HLLs of nineteen non-NALs were more integratively motivated while non-HLLs were more instrumentally motivated. Interestingly, only the narrow HLLs in this study showed to be primarily integratively 
motivated. Additionally, the narrow HLL subgroup had a much higher concentration of students who had taken non-university classes in the language and who would be interested in pursuing a minor in the language. The broad HLL subgroup showed no such trends. In labeling these two groups, the narrow HLL group may be more accurately referred to as endangered heritage language learners. This label reflects their community involvement and/or linguistic background with the NAL. The broad HLLs, as suggested previously, may be best described as learners with a heritage motivation, reflecting their desire to learn more about their ancestry, possibly as a means of indentifying more with the NAL community.

\section{Possible Pedagogical Implications}

Identifying the types of learners in the classroom can help instructors identify and better meet their needs. Other researchers have already proposed recommendations for teaching to the different subtypes of HLLs and to non-HLLs (essentially L2Ls), and their suggestions can be specifically applied to the context of teaching NALs at OU.

The HLLs in the NAL Program have needs that are different from those students who are learning the NAL as a non-heritage second language. Additionally, the narrow and broad HLLs have different needs from each other. For the broad HLLs (nearly half of all the NAL students at $\mathrm{OU}$ ), instructors may want to reinforce their identity and provide them opportunities to interact more with the NAL community. Carreira (2004) suggests validating these learners' right to identify with their ancestry and promote involvement with the HL community by attempting to actively connect these learners with the community. Similarly, Morgan (2005) attributed the success of the Ojibwe program at MSU especially to the involvement of the community, which is emphasized and sought out via language events that bring together the university language learners and native speakers and extends the classroom experience beyond the university. She describes this as "grounding language learning in community life" (p. 100). For narrow HLLs, Carreira (2004) suggests emphasizing the learner's role in "preserving the cultural and linguistic legacy" of his/her community (p. 20). The recommendations of Morgan (2005) and Carreira (2004) to include community involvement and encourage awareness of language endangerment may be particularly relevant to HLLs, particularly the narrow subgroup.

For the non-HLLs (the majority of NAL students at OU), instructors may wish to incorporate more cultural material in an effort to interest students in the language and increase their integrative motivation, as integrative motivation has been associated with oral proficiency in the target language (Hernández, 2008; Thomas, 2010). Activities that promote integrative motivation may include encouraging students to engage with the target language community by interviewing native speakers or inviting speakers to visit the classroom. Hernández (2008) also encourages instructors to use authentic materials and authentic language in the classroom, though this is more difficult for NAL instructors to achieve as endangered languages have fewer resources, fewer speakers, and fewer teaching materials (authentic or otherwise) available to them.

All of these recommendations, for non-HLLs and HLLs alike, advocate creating an active relationship between the students in the university classes and the language community. One way to foster this relationship would be to build a network of support 
between the university, the community, and other instructors and classes similarly working to teach a NAL to adult learners (high school classes and community classes). For example, the university and high school students could be informed about the other NAL classes (e.g., inform high-schoolers about community classes and which universities have the same NAL classes, etc.). Additionally, university and high school students could be invited to visit community classes and vice versa. However, these classes can also be viewed as a resource for the community. Morgan (2005) discusses the university program as a way to create language spaces that are equally important to the community, as they promote language use among community members and provide a specific space for the language to be used. Everyday language use in the community is the goal of most community language classes, and partnering with other adult language instructors to create language events could connect the web of opportunities available through community, high school, and university-level NAL classes. The involvement of the community does not have to remain removed from the university. As Morgan (2005) states, teaching NALs demands "innovative, community-linked forms of instruction" (p. 97).

Being able to study the NAL as a means for fulfilling the university foreign language requirement is a very important motivational factor for many students enrolled in these classes, even those that may be considered narrowly defined HLLs. Recent studies concerning less commonly taught languages have found that when the language programs are included in a university's foreign language requirement, they generally have higher student enrollments (Ueno, 2005). Allowing students studying NALs to fulfill their language requirement is obviously a powerful motivational factor. Future university programs including NALs should be aware of the importance of receiving language requirement credit to these endangered language learners.

\section{Other Limitations}

The wording of some of the questions on the survey may have limited the results. For example, student responses to Question 9 on motivators would have been more comparable had the survey required students to select and rank a specific number (e.g., three) of the factors. However, some students may only be motivated by one of the ten factors, and by allowing the students to choose the number of relevant factors, I believe that the complex, multifaceted, and individual nature of motivation is perhaps more accurately reflected in the results. For example, 44 students who participated in the survey only selected one first choice motivator and did not select or rank any other factors on Question 9 of the survey. Of the 167 students who selected "This course satisfies the university foreign language requirement" as their primary motivator, 36 did not select any other factors, meaning that $21.5 \%$ of students who were primarily motivated to enroll in the NAL course because of their need to fulfill the university requirement felt as though this was the only factor, of the ten provided on the survey, which described why they were taking the course. Had the survey required the students to select a certain number of factors, some students may have been forced to select factors that did not accurately reflect their motivation.

The design of the survey made distinguishing HLLs somewhat ambiguous. For this study, HLLs were primarily identified by their responses to one question about motivators 
and one about language use in their home. However, these questions may not have been direct enough to accurately identify all HLLs. For example, a student may have Native American ancestry but not feel motivated by this fact to take a NAL course, or they may have been exposed to the language frequently outside of their home. Future surveys will include questions to respond to these limitations, particularly in identifying the different subgroups of HLLs, by asking more detailed questions about student backgrounds in terms of previous linguistic exposure, community involvement, Native American ancestry, and linguistic proficiency prior to enrolling in a class.

\section{Conclusion}

More research is necessary on the motivation of students in college level NAL classes. This first survey can conclude that the majority of the students studying NALs at OU are primarily motivated to fulfill the university language requirement, with no intentions to continue their study of the language further. These results are similar to those found by other studies that surveyed students of other more commonly taught non-NALs. The results of this survey additionally indicated that integratively motivated NAL students are less likely to intend to only study the language as far as needed to fulfill the requirement. Students most interested in furthering their study of the language are narrow HLLs, who have had more previous contact with the language and who are more connected with and interested in the NAL community. Increasing all NAL students' contact and involvement with NAL communities may promote integrative motivation and interest in a minor.

Future research can address the best way to meet the unique needs of endangered language learners, especially those who are endangered heritage language learners (narrow HLLs) and those who are learners with a heritage motivation (broad HLLs). However, Native languages are inseparable from their community. Recommendations about increasing integrative motivation in L2Ls (Hernández, 2008), about the success of a NAL program at the university level (Morgan, 2005), and about meeting the needs of different types of HLLs (Carreira, 2004) all endorse increased involvement of and with the target language community. As Oklahoman NALs continue to be taught at the university level, and as their situation in language learning paradigms is explored, the similarities between these learners and other adult language learners, NAL learners, and HLLs must be understood in order to create the most effective forms of instruction.

\section{References}

Carreira, M. (2004). Seeking explanatory adequacy: A dual approach to understanding the term "Heritage Language Learner." Heritage Language Learner, 2(1), 1-25.

Gardner, R. C. (1985). Social psychology and second language learning: The role of attitudes and motivation. London: Edward Arnold.

Gardner, R. C., \& Lambert, W. E. (1959). Motivational variables in second language acquisitions. Canadian Journal of Psychology, 13(4), 266-272.

Haag, M., \& Willis, H. (2001). Choctaw language and culture: Chahta Anumpa. Norman: University of Oklahoma Press. 
Hernández, T. (2008). Integrative motivation as a predictor of success in the intermediate foreign language classroom. Foreign Language Annals, 39(4), 605-617.

Hinton, L. (2008). Learning and teaching endangered indigenous languages. In N. Hornberger \& N. van Deusen-Scholl (Eds.), Encyclopedia of language and education: Vol. 4. Second and foreign language education (pp. 157-168). New York: Springer.

Hinton, L. (2011). Language revitalization and language pedagogy: New teaching and learning strategies. Language and Education, 25(4), 307-318.

Linn, M. S. (2011, April). State of the state: Oklahoma native languages in the 21st century. Presented at the Oklahoma Workshop on Native American Languages. Tahlequah, OK.

Mandell, P. B. (2002). On the background and motivation of students in a beginning Spanish program. Foreign Language Annals, 35(4), 530-542.

Martin, J. B., \& Mauldin, M. (2001). Creek. In J. Garry \& C. Rubino (Eds.), Facts about the world's languages: An encyclopedia of the world's major languages, past and present (pp. 173-176). New York: H. W. Wilson.

McCarty, T.L. (2008). Native American languages as heritage mother tongues. Language, Culture, and Curriculum, 21(30), 201-225.

McCarty, T. L., \& Zepeda, O. (2010). Native Americans. In J. A. Fishman \& O. García (Eds.), Handbook of language and ethnic identity. Vol. 1: Disciplinary \& regional perspectives (2nd ed., pp. 323-339). New York: Oxford University Press.

Morgan, M. J. (2005). Redefining the Ojibwe classroom: Indigenous language programs within large research universities. Anthropology \& Education Quarterly, 36(1), 96103.

Oklahoma State Department of Education Data Services (2009). Data reported by K-12 schools to Oklahoma State Department of Education.

Reynolds, R. R., Howard, K. M., \& Deák, J. (2009). Heritage language learners in first-year foreign language courses: A report of general data across learner subtypes. Foreign Language Annals, 42(2), 250-269.

Saville-Troike, M. (2006). Introducing second language acquisition. New York: Cambridge University Press.

Thomas, J. A. (2010). How do I satisfy the general education language requirement? University students' attitudes toward language study. Foreign Language Annals, 43(3), 531-550.

Ueno, J. (2005). An analysis of learner motivation of less commonly taught languages. Journal of the National Council of Less Commonly Taught Languages, 2, 45-72.

University of Oklahoma Institutional Research and Reporting. Enrollment analysis 2010.

Retrieved from http://www.ou.edu/provost/ir/enrollment-

analysis/Fall2010All.pdf 
Valdés, G. (2001). Heritage language students: Profiles and possibilities. In J. K. Peyton, D. A. Ranard, \& S. McGinnis (Eds.), Heritage languages in America: Preserving a national resource (pp. 37-77). Washington, DC: Center for Applied Linguistics.

White, F. (2006). Rethinking Native American language revitalization. American Indian Quarterly, 30(1/2), 91-109.

\section{Appendix}

\begin{tabular}{l|l}
\multicolumn{1}{c|}{ Instrumental } & \multicolumn{1}{c}{ Integrative } \\
$\begin{array}{l}\text { This course satisfies the university foreign } \\
\text { language requirement }\end{array}$ & $\begin{array}{l}\text { I wish to connect with } \\
\text { of my community }\end{array}$ \\
\hline$\_$is easier to learn than other languages & I have had positive past experience with \\
\hline classes are easier than other language & $\begin{array}{l}\text { I wish to talk with } \\
\text { members of my family }\end{array}$ \\
\hline $\begin{array}{l}\text { classes at this University } \\
\text { wanted to study something friends or }\end{array}$ \\
\hline $\begin{array}{l}\text { I feel it will be professionally advantageous } \\
\text { I have Native American ancestry }\end{array}$ \\
\hline
\end{tabular}

Table 1. Instrumental and Integrative Motivators of the Survey

\begin{tabular}{|l|r|r|r|r|r|} 
& \multicolumn{1}{|c|}{$\begin{array}{c}\mathbf{1}^{\text {st }} \\
\text { semester }\end{array}$} & $\begin{array}{c}\text { 2 } \\
\text { semester }\end{array}$ & $\begin{array}{c}\text { 3 }^{\text {th }} \\
\text { semester }\end{array}$ & semester & TOTALS \\
\hline CHR & 47 & 27 & 0 & 0 & $\mathbf{7 4}$ \\
\hline CHY & 0 & 0 & 0 & 5 & $\mathbf{5}$ \\
\hline CHO & 40 & 19 & 18 & 0 & $\mathbf{7 7}$ \\
\hline MUS & 19 & 14 & 9 & 2 & $\mathbf{4 4}$ \\
\hline KIO & 32 & 23 & 18 & 0 & $\mathbf{7 3}$ \\
\hline TOTALS & $\mathbf{1 3 8}$ & $\mathbf{8 3}$ & $\mathbf{4 5}$ & $\mathbf{7}$ & $\mathbf{2 7 3}$ \\
\hline
\end{tabular}

Table 2. Participants by Semester Level of Study and Language 


\begin{tabular}{|c|c|c|c|c|c|c|}
\hline & Cherokee & Cheyenne & Choctaw & Creek & Kiowa & TOTAL \\
\hline Grammar & 9,31 & 0,3 & 17,27 & 15,17 & 24,25 & $\begin{array}{r}65 \\
103\end{array}$ \\
\hline Conversation & 20,32 & 2,2 & 19,35 & 15,21 & 16,28 & $\begin{array}{r}72 \\
118\end{array}$ \\
\hline Lectures & 1,19 & 0,1 & 6,20 & 0,18 & 5,6 & $\begin{array}{r}12, \\
64\end{array}$ \\
\hline Homework & 1,9 & 0,0 & 2,2 & 3,5 & 0,3 & 6,19 \\
\hline Compositions & 2,4 & 0,0 & 6,5 & 4,3 & 5,3 & $\begin{array}{r}17 \\
15\end{array}$ \\
\hline Listening & 11,15 & 0,2 & 18,29 & 12,13 & 13,21 & $\begin{array}{r}54 \\
70\end{array}$ \\
\hline Speaking & 12,16 & 3,2 & 13,22 & 12,17 & 19,17 & $\begin{array}{r}59 \\
74\end{array}$ \\
\hline Tests & 0,4 & 0,1 & 1,7 & 1,5 & 1,5 & 3,22 \\
\hline Culture & 23,51 & 1,5 & 18,59 & 11,33 & 18,31 & $\begin{array}{r}71 \\
179\end{array}$ \\
\hline Other & 16,12 & 0,0 & 5,5 & 2,7 & 9,7 & $\begin{array}{l}32 \\
31\end{array}$ \\
\hline
\end{tabular}

Table 3. Favorite and Needed Classroom Activities of Students by Language

Note: (Needed, Favorite) 


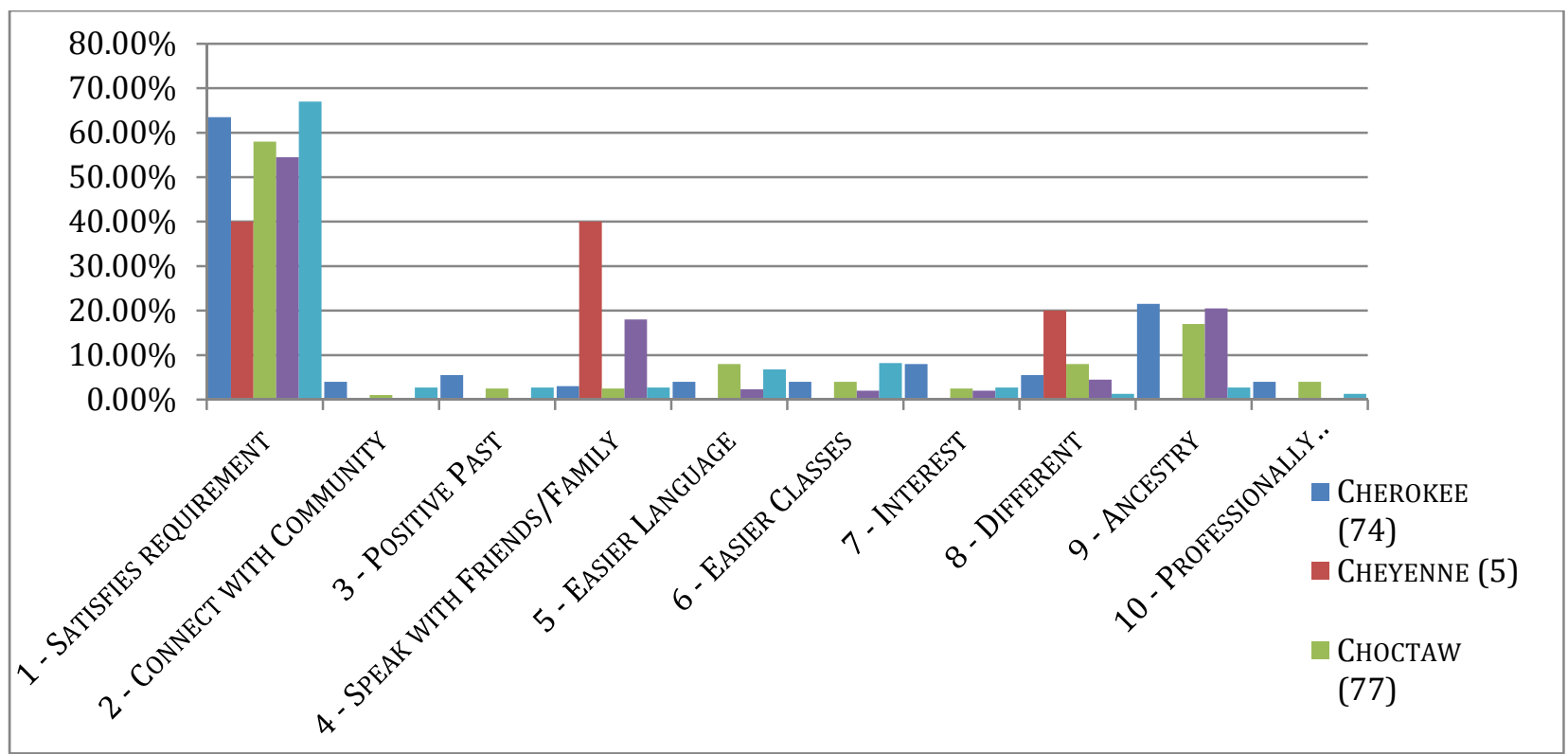

Figure 1. Overall First Choice Motivator by Language

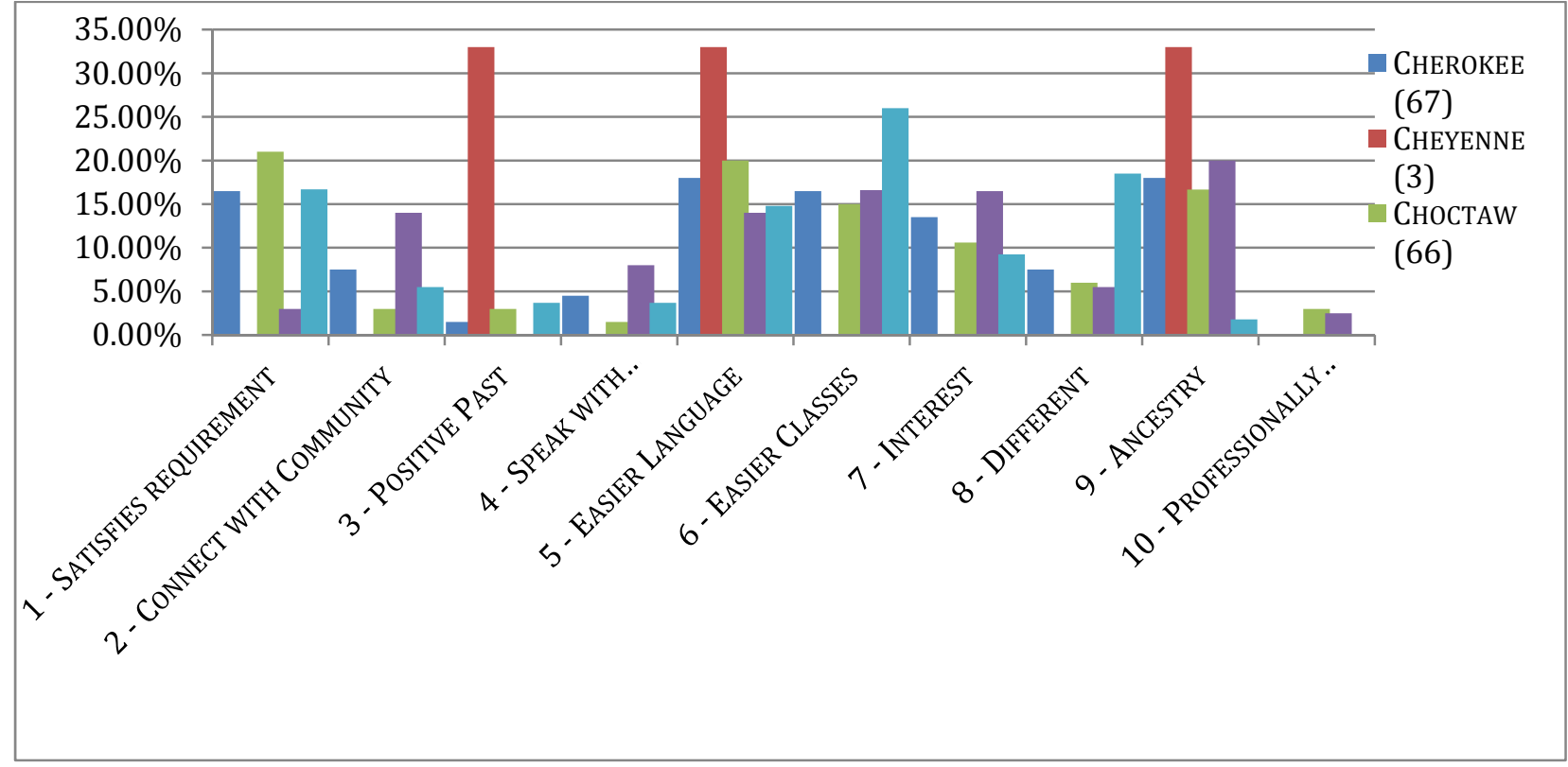

Figure 2. Overall Second Choice Motivator by Language 


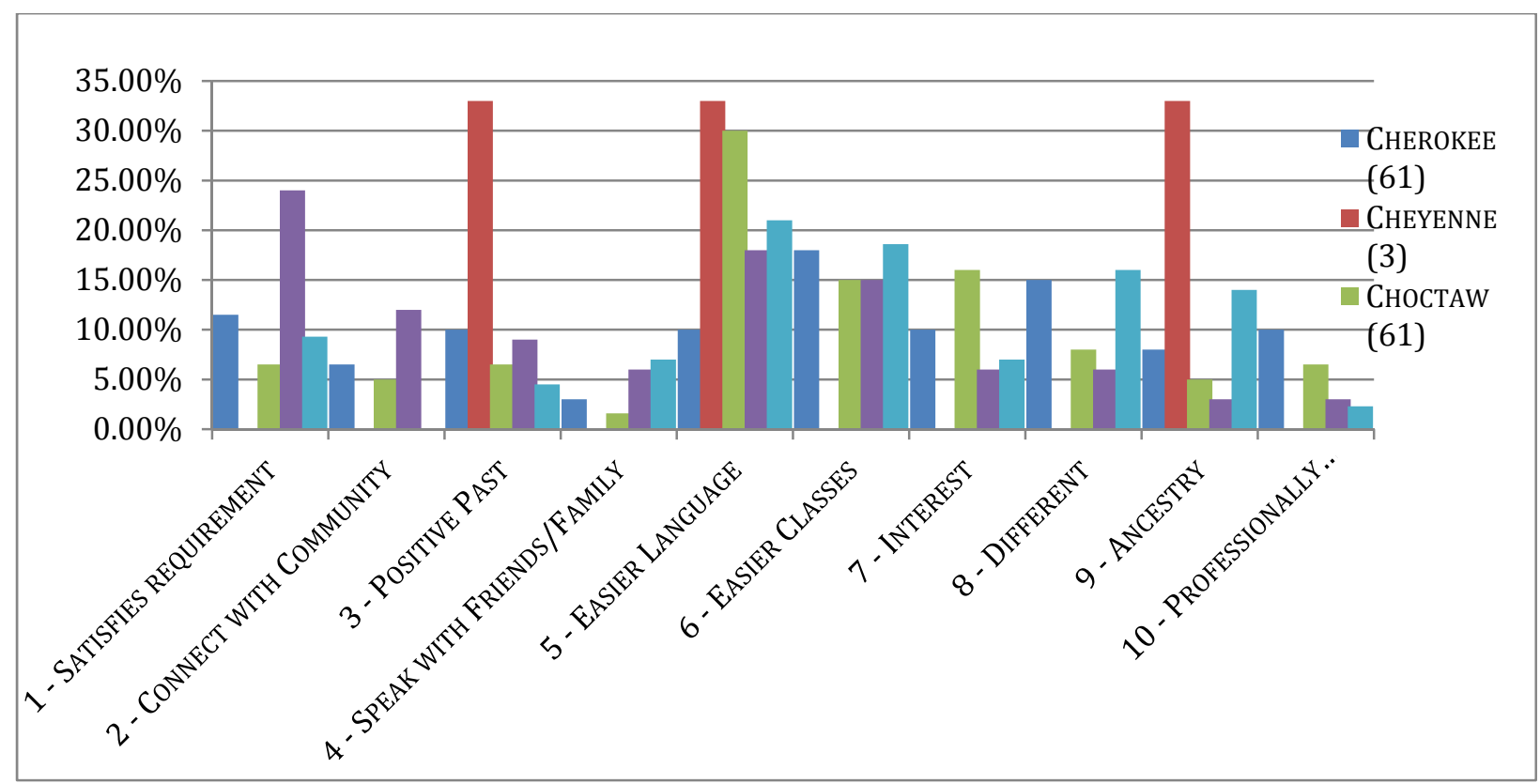

Figure 3. Overall Third Choice Motivator by Language

\begin{tabular}{|lcc|}
\hline & INTEGRATIVE & INSTRUMENTAL \\
\hline $\begin{array}{l}\text { First } \\
\text { Choice }\end{array}$ & - & Satisfies Requirement \\
\hline $\begin{array}{l}\text { Second } \\
\text { Choice }\end{array}$ & - & Easier Classes \\
\hline $\begin{array}{l}\text { Third } \\
\text { Choice }\end{array}$ & - & Easier Language \\
\hline
\end{tabular}

Table 4. Students' Overall Highest Ranked Integrative/Instrumental Motivators 


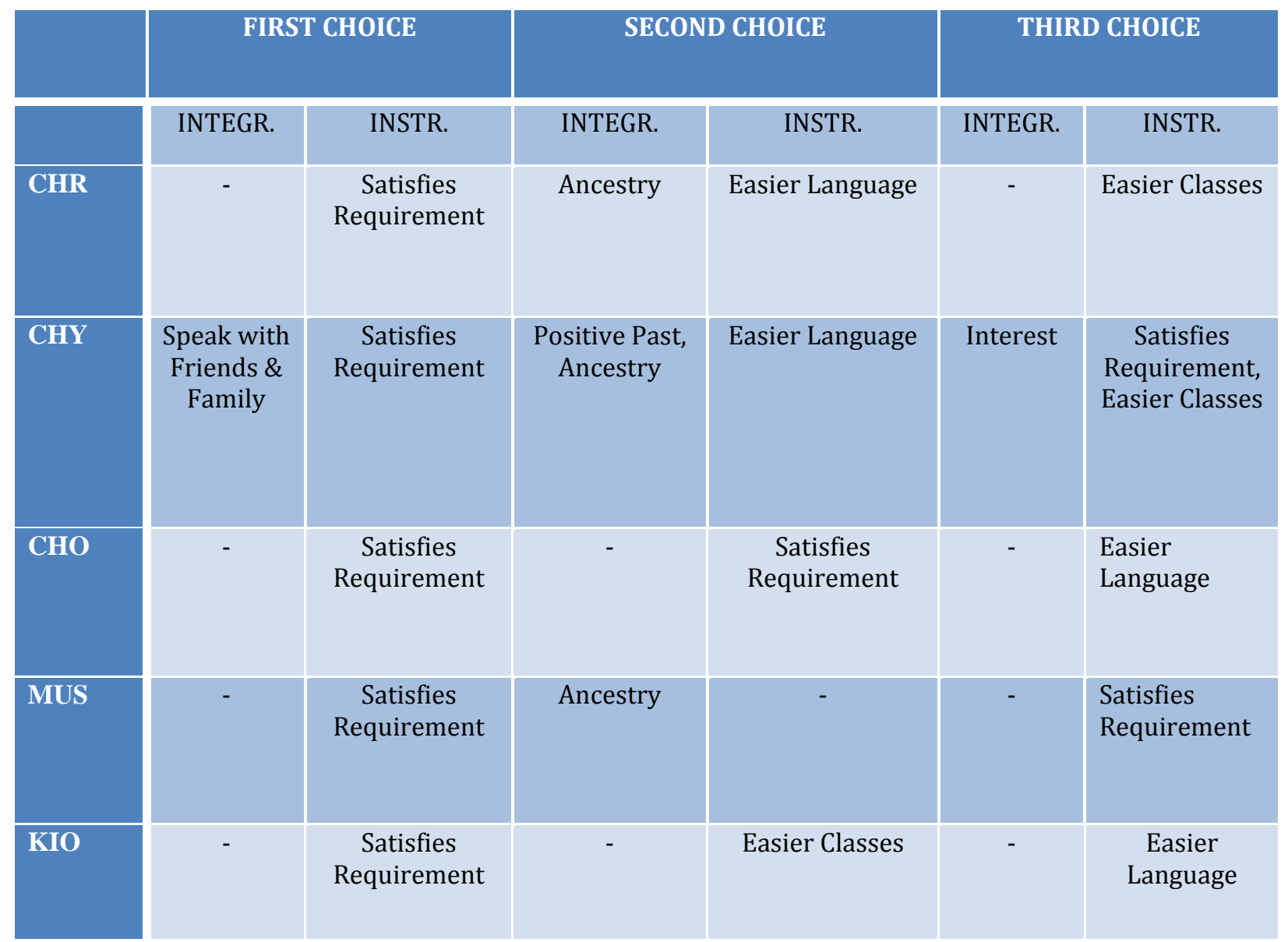

Table 5. Highest Rated Integrative/Instrumental Motivators by Language

\begin{tabular}{|l|c|c|c|c|c|c|c|c|} 
& CHR & CHY & CHO & MUS & KIO & $\begin{array}{l}\text { NARROW } \\
\text { (HLLs) }\end{array}$ & $\begin{array}{l}\text { BROAD } \\
\text { (HLLs) }\end{array}$ & TOTAL \\
\hline FULFILL & $62 \%$ & $0 \%$ & $59 \%$ & $38 \%$ & $52 \%$ & $36 \%$ & $65 \%$ & $55 \%$ \\
\hline LAST & $6 \%$ & $50 \%$ & $15 \%$ & $22 \%$ & $30 \%$ & $12.5 \%$ & $13 \%$ & $18.5 \%$ \\
\hline MINOR & $16 \%$ & $17 \%$ & $12 \%$ & $20 \%$ & $7 \%$ & $33 \%$ & $9.5 \%$ & $14 \%$ \\
\hline UNCERTAIN & $16 \%$ & $33 \%$ & $14 \%$ & $20 \%$ & $11 \%$ & $21 \%$ & $19 \%$ & $16 \%$ \\
\hline
\end{tabular}

Table 6. Students' Future Intentions of Study by Language 


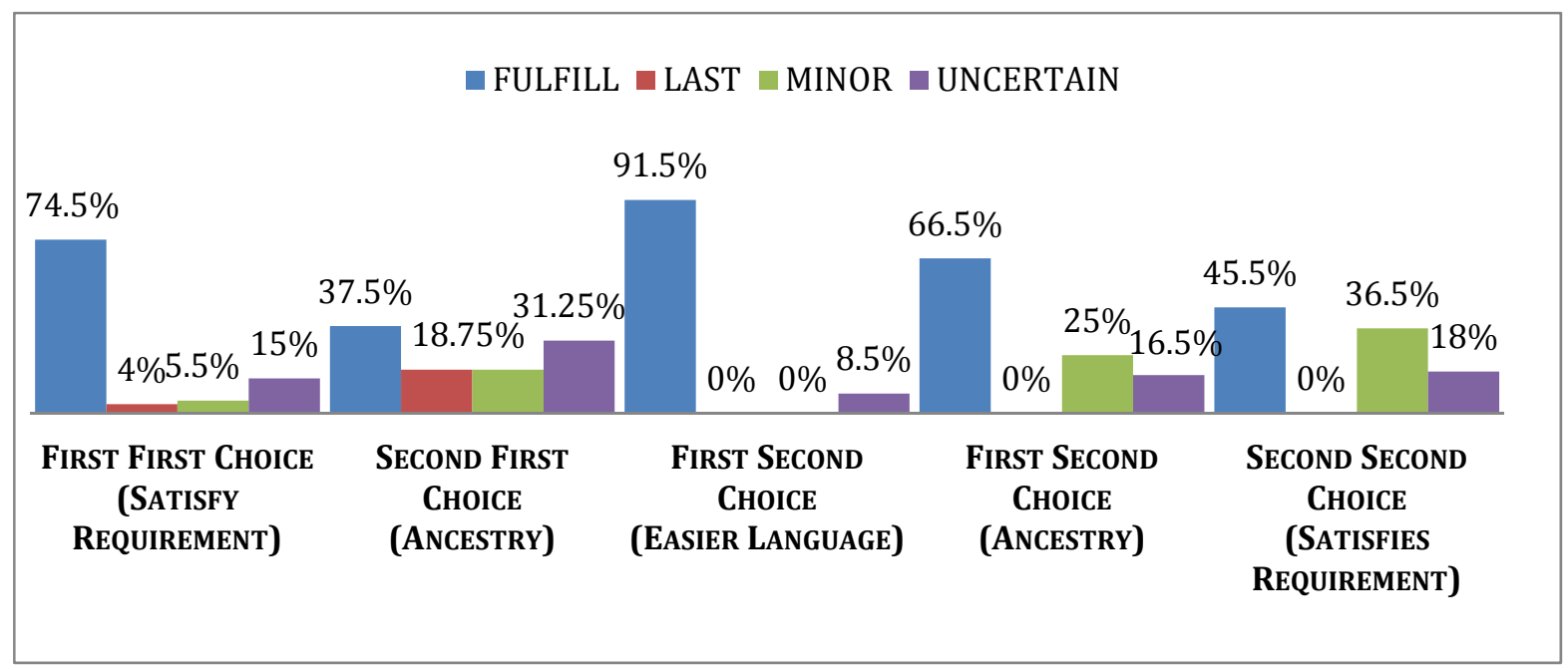

Figure 4. Cherokee Students' Future Intentions of Study by Highest Rated Motivators

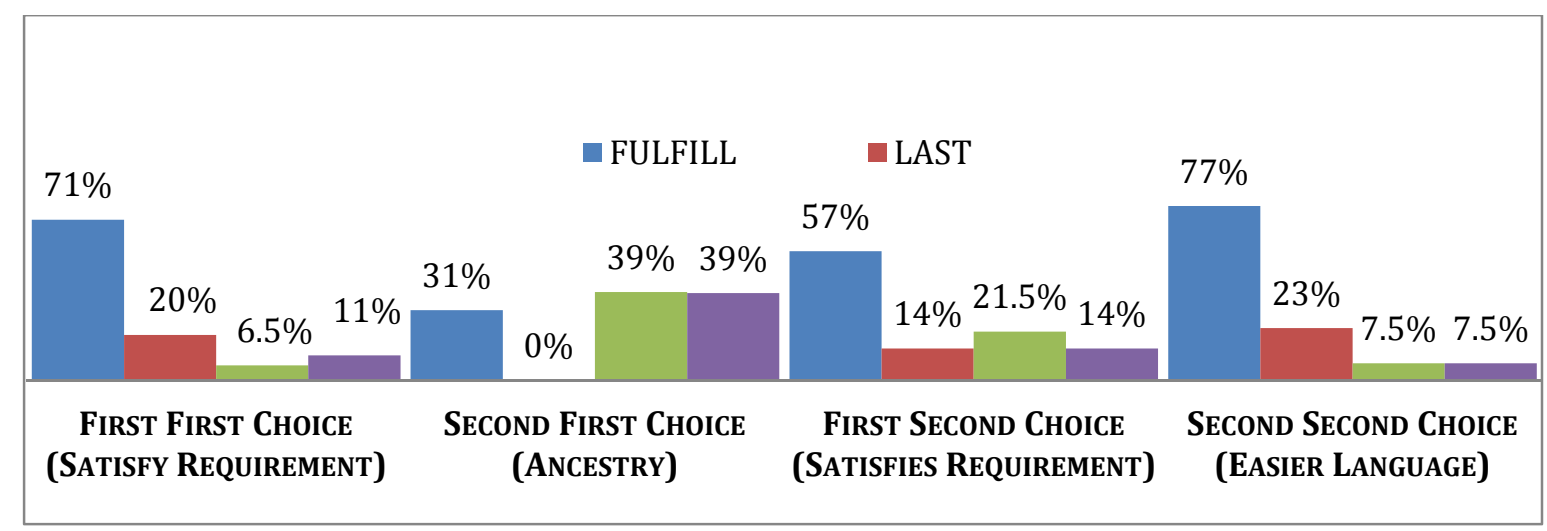

Figure 5. Choctaw Students' Future Intentions of Study by Highest Rated Motivators

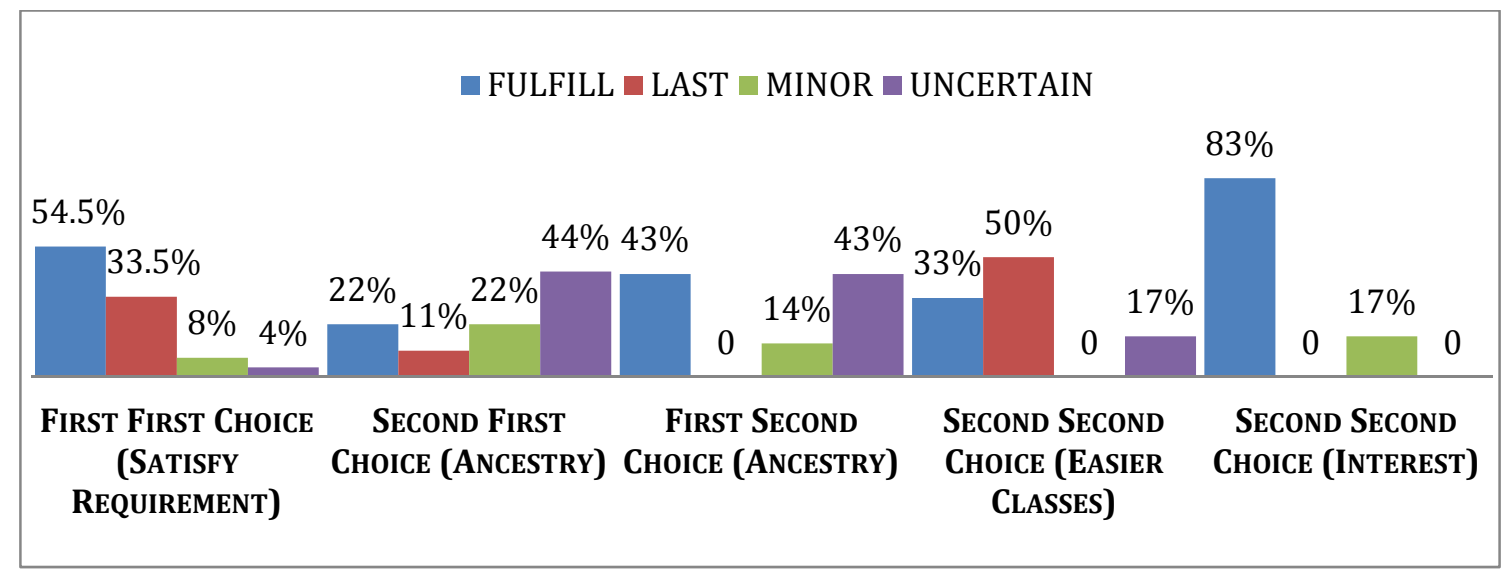

Figure 6. Muscogee Creek Students' Future Intentions of Study by Highest Rated Motivators 


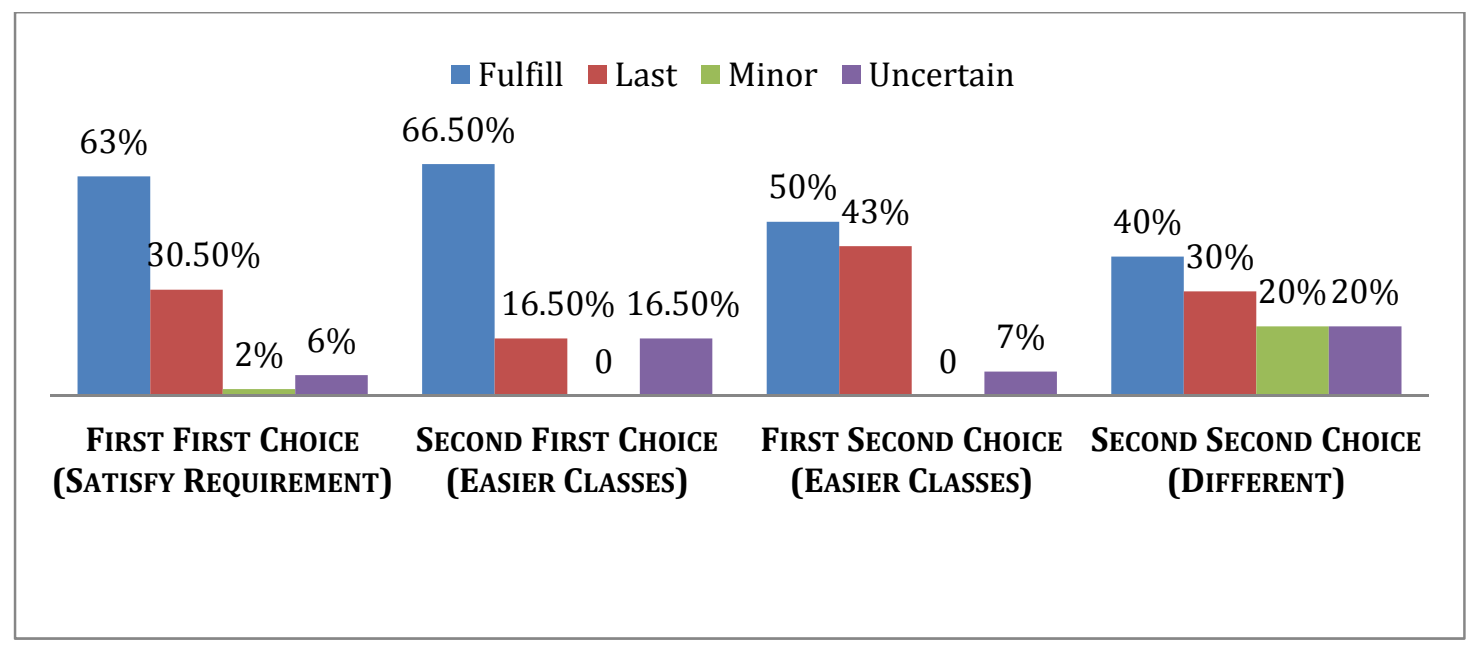

Figure 7. Kiowa Students' Future Intentions of Study by Highest Rated Motivators

\section{Model Questionnaire Administered to the NAL Classes (with truncated spacing)}

(Note: Blanks were filled in with the specific language of each class)

\section{General Information}

1. Level at the University: $\square$ freshman $\square$ sophomore $\square$ junior $\square$ senior $\square$ graduate

2. Sex: $\square$ Male $\square$ Female

3. Age: $\square$ Less than $18 \square$ 18-22 $\square$ 23-27 $\square$ 28-32 $\square$ 33-40 $\square$ 40-55

\section{Language Background}

4. Non-University language classes taken (circle): 1 yr high school, 2 yrs high school, 3 yrs high school, 3+yrs high school, no previous experience, community classes, online classes 5. University-level __ classes taken, if applicable (circle): 1 semester, 2 semesters, 3 semesters, $3+$ semesters

6. Do your parents or family members speak at home? (circle): Always Usually Occasionally Never

\section{Course}

7. My favorite part of this course is (check all that apply):

$\square$ grammar explanations/exercises $\square$ conversation activities $\square$ lectures $\square$ homework

$\square$ compositions $\square$ listening activities $\square$ opportunities to speak with others in class $\square$ tests

$\square$ cultural and historical information $\square$ other:

8. I feel I need more (check all that apply): 
grammar explanations/exercises $\square$ conversation activities $\square$ lectures $\square$ homework

$\square$ compositions $\square$ listening activities $\square$ opportunities to speak with others in class $\square$ tests

$\square$ cultural and historical information $\square$ other:

\section{Motivation}

9. I am taking this course because: (check all that apply to you; if you check more than one, please rank all of your choices in order of importance, with 1=most important)

$\square$ This course satisfies the university foreign language requirement

I wish to connect with -speaking members of my community

I have had positive past experience with

I wish to talk with -speaking friends or members of my family is easier to learn than other languages classes are easier than other language classes at this University

$\square$ I have an interest in foreign languages and other cultures

I studied another language in high school and wanted to study something different in college

I have Native American ancestry

I feel it will be professionally advantageous

\section{Future Study}

10. How far will or would you go in your study of ?

$\square$ This is the last course I will be taking.

I am uncertain.

$\square$ I would pursue a minor in , if it were offered.

$\square$ Only as far as needed to fulfill the foreign language requirement. 


\title{
Complexities of Immigrant Identity: Issues of Literacy, Language, and Culture in the Formation of Identity
}

\author{
Bita H. Zakeri
}

\begin{abstract}
Identity is an issue that everyone struggles with on a daily basis while constantly changing, adapting, and becoming agents of the social spheres in which we participate. At large, a society and its social demands mold us into becoming agents of that society. Literacy and education are at the heart of this social molding, from within the family sphere to the larger social spheres. But how can one reformat all the sociocultural training he/she has received in order to adapt to a new social sphere and simply change, lose, and gain identity? These questions are significant to multicultural societies such as US and Canada, and even more prevalent with respect to immigrant populations. Using autoethnographical data and literature in this area, this paper discusses the issues of immigrant identity and literacy in twofold: a) the lack of attention to immigration and acculturation phenomena; b) the importance of understanding immigrant students' experiences and the need for diversification of teachers and teaching methods, concluding with suggestions for further research.
\end{abstract}

\section{Introduction}

Who am I? Where did I come from? How did I become who I am? What are my roots? Where am I going? Identity is an issue that everyone struggles with on a daily basis. We are constantly changing, adapting, and becoming agents of the social spheres in which we participate. At large, a society and its social demands mold us into who we must become to be respectable agents of that society. Literacy and education are at the heart of this social molding, from within the family sphere to the larger social sphere. When one is born into a social system, adapting is not necessarily an issue. But what about an adult whose social conditioning belongs to another society with very different cultural and social training and conditioning? How can one reformat all the sociocultural training he/she has received in order to adapt to a new social sphere? How can one simply change, lose, or gain an identity? These are the questions my family and I have struggled with as immigrants. Although it has been almost twenty years since we left our native land, there are still cultural barriers that are difficult to cross. This difficulty is more evident for my parents than for me since I was young when we moved; therefore, I am a product of western society in whom only certain eastern cultural practices have been ingrained. But in retrospect, the questions of identity and heritage are more problematic for me as a first generation westernized immigrant woman.

Although these questions may seem more prevalent with respect to immigrant populations, they are relevant to multicultural societies such as the US and Canada that include diverse cultures within their own social frameworks. Thus the issue of literacy and 
identity begin from the microlevel family sphere, or primary discourse (Gee, 1992), to the macrolevel social sphere involving various secondary discourses (Gee, 1992), including the educational systems. To complicate matters more, gender-specific cultural training at micro and macro sociopolitical levels has a great influence on literacy, especially at higher levels. This is complicated even more in the case of adult immigrant literacy, especially with regards to women's education. However, women's struggle in education is not limited to immigrants only, as gender is the central issue affecting their literacy acquisition. Women, whether immigrants or natives, face similar issues with regards to crossing sociocultural boundaries and gaining new identities, except that immigrant women have the additional complexity of alien identity and cultural practices.

This paper discusses the issues of immigrant identity and literacy in twofold: a) it brings forth the lack of attention to immigration and acculturation phenomena, as well as the multifaceted issues of identity, culture, and language prevalent in the lives of immigrants in the US and Canada, with a special focus on immigrant women's education and identity across cultures; and b) it discusses the importance of awareness and understanding of immigrant students' experiences and the need for diversification of teachers and teaching methods to better address the needs of the constantly growing immigrant population. It concludes with suggestions for further research.

The data used for this analysis is autoethnographical: as a first generation female immigrant, I look back at some of the struggles my family faced as immigrants and the trajectory of my experience as an ESL student to showcase some of the prominent struggles faced by immigrants in academic institutions and society at large.

\section{Immigrant Families' Struggles with New Literacies and Identity}

According to Ferdman and Weber (1994), literacy has been portrayed as the "vehicle for social and economic advancement as well as means of enhancing individual lives and fostering equal opportunities" (p. 3). In 1994, Ferdman and Weber examined literacy research across the field and found that although there has been much research done with regards to better understanding literacy and literacy acquisition, most studies concentrate on first-language and mother-tongue literacy, and mainly English literacy in the US. Therefore, they argued, "insufficient attention has been given in this scholarly literature to the particular issues facing people who are immigrants, members of ethnographic minorities, or cross-nationals" (1994).

Ferdman and Weber (1994) assert that the aforementioned categories of people are trying to acquire literacy in English while already possessing a language and a culture from their native land that differ from the literacy and cultural practices that surround them in the US (pp. 4-5). The authors point out that according to the Census Bureau, "in 1990 members of non-European groups, including African-Americans, Latinos, Asians, and Native Americans, accounted for 25 percent of the US population" (p. 5). Bornstein, DeaterDeckard, and Lansford in 2007 stated that 12.4\% of the US populations (approximately 35.7 million people) were immigrants (p. 1). "According to the International Organization for Migration and estimates from the United Nations, in 2000 approximately 160 million people were thought to be living outside their country of birth or citizenship, up from an estimate of 120 million in 1990" (p. 2). Furthermore, based on assumptions that no major 
changes would occur, the US Census Bureau projected in 2004 that by 2030, the number of European-American children will decline by $50 \%$, and the population of Hispanic-American children will rise by $26 \%$, African-Americans by $16 \%$, Asian-Americans by $5 \%$, and Native Americans/Hawaiians/Pacific Islanders by 4\% (Hernandez, Denton, \& Macartney, 2007, pp. 10-11). Regardless of rapid migration across the globe, Bornstein et al. state that "immigration and acculturation phenomena are underresearched and still poorly understood" (p. 3).

As Phinney and Ong (2007) claim,

[w] hen immigrants leave one culture and settle in another, they are faced with fundamental questions regarding who they are and who they will become in the new country. Their ethnic identity, that is, their sense of belonging to their cultural origin, is a key factor in the way they adaptively respond to challenges in their new country. (p. 51)

Most immigrants who come to the US are literate to varying degrees, often possessing literacy skills in more than one language other than English. In order for them to gain citizenship, they are required to acquire literacy in English at a functional level, a process in which culture and identity play a significant role (Ferdman \& Weber, 1994, pp. 10-12). In the case of the more literate and elite categories of immigrants, this struggle is enhanced on a different level. In my father's case, for instance, for an immigrant in his forties with a Ph.D. in Civil Engineering, the struggle to gain access to his professional field in Canada at the same level as his position in Iran triggered an identity crisis for him. To my father, it was a conceptual struggle with pride and identity as he had to start his career from the beginning all over again.

My father's identity crises still remain, as no matter how far he has advanced professionally, and regardless of his superior knowledge in the field and his fluency in English, there is still a linguistic and cultural gap between him and his younger clients. His accent will always speak for him first and his age second. Ironically, this gap is not as evident among the older clients and colleagues regardless of their cultural and linguistic differences. In this case, age and experience seem to pre-empt cultural differences, as the older population can identify with one another in terms of lived experiences and acquired knowledge. My father often talks about his life in Iran in a positive light, as does any adult immigrant I have ever known. Somehow life was always better back home; it had more meaning and it was more pleasant. Every immigrant was always "somebody important" back home, wherever that home may be. This is the same in the case of any older person, as the hardships of youth seem not so hard with the passing of the years. The past is always sweeter for the immigrant, because it owns that native culture in which their identity was formed. The question I always pose in response is, "Then how come you moved?" And often the answer is, "To give my kids a better life," or "Life was better but the government would not leave you alone." And sometimes the answer is a simple "I don't know. I ask myself the same question." Thus, sadly, even though immigrants may be very literate and knowledgeable in their own culture and language, they are often not regarded as such by English-speaking society. 
Likewise, the children of immigrants face the issue of identity and cultural struggle, but this struggle is intensified since the culture is threefold between their parents' culture, that of the current society in which they live, and their own culture, one that sets them apart from those cultures they defy. As one belonging to this category, I continue to struggle with the concept of culture and identity. Growing up "different" is not an easy task. When you are "different" from your parents, from your classmates, from your cousins, and the conflicting social circles through which you move, a struggle with identity is inevitable, especially as you grow older.

The identity of adult immigrants is a complex issue. Immigration is often a result of a desire to improve one's life and living situation, which includes removing oneself and one's family from a hostile environment. But while improving or saving their lives in one way, immigrants lose a lot as a result of their immigration, including much of their literacy skills and their identities. Immigrants who were sufficiently literate in their homeland are forced to acquire new literacies and identities, a new language and culture, as they adapt to their social surroundings.

As Phinney and Ong (2007) argue, the immediate family sphere is where ethnic identity is formed and cultivated. The family environment provides the foundation for the formation of identity, especially in the case of children and adolescents (pp. 55-57). In addition, Phinney and Ong assert that ethnic identity continues to form in relation to school, community, and professional spheres as well as historical context (p. 57). Often immigrants find comfort in forming new communities with similar backgrounds, and find relief in helping one another improve their lives as immigrants and developing the necessary literacies for their advancement. The authors agree with Rosenthal and Hrynevich (1985) that "more cohesive and well-structured communities contribute to stronger ethnic identity" (p. 57). However, at the same time that they belong to a certain marginal community, immigrants struggle to become part of the larger social sphere and acquire the necessary literacy, cultural, and linguistic skills required to tap into the world of the middle-class American social sphere. Even if one is able to rise above the social conditionings and acquire the academic, social, and political literacies of middle-class American society against all sociocultural economic odds, he/she will always continue to struggle, as his/her primary discourse is at odds with his/her secondary discourse. This struggle may not be evident professionally because it is personal with regards to one's ethnic and sociopolitical identity.

Adapting is often not a smooth transition, if a transition at all; rather, immigrants may look for ways to simply cope and deal with their struggles. This sense of loss and lack of meaning-making is a part of immigrant life. However, even though identity crisis has its roots in many domains such as cultural, social, and political, language always remains at the core. Language, according to Bonny Norton (2010), "is not conceived of as a neutral medium of communication [as poststructuralists claim], but it is understood with reference to its social meaning, in a frequently inequitable world. It is this conception of language that poststructuralists define as 'discourse'" (p. 350). Immigrants gain agency within the dominant culture through the acquisition of language and appropriate discourse. In his history of sexuality, Foucault (1978) describes dynamics of power relations and discourse. "Power," Foucault argues, 
must be understood in the first instance as the multiplicity of force relations immanent in the sphere in which they operate and which constitute their own organization; as the process which, through ceaseless struggles and confrontations, transforms, strengthens, or reverses them; as the support which these force relations find in one another, thus forming a chain or a system, or on the contrary, the disjunctions and contradictions which isolate them from one another; and lastly, as the strategies in which they effect whose general design or institutional crystallization is embodied in the state apparatus, in the formulation of the law, in various social hegemonies. (pp. 92-93)

Power in this sense, in the case of immigrants, is gained through reinforcing and strengthening identities within the family and community spheres, as well as learning literacy skills that would gain them access to the dominant discourse (Gee, 1992).

In retrospect, these difficult situations for adult immigrants affect their children's lives in many ways. The children's identities are formed within the home sphere and outside of it, two conflicting spheres in many respects. The struggles may push the children to work harder to become a part of middle-class society by acquiring the necessary literacy to gain access to that social sphere. Some may move away from the idea of empowerment through literacy by "keeping it real" and remaining within their social communities, protecting what has become their new identity, while others may not have the chance to pursue an education due to economic difficulties.

\section{Immigrant Women's Identity and Education}

In her article "Social Identity, Investment, and Language Learning," drawing on the poststructuralist conception of social identity, Norton (1995) puts forth a "theory of social identity which assumes that power relations play a crucial role in social interaction between language learners and target language speaker" (p. 12). She outlines deficiencies of the theories in second language acquisition (SLA) due to their failure to conceptualize the relationship between the individual language learner and the larger social context that affects the process of language learning (p. 10). She further argues that this disagreement in SLA scholarship should not be dismissed, and suggests that "this confusion arises because artificial distinctions are drawn between the individual and the social, which lead to arbitrary mapping of particular factors on either the individual or the social, with little rigorous justification" (p. 11). While outlining the gaps in SLA theories and calling for the reconceptualization of the SLA theory of the individual, Norton suggests that the language learner's introversion or silence in the second language should be looked at in terms of the social context, which can affect the learner's self-confidence and worth and either encourage them to speak or mute them (pp. 11-12).

In support of her social identity theory, Norton (1995) provides an account of her research in 1990, a case study of the language learning experiences of five immigrant women: Mai from Vietnam, Martina from Czechoslovakia, Felicia from Peru, and Eva and Katarina from Poland. Norton's research was focused on addressing two major questions: (1) The available opportunities socially structured outside the classroom for immigrant women in Canada to practice and use English, their responses to the social opportunities to 
create, use, or resist the use of English, and to what extent their actions in taking or avoiding opportunities to practice English could be understood with regards to their investment in English or their changing social identities; and (2) how could this enhanced understanding of social identity and natural language learning of immigrant women inform SLA theory and ESL pedagogy in Canada? (pp. 13-14).

Norton (1995) indicates that motivation to learn English was not a concern among these women, as they all went to extra lengths to take courses and participate in this diary study, as well as indicating a desire to have more social contact with Anglophone Canadians. Moreover, Norton explains that all the women, except Martina, expressed comfort speaking English with friends. However, Norton found that all five women were uncomfortable conversing in English with people in whom they had "a particular symbolic or material investment." "Eva, who came to Canada for 'economical advantage', and was eager to work with [A]nglophones, practice her English and get better jobs, was silenced when the customers in her workplace made comments about her accent." Mai, who felt her future, job security, and financial independence were in the hands of management, was most uneasy conversing with her boss. And Katarina, who escaped from a communist society, was stressed by speaking English with her Anglophone doctor, teacher, and professionals. For Martina, who occupied a surveyor's job in her own country and immigrated "for her children," her frustration lay in her inability to "defend her family's rights in the public world," while Felicia from Peru, "who had come to Canada to escape 'terrorism,' and had great affective investment in her Peruvian identity," felt uncomfortable speaking English in front of fluent Peruvian English speakers (all quotes p. 19).

Norton's research shows that power dynamics play a crucial role in the formation of social identity in a particular discourse. In the case of Felicia, the Peruvians who have advanced linguistic skills have gained access to the dominant discourse which Felicia struggles to reach. Her feelings of discomfort relate to her identity as a Peruvian who has not yet acquired the language other members of her ethnicity have mastered. Furthermore, Norton's research outlines the multiplicity of immigrant women's identities, from the private family sphere to the many social spheres in which they participate. For instance, in Martina's case, whose identity as a primary caregiver was the driving force of her investment in English, her central concern was burdening her children with "taking on more public and domestic tasks than were absolutely necessary" (p. 21) due to her struggles with English. Norton points out that primary caregiver is only one of the multiple sites that affect the formation of Martina's identity; others include being an immigrant, a woman, a mother, a language learner, a worker, a wife, etc. Norton's case study supports her argument that "the individual language learner is not ahistorical and unidimensional but has a complex and sometimes contradictory social identity, changing across time and space" and that "motivation is not a fixed personality trait but must be understood with reference to social relations of power that create the possibilities for language learners to speak" (pp. 25-26).

Norton's arguments are not limited only to language learners, but apply to all learners in general. The multiplicity of adult identities and social conditionings that contribute to the formation of individual identity is what scholars like Bourdieu (1987), Gee (1992), and Anderson (1994) have emphasized and made the basis of their theories. 
Bourdieu (1987) asserts that a language learner's habitus must be taken into account in order to provide a more inviting and effective environment for acquisition.

According to Anderson (1994), the "reader's schema, or organized knowledge of the world, provides much of the basis for comprehending, learning, and remembering" ( $p$. 465). And Gee (1992) defines "discourse" through its association with language, thinking, and acting within a social network. One of the most important factors Gee points out is that "discourses are inherently related to the distribution of social power and hierarchical structure in society" (p. 14). Thus, the importance of mastery of certain discourses is magnified in society in order to attain control over a certain medium and gain social and/or political power. In the case of immigrants, women in particular, whose primary discourse does not match the dominant secondary discourse, access to this discourse is far more difficult than for native speakers.

It is important to note that the women in Norton's case study mostly come from European cultural backgrounds, which makes their cultural transition much easier than those from entirely different cultural spheres such as the Middle East. These women are just a few among the massive numbers of immigrants who struggle to form, defend, and gain identity and space in their new social sphere.

The issue of immigrant struggle and identity crisis is not a newly recognized phenomenon. In a case study conducted by Shiva Sadeghi (2008) on immigrant Iranian students in Canadian institutions of higher education, she found commonalities in the underlying themes of the six female participants' experiences and the meanings they all attributed to these experiences. Sadeghi states that the "desire for 'learning'-influenced by complex and intertwined interactions between their cultural values and perceptions and their unique historical and social stances as women and first-generation immigrantsseemed to play an important role in the lives of these six women" (p. 221). The results of the study further indicated that the new country presented women with the opportunities to "redefine their roles" with regards to their multiple sites of identity "as women, mothers, wives, daughters, and educated individuals; however, their immigrant status was intertwined with complexities of living and learning in the margins of the new country" (p. 222). In retrospect, Sadeghi's research also showed that their efforts to "renegotiate their new identities as educated women in the face of traditional cultural images as housewives meant that these women found themselves at the periphery of their families, often questioning, objecting, and resisting men's domination" (p. 222).

\section{Immigrant ESL Students in the Classroom}

To be multicultural is to be diverse, which is the foundation of today's societies in North America, Australia, and parts of Europe. Thus, these societies demand diversity in all aspects of social and professional life; the United States in particular has one of the largest multicultural populations in the world. And yet we struggle to meet the educational demands of our multicultural society, even though we continue to accept new immigrants and refugees that add to the rich makeup of our heterogeneous culture. So the question that has been raised and explored by many researchers remains: how can we teach ESL or bilingual students whose dominant language is not English and address the learning needs 
of such students in multicultural classrooms? Furthermore, what teaching methods could be applied to encourage the progress and learning of these students?

Based on the literature review and my personal experience as an ESL student exposed to and influenced by several cultures, I find the classroom to be the most crucial place that affects and encourages or discourages students' linguistic and academic learning. Even if students have strong family support encouraging their academic progress, what takes place in school can solidify the learning process or disintegrate it and cause students to become introverts and avoid recognition of their skills and potentials. This section emphasizes the importance of three elements that can potentially improve language learning process of ESL students and ultimately, success in school: (1) utilizing narrative as a cultural and personal exposure to understand students' backgrounds and learning foundations, as well as triggering investigation and communication of their cultural capital (Bourdieu, 1987) and further exploration of their related interests; (2) teacher-student relationships, understanding, and trust, (3) teacher training in cultural studies and diverse teaching methodologies that target multicultural classrooms.

In her article "Barriers to Meaningful Instruction for English learners," Lois Meyer (2000) discusses the obstacles that hinder effective instruction for ESL students who face linguistic and cultural difficulties in the classroom. Meyer begins her discussion by stating, "[t]he English learner sits in class, not completely understanding or fluently speaking English and possessing limited experience with the cultural practices and expectations of school," and goes on to ask:

What is it like for this student to go to school in English only? When the learner's language is not the school's language, how does he or she feel when confronted with academic lessons, school texts, and classroom learning activities that are partially or totally incomprehensible? (p. 228)

As a scholar, I consider myself lucky in having the ability to answer all of these questions and more, as I was the unfortunate culturally shocked ESL student who sat in many classrooms without understanding the subjects being discussed. Numbers were my savior and words my enemy. Reading aloud was a horrendous experience that caused me nightmares each night. And though science was interesting and exciting, the language barrier caused difficulty in comprehending directions and explanations, which manifested itself in negative instructor and peer commentaries and dreading the classes entirely.

Few mainstream educators can comprehend the magnitude of confusing experiences the individual ESL student goes through based on their personal background and change in habitus, a concept that, according to Bourdieu (1987), refers to a person's disposition and beliefs based on personal environment and experience that condition a person to act and think in a certain way. ${ }^{1}$ However, by examining individual cases, we can gain a glimpse of their experience and better understand their needs in order to design

\footnotetext{
${ }^{1}$ As Bourdieu stated,"The habitus entertains with the social world which has produced it a real ontological complicity, the source of cognition without consciousness, of an internationality without intention, and a practical mastery of the world's regularities which allows one to anticipate the future without even needing to posit it as such" (quoted in Kramsch, 2008, p. 38, see also Kramsch, 2009).
} 
teaching strategies and learning environments that encourage their progress and remove the negative labels and connotations attached to their learning process. After all, the immigrants of today build the future of our nation. Thus, I will conduct this investigation through an autoethnographical examination of my own literacy process as a young girl in Iran and an Iranian ESL Middle School student in England, and briefly discuss two negative literacy experiences as an undergraduate immigrant student in Canada, and an adult US immigrant in graduate school. Removing myself from the context, I will briefly examine a poem I wrote in English at the age of 13 after less than a year of being exposed to English, in order to assess cognitive process and cultural background and experience.

\section{Literacy and Linguistic Autoethnography Education in the Islamic Republic of Iran}

My personal memories of Iran among family and friends, behind closed doors where the Islamic government did not have the opportunity to impose and suck the joy out of life, are happy ones. I had a rich childhood with a scholarly family who encouraged academic and social learning and personal growth. However, school was another story. My education in Iran from first to sixth grade consisted of rigorous memorizations and tests almost every day. This education system was very much what Freire (1970) calls a banking system, where the teacher was the depositor, the mechanical narrator of abundant information, and the students were the depositories, the pit into which teachers dropped information and expected its regurgitation the following day on a test (p. 79). Not much communication in terms of critical thinking or discussion of subjects that triggered cognition or the invention and reinvention of knowledge took place in the classrooms.

When it came to religious and social studies courses, the material would become frustrating and the tests themselves nonsensical since the correct answers were those of the teachers' and the books'. Questioning the logistics was dangerous, especially pertaining to theology. In fact, if teachers discussed anything, it was to relay what we "should" believe and know according to Islamic laws; to question Islam and its laws was to question the faith and god, which was a sin. Freire's (1970) statement that the "banking concept of education, which serves the interests of oppression, is also necrophilic" (p. 77) is a perfect description of this teaching methodology.

Cultural Studies was exposure to cultural norms within the Islamic Iranian social sphere and excluded pre-Islamic history and culture or non-Muslim Iranians. Further, with the exception of other Islamic countries, Europe and the Americas were the evil "others" whose cultural norms were in conflict with those of the Islamic Republic. As Freire (1970) argues, "[o]ne of the gravest obstacles to the achievement of liberation is that oppressive reality absorbs those within it and thereby, acts to submerge human beings' consciousness" (p. 51). Needless to say, students did not, and, as we can witness from the events taking place in Iran today, do not have a voice. In fact, they are dehumanized if they attempt to gain a voice that does not promote the Islamic Republic's ideals, and are severely and violently discouraged by the government of having or portraying different perspectives. This is the concept of dehumanization of the oppressed stressed by Freire $(1970$, p. 88). This is not to say that Islam itself dictates such a teaching methodology. In fact, pursuit of knowledge is very much promoted and encouraged in Islam. Further, the implementation 
of such teaching methodology as well as inhibition of access to various kinds of knowledge does not prescribe to the Islamic doctrines about pursuit of knowledge.

\section{Move from Islamic Republic of Iran to England}

At the age of twelve, I moved to England, where I was first exposed to the English language in a West-Midland Black-country accent. At first, it was very difficult to learn this language as the people around me spoke English in a very different accent than my parents. Whatever my parents taught me would help others understand me but did not help me understand anything anyone else said. The change in social location and lack of knowledge about the new location caused much confusion and displacement. It took about six months for me to become somewhat fluent in English and learn to understand the black-country dialect and recognize the differences between various English accents.

According to Campano (2007), in contrast to the "subtle yet pervasive image of the ideal student," there is "the less-than-ideal student, whose education is framed as a series of problems: of language, cultural integration, parental participation, school readiness, and classroom decorum, to name a few" and in his experience it was often "the poorer students from immigrant, migrant, and refugee backgrounds" who did not fit into the misguided ideal. Campano indicates that they received various instructional and social interventions that "often barred these students from the kinds of rich curricular experiences necessary for success in higher education and beyond" (both quotes, p. 49).

This was certainly the case for me in the first two years of my schooling in England. The school I attended did not have a program for nonnative English speakers; in fact, I was the first student at that school who could not speak English. Thus, I was the problem child with close to zero level of comprehension, and as a desperate resort, the Headmistress assigned a male teacher to work with me individually in all subjects. It was ironic that the Headmistress paid no consideration to my cultural background and experience in assigning a male instructor to a girl freshly arrived from a rigid Islamic country that did not allow for male-female interaction. Regardless of the discomfort caused by the instructor's gender, our method of communication was through drawings and numbers, and as I remember, he was not a very talented artist! Furthermore, this instructor, who I believe was ignorant of the negative effects, constantly made me aware of my deficiencies in language and caused me much humiliation by chuckling or showing signs of frustration as I made mistakes. However, he tried very hard to trigger communication and understanding.

Meyer (2000) notes that "there are predictable areas of confusion for Limited English Proficient (LEP) students any time an academic lesson is taught through English." If the teacher does not do the instructional work to "help construct their understanding and participation," these lessons will be "confusing and even overwhelming" for the students (p. 228). The time I spent with the instructor was certainly confusing and frustrating. Had the instructor been female and had there been some formal language instruction instead of free-form language learning, and planned lessons with the instructor on subjects such as science, geography, and math, which were familiar to me, I believe learning at a productive and cognitive level could have been achieved through one-on-one instruction. Furthermore, the instructor could have asked me to draw something that represented my life, background, or interest in order to tap into what Bourdieu (1987) calls "cultural 
capital" and Meyer (2000) refers to as "funds of knowledge" (p. 230). By utilizing my experiences, asking me to narrate through drawings, and attempting to explain the stories or events, the instructor could have given the impression that he valued my personal knowledge, what I had already learned and experienced, which would have triggered my interest and enthusiasm to communicate something about myself and encouraged higher cognitive learning.

When the method of one-on-one instruction failed after a few weeks, the Headmistress's next strategy was to place me in the same classrooms as native English speakers with this instructor by my side as a personal tutor. Thus, I sat there in classes such as history, religion, English, and science where the teacher spoke a language I did not comprehend and did not require me to participate. I was a nonentity among the learning students.

At first, having the instructor there with me was comforting, but I soon realized that his presence caused me much grief and made me the subject of ridicule. As a result, the instructor was removed from classes in which his presence might not be needed as much. I was stuck in classrooms where I failed to comprehend the content and was completely unable to participate in class projects, too afraid to raise questions, and failed to engage in discussions. Thus, not having access to the dominant language (Gee, 1992) excluded me from the dominant discourse academically and socially.

With the move, my environment changed dramatically and I experienced drastic culture shock. I now sat in a coed classroom where boys and girls passed notes and commented on each other's physical attributes. I tried to avoid the boys and their comments and could not relate to the girls in my class. Based on my habitus at the time, my classmates' behavior seemed disrespectful to each other, to the teachers, and to their families. They would openly discuss their families and express hatred towards them; they swore at each other and their parents, and all their dilemmas and hardships centered on rejection from the opposite sex and discipline from their parents. I remember thinking that none of these children would survive if they were in Iran during the war. They would not know how to act when the bomb-siren went off and they would certainly face detention with severe consequences for speaking and behaving this way. This was a massive culture shock and made it increasingly difficult for me to communicate with the other children, as we were so different and did not understand each other's behavior.

In terms of fitting in socially, there were two categories of girls: the popular girls who wore shorter skirts (though we had uniforms) and makeup, and flaunted themselves at boys, and the timid girls who were categorized as the "nerds" because they paid attention in class and spoke "correctly." I fit in neither category at this time, since I was trying to learn the English language and just survive. I still had the nightmares of war and the memories of being almost kidnapped three times. However, the nightmares of school and failure to speak to my peers and not doing well in class and saying the wrong thing or mispronouncing a word and getting laughed at, were now part of those nightmares.

Nonetheless, the teaching methodology in England, which was a problem-posing method (Freire, 1970) where the teachers present students with a problem and encourage students to provide various solutions to it, was refreshing; and even though I did not speak 
the language, I was able to learn through practice. Ironically, my English class was always my favorite and my most dreaded period as I had the opportunity to read, comprehend, and practice writing but detested reading aloud. After reading the poems of William Blake and William Butler Yeats, Mr. Yeats, my English teacher, encouraged us to write a poem. The following was mine.

\section{Wish for Peace (1992)}

Every night in my sleep

I live in a world of dreams.

In this world of dreams, Whatever I have seen, Is nothing like reality;

There is no responsibility. There's no gun; there's no blood;

Everything is fine cut.

In this world there are no cars,

No pollutions, just stars.

Everywhere is filled with joy, Children's laughter, rock ' $n$ ' roll!

Everyone is left in peace, No kidnappers, nor a thief. Everyone's proud and happy, Like I said: "nothing like reality."

Everyone's like they seem In this wonderful dream.

Then again, it's all a dream!

Does it have to be like this? Filled with anger, not with peace? The real world, that's what I mean,

Does it have to be so mean? Filled with rage and gun-machines, Blood's everywhere like a stream.

Children crying out, begging for mercy, Just want to have a home amongst their family.

Parents are crying who lost their loved ones,

Cursing the people who brought them the song

That says: "fighting for your country

Will bring you dignity."

But all it does is to bring

Pain to the hearts of their family. 
Why should we fight?

Why should we kill?

To bring power just to thrill

The people who want more power

To rule the world and build their tower.

We are killing real people

To get one thing out of it all

And that one thing is more power

Which has never lasted forever.

If I could, I would remain

In my own world all the same.

But I know whatever I may see

In this world, can never be.

Because all this that I see,

Is nothing more than just a dream.

Removing myself and examining the content, I am speechless at my ability to express so much in one poem. This is a morbid poem written from a 13-year-old's perspective that portrays the student's experience of chaos, responsibility, pollution, death, and war; something of which many of our US born children and adults have no conception today. As Campano (2007) states, "stories have an obvious interpersonal value because they enable students to weave their unique histories into the fabric of the classroom community" (p. 50). Thus, recognition and utilization of students' cultural capital to build cognitive progress is very important. Were this submitted to me by a student, I would be able to recognize some of the student's experiences and his/her background, and would have encouraged the student to further develop those experiences in prose perhaps, or investigate the history of the war and express his/her opinion on it, and so on.

Of course it is very difficult to relate to such a student as a teacher who has no conception of the magnitude of emotional scarring such experiences can leave. So, how could a teacher teach this student without having the ability to relate to his/her experiences? My teacher's response, as I remember, was that I had done a good job with writing and I had advanced so much in English. Though he was encouraging, his response was inadequate in raising my interest to continue this project.

Luckily my teachers were fascinated by me; I was an unusual case, a chance for experimentation. My homeroom teacher, who was also my English teacher, used various methods to encourage my learning through writing. Although he did not tap into my cultural capital, his praising of my progress was encouragement enough to keep me on track. However, my mother was the real driving force behind my academic learning progress. As Orellana and Gutiérrez (2006) suggest, we must challenge the notion of an individual's separability from his/her context and encourage integration of primary and secondary social spheres of the nondominant and immigrant student. This promotes development of individual identity and progress of the nondominant individual through the use of personal domain and experiences, as well as school-dominated experiences. My mother, being an academic, emphasized the importance of academic progress and 
therefore, my primary discourse was only different from my secondary discourse in language; and even that difference my mother worked hard to minimize. Thus, through the integration of my primary and secondary spheres, I was able to overcome language and cultural barriers, gain access to the dominant language, and succeed and excel in school.

\section{Mastering the Dominant Discourse}

According to Gee (1992), "discourses are inherently related to the distribution of social power and hierarchical structure in society" (p. 14). Thus, the importance of mastery of certain discourses is magnified in society in order to attain control over a certain medium and gain social and/or political power. Gee explains that in order to control discourses, one must acquire and learn those discourses, and that middle-class children acquire literacy within their family sphere (primary discourse) and develop meta-level cognition through learning at school (secondary discourse). However, it is questionable whether this rich acquisition and learning combined for the ESL student can be powerful enough to tap into the dominant discourse without discrimination. Even though I had managed to learn the dominant literacy and language at school, was fortunate to acquire both the dominant academic and social literacies from my family, and had access to the dominant discourse, I still encountered numerous obstacles due to being a nonnative English speaker and the "other" in both undergraduate and graduate school.

During my second year of undergraduate studies in a Canadian university, I had a conflict of opinion with one of my male professors over having cited a work inaccurately in one of my papers. In our meeting in his office, he observed me from head to toe and questioned my academic achievements saying, "I don't know what you do for your other professors to get the As and Bs you have on your transcript, but you are not receiving an A from me and I don't think you can make it as a journalist. I highly encourage you to rethink your future aspirations." His words still echo in my head. When I reported this incident to the Dean, she seriously discouraged me from pursuing it any further as he was a prominent professor and I could not provide an audio recording of his comments. The Dean emphasized that it would affect my relationship with the other professors in the department if I decided to pursue the matter. She indicated that she had dealt with similar complaints from several female students in the past about this professor and they similarly decided to drop their pursuit.

At that point I realized that I had overcome so much to reach this stage, to be an English literature major and do so well, and yet having access to the dominant discourse was not enough. There were still many social and political barriers to overcome. What seemed ironic to me was that this professor was a second-generation immigrant and not from a highly educated family, as he had confessed in class. And yet, he questioned my abilities for academic success, not based on my academic performance, but based on my gender and his notion of my inability to cite accurately, which was due to his lack of teaching the matter in class. It was amazing how indiscreet this professor was about his gender bias. He only addressed the boys in class and praised them for their accurate interpretations of poems, which were in line with his own; the girls were just bodies filling the seats. Obviously such teachers should not be in classrooms, as they hinder learning and discourage progress. But what can be done when the system provides support for such 
professors to flourish in the field and Deans support them by scaring students and discouraging them from filing complaints against them?

Even as a graduate student who had learned to negotiate the dominant discourse by gaining access to the language and culture, socially and through education, and had become a part of it, I was faced with discrimination based on being a nonnative speaker, and one whose writing style was not up to par with the American standard. At this time, when I inquired about my B+ grade on a paper, after her many attempts to give valid reasoning of her grading process, my professor in an aggravated tone indicated that it was evident from my writing that I was not used to the American composition style, which was the appropriate form of discourse at that university and in the US. She indicated that the British and Canadian narrative styles leaked throughout my paper and this was not the desired assertive discussion form. Therefore, in order to succeed there, I had to change my writing style and adopt a more aggressive American tone. Though I do not think that this professor's comments were ungrounded, I believe her strategy for addressing the importance of conforming to a specific composition style in order to become part of the discourse was not that helpful. Constructive criticism would have gone much further in helping me address what she termed my weakness. Instead, I walked out of her office feeling completely inadequate as a writer, and this feeling lasted through the first two semesters of my graduate studies.

When thinking about my linguistic autobiography, it is hard to narrow down what specific events in my life influenced the development of my language. In fact, my language skills are still evolving. I am forever the ESL student who has moved between countries and continents and still struggles with perfecting her knowledge of one language. However, even though English is my adopted language and secondary discourse, I am most fluent in and comfortable with English. This is because I adopted English as my dominant language and sometimes use it even in my primary discourse with family and friends. I sometimes still feel inadequate compared to my colleagues who have had the benefit of learning English and its structure since childhood in a single dialect or culture, whereas I have had to learn, adopt, and use three different dialects of this language: British, Canadian, and American, and all of the subdialects within each culture. This feeling of inadequacy is the result of years of humiliation and negative commentaries and categorization as an ESL student. Ironically, it is this feeling of inadequacy that had driven me to learn and strive to access and become a part of the dominant discourse. Paradoxically, I spent five years of my graduate career teaching undergraduate students how to properly use the English language in their compositions in a professional context. Thus, as a nonnative English teacher and researcher, I am interested in investigating the struggles of nonnative English learners and ESL students in order to develop teaching strategies that improve the learning experience and growth of these students.

\section{Emphasis on Implementation of Strategies to Encourage ESL Students' Learning}

As discussed earlier, narrative is a powerful way to tap into the ESL, immigrant, and socioeconomically disadvantaged students who do not have the benefit of a correlation between their primary and secondary discourses. A poem or a personal narrative reveals a great deal about its author and can be used as a stepping stone for the student's utilization 
of their cultural capital to access the dominant discourse. As Campano (2007) stresses, "[o]ne purpose of inviting the students to share their stories is to better understand how the students can use their background knowledge to gain access to curricular content" ( $p$. 50).

It is apparent that none of the teachers I encountered in England had training in teaching ESL students or in multicultural classrooms. Lack of training and preparation causes frustration and confusion for both the students and the teacher and vastly hinders students' learning. As Meyer (2000) discusses, lack of cultural knowledge is a great barrier to effective instruction. Exposure to various cultures and practices through teacher training and academic courses on various cultures is an excellent way to enhance teachers' understanding of students' cultural and social capital. Furthermore, adopting critical literacy in the classroom, especially from the elementary level, is crucial to students' development and cognitive process. As Lewison and Harste (2008) assert, research shows that implementing critical literacy in the classroom starting at the elementary level results in students' increased engagement with the topic and its exploration, triggering more substantial classroom discussions and increasing students' success level as they become critical thinkers and learners. Narrative can be the first step to critical literacy.

\section{Implications for Research}

This paper has outlined some of the leading discussions surrounding immigrant literacy and identity, focusing on women and their negotiations of their identities as they begin their struggles as immigrants. Although there is vast research in the field of immigrant identity and literacy, the focus seems to rest on immigrant families' struggles in the new country in terms of attaining literacy, negotiating identities, and crossing boundaries. Furthermore, scholarship seems to focus predominantly on dealing with immigrant children's identity and motivation to pursue education in schools. However, there is still a demand for extensive research in this area that would encourage changes in policies and curriculum to address the needs of our multicultural classrooms.

With regards to immigrant adult literacy, what is seen in the literature seems to center on the deficits of second language learners' acquisition, whether individually or socially. More research needs to be conducted on the positive aspect of immigrants' struggles that motivate and lead to individual desire for higher education and success in the new sociocultural sphere. My research has led me to the belief that there is a major gap in scholarship with regards to examining the struggles of highly literate adult immigrants. I believe there is a need to examine highly educated immigrant families, their position on education, and their struggles with attaining access to the dominant discourse and succeeding in the new society. Is Bourdieu's theory of agreement of primary and secondary discourses leading to success in the dominant discourse correct in the case of educated immigrants even though they are second language learners? It seems that once they are considered to have access to the dominant discourse in one society, their struggles appear less relevant compared to the immigrants from lower socioeconomic and cultural spheres. What is more, the education of the intellectual immigrants often does not gain them status in the new country. In a way, their struggles with identity and displacement are far more complex than those of the working class. This was certainly the case for my family. 
Furthermore, in the case of the adolescent children of highly educated immigrants, the pressures of gaining access to dominant discourses and succeeding in pursuit of higher education add to their struggles to learn the language and succeed as immigrants in the new country without losing their heritage and cultural identity.

Sadeghi's (2008) research presents an important aspect of immigrant desire for higher education in relation to attaining individual and social agency and power by entering the dominant discourse. Education in past 20 years has presented a new avenue for the immigrant women who seek to overcome the struggles of being in a foreign sociocultural setting and breaking the cultural boundaries of their identity as only the mother, wife, and caregiver in the family by becoming an active participant in the larger sociopolitical sphere through gaining access to and engaging in the dominant discourse. In my own case, having experienced the pressures of succeeding in the academic world by following in the footsteps of my immigrant parents, I find myself extremely challenged in trying to balance between time, sociocultural spaces, and various sites of identities. I am an Iranian woman who married an American; and as a mother, I struggle to raise my children as bilingual American-Iranians while trying to instill certain cultural values, among which is the emphasis on education. As a wife, I struggle with power relations with my husband in the household, as I see my role in the family and social sphere equal to his, if not greater. As a strong and educated woman, I struggle to keep up with my social identity when difficulties in the family sphere influence my performance and participation in the social sphere. As a product of my cultural and family upbringing, I see no other choice than to raise my children with the belief that they must attain the highest level of qualification possible in their desired profession and leave no room for negotiation. And finally, as a professional, I see the problems with such strong beliefs and assertions on my children's future identities and place in society.

The American ideal of being who one wants to be did not apply in my case, as my parents always emphasized that being who one wants to be should be following the desire to reach the highest level of knowledge in the path one wants to pursue. Value of one's identity in Iranian culture is measured by one's knowledge and qualifications in that culture. This belief is ingrained in the child at an early age, which becomes the most important factor of shaping that child's identity with regards to the position they hold in society.

Having briefly discussed the complexities of my own identity formation as a firstgeneration Iranian immigrant woman and the child of highly educated immigrant parents, and having witnessed the same phenomena in my culture with other Iranian immigrant families, I see a great need for more research in this area. In order to understand the immigrant experience and identity, all classes of immigrant populations need to be studied. Therefore, examination of the educated immigrant population's adjustment to the new sociocultural sphere and workplace with limited language acquisition or questions of identity is needed to show how this affects the education of second-generation immigrants. Finally, I propose that in order to better understand the social practices of immigrants and their struggles in the new country, such research should be approached from a cultural studies perspective in order to effectively examine the integration of cultural identities with regards to educational training. 


\section{References}

Anderson, R. C. (1994). Role of the reader's schema in comprehension, learning, and memory. In R. B. Ruddell, M. R. Ruddell, \& H. Singer (Eds.), Theoretical models and processes of reading (4th ed., pp. 469-482). Newark, DE: International Reading Association.

Bornstein, M. H., Deater-Deckard, K., \& Langford, J. (2007). Introduction. In J. Langford, K. Deater-Deckard \& M. H Bornstein (Eds.), Immigrant families in contemporary society (pp. 1-6). New York: Guilford Press.

Bourdieu, P. (1983). The forms of capital. In J. G. Richardson (Ed.) Handbook of theory and research for the sociology of education. Westport, CT: Greenwood Press.

Campano, G. (2007). Honoring student stories. Educational Leadership, 65(2), 49-54.

Ferdman B. M., \& Weber, R. M. (1994). Literacy across languages and cultures. In B. M. Ferdman, R. M. Weber, \& A. G. Ramírez (Eds.), Literacy across languages and cultures (pp. 3-29). Albany: State University of New York Press.

Foucault, M. (1978). The history of sexuality: An introduction (vol. 1; R. Hurley, Trans.). New York: Random House. (Original work published in 1976).

Freire, P. (1970). Pedagogy of the oppressed. (M. B. Ramos, Trans.). New York: Continuum.

Gee, J. P. (1992). What is literacy? In P. Shannon (Ed.), Becoming political: Readings and writings in the politics of literacy education (pp. 21-29). Portsmouth, NH: Heineman. (Original work published in 1987).

Hernandez, D. J., Denton, N. A., \& Macartney, S. E. (2007). Family circumstances of children in immigrant families. In J. Langford, K. Deater-Deckard \& M. H. Bornstein (Eds.), Immigrant families in contemporary society (pp. 9-29). New York: Guilford Press.

Kramsch, C. (2008). Pierre Bourdieu: A biographical memoir. In J. Albright \& A. Luke (Eds.), Pierre Bourdieu and literacy education (pp. 50-67). New York: Routledge.

Kramsch, C. J. (2009). The multilingual subject: What foreign language learners say about their experience and why it matters. Oxford: Oxford University Press.

Lewison, M., \& Harste, J. C. (2008). Creating critical classrooms: $K$-8 reading and writing with an edge (pp. 1-23). Hillsdale, NJ: Lawrence Erlbaum.

Meyer, L. M. (2000). Barriers to meaningful instruction for English learners. Theory into Practice, 39(4), 228-236.

Norton, B. (2010). "Language and identity." In N. H. Hornberger \& S. McKay (Eds.), Sociolinguistics and language education (pp. 349 - 369). Clevedon, UK: Multilingual Matters.

Norton, B. (1995). Social identity, investment, and language learning. TESOL Quarterly, 29(1), 9-31.

Orellana, F. O., \& Gutiérrez, K. D. (2006). What's the problem? Constructing different genres for the study of English learners. Research in the Teaching of English, 41(1), 118-123. 
Phinney, J. S., \& Ong, A. D. (2007). Ethnic identity development in immigrant families. In J. Langford, K. Deater-Deckard, \& M. H. Bornstein (Eds.), Immigrant families in contemporary society (pp. 51-68). New York: Guilford Press.

Sadeghi, S. (2008). Gender, culture and learning: Iranian immigrant women in Canadian higher education. International Journal of Lifelong Education, 27(2), 217-234. 


\title{
Students Writing across Cultures: Teaching Awareness of Audience in a Co-curricular Service Learning Project
}

\author{
Beth Lewis Samuelson \\ James Chamwada Kigamwa
}

\begin{abstract}
We examine a model for out-of-school literacy instruction using language and cultural available designs for teaching awareness of audience across cultures. The literacy model described here engages undergraduate and secondary students in a crosscultural story-telling exchange and calls for anticipating the needs of young readers who do not share linguistic or cultural backgrounds. We describe the process of helping the writers to understand their Rwandan audience and highlight some of the linguistic and cultural issues that arose in the early drafts and persisted throughout the editing process despite direct feedback. We describe the workshops in which we discussed available linguistic and cultural designs and track some of the responses of the writers. And finally, we examine a story from the third volume for evidence that the writers had addressed the needs of the Rwandan readers in their stories.
\end{abstract}

\section{Introduction}

Audience is a crucial consideration for effective writing, yet many students struggle with imagining an audience for their work. Questions about how to define and address the audience for a written text and how to teach students to "write to the world" (Lunsford \& O'Brien, 2008, p. 234) are staple issues in the study of composition and rhetoric (Ede \& Lunsford, 2003). These questions have re-emerged in theories of multimodality and literacy as a matter of design (Kress, 2010), where production and presentation of knowledge via multimodal means positions the communicator as a rhetor.

[T] he rhetor as maker of a message now makes an assessment of all aspects of a communicational situation: of her or his interest; of the characteristics of the audience; the semiotic requirements of the issue at stake and the resources available for making an apt representation; together with establishing the best means for dissemination ... (Kress, 2010, p. 26).

We also adopt Bakhtin's (1986) notion of addressivity as a constitutive feature of the utterance, which always possesses the quality of speaking from a point of view, always responds to something previous, and always anticipates a response. Just as an utterance always exhibits addressivity, it is also always 
permeated by the social, cultural, political and historical contexts from which it emerges, providing the basis for understanding rhetorical concepts such as audience (Weiser, Fehler, \& Gonzalez, 2009), voice (Sperling \& Appleman, 2011), and style from sociocultural perspectives on the socially situated nature of language and literacy.

The research agenda for the New Literacy Studies (NLS) builds on anthropological work that has investigated various socially and culturally situated contexts for literacy use (Akinnaso, 1991; Heath, 1983, 1994; Scribner \& Cole, 1981). This agenda challenges dominant perceptions of literacy by developing models for pedagogy that can capture the diversity of and variety of literacy practices across cultures and in out-of-school contexts (Pahl \& Rowsell, 2005). As the insights drawn from studies of culturally and socially situated literacy practice are put to pedagogical use, one of the ongoing concerns of composition and rhetoric has continued to appear as an area that needs attention: awareness of the audience and the ability to adjust to the communicative contexts and demands of different audiences. For example, in an exchange of alphabet books between schoolchildren in South Africa and Australia, much of the revision of the texts and illustrations was orchestrated around helping students to realize that their local funds of knowledge (Moll, 1994) would not travel well between schools. Through feedback from their teachers and from the university collaborators, the students in South Africa considered how representations of violence in their community might be understood by the schoolchildren in Australia who were the audience for their stories (Janks \& Comber, 2006). In an earlier study, Freedman (1994) and a team of US and British teachers engaged middle school students in a year-long exchange of writing projects and found the different audience to be a highly motivating factor for most students.

In this working paper, we build upon these insights and examine a model for using linguistic and culturally available designs (Kern, 2000) for teaching awareness of audience by engaging in purposeful communication across cultures and by anticipating the needs of young readers who do not share linguistic or cultural backgrounds with the writers.

\section{The Storytelling Project: Teaching Students to Write for a Cross-Cultural Audience}

The Storytelling Project involves undergraduate and secondary students in a crosscultural story-telling exchange that calls for anticipating the needs of readers who do not share linguistic or cultural backgrounds with the writers. It was initiated in 2008 to help students and teachers from the United States and Rwanda exchange stories about common themes and learn about each other. On the initiative of a group of middle school students and their teacher at the charter school, a partnership was formed between a living-learning residential program (Brower \& Inkelas, 2010) at a major Midwestern research university, a charter school serving an urban community in the northeastern United States, and a rural Rwandan primary school to create and share collections of illustrated stories. The students 
wanted to share stories and learn about their Rwandan counterparts, but they also wanted to publish materials that could be sold to support infrastructure improvements at the Rwandan school. The university students participated as mentors and facilitators to help the secondary students with authoring, illustrating, publishing and marketing a collection of their short stories. The undergraduates, usually freshmen or sophomores and residents of the living-learning center, were paired with the writers and mentor them with brainstorming, drafting, revising, editing, illustrating and publishing. In addition to the writing mentors, other undergraduates served as "collaborators," whose duties included editing and laying out the book and studying the history and culture of Rwanda so they could serve as resources to the writing partners.

In the second year of the project, with the help of their teachers and local secondary school students, the Rwandan elementary students also created their own stories to include in the collection. Each year, an anthology is printed and distributed to all of the children at the participating schools.

\section{The Storytelling Project and the New Literacy Studies}

As a collaboration across three schools and two continents, the project has several stated goals that are consistent with New Literacy Studies: (1) to foster global citizenship by promoting communication and understanding amongst students from diverse backgrounds in the United States and Rwanda; (2) to develop globallyminded students with critical literacy skills through models for cross-cultural teaching and learning; (3) to use mentoring to encourage younger students to prepare for higher education; and (4) to teach skills in authoring, illustrating, editing, publishing and marketing a yearly collection of stories written by students in Rwanda and the United States.

The Storytelling Project presented special challenges in terms of helping US students to select topics and concepts that the Rwandan children would find easy to understand. ${ }^{2}$ During the first year, the strategy that worked the best was to provide individual feedback on each of the twelve stories that appeared in the book. Samuelson, Kigamwa, and other team members read each draft twice and wrote comments on linguistic and cultural concerns, which were sent back to the writing mentor, who communicated the suggestions to the writer.

Three major areas came to light as challenging issues for the writers and their mentors. Without prior preparation to help them understand the linguistic needs of their Rwandan counterparts, who were trying to learn English rapidly as their school system had recently switched from French to English as the language of instruction (Samuelson \& Freedman, 2010), the US writers wrote prose that was too difficult for the Rwandan students to read. Without understanding the cultural context of the Rwandan students' lives, the US students referred to cultural

\footnotetext{
${ }^{2}$ At the Rwandan school, the focus of the storytelling has been to help the students improve their English skills. The question of writing for a US audience has not emerged as an important concern. The Rwandan writers have often written stories that are familiar to them from Rwandan oral storytelling traditions.
} 
constructs that did not translate well. Furthermore, the US students relied on assumptions about Rwandan culture that were poorly informed and reflected stereotypes that they had not considered critically.

Since the project is a youth-led initiative in which the students take leadership roles, the actual decisions about what to change in the story drafts were made by the student writer (mentee) and the university student (mentor) together. Some editing in the final stages of book production would occasionally override the work of the writing pair, but this was only done when there was serious concern that without the changes the stories would not be enjoyable and comprehensible for the Rwandan readers. This approach was very labor-intensive, and although the writers made some changes as a result of the feedback they received, the resulting stories needed extensive editing by a team of undergraduates and faculty advisors before they were ready to go to the printer. As a result of these challenges, our question became: How do we help the student writers and their mentors realize that the cultural differences between Rwanda and the United States will have significant impact on their writing at all levels?

With this critical question guiding our work, we turned to the research literature to learn how to help the writers and their mentors see how linguistic and cultural differences would play a critical role in their composing process. We asked if an international storytelling exchange could help students develop command of available designs in a variety of rhetorical and cultural situations (Cope \& Kalantzis, 2000; Kern, 2000). Audience emerged as a central concept as we asked ourselves what steps we could take to help relatively inexperienced writers envision the cultural situations, linguistic skills, and background knowledge of English language learners living in East Africa.

Contrastive rhetoric, based originally on theories about different expository text structures as the products of major world cultures and rhetorical traditions (Kaplan, 1966, 1987), has been a productive line of inquiry in the areas of English for Academic Purposes (Casanave, Belcher, \& Liu, 2004; Hamp-Lyons \& Hyland, 2004) and intercultural rhetoric (Connor, 2004; Jordan, 1997; Kaplan et al., 1994). This theoretical framework is mainly concerned, however, with flows of literacy from L1 to L2 contexts in which an L2 writer, typically an international student in a Western academic context, is composing a text for academic, professional, or technical communication. For example, the writer might be a Chinese student studying in a college ESL program (Cai, 1999) or an international student writing a personal statement for admission to a graduate program (Barton, Bragg, \& Serratrice, 2009). Alternatively, the writer might be a business or technical communication specialist composing a text for similarly educated readers of other Westernized, industrialized societies.

A recent adaptation of contrastive rhetoric directed at a well-educated, Western or Westernized writer is McCool's (2009) description of reader responsible and writer responsible cultures. In a reader responsible culture, the readers of the text are expected to make the necessary efforts to follow the writer's argument. As a result, prose can be embroidered and complicated, with the burden for any 
misunderstanding falling on reader. In a writer responsible culture, the writer has the task of making the text accessible and simple, as the burden for comprehension falls on the writer. McCool's guide echoes prior cognitive models for writer-based and reader-based prose (Flower, 1979; Flower \& Hayes, 1994; Hayes, 1996) and does not provide a model for situated literacy that fits with the needs of young writers learning to communicate effectively with peers who do not share their culture and who are still developing their English proficiency.

The contrastive rhetoric and intercultural communication models did not adequately account for the flow of literacy from US students to Rwandan students. Instead of trying to guide each international student on how to fit into mainly Western and writer-responsible academic and professional writing cultures, we were asking writers in North America to compose texts for non-Western English learners who were not transplanted from their own culture or educated into a globalized business culture.

The following sections provide an account of our involvement in assisting the writing partners with understanding their Rwandan audience. In the first section, we describe some of the linguistic and cultural issues that arose during the first year of the project. In the second section, we describe the training sessions and the linguistic and cultural designs we discussed with the writing partners during the second and third years of the project. In the final section, we examine a story from the third year for evidence that the writers are more familiar with the needs of the Rwandan readers.

\section{Direct Feedback in Year One}

"Naomi Goes to Summer Camp"

During the first year of the project, when asked to consider what the Rwandan students might be interested in reading, the US students initially wrote about what they believed the lives of the Rwandan students to be like. Since the students had limited exposure to Rwandan culture, mainly through discussions with their teacher and through some assigned reading, many stereotypical images emerged in their writing. In Figure 1, an early draft of a story about a young girl referred to "small African village," "two tiny classrooms," "a two-mile hike from school," "orphans," and "a place of hope." Some of this imagery may have been true. 
to the lives of the Rwandan children, but the authors were asked to share the details of their lives with the African children, not reflect their stereotypes about Africa back at the Rwandan children.

\section{Naomi}

Once there was a girl that lived in a small African village and her name was Naomi. She was an eight year old girl who loved to sing. She lived with her father and brother and went to an all girls' school in her village that taught all grades from 2 nd to 8th grade in two tiny classrooms. Naomi disliked her school because it did not have a music class.

One night it was dark and cloudy when she arrived home from her 2 mile hike from school. As she walked into the house she spotted her father and brother packing things. But the whole family wasn't moving, only her. Her father was sick and her brother wasn't able to care for her because he wasn't well either.

"Father, Father!! What is this?! What is becoming of our family?" said Naomi.

"Naomi, I and your brother have become ill and you will be better off without us right now."

"But where are you sending me father? I don't want to be an orphan and all alone" Naomi said.

"Don't worry my child, you will go to a place of hope, where you can be healthy and have a chance to succeed."

Figure 1: Excerpt from an early draft of "Naomi" [emphasis added]. Source: Reprinted with permission of the Storytelling Project.

\section{p. 2}

\section{Naomi Goes to Summer Camp [title page]}

Naomi is ten years old. Her father tells her she is a big girl now and that this summer she will go to a summer camp for the very first time. "Daddy, what will I be doing at summer camp?" Naomi asks. "You will be sleeping in the woods, learning how to swim, and making lots of new friend," he replies.

p. 3

As Naomi lies in her bed that night, she talks to Gula, her teddy bear, about going to summer camp. "What if when I am sleeping in the woods the tree monsters come out? I've heard they are very scary and like to kidnap children."

What if when I am learning to swim, the lake goblin comes out?" she asks Gula. "I've heard they are very slimy and like to grab children's feet."

p. 4

"Who else is going to be there?" she asks Gula. "I've heard that camps are run by evil witches who like to turn kids into frogs." As Naomi drifts off into sleep, images of scary tree monsters, slimy lake goblins, and evil witches go through her mind.

Figure 2. Excerpt from an intermediate draft of "Naomi" [emphasis added]. Source: Reprinted with permission of the Storytelling Project. 
With some feedback from Samuelson and the undergraduate writing mentor about the importance of writing from her own experience instead of trying to guess what the lives of the Rwandan children might be like, the author remade Naomi as an American girl going off to summer camp for the first time (see Figure 2). The question of cultural communication persisted, however, with the introduction of tree monsters, lake goblins and wicked witches, which may be frightening for some young readers. Samuelson provided the following feedback on the intermediate draft to the writing pair: Witches, goblins and monsters are much too scary. Try to have her be afraid of much more predictable things such as sleeping in a strange place or learning to swim.

Another issue that emerged with the early drafts was the use of complex grammar and vocabulary that was too difficult for English learners. In addition to the potentially scary topics, feedback for the intermediate draft of Naomi (Figure 2) focused on verb tenses. On this subject, Samuelson made the following suggestion: "If you change your story into simple past tense, you won't lose anything, but it will be much easier for low-level English learners to read."

Using the simple past or simple present tenses helps the writer use tensed verbs and avoid more complex verb structures containing modals, infinitives, and past or present participles (Lester, 2001). These multiple-word verb forms can create confusion for new English learners and can often be avoided by using a simple present or past tense verb. The resulting printed story incorporated these suggestions (see Figure 3). The writer also decided to remove the teddy bear, Gula, as an unnecessary character. The resulting story successfully achieved the goal of the project, which was to have the US children share aspects of their own lives with the Rwandan students in ways that were linguistically and culturally accessible.

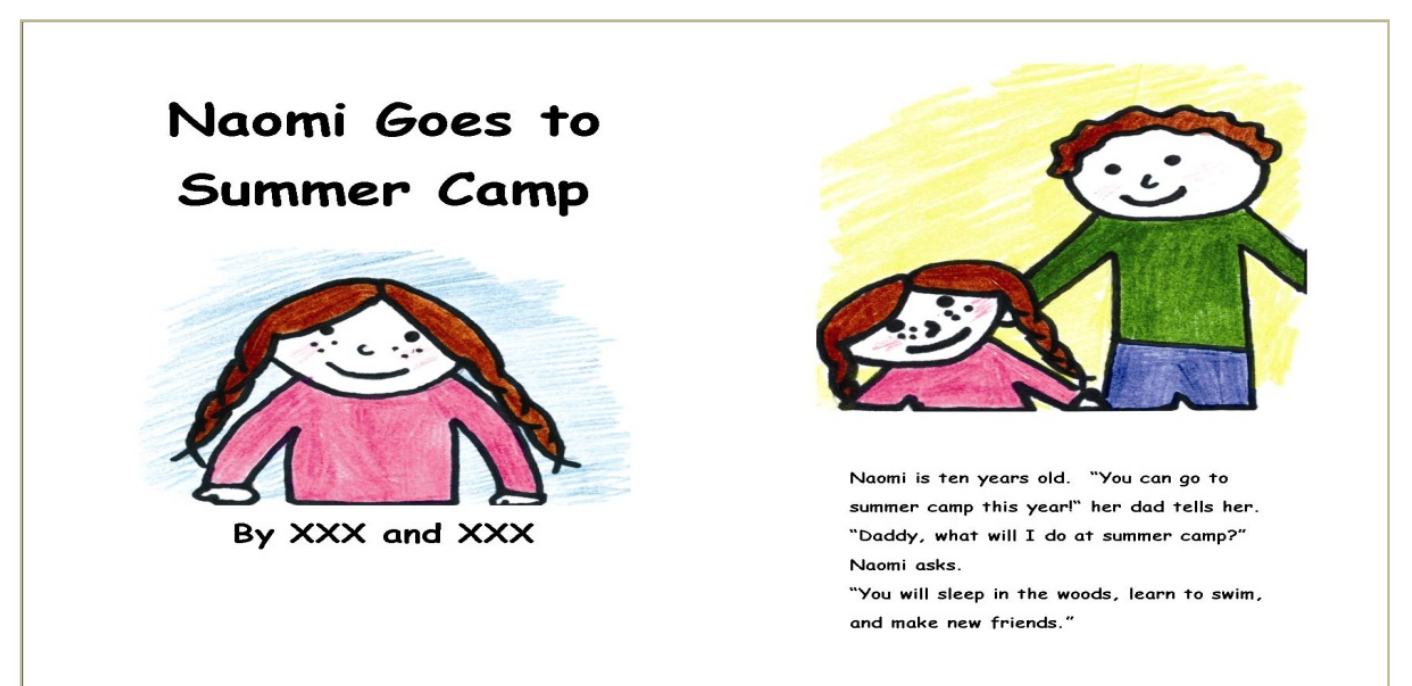

Figure 3. Published excerpt from "Naomi Goes to Summer Camp." ${ }^{3}$ Source: Reprinted with permission of the Storytelling Project.

\footnotetext{
${ }^{3}$ The names of the authors have been removed to preserve confidentiality. Multiple authors were listed for each story because the undergraduate writing mentors and collaborators who contributed substantially to a story would also receive a byline.
} 


\section{"Lux and Estelle"}

Another early draft, the story of "Lux and Estelle," highlighted some other language design issues that emerged in the stories during the first year of the project (see Figure 4). The writer started out with "once upon a time," a formulaic opener for a narrative genre that could potentially create confusion for English learners. Other features of this paragraph that could cause problems for beginning English learners included "there lived alone a boy," and "as brightly colored as the sun."

\section{Lux and Estelle}

Once upon a time in a small village outside of a large castle, there lived alone a boy with no past. He was strange - quiet and serious for his age - and he had no friends. His eyes were as brightly colored as the sun and his hair shone like the moon. Odd things happened when he was around, so the villagers and those who lived in the castle feared him.

Figure 4. Excerpt from an early draft of "Lux and Estelle" [emphasis added]. Source: Reprinted with permission of the Storytelling Project.

With this story, however, the author and her mentor did not make the changes suggested by the editors. Because of the Storytelling Project's strong emphasis on leadership by students, the editors made only minimal changes to the final proofs. The results can be seen in a published excerpt from "Lux \& Estelle" (Figure 5).

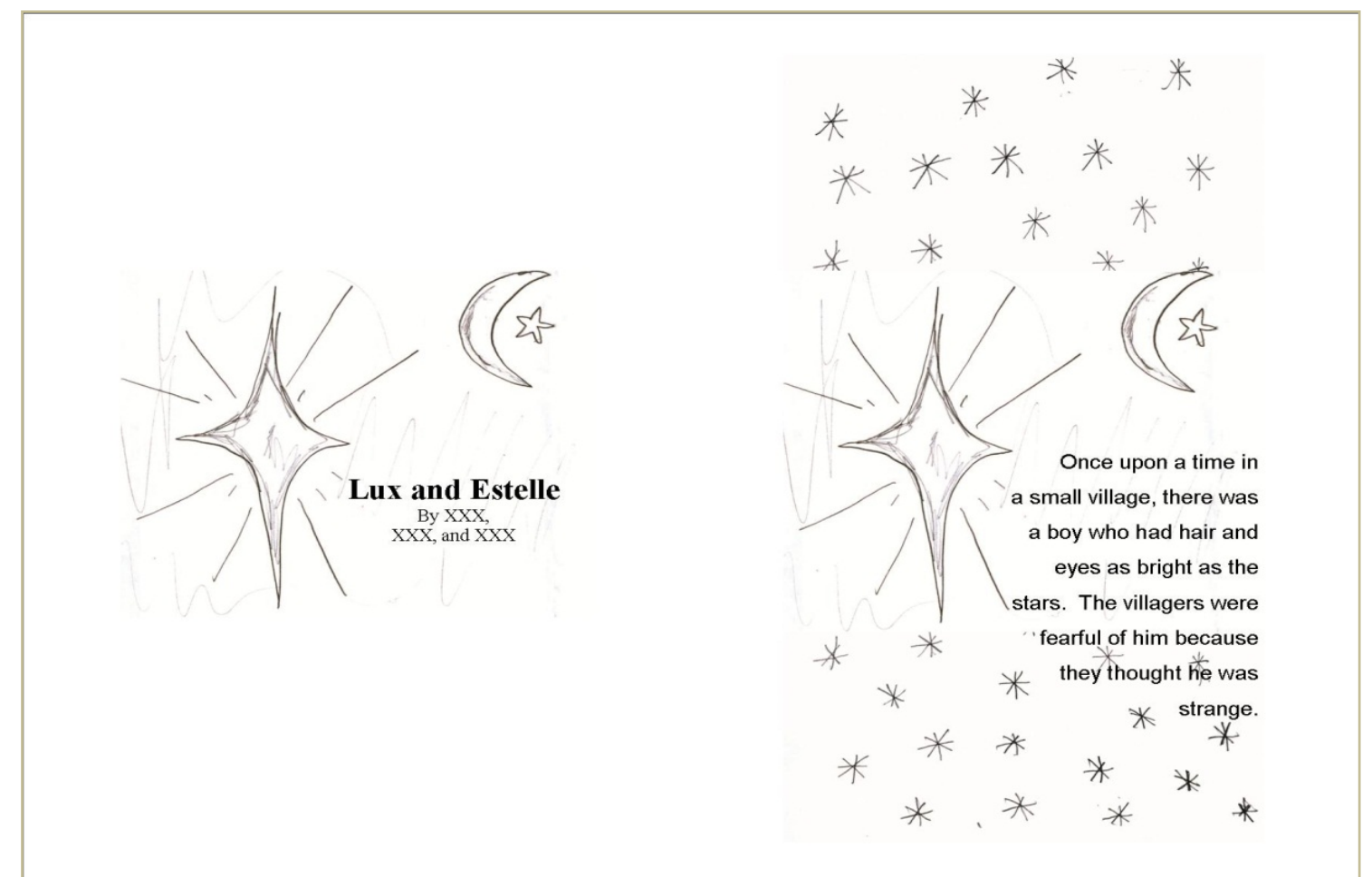

Figure 5. Published excerpt from "Lux \& Estelle." Source: Reprinted with permission of the Storytelling Project. 


\section{Teaching Available Designs for Cross-Cultural Storytelling}

At the invitation of the project organizers, we taught seminars in 2009 and 2010 that attempted to address the kinds of issues with audience that we observed in the writing of the first collection of stories. In 2010, we collected written feedback from the students to investigate what the writers and mentors had learned about considering their Rwandan audience. The participants in the 2010 seminar were 14 undergraduates and 14 middle and secondary students. The undergraduates (9 female, 5 male) were predominantly freshmen and sophomore volunteers living in the residential living-learning center. For these mentors, the Storytelling Project was a non-credit service-learning opportunity sponsored by the living-learning center as a way of engaging students in civic service. The younger students (seven female, seven male) were in grades 6 through 11. All were enrolled in one of three different schools (two middle schools, one high school) that formed part of a consortium of charter schools in their community. They participated in the program as part of an after-school volunteering activity, and were visiting the university campus to meet their mentors and learn more about the possibility of attending university someday.

The seminars covered two critical areas: cultural and linguistic available designs that could make the reading easier for the English learner. We had approximately two hours, and we knew that the students would be in charge of peer-editing afterwards. Kigamwa prepared a checklist (see Appendix A) that provided the basis for the seminars, and gave students a guide to follow throughout the year. The checklist asked students to consider whether or not they were relying on stereotypes or providing an incorrect view of gender roles in their own society or in Rwandan society. Samuelson prepared a simple guide for looking at language choices that might negatively affect comprehension for English learners in Rwanda (see Appendix B). What follows is a summary of some of more important points that we covered in the seminars.

\section{Cultural Available Designs in Writing for English Learners in Rwanda}

The fact that cultures across continents differ should not be taken simplistically to mean that in developing countries there exist only unitary cultural practices. We discussed what should be portrayed as representative practices given that within every culture most practices, values and beliefs exist in continua. The writing partners were cautioned against portraying the ideal society in short stories that will be shared with students from other cultures. They were also encouraged to revise sad stories and those with conflict, to allow them to end well, ensuring that all conflict is resolved. Furthermore, it was important to avoid themes that create controversy and to avoid extreme positions when sharing short stories about daily life. Taking the position of an insider would make the stories interesting and believable; participants were encouraged to use pronouns such as "I" and "we" rather than "they" when making reference to their communities.

Similarly the writers were asked to ensure that pictures and illustrations should represent all the races or people groups found in that community. Kigamwa 
led the writing partners in discussing the roles played by the pictures and artwork in conveying the message in stories. The writing partners worked in small groups to evaluate some children's storybooks and discussed how the illustrations made them feel, whether they presented people in stereotypical roles, and whether they ridiculed or made fun of any particular culture (Office of the Superintendent of Public Instruction, 2011). Tokenism and gender stereotypes received attention as well.

The writers also discussed the importance of understanding the histories of their intended audience. They reviewed the relevance of the 1994 Rwandan genocide to the stories that they were going to write. The group agreed that traumatic issues such as violence, war orphans, traumatism, and related subjects would have to be addressed in a sensitive manner since children in Rwanda must live with the aftermath of the genocide, even though they were born after it occurred.

The participants also learned about the importance of understanding the daily life practices of children in Rwanda. The participants were challenged to set aside stereotypical portrayals of children in Africa and do some research to help them understand their audience. Some possible questions to ask might be: What kinds of occupations do Rwandans have? Are they farmers? Do they keep animals? If yes what kind? What are some of common business and trade practices in the community? What kinds of shops are nearby? What kind of market would the Rwandan children typically visit, and what kinds of products are available?

African art, music and dance were addressed as important markers of a culture. The writing partners viewed short video clips from YouTube presenting the different genres of music and dance that exist in the Rwandan culture. Many participants were surprised by existence of modern Rwandan pop music alongside the traditional Rwandan music.

The session ended with a detailed discussion of the role of proverbs in African cultures. Working in groups, the writing partners discussed the meanings of proverbs from different parts of Africa. They tried to identify similar proverbs in Western societies as a way of bridging common values. The students learned that in many East African cultures, people often use proverbs when they want to be indirect and yet want to communicate effectively. They discussed possible meanings for proverbs such as:

"He who is being carried does not realize how far the town is."

"Someone with eyes is not told 'Look!'”

"The rich man never dances badly."

The participants identified the following similar proverbs in English:

"Bad news travels fast."

"Don't count your chickens before they're hatched." 
Finally, Kigamwa emphasized that if the concepts in the story don't exist in the target community, then the writers must make sure to provide adequate background information. For example, a story on using recycling bins to recycle aluminum cans would need some explanation for Rwandan children.

Feedback from students. At the end of the session on cultural considerations, Kigamwa asked the students to write down some insights that they had gained from the session. Many of the students reported a better understanding of how language and cultural considerations should inform their stories. One student commented on the need to "be culturally mindful about our audience's ways of life;" another observed that "background knowledge of Rwanda's culture is essential for a good story." Another student stated that she had learned "how to show different things without going all over the place in the story." Still another focused more on an appreciation of the need to "give connections to your reader and the needs of your reader are the priority."

\section{Language Choices in Writing for English Learners}

The focus of the session on languages choices emphasized the needs of the audience, and highlighted some simple strategies for keeping the language of the stories simple and accessible. Each of the suggestions follows current strategies in pedagogical grammar for teaching grammar in the context of writing (Noden, 1999; Weaver, 1998). Figure 6 illustrates the principles that were emphasized and Appendix B provides a copy of the handout that the students received.

1. Limit passive verbs

2. Stick to simple present and simple past

3. Keep it short and simple

4. Limit use of slang

5. Limit use of 'there are/was/is'

Figure 6. Guidelines for writing simple prose for English learners. Source: Reprinted with permission of the Storytelling Project.

The principles covered in this seminar echo writing instruction that the writing partners have no doubt received from their English or language arts teachers. The partners were reminded to minimize their use of multi-word verb constructions by avoiding passive constructions and sticking to simple past or simple present as much as possible. They discussed keeping sentences short and simple by removing unnecessary words and practiced reading through some sentences taken from early drafts and removing any words that weren't absolutely necessary for conveying the basic idea. Simple sentences containing a single clause were ideal. Colloquialisms and slang were acceptable, but should be used mindfully and with restraint, limiting instances to one or two at the most. Finally, the writing partners discussed the need for avoiding "there is/are/was" (There + BE + noun). 
An example from a Year 1 draft is "There is plenty of prey that I like to hunt," which the partners discussed changing to "I can find lot of animals to hunt." This construction can cause comprehension problems because the subject of the sentence is delayed. Native speakers of English don't experience difficulties, but beginning English learners can find the construction distracting.

Feedback from students. At the end of the session on linguistic issues, the students also reported a more nuanced understanding of the importance of keeping their stories simple and avoiding certain problematic grammatical structures. Learning to write for English learners requires students to actively seek out information about their audience and tailor their writing accordingly. The middle and secondary students submitted these statements:

- I learned that the usage of phrases such as there is or there was can be confusing for an English learner.

- What I learned from this session is that writing in slang will most likely confuse a child in Kenya or Rwanda a lot.

- I learned that sentence structure is more than just changing words around. You have to put yourself in the reader's shoes and think about how it is learning a language as hard as English.

- It has helped me understand the kind of sentence you should right [sic] for different age groups. It also helps me understand how to break down a compound or complex sentence to a simple sentence. Keep audience in mind that their first language isn't English.

- I learned to keep my sentences sweet, short, and simple and to keep my reader in mind, knowing that they're trying to learn English.

\section{Follow-Up to Training Sessions}

We examined drafts of stories written after the workshops for any impact of the audience awareness discussion, and particularly for any impact on kind of feedback that the undergraduate writing mentors and collaborators were giving their mentees. In particular, we focused on the draft and subsequent revision of a story written by a high school student who had been with the project since 2008. What follows is a brief review of her early draft of "Going to School," and the comments that her writing mentor gave her. 


\section{Going to School}

Hey, what's this? It looks like a book to me. I love books. Everywhere I go, I find them in my school, in my house, and at the library. They're just all over the place. Wait there aren't any words in this book... that's strange. Well, I guess that's what I'll just have to do.

Where should I start? I love my school, so I guess that's what I'll write about. Every day I get up and the first thing I do is take a shower. I don't have much time until I need to get to school so I grab a quick snack and head off to school.

Wow, what a sight. All of my friends are standing around, waiting for a bell to ring so we can get to our first class. I just remembered that I need to go to my locker so that I can get my papers and books for my first class. Off to class now the first bell has rung.

I have no time to write now. It's time for class, so I'll finish later.

Figure 7. Early draft of "Going to School" [emphasis added]. Source: Reprinted with permission of the Storytelling Project.

Figure 7 is an early draft showing some improvement over the drafts we reviewed from previous years in the project. The writer has avoided making simple assumptions about Rwandan culture after the manner adopted by the author of "Naomi Goes to Summer Camp." She used concepts from her school day that she thought would be more likely to fit the universal experience of going to school. This writer also used simple language, sticking with simple present and constructing simple sentences. Her writing mentor used the checklists to guide her feedback and focused on stereotypes, conflict, language choices, and unfamiliar concepts (see Figure 8). For instance, the mentor pointed out that the Rwandan students might not have as many books in their school and that they might not be familiar with school bells ringing to mark the division between classes or with using lockers to store their books. The mentor also identified language choices that could be confusing, such as "grab a snack," or "head off to school." These more idiomatic expressions could be revised or kept to a minimum and explained in study notes. The author made some substantial revisions to their early draft, finishing with a story about Jada, who forgot her math homework at home. A page from the prepublication copy of the story appears in Figure 9. The recess bell has been left out, but the lockers remain, and the author has provided a picture of school lockers to help to clarify the concept for the Rwandan readers. 
In the workshop, we went over a checklist or whatever to check for some things in the stories. Some things I noticed in yours were:

Stereotypes: Maybe you should state that this is in fact a school in the States, because if this were elsewhere there might not be books everywhere.

Conflict: Apparently our story needs to have a conflict...

Language: We might need to change some things around, like...

- "grab a snack" to "have a small meal"

- "head off to school" to "go to school"

- "wow, what a sight" to... something I'm not quite sure about yet

Concepts that might need to be explained: lockers, bells ringing for class, etc.

Figure 8. Writing mentor feedback on "Going to School." Source: Reprinted with permission of the Storytelling Project.

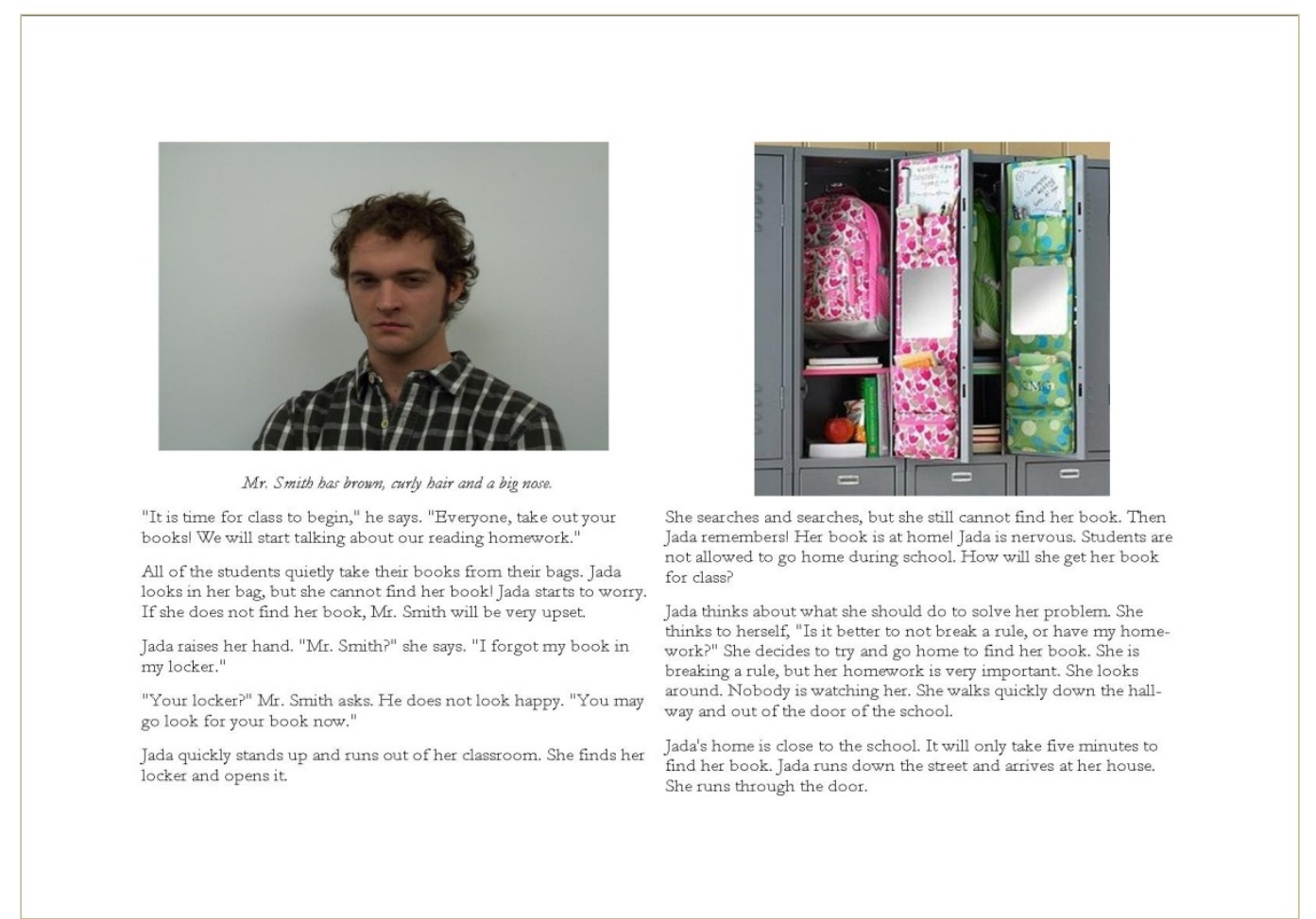

Figure 9. Pre-publication manuscript of "Going to School." Source: Reprinted with permission of the Storytelling Project.

\section{Conclusion}

Future directions for research in this vein include questions about how classic rhetorical concepts such as audience can be further adapted into a sociocultural paradigm in line with the New Literacy Studies, which has used identity as one of its major organizing themes for examining writing instruction and academic literacies (Ivanic, 1998). The gradual diminishing of the role of 'experts' in the project and the handing off of responsibility to well-prepared undergraduates suggests that the 
students can develop their own understanding of their cross-cultural audience and consider how they could adapt their stories.

Further research must also adopt an approach to data analysis that is explicitly multimodal. The project is currently limited in terms of fostering digital communication with the Rwandan students simply because the Rwandan school does not yet have the capacity to provide computers for frequent emails or use of social media for networking between the students. Once this hurdle has been crossed, however, and the students are able to use digital media to create and share their stories, we will be able to follow the development of audience awareness as the students have wider selection of available designs or semiotic resources to use in creating their stories.

This working paper suggests rich pedagogical possibilities for engaging students from vastly different cultures in meaningful, planned communicative activities that not only build their language arts skills, but also help them to see the world in different ways by introducing them to an explicit awareness of their cultural differences. As the project develops and expands, we will continue to follow and report on the ways in which the Storytelling Project promotes the development of intercultural rhetorical and cultural awareness.

\section{References}

Akinnaso, F. N. (1991). Literacy and individual consciousness. In E. Jennings \& A. Purves (Eds.), Literate systems and individual lives: Perspectives on literacy and schooling (pp. 73-94). Albany: SUNY Press.

Bakhtin, M. (1986). Speech genres and other late essays. (V. McGee, C. Emerson, \& M. Holquist, Trans.). Austin: University of Texas Press.

Barton, A., Bragg, J., \& Serratrice, L. (2009). "Discovering language" in primary school: An evaluation of a language awareness programme. Language Learning Journal, 37(2), 145-164.

Brower, A. M., \& Inkelas, K. K. (2010). Living-learning programs. Liberal Education, 96(2), 36-43.

Cai, G. (1999). Texts in contexts: Understanding Chinese students' English compositions. In C. R. Cooper \& L. Odell (Eds.), Evaluating writing: The role of teachers' knowledge about text, learning, and culture (2nd ed., pp. 279-297). Urbana: National Council of Teachers of English.

Casanave, C. P., Belcher, D., \& Liu, J. (2004). Controversies in second language writing: Dilemmas and decisions in research and instruction. Ann Arbor: University of Michigan Press.

Connor, U. (2004). Intercultural rhetoric research: Beyond texts. Journal of English for Academic Purposes, 3, 291-304. 
Cope, B., \& Kalantzis, M. (Eds.). (2000). Multiliteracies: Literacy learning and the design of social futures. New York: Routledge.

Ede, L., \& Lunsford, A. (2003). Audience addressed/audience invoked: The role of audience in composition theory and pedagogy. In V. Villanueva (Ed.), Crosstalk in comp theory: A reader (pp. 77-94). Urbana, IL: NCTE.

Flower, L. (1979). Writer-based prose: A cognitive basis for problems in writing. College English, 41, 19-37.

Flower, L., \& Hayes, J. (1994). A cognitive process theory of writing. In R. Ruddell, M. Ruddell \& H. Singer (Eds.), Theoretical models and processes of reading (4th ed., pp. 928-950). Newark, DE: International Reading Association.

Freedman, S. W. (1994). Exchanging writing, exchanging cultures: Lessons in school reform from the United States and Great Britain. Cambridge, MA: Harvard University Press.

Hamp-Lyons, L., \& Hyland, K. (2004). Contrastive rhetoric in EAP. Journal of English for Academic Purposes, 3(4), 271-359.

Hayes, J. (1996). A new model of cognition and affect in writing. In C. M. Levy \& S. Ransdell (Eds.), The science of writing (pp. 1-30). Hillsdale, NJ: Lawrence Erlbaum.

Heath, S. B. (1983). Ways with words. New York: Cambridge University Press.

Heath, S. B. (1994). The children of Trackton's children: Spoken and written language in social change. In R. Ruddell, M. Ruddell \& H. Singer (Eds.), Theoretical models and processes of reading (4th ed., pp. 208-230). Newark, DE: International Reading Association.

Ivanic, R. (1998). Writing and identity: The discoursal construction of identity in academic writing (Vol. 5). Philadelphia: John Benjamins.

Janks, H., \& Comber, B. (2006). Critical literacy across continents. In K. Pahl \& J. Rowsell (Eds.), Travel notes from the New Literacy Studies: Instances of practice (pp. 95-117). Buffalo, NY: Multilingual Matters.

Jordan, R. (1997). English for academic purposes: A guide and resource book for teachers. New York: Cambridge University Press.

Kaplan, R. (1966). Cultural thought patterns in intercultural education. Language Learning, 16, 1-20.

Kaplan, R. (1987). Cultural thought patterns revisited. In U. Connor \& R. Kaplan (Eds.), Writing across languages: Analysis of L2 text (pp. 9-21). Reading, MA: Addison-Wesley.

Kaplan, R., Cantor, S., Hagstrom, C., Kahmi-Stein, L., Shiotani, Y., \& Zimmerman, C. (1994). On abstract writing. Text, 14(3), 401-426.

Kern, R. (2000). Language and literacy learning. New York: Oxford University Press. 
Kress, G. R. (2010). Multimodality: A social semiotic approach to contemporary communication. London: Routledge.

Lester, M. (2001). Grammar and usage in the classroom (2nd ed.). Boston: Allyn and Bacon.

Lunsford, A., \& O'Brien, A. (2008). The St. Martin's handbook: Instructor's notes (6th ed.). New York: Bedford/St. Martin's Press.

McCool, M. (2009). Writing around the world: A guide to writing across cultures. New York: Continuum.

Moll, L. (1994). Literacy research in community and classrooms: A sociocultural approach. In R. Ruddell, M. Ruddell \& H. Singer (Eds.), Theoretical models and processes of reading (4th ed., pp. 179-207). Newark, DE: International Reading Association.

Noden, H. R. (1999). Image grammar: Using grammatical structures to teach writing. Portsmouth, NH: Heinemann.

Office of the Superintendent of Public Instruction. (2011). Evaluating children's literature. Retrieved from http://www.k12.wa.us/CISL/EliminatingtheGaps/CulturalCompetence/Evaluating Literature.aspx

Pahl, K., \& Rowsell, J. (2005). Literacy and education: Understanding the New Literacy Studies in the classroom. London: Paul Chapman.

Samuelson, B. W., \& Freedman, S. W. (2010). Language, multilingual education, and power in Rwanda. Language Policy, 9(3), 191-215.

Scribner, S., \& Cole, M. (1981). Unpackaging literacy. In M. F. Whiteman (Ed.), The nature, development, and teaching of written communication (pp. 71-87). Mahwah, NJ: Lawrence Erlbaum.

Sperling, M., \& Appleman, D. (2011). Voice in the context of literacy studies. Reading Research Quarterly, 46(1), 70-84.

Weaver, C. (Ed.). (1998). Lessons to share: Teaching grammar in context. Portsmouth, NH: Boynton/Cook.

Weiser, M. E., Fehler, B., \& Gonzalez, A. M. (Eds.). (2009). Engaging audience: Writing in an age of new literacies. Urbana, IL: National Council of Teachers of English. 


\section{Appendix A: Some guideline questions for writing across cultures}

1. Has the conflict in your story been resolved?

2. Is your story free from negative stereotypes?

3. Does your story portray a balance of genders in the main characters and others?

4. Does your story portray an honest and balanced picture of your society?

5. If your story is religious, does it present religion respectfully and neutrally?

6. Are your illustrations and photographs modest and inclusive of your society?

7. Are some of the concepts you are introducing common in the target culture? If not, have you offered adequate background information?

\section{Appendix B: Writing for beginning and intermediate English language learners}

\section{You are the authors!!}

Editing always creates tensions between your unique style and the needs of your readers.

\section{Overview of seminar}

1. Describing good writing for beginning and intermediate English learners: Some guidelines to keep in mind

2. YOUR TURN: Practice editing

3. Three different levels for stories: beginner, high beginner, intermediate

\section{Guidelines to keep in mind}

1. Limit passive verbs

2. Stick to simple present and simple past

3. Keep it short and simple

4. Limit use of slang

5. Limit use of 'there are/was/is'

\section{Limit use of passive verbs}

"She was accepted into one of the top schools in the country."

Change to: "She planned to study at one of the top schools in the country."

\section{Stick to simple present and simple past}

I used to write rap music.

I had been playing tennis.

Wasn't the bus going to be leaving at 8 AM?

She would always forget her purse.

He has forgotten his wallet.
Change to: I write rap music. Change to: I played tennis. Change to: Did the bus leave at 8 AM? Change to: She forgot her purse again. Change to: He forgot his wallet.

\section{Keep it short and simple}

"Estelle would do most of the talking, but Moon would listen to every word that she said, no matter the subject."

Change to: "Estelle talked a lot, but Moon always listened."

"My home is a forest, filled with tamarind trees that have tasty fruit that I love to eat." Change to: "My home is a forest. I like to eat the tasty tamarind fruit there." 


\section{Limit use of slang}

"Me and Tookie was walking going to class."

Change to: "Tookie and I walked to class."

5. Limit your use of 'there are/was/is'

"There is plenty of prey that I like to hunt."

Change to: "I find lots of prey. I like to hunt."

\section{Practice together}

Edit this excerpt from the drafts. Decide how you would simplify it to help English language learners. When you are done, we will compare your versions with the published version.

When they arrived at the hideout, Allen immediately began planning. "How about we run home, put the money back where we got it from in Mom's purse and act like nothing ever happened," said Allen.

\section{$\underline{\text { Reflection }}$}

Write one sentence about something new that you learned from this session. Please hand in your paper before you leave the room. 


\title{
The Curriculum as Cultures in Conflict: Exploring Monocultural and Multicultural Ideologies through the Case of Bilingual Education
}

\author{
Juanjuan Zhu \\ Steven P. Camicia
}

\begin{abstract}
Curriculum contentions are cultural struggles. As an illustration, we examine contention surrounding which and how languages are taught in the curriculum. We (the authors) locate this struggle within our positionalities, as a departure for our analysis of competing ideologies surrounding language and curriculum. We use a dialogical methodology to examine tensions between monocultural and multicultural ideologies. An imaginary dialogue between us, Hirsch, and Bakhtin provides an illustration. Based upon the struggles located in the bodies of the authors and the imaginary dialogue of two cultural theorists, we conclude that a monological curriculum represents the domination of one cultural group over others rather than the pedagogical and social rationales provided by opponents of multilingual education.
\end{abstract}

\section{Introduction}

Ideological struggles find their way into the public school curriculum because the curriculum contains assumptions about what knowledge society judges as "legitimate", "good", "true", "neutral", and "official” (Apple, 2000). These struggles emerge from normative sociocultural disputes over ideologies concerning, for example, family (Turner-Vorbeck, 2006), community (Katriel \& Nesher, 1986), race (Banks, 2002), gender (Baxter, 2002), and history (Evans, 2004; Wertsch, 2002). Contention surrounding curriculum in general (Kliebard, 2004; Zimmerman, 2002), and the inclusion of languages other than English in particular, have been a source of continuous cultural tension in the United States (Crawford, 2000b; Demas \& Saavedra, 2004; Gann, Dean, \& Márquez, 2005; Stritikus, 2002).

In this article, we use the dominance of English as a case to show how curriculum struggles reflect larger contentions within society. We examine competing ideologies concerning the inclusion of languages other than English in the curriculum of America's public schools. Aligned with the topic at hand, we have chosen a dialogical method to illustrate these tensions. We construct an imaginary dialogue between two different ideologies, with E. D. Hirsch representing a monolingual ideology and Mikhael Bakhtin representing a multilingual ideology. Our goal is not to present a definitive dialogue about the struggle over language but 
to tease out some of the different ideological forces at work in curriculum struggle writ broadly.

We begin by presenting the tension that exists between the positionalities of us as the authors. This tension locates our involvement with this article as a site of political struggle similar to the kinds of struggles that happen in curriculum disputes, and as a result, curriculum reform. As authors, we embody this struggle through our different lived experiences and complex mix of identities. We maintain that curriculum struggles, such as those over language, are fueled by contact between individuals and groups that are inscribed by different identities.

This said, the following question might be asked: Why are we, the authors, comparing two men? We present these two White men (Hirsch and Bakhtin) because while they embody many of the same identities, they present another level of complexity to the ideology mix. We define ideology as a system of thoughts, perceptions, interpretations, and discourses. Ideologies often cut across the embodiment of different identities. I, Juanjuan, am a Chinese female, and I, Steven, am a White American male. We present an imaginary dialogue between Hirsch, Bakhtin and us, the two authors, in order to illustrate this complexity between identity and ideology. We conclude by extending the dialogue toward a new understanding of language, culture, and conflict within the public school curriculum. We use the duoethnography method (Lund \& Navabi, 2008; Norris, 2008) as a guideline in our examination because duoethnography focuses upon the dialogical and contextual nature of understanding. In addition, duoethnography emphasizes the positionality of the researchers and the participants by making a link between perspectives and the unique identities and histories that they include. Rather than view positionality as a weakness or bias, the researchers embrace it as a way to show how their identities and histories inform investigation.

\section{Juanjuan's Positionality}

As an English language learner (ELL), I majored in English literature in college and devoted another two and half years to pursuing my Master's degree in Applied Linguistics in China. Immediately after graduation, I was offered a position as an EFL teacher at a college in Shanghai, China. Dissatisfied with China's foreign language education over the years while I was teaching, I came to the US for a better solution to the needs of my country, as well as a better education for myself. Unfortunately, I found that bilingual education in the US was also mired in difficulties, disputes, and contention. Much to my surprise, I found myself thinking that the country with the reputation for being the most diversified and internationalized in the world has been very parochial, egocentric, and malnourished linguistically (Simon, 1980; Panetta, 1999). Like many ELLs in this country, I sense displacement and dispossession keenly within a context where English is viewed as the only standard and valued language. Instead of being valued, as is the experience of many who speak languages other than English, my language serves to disgrace and degrade me, pushing me toward the margins of society. 
In classrooms, we ELLs are silenced and neglected when teachers and our classmates are using and can only use their Standard English to joke, chatter or protest. In schools, we are judged academically capable or not depending on how well we understand/speak/write English. In social situations, we are forced to follow the rules set by the Standard-English-speaking authorities and are rendered less opportunity to be engaged. For example, I have been constantly denied opportunities to work voluntarily as a teacher's assistant and tutor, as school authorities wanted native speakers. In this anguish, I asked Steven to join me in an effort to deconstruct monolingual language ideology and policy. My lived experiences and positionality encourage me to challenge the underpinnings of structuralists' perspectives toward language, transform relevant oppressive educational practices, and resist "the hegemony of English" (Demont-Heinrich, 2007) prevalent in this country and the world. In many ways, my body is a battleground for many of the curriculum struggles in the United States, a battle that I did not expect before I came here.

\section{Steven's Positionality}

As a White male who speaks only English, my positionality is privileged by the dominant culture of the United States. This privilege is reified through everything from textbooks to the unearned advantages given to me throughout my life. In addition to growing up in the San Francisco Bay area, I lived in Hong Kong during high school. Although there were many contexts within these communities where English was not the most widely spoken language, it was still the dominant one. This dominance was maintained through an intricate network of social structures such as curriculum, culture, and capital. It is within these structures that virtually all my identities were located upon the top of a hierarchy of oppression. In addition to my identity as a White male, my family was upper middle class. My ability to move seamlessly across borders added to my privilege, because not only was I able to escape oppression directed at "other" identity markers such as language, race, class, and gender, but I was also able to cross the bounds of geopolitical borders, what Ong (1999) terms as a "flexible citizen." In many ways, my body serves as a wall to those bodies, such as Juanjuan's, that are inscribed by identities different from the dominant culture.

In sum, our positionalities serve as an embodiment of the tension that we describe in the following imaginary dialogue. The dialogue illustrates a battle of ideologies found in many curriculum battles, but that is only part of the story. The other part of the story is the material reality of the bodies in which those battles occur. In the United States, these bodies are often those of ELL students. I, Juanjuan, stand on the margin looking in on a dominant culture that has little regard for my language and culture. I, Steven, stand in the center as an embodiment of the mainstream culture. It is within this tension that we hope to work together against the hegemony of the monocultural ideology that dominates many curriculum battles and much of the discussion surrounding bilingual education. 


\section{Bilingual Education in the US}

Before the imaginary dialogue on the US's bilingual education is presented, it would be helpful to have a quick overview of the background and context of this issue. According to Crawford (2000b) and Donegan (1996), bilingual and even multilingual education can be termed an early American tradition and norm. Before the $20^{\text {th }}$ century, bilingual public and vernacular private schools were commonly seen throughout the US as "a product of practical necessity or local choice" (Crawford, 2000 b, p. 100). This was due to efforts made in local schools to support the requests of immigrant parents and the lack of fully English-proficient teachers in large expanses of the country. Besides the most extensive German-English programs, French-language schools could be found in the Northeast, and Dutch-language schools in the middle states (Donegan, 1996).

However, at the beginning of the $20^{\text {th }}$ century, with the arrival of vast numbers of Southern and Eastern European immigrants in the US, certain state and federal laws were passed that restricted immigration and banned the teaching of foreign languages, especially German to schoolchildren. Then, "from World War I through the early 1950s, bilingual education lay dormant while a number of states passed laws forbidding the use of languages other than English at school" (Donegan, 1996, p. 62).

Since the 1960s, the rise of bilingual education in its modern form has caught wide attention and ignited ongoing debates (Bilingual Education Essays and Articles, 2011). This time, bilingual education was envisioned as a way to meet the needs of "the invisible minority" of Spanish-speaking children (National Education Association, 1966) and help reduce the high dropout rate among this group. One landmark event was the passage of Title VII of the Elementary and Secondary Education Act, also called the Bilingual Education Act, in Congress in1968. Born out of the civil rights movement and specifically rooted in the Civil Rights Act of 1964, the Bilingual Education Act sought to improve educational opportunities for language-minority children by providing federal funding to schools that serve children with limited English-speaking ability. Six years later, the US Supreme Court ruled in Lau v. Nichols that under the Civil Rights Act, LEP students have the right to special instructional materials in learning English. In the same year of 1974, Congress passed legislation that "required native-language instruction for nonEnglish-speaking students in school districts that applied for federal bilingualeducation grants" (Donegan, 1996, p. 62-63).

However, federal and state mandates for bilingual education soon provoked an antibilingual backlash. Starting from the early 1980s, national sentiment towards bilingual education began to shift, with critics questioning the effectiveness of such programs. Some opponents complained that too many children stayed too long with their mother tongue and "have failed to become fluent in English" (Bennett, 1985, as cited in Donegan, 1996, p. 59), while others cited the persistently high failure and dropout rate among Hispanic children after many years of bilingual education 
implementation (Crawford, 2000b). It is in reaction to these problems that a series of English-only laws came about. In 1983, US ENGLISH was founded by Sen. Hayakawa, R-Calif., as an organization promoting the legislation of English as the official language of the US. Three years later, a majority of California voters approved Proposition 63, declaring English as the state's official language. Disregarding professional advice from the field, in 1998 Californians also voted against bilingual education. Proposition 227 was passed; its aim was to drastically limit bilingual education in public schools in the state. Californians were definitely not alone in their opposition to bilingual education. Following suit, states like Arizona and Massachusetts approved similar initiatives against bilingual education in the early 2000s. Moreover, by now, 31 states have enacted official English laws (US ENGLISH, 2011), with various bills introduced in Congress to make English the official US language or to abolish government-mandated bilingual education on the national level.

To sum up, the past 50 years or so have witnessed a fierce competition between advocates and critics of bilingual education in the US. No final word has been made on the subject, as both the pro-bilingual-education camp and the proEnglish camp have drawn a considerable amount of money and support. With conservative forces gaining ground and restraints on bilingual education gaining momentum in the most recent years, the debate may become more intense. The following dialogue seeks to add complexity to the debate.

\section{An Imaginary Dialogue between Competing Ideologies}

At noon on a chilly October day in Logan, Utah, the Bluebird Cafe was unusually warm and illuminated by the presence of intellectuals whose ideas have greatly shaped and/or challenged the educational picture of this century and beyond. They were at the cafe to take an intermission from the Centennial International Education Forum, where we were voluntary interpreters for Mikhail Mikhailovich Bakhtin, a Russian philosopher and advocate for "heteroglossia and dialogic intertexuality" (Ball \& Freedman, 2004) and Eric Donald Hirsch, Jr., an American conservative scholar concerned with school curricula (Schultz, 2001, p. 13). They began to speak about bilingual education in the US:

Hirsch: Welcome, Mr. Bakhtin. How have you enjoyed your stay at Logan? Have you had a chance to visit the beautiful canyons or meet the people?

Bakhtin: The people are very friendly and the landscape is incredible. I love talking with the young people because they have such enthusiasm and great ideas. The only pity is that so far I haven't met anyone who can communicate with me well in Russian. Is it still common for people like me who speak a language other than English to encounter this problem in the US?

Hirsch: Very much so, especially when the people who speak the same language as you don't constitute a large portion of the US population. Monolingualism is, by and large, taken as an "unsullied essence" (Moraes, 1996, p.43). 
Juanjuan: Sorry to interrupt, but I need to add that it's also my experience here. As a speaker of Mandarin Chinese, the language spoken by the largest population in the world, I could hardly make any use of it after I arrived in the US, except with my native friends. Luckily, given my age, my Chinese hasn't eroded much. But I'm in total sympathy with immigrant children here and all over the world because I have experienced their sufferings to a great extent.

Steven: Having grown up in the United States, I have never had to learn any language except for English. I value friends and colleagues such as Juanjuan who help me understand what it might be like to live in a country where something as important as my first language is not valued, at best, and seen as a deficit, at worst.

Bakhtin: Interesting. What all of you said reminds me of the heated debate on bilingual education worldwide. Perhaps the US has experienced-and will continue to experience-one of the fiercest quarrels over this issue. In my mind, it illustrates how struggles over language are power struggles over culture.

Steven: Yes. As part of the dominant culture in the United States, I have seen this struggle through the discourses surrounding bilingual education and immigration policy. While opponents of bilingual education support their position through claims for the "common good," I see these as veiling the true issue, which is "protecting" the position of the dominant culture in the curriculum.

Hirsch: Speaking of that, I have some strong opinions against the progressive's vision of bilingual education and culture. You, Mr. Bakhtin, also have a strong vision of language, literacy, learning, curriculum, and culture. If you don't mind, why don't we talk a bit about bilingual education to see if we can work out a better solution for everyone? It seems like the perfect issue in curriculum contention to understand how curriculum is integral to culture. While I am sympathetic to Juanjuan and other marginalized students, what I propose will be good for them and the country. While I value Juanjuan's first language, I think that she is better served by immersion into the dominant language in this country, because English "is the ticket to the American dream" (Dole, 1995, as cited in Donegan, 1996, p. 51).

Bakhtin: Before we start, we need to define bilingual education.

Hirsch: Maybe we can use this one. (Opening his computer and searching online for National Association of Bilingual Education[NABE]) Let's see. Eh, right here on the NABE website:

What Is Bilingual Education? [...] Defined broadly, it can mean any use of two languages in school-by teachers or students or both-for a variety of social and pedagogical purposes. In today's context, a period of demographic transformation in United States [sic], bilingual education means something more specific. It refers to approaches in 
the classroom that use the native languages of English language learners (ELLs) for instruction. (NABE, 2008)

However, I don't agree with this. (Clicking on another webpage) The Wikipedia website states, "Effective bilingual programs strive to achieve proficiency in both English and the students' home language" (Bilingual Education, n. d.). It's a progressive view. I believe that a student's native language should be abandoned after students are transitioned entirely to the official standard language of English (Saville-Troike, 2006, p. 129). We used to name ELLs as LEP (limited English proficiency) students (August \& Hakuta, 1997). This placed an emphasis upon English as the dominant language. A strong nation must have a unified and dominant language and culture. Otherwise, a big and multiethnic nation like the US will be separated "into warring ethnic camps", with people "confined to language ghettos, isolated from economic opportunity and contemptuous of US culture" (Donegan, 1996, p. 52).

Juanjuan: With due respect, I have always seen such claims for "unity" and "dominance" as a convenient excuse for the marginalization and oppression of certain minority groups, in this case, language minorities. Such a practice cannot help build a strong nation. If you have studied Chinese history, you will find abundant examples where dominance only led to resistance, rebellion, and the demise of a dynasty. Instead, prosperity existed when diverse languages, cultures, and voices were valued in the nation. Ironically, such crucial knowledge embraced by language minority groups is exactly what has been disregarded in the mainstream culture of America.

Bakhtin: Courtney Cazden and Catherine Snow (as cited in Moraes, 1996, p. 41) once commented that "Bilingual education' is a seemingly simple label for a complex phenomenon." This is due to the influence of power on the struggle over language in the curriculum, a struggle of competing cultures and ideologies. There can be no question that ELLs are placed in "predetermined positions of powerlessness" (Moraes, 1996, p. 66). This is only strengthened by the mainstream preference for a unified language and culture.

Steven: As a White male, I grew up with this conception of a "unified language and culture." I am amazed that it wasn't until my 20's that I began to question why such concepts of unification exist. My entire education, from history to language arts, was bolstered by this assumption. I can't help but wonder how much richer the world would have seemed had I been taught to embrace difference as a strength rather than a weakness.

Bakhtin: You, Mr. Hirsch, construct a dichotomy between ELLs and native English speakers. This is illustrated by the label "LEP." The implication is that English is the only official or valued language in the US. In fact, many states have English-only laws (English-Only Movement, n. d.). The movement toward English-only has boomed as the population of English-language learners increases. According to the National Center for Education Statistics (2009), 
"between 1979 and 2007, the number of school-age children (children ages 5-17) who spoke a language other than English at home increased from 3.8 to 10.8 million, or from 9 to 20 percent of the population in this age range." When we deny students the opportunity to include their languages in the curriculum, we deny their voice, their real selves and their culture. I can't help but think that this is an attempt by one culture to use language as a way to dominate another culture (Reagan \& Osborn, 2002). And such ideology well explains why living, and schooling in particular, in English-only America could be a painful experience for students like Juanjuan and numerous immigrant families (Kouritzin, 2000; Wong Fillmore, 1991).

Hirsch: So you think the bilingual education policy in the US should not only be addressed to ELLs, but to all Americans, allowing equal treatment and encouraging learning of multiple languages?

Bakhtin: You are getting close, but to really appreciate my vision, you first need to tell me more about your understanding of language.

Hirsch: Well, I'm not a linguist. But I'm for Saussure's conception of language, which has shaped our traditional linguistics. He is a structuralist because he interprets language as a homogenously used abstract semiotic system, which "must be studied in itself" (1959, p. 16). His view was extended by Noam Chomsky, whose hypothesis of Universal Grammar has gained wide recognition. They both believe in the existence of a unitary standard language. And as language is objective, it can be analyzed outside of the context in which it is used, a context involving differences in power and people.

Bakhtin: According to my understanding, language is "a semiotic social-cultural entity that is dialogically alive and mutable" (Moraes, 1996, p. 91). Let me explain. First of all, every word becomes a meaningful embodiment of ideologies and cultures when used in human communication (Moraes, 1996, p. 92). During the dialogical exchange of consciousness between the speaker and the listener, language exists and can only be understood through social, cultural, and historical contexts. Given that language is a living and changing thing, or in Moraes' words, "a dynamic social entity and a socio-cultural phenomenon" (1996, p. 92), we cannot analyze it outside of social relations. Therefore, language education should not be restricted to a study of language; rather, it should be extended to attain a comprehensive, historical knowledge of the culture encompassed in that language. Bilingual education is and should be bicultural education, or even multicultural education on account of the in-use plurality of life experience, a plurality that should be encouraged to thrive in the US. Language minority groups should not be discriminated against because of their native language. Instead, individuals like Juanjuan should be valued and respected for bringing different social, cultural, and historical perspectives into the US so that everyone can better understand themselves and the world and thus embrace democracy in a more universal sense. 
Hirsch: You might be right there. But what I'm concerned about is that language freedom might ferment separatism and fragmentation by maintaining immigrants' ties with their old country, posing a threat to American civilization and the unity and solidity of America as one powerful democratic nation. Clearly, I am not the only person who is bothered by this thought. As early as 1787, one of our founding fathers, Thomas Jefferson, had warned that European immigrants would transmit with their language antidemocratic principles to their children. More than two centuries later, Newt Gingrich (1995), a politician of our time, commented in his book To Renew America that

Bilingualism keeps people actively tied to their old language and habits and maximizes the cost of the transition to becoming American. As a result, poor Americans and first-generation immigrant children have suffered pain and confusion[...] The only viable alternative for the American underclass is American civilization[...] Without English as a common language, there is no [American] civilization. (p. 162)

Therefore, bilingual education with the ultimate goal of helping immigrant children become fluent in the dominant language of English, not their native language, would "halt the 'tribalization' of US culture, diminish separatism, reinforce the shared values of a common culture" (Donegan, 1996, p. 58) and keep the democracy of America intact.

Bakhtin: I can't agree with that. Quite to the contrary, anyone who's championing English-only is actually exerting "a form of ethnic suppression" (Moraes, 1996, p. 62). Just as Peter McLaren argued, the conservative notion of nationalism would produce citizens "who are committed to entrepreneurship, who will fight to keep English the official language of the country[...] who will cherish and defend neocolonial imperatives of a new world order ruled by the United States" (Steinberg, 1992, p. 403). Taking it a step further, Thomas (1996), in his critical analysis of the agenda of US ENGLISH, concluded that "history indicates that restricting language rights can be divisive and can lead to segregationist tendencies in a society. At the same time, such legislation rarely results in a unified society speaking solely the mandated language(s)" (p. 129). Arturo Madrid (1990) summarized what I believe: For any nation, "far more important as forces to get itself unified were individual rights, freedoms, and protections; governmental and societal tolerance for cultural, linguistic, and religious diversity; democratic representation; and unfettered commerce" (p. 63).

Hirsch: You make some good points, but your philosophy is easier said than done. Your vision of bilingual education is not that feasible. In contrast, my vision is more down-to-earth. In fact, the past decades have witnessed the large-scale implementation of several bilingual instructional programs with, in Lambert's (1974) taxonomy, a subtractive outcome (as cited in Saville- 
Troike, 2006, p. 127). Transitional Bilingual Education (TBE) is a prime example, as it aims at "fluency in English without considering bilingualism as necessary" (Moraes, 1996, p. 43).

Bakhtin: But its effectiveness has been under severe criticism. Being applied widely is no argument for its use. In fact, educators sharing my vision of bilingual schooling have been innovative enough to revolutionize, first of all, teaching methodologies. We challenge the "student-as-worker, teacher-as-coach" concept advocated by your ally Theodore Sizer in his nine common principles, and the didactic approach backed by Mortimer Adler (1982), another companion of yours. This teaching model not only bores students but perpetuates education as a reproductive process that maintains existing inequalities and hegemony.

Hirsch: But we should maintain teachers' authority in front of students when dispensing knowledge. In the pedagogical relations, teachers are naturally in a more authoritative and higher position than students. Teachers earn this position because they tend to be more mature in character, more experienced in problem solving, and more knowledgeable in at least the content area(s) they teach than their students. Therefore teachers should be given the power to transfer knowledge to students through, say, lecturing and drilling, choose the program contents as they see appropriate for students' developmental levels, and discipline students to maintain an orderly learning environment. Students, on the other hand, should listen and strictly follow directions from teachers, adapt to the contents as prescribed, and comply with established disciplines (Freire, 2000). Especially when it comes to language education, teachers should be treated as indisputable authorities with absolute respect because they are usually the native speakers. They aid in their immigrant students' acquisition of Standard English by filling the latter with crucial linguistic and cultural knowledge, and setting up an authentic model for the latter to imitate.

Bakhtin: What you are describing is Freire's $(1998,2000)$ notion of the banking system of education where teachers deposit and withdraw knowledge from the minds of students. As far as language education is concerned, a monologic or standardized form of language is encouraged in your model. The teacher and society are in the position to judge "which languages are appropriate and which must be marginalized" (Moraes, 1996, p. 95) thus positioning students into hierarchical relationships in their classrooms and society.

Hirsch: Then what would you propose instead?

Bakhtin: I suggest a dialogical approach, which might be close to Freire's theory of a dialogic pedagogy (Moraes, 1996, pp. 103-104). I agree with Denzin (2009), who writes, "Critical pedagogy is a dialectical and dialogical process. Revolutionary, radical (and reflexive) performance pedagogy critically situates agency, identity, and discourse within and against a broader historical landscape" (p. 382). In the dialogue, two parts are coexistent: "the 
self and the other;" and "the other cannot be silenced and excluded" (Moraes, 1996, p. 94). We must interrogate the way that dominant culture uses language to sustain and strengthen hierarchies of oppression. Therefore, when it comes to teacher-student relations, they are both equal entities in the educational practices and they both "become agents in a struggle for social and political transformation" (Moraes, 1996, p. 111). In the case of language education, teachers should appreciate "multivoicedness" (Moraes, 1996, p. 126), or what students from diverse backgrounds bring into their classrooms. They should learn with all students by including a dialogue based upon one another's cultures and experiences. My educational vision is transformative because it cultivates responsible citizens and critical thinkers.

Hirsch: Could such a relation be kept the same when evaluation is involved in your model? To be frank, I really doubt it, because educators need standards to ensure objectivity. Here I have to resort to Saussure and Chomsky again as their philosophy of language enables us to measure student success with well-defined parameters such as grammatical mistakes. When we interpret language as a uniform, homogenously used abstract system, it naturally follows that language competence can be assessed through a set of standardized tests, which present an objective reflection of the learners' factual mastery of all linguistic components, such as grammar, vocabulary, listening and writing skills. Moreover, the errors made by language learners should be quantifiable and identifiable so that students can have a clear idea as to what their weaknesses are and how far away they are from acquiring the standard language.

Bakhtin: That is exactly the point I want to counter. Yes, we do need some standards to make judgments accordingly. However, standards blind us to the fact that we are using them only for the sake of convenience, and they perpetuate structures of dominance and subjugation (Fulcher \& Davidson, 2008). When assessed, students are no longer lively beings unique in certain aspects; rather, they are reduced to a combination of lifeless numbers. If I were an evaluator in a language program, I would not use tests that isolate different aspects of language acquisition like reading, listening, or focusing on grammar only, or fabricating fictional situations for speaking. I would, instead, examine students in different discourses and contexts, trying to seek as wide a variety of information as possible. I also prefer to focus upon personal growth. I prefer to cherish their language profile, "living trace" (Dressman, 2004, p. 35) and culture stock (Delpit, 1995) as a way to understand their educational needs. These needs are never static. They change just as language changes. Words such as less intelligent or less competent are not in my lexicon, especially when non-native-speakers are concerned.

Juanjuan (exclaiming): I like this idea! This way students like me could be relieved of the constant pressure to be judged upon our grasp of meticulous language points. 
Steven: I agree. In addition to being a more just and compassionate approach to educating non-English-speaking students, this approach provides a context for students like me from the dominant culture to understand the perspectives of student who speak little or no English. This is the first step away from discourses that portray non-English speakers as having a deficit.

Hirsch: But you have neglected the fact that objective results obtained in evaluation would be instrumental in helping us carry out research more easily and persuasively to direct our curriculum decisions. The fact that we are having this debate here is largely because the past studies in this field only present indefinite findings (Bilingual Education Essays and Articles, 2011; Donegan, 1996) and divisive opinions (e.g., Kouritzin, 2000; Samimy, 2001). Therefore, I hold that more research should be conducted objectively so as to inform us of the correct way of implementing bilingual education.

Bakhtin: Talking about research, we are now approaching the third aspect of language education. Given the fact that our ideologies are discordant in the first two aspects, namely, teaching methodology and assessment, I have every reason to believe we would also differ considerably in this aspect as well.

Hirsch: It seems that under the influence of Saussure and, in particular, Chomsky, linguists favor the cognitive-computational tradition, as Johnson (2004) mentioned in her overview of three major SLA research traditions. Quantitative methods are employed to prove man's homogeneity based on the assumption that processes of language production are rule-governed (Johnson, 2004, pp. 11-16). Moreover, researchers involved in this tradition tend to hold a positivistic epistemology and believe "there is a single tangible reality 'out there'" (Lincoln \& Guba, 1985, p. 37). It is the strongest tradition so far and widely conducted by the mainstream SLA community (Johnson, 2004, p. 15).

Bakhtin: Exactly. But please forgive me for my boldness in saying that it makes me see the weakness of your theory more clearly. First of all, the tradition runs the risk of "overgeneralization" (Moraes, 1996, p. 88) because it fails to study language in ever-changing sociocultural and historical contexts. Secondly, as Nunan (1991) noted, "little second language research is actually carried out in language classrooms, and [...] we know comparatively little about what does or does not go on there" (p. 265). That is to say, what is overlooked in standard research is the fact that "the dimension of the development in any process of learning cannot be just measured on the basis of tests" (Moraes, 1996, p. 88). Therefore, what I'm constructing is a qualitative approach or longitudinal case study, if possible. Understanding that language is a medium for social life (Halliday \& Hasan, 1985), I believe "there are multiply constructed realities" (Lincoln \& Guba, 1985, p. 37) to explain personal encounters. Besides that, the dialogical research following my vision allows language studies done in real contexts and results applied to real contexts. As such, I'd like to quote the metaphor that Voloshinov (1973), my close friend 
who specializes in linguistics, made once to elucidate my point: "in order to observe the process of combustion, a substance must be placed into the air. In order to observe the phenomenon of language, both the producer and the receiver of sound and the sound itself must be placed into the social atmosphere" (as cited in Moraes, 1996, p. 88).

Mr. Bakhtin is about to say more, but Mr. Hirsch glances at his watch, suggesting it's time for us to leave. Reluctant to depart, we are full of gratitude to both of the gentleman for allowing us to interpret for and converse a bit with them. Mr. Bakhtin, sharp as usual, asks about our final thoughts before we go.

\section{Conclusion}

We conclude by saying: Mr. Hirsch, please forgive us for saying that social life is embedded within dynamic and complex sociocultural contexts. Hierarchies of oppression are an integral part of these contexts and your vision seeks to reinscribe these hierarchies on the bodies of new generations of children by placing English at the top of the hierarchy of identities. This has served to privilege some, such as me, Steven, and oppress others, like me, Juanjuan. We embody the struggle which your ideological dialogue with Mr. Bakhtin represents. While neither of us asks for privilege or oppression, it is something that is cast on us by society and perpetuated with policies such as English-only laws in public schools.

Dressman (2004) once described the two aspects of pedagogy of literature, namely, instruction and curriculum, as forming a two-dimensional world. However, your ideological disputes over language education today reveal a slightly different, but more detailed, vivid, three-dimensional plane for us (See Figure 1 in Appendix). It seems that you two are dwelling in the two opposite spaces, with Mr. Hirsch and his monolingualism occupying the northeast quadrant of the figure and with $\mathrm{Mr}$. Bakhtin and his multilingualism occupying the southwest quadrant. To be specific, along the horizontal, or instructional method, axis, you place yourselves at the two ends of a continuum, championing the banking/monological approach and dialogical approach respectively. Along the vertical, or assessment, axis, you locate yourselves at the two ends of another continuum, one advocating a single dominant epistemology and the other advocating multiple epistemologies. Concerning the last axis of research paradigm, Mr. Hirsch represents a post-positivist perspective while Mr. Bakhtin represents a critical perspective.

We, Juanjuan and Steven, agree with Mr. Bakhtin, especially where critical issues determining our future development are concerned. Given that this country's demographic texture is changing every day and globalization is speeding up ever faster (Held, McGrew, Goldblatt, \& Perraton, 1999), bilingual education is at the top of our concerns. To defend our ideal of democracy from the attack of market rationality, we should cultivate bilingual or even multilingual people who embrace knowledge about cultures other than their own. They are the ones who generously share their legacy with other nations and are open-minded enough to appreciate truth and beauty from other parts of the world. Most importantly, they are the ones who never get tired of striving for an equal, democratic, non-hierarchical and 
peaceful coexistence of all human beings. In this regard, we believe Mr. Bakhtin's poststructuralism could better cater to contemporary demands, because critical thinking and deconstruction are at the heart of dismantling hierarchies that privilege dominant cultures and perspectives.

In this article, we, Juanjuan and Steven, have taken steps toward dismantling hierarchies embedded in issues such as bilingual education. We hope that our dialogical perspective will promote other dialogues surrounding curriculum struggles in the schools. The conflicts in such struggles are productively examined through the lens of cultural conflict. In addition to language education, this dialogue can occur in other curriculum struggles such as mathematics, social studies, and science. We propose starting these dialogues by asking questions such as: What culture has most defined success? And how does the curriculum position students within hierarchies of oppression? We, Juanjuan and Steven, have experienced the effects of curriculum in their material, psychological, and spiritual repercussions in our lives. Thus, we hope to alleviate the suffering of unjust repercussions in future generations of students through the dialogue we open up in this article.

We chose to use a method similar to duoethnography by presenting different positionalities within a dialogue. The challenge of this method is that it encourages a multivocal text. Because standard or dominant academic discourse privileges collapsing different perspectives into one, it can be difficult to break away from that model in favor of a multivocal text or examination. This can also lead to a multiplication of complexity because issues are examined from multiple perspectives. Finally, we believe that explicit dialogue around positionality and controversial issues is an important part of moving toward the empowerment of marginalized voices. This dialogic approach can provide the space for multiple perspectives to emerge that are normally silenced within a movement toward dominant positionalities and perspectives.

\section{References}

Adler, M. (1982, July). The Paideia proposal: Rediscovering the essence of education. In F. Schultz (Ed.), Notable selections in education (3 ${ }^{\text {rd }}$ ed., pp. 32-38). Guilford, CT: McGraw-Hill/Dushkin.

Apple, M. W. (2000). Official knowledge: Democratic education in a conservative age (2nd ed.). New York: Routledge.

August, D., \& Hakuta, K. (Eds.). (1997). Improving schooling for language-minority children. Retrieved from http://books.nap.edu/openbook.php?record id=5286\&page $=2$

Ball, A. F., \& Freedman, S. W. (Eds.). (2004). Bakhtinian perspectives on language, literacy, and learning. Cambridge, MA: Cambridge University Press.

Banks, J. A. (2002). Race, knowledge construction, and education in the USA: Lessons from history. Race, Ethnicity, and Education, 5(1), 7-27. 
Baxter, J. (2002). Competing discourses in the classroom: A post-structuralist discourse analysis of girls' and boys' speech in public contexts. Discourse and Society, 13(6), 827-842.

Bilingual education. (n. d.). Retrieved from http://en.wikipedia.org/wiki/Bilingual education\#United States

Bilingual Education Essays and Articles. (2011). Retrieved from http://www.enotes.com/bilingual-education-article

Crawford, J. (2000a). At war with diversity: US language policy in an age of anxiety. Clevedon, UK: Multilingual Matters.

Crawford, J. (2000b). Language politics in the United States: The paradox of bilingual education. In C. J. Ovando \& P. McLaren (Eds.), The politics of multiculturalism and bilingual education: Students and teachers caught in the crossfire (pp. 106-125). Boston: McGraw-Hill.

Delpit, L. (1995). Other's people's children: Cultural conflict in the classroom. New York: The New Press.

Demas, E., \& Saavedra, C. M. (2004). Reconceptualizing language advocacy: Weaving a postmodern mestizaje image of language. In K. Mutua \& B. B. Swadener (Eds.), Decolonizing research in cross-cultural contexts: Critical personal narratives (pp. 215-234). New York: SUNY Press.

Demont-Heinrich, C. (2007). Globalization, language, and the tongue-tied American: A textual analysis of American discourses on the global hegemony of English. Journal of Communication Inquiry, 31(2), 98-117.

Denzin, N. K. (2009). Critical pedagogy and democratic life or a radical democratic pedagogy. Cultural Studies/ Critical Methodologies, 9(3), 379-397.

Donegan, C. (1996). Debate over bilingualism. CQ Research, 6(3), 49-72.

Dressman, M. (2004). Deway and Bakhtin in dialogue: From Rosenblatt to a pedagogy of literature as social, aesthetic practice. In A. F. Ball \& S. W. Freedman (Eds.), Bakhtinian perspectives on language, literacy, and learning (pp. 34-52). Cambridge, UK: Cambridge University Press.

English-only movement. (n. d.). Retrieved from http://en.wikipedia.org/wiki/English-only movement

Evans, R. W. (2004). The social studies wars: What should we teach the children? New York: Teachers College Press.

Freire, P. (1998). Pedagogy of freedom: Ethics, democracy, and civic courage (P. Clarke, Trans.). Lanham, MD: Rowman \& Littlefield.

Freire, P. (2000). Pedagogy of the oppressed (30 th anniversary ed.). (M. B. Trans.). New York: Continuum.

Fulcher, G. \& Davidson, F. (2008). Tests in life and learning: A deathly dialogue. Educational Philosophy and Theory, 40(3), 407-417. 
Gann, R. R., Dean, B. P., \& Márquez, J. (2005). Beyond English hegemony: Language, migration and Appalachian schools. Changing English, 12(3), 431-441.

Gingrich, N. (1995). To renew America. New York: HarperCollins.

Halliday, M., \& Hasan, R. (1985). Language, context and text: Aspects of language in a social-semiotic perspective. Victoria, Australia: Deakin University Press.

Held, D., McGrew, A., Goldblatt, D., \& Perraton, J. (1999). Global transformations: Politics, economics and culture. Palo Alto, CA: Stanford University Press.

Johnson, M. (2004). A philosophy of second language acquisition. New Haven, CT: Yale University Press.

Katriel, T., \& Nesher, P. (1986). Gibush: The rhetoric of cohesion in Israeli school culture. Comparative Education Review, 30(2), 216-231.

Kliebard, H. M. (2004). The struggle for the American curriculum: 1893-1958 (3rd ed.). New York: RoutledgeFalmer.

Kouritzin, S. G. (2000). A mother's tongue. TESOL Quarterly, 34(2), 311-324.

Lincoln, Y., \& Guba, E. (1985). Naturalistic inquiry. Newbury Park, CA: Sage.

Lund, D. E., \& Nabavi, M. (2008). Duo-ethnographic conversation on social justice activism: Exploring issues of identity, racism, and activism with young people. Multicultural Education, 15(4), 27-32.

Madrid, A. (1990). Official English: A false policy issue. The Annals of the American Academy of Political and Social Science, 508, 62-65.

Moraes, M. (1996). Bilingual education: A dialogue with the Bakhtin Circle. New York: State University of New York Press.

NABE. (2008). What is bilingual education? [Data file]. Retrieved from http://www.nabe.org/education/index.html

National Center for Education Statistics. (2009). Language minority school-age children. Retrieved from

http://nces.ed.gov/programs/coe/2009/section1/indicator08.asp

National Education Association. (1966). The invisible minority: Report of the NEATuscon survey on the teaching of Spanish to the Spanish-speaking. Retrieved from http://www.eric.ed.gov/PDFS/ED017222.pdf

Norris, J. (2008). Duoethnography. In L. M. Given (Ed.), The Sage encyclopedia of qualitative research methods (pp. 233-236). Thousand Oaks, CA: Sage.

Nunan, D. (1991). Methods in second language classroom-oriented research. Studies in Second Language Acquisition, 13(2), 249-269.

Ong, A. (1999). Flexible citizenship: The cultural logics of transnationality. Durham, NC: Duke University Press. 
Panetta, L. E. (1999). Foreign language education: If "scandalous" in the 20th century, what will it be in the $21^{\text {st }}$ century? Retrieved from https://www.stanford.edu/dept/lc/language/about/conferencepapers/pan ettapaper.pdf

Reagan, T. G., \& Osborn, T. A. (2002). The foreign language educator in society: Toward a critical pedagogy. Mahwah, NJ: Lawrence Erlbaum.

Samimy, K. K. (2001). Comments on Sandra G. Kouritzin's "A mother's tongue": A reader reacts. TESOL Quarterly, 35(2), 323-325.

Saussure, F. (1959). Course in general linguistics. (W. Baskin, Trans.). New York: McGraw-Hill.

Saville-Troike, M. (2006). Introducing second language acquisition. Cambridge, UK: Cambridge University Press.

Schultz, F. (Ed.). (2001). Notable selections in education (3 $3^{\text {rd }}$ ed.). Guilford, CT: McGraw-Hill/Dushkin.

Simon, P. (1980). The tongue-tied American: Confronting the foreign language crisis. New York: Continuum.

Steinberg, S. (1992). Critical multiculturalism and democratic schooling: An interview with Peter McLaren and Joe Kincheloe. International Journal of Educational Reform, 1(4), 392-405.

Stritikus. (2002). Immigrant children and the politics of English-only: Views from the classroom. New York: LFB Scholarly Publishing.

Thomas, L. (1996). Language as power: A linguistic critique of US English. The Modern Language Journal, 80(ii), 129-140.

Turner-Vorbeck, T. (2006). Representations of family in curriculum: A poststructural analysis. In A. Segall, E. E. Heilman \& C. H. Cherryholmes (Eds.), Social studies: The next generation (pp. 153-169). New York: Peter Lang.

US ENGLISH. (2011). 31 states have enacted official English. Retrieved from http://www.us-english.org/

Wertsch, J. V. (2002). Voices of collective remembering. New York: Cambridge University Press.

Wong Fillmore, L. (1991). When learning a second language means losing the first. Early Childhood Research Quarterly, 6, 323-346.

Zimmerman, J. (2002). Whose America? Culture wars in the public schools. Cambridge, MA: Harvard University Press. 


\section{Appendix}

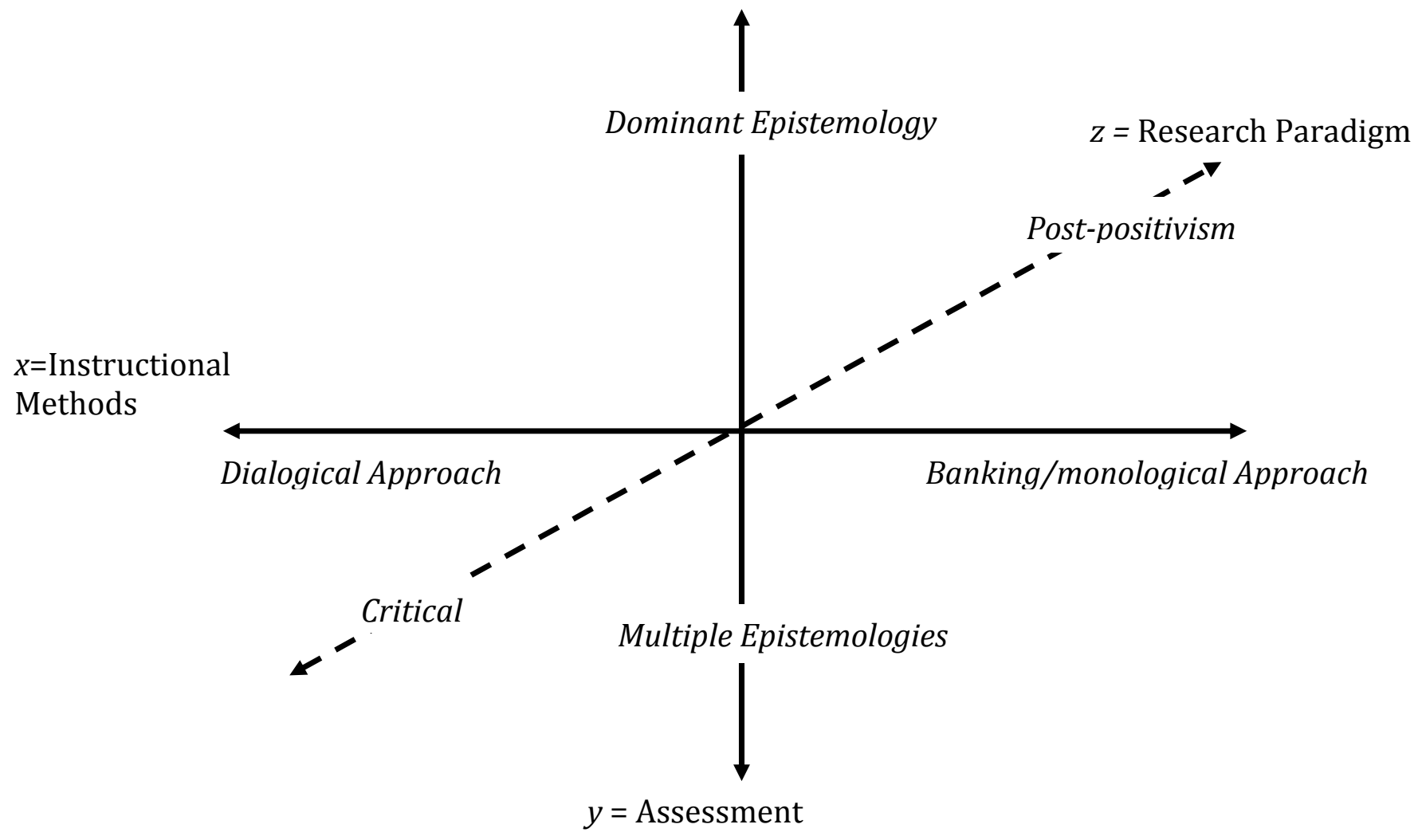

Figure 1. Three dimensions of language education 


\section{LITERACY STUDIES}




\title{
One Story, Many Perspectives: Reading and Writing Graphic Novels in the Elementary Social Studies Classroom
}

\author{
Erica Christie
}

\begin{abstract}
Though elementary students often read picture books in school, the growth of critical literacy has inspired teachers to select texts that engage students with literacy and social studies in more meaningful ways. Although many of these texts are traditional picture books, alternative formats like the graphic novel are also being used to invite student questioning and share multiple perspectives. This study examines the ways elementary students understand and retell a complex social studies story using multiple textual formats. Third-grade students were exposed to a picture book and graphic novel version of the true story of Alia Muhammad Baker, a courageous Iraqi librarian. After reflecting on the texts, students renarrated the story; many chose to write graphic novels. Students expressed high levels of interest in graphic novels, exhibited new perspectives on the Iraq War and active citizenship, and utilized key features of graphic novels to tell complex and multilayered social stories.
\end{abstract}

\section{Introduction}

Elementary teachers have long known the power of children's literature to bring social studies topics to life for their students. Indeed, since 1972, the National Council for the Social Studies has published an annual bibliography of social studiesthemed books, entitled Notable Social Studies Trade Books for Young People, providing K-8 educators with a comprehensive source for texts that can enhance and deepen their teaching of the subject. Such picture books provide young students with rich accounts of historical events, multiple perspectives on social studies topics, and captivating illustrations, characteristics uncommon in traditional social studies textbooks.

In recent years, a new kind of picture book has emerged in the form of the graphic novel. Graphic novels, an outgrowth of comic books, "are a hybrid comprising both visual and print texts" (Cromer \& Clark, 2007, p. 57). Graphic novels often tell lengthy and detailed stories about significant historical or sociocultural issues. In a sense, graphic novels resemble the more familiar format of picture books, as they contain the same basic elements of images and text. However, in picture books, these elements typically exist as mere accompaniments to each other. Consider the way elementary teachers often read picture books aloud, reading the text first and then turning the book towards the students to display the 
illustrations; this style of reading illustrates the disconnect between text and words sometimes found in picture books, for students can make initial meaning of the text without viewing the images, though the illustrations certainly enhance and deepen this understanding. In graphic novels, however, "the words are interpreted through the images and the images through the words" (Cromer \& Clark, 2007, p. 579). Indeed, words and images are so intertwined in graphic novels that the story itself cannot be understood without making sense of both elements simultaneously.

Despite the unique features of graphic novels, they remain an uncommon feature in the elementary curriculum, even as high-quality graphic novels are becoming more abundant in elementary school libraries (Gorman, 2008). Some educators worry that these texts are inappropriate or too explicit for young children, while others fear that the format "pander[s] to kids' wants without meeting their educational needs" (Lyga, 2006, p. 56). Mostly, though, elementary teachers seem to lack information about the genre of graphic novels and their potential within the curriculum, particularly as they relate to helping students understand social studies topics. Indeed, the little research available on graphic novels pertains mostly to secondary and post-secondary settings, leaving elementary educators to wonder if and how graphic novels can be effectively used with young students.

This paper explores the potential for utilizing graphic novels to help young students make sense of complicated social studies topics, understand multiple perspectives on social issues, and develop a critical stance. First, the unique features of graphic novels are explicated and the theoretical lens of critical stance is explored. Next, I examine the ways that students in one third-grade classroom engage with, understand, and retell a complex social studies narrative about active citizenship amid the Iraq War presented to them through both picture book and graphic novel formats. Finally, I consider the implications of this case study for elementary social studies educators, providing valuable insights as to how young students understand graphic novels, the power of retelling the story using alternative formats, and the potential for students to develop a critical stance as they engage with these new literacies.

\section{Making Sense of Graphic Novels}

Reading a graphic novel is a decidedly different experience than reading a picture book or traditional novel. Cromer and Clark (2007) assert that successful student interactions with this format require recognition and development of four unique features or skills: time, intertextuality, visual literacy, and hypertextuality (p. 578). First, reading graphic novels is often more time consuming than reading picture books, as readers need extra time to examine each frame, decipher text and images in relation to each other, and identify multiple pathways through the story. Second, graphic novels rely on a dynamic interplay between text and images. Known as intertextuality, words and images are intimately linked in graphic novels, making it impossible to make sense of either without the other. Readers of graphic novels must learn to interpret words through the images and images through the words in 
order to completely understand the story, a skill that is not typically required when reading other literary formats (Cromer \& Clark, 2007). Hammerberg (2001) describes this relationship as synergistic: “'Text' becomes a conglomeration of both. Words appear in pictures and over pictures in ways that require a nonliteral reading of the printed text, for to only read the words for their literal meaning would be to escape with no meaning whatsoever" (p. 209).

Third, graphic novels require readers to hone their visual literacy skills, analyzing images in highly nuanced and complex ways. Because images are such an essential component of graphic novels, readers must learn to read images as they do text, analyzing facial expressions, extrapolating mood and tone, and decoding scenes to search for meaning and fully understand the plot. Moreover, graphic novels often vary the size of the frames or panels of the story, challenging the visual literacy skills of readers. For example, authors might add spaces between panels, use a wide variety of panel sizes and shapes, or overlap frames, creating different visual effects for readers to interpret as they read (Cromer \& Clark, 2007). Understanding these visual changes is crucial to understanding the sequence and relative importance of events within the story. One large panel on a page, for instance, likely depicts a moment of great importance within the plot, whereas a page with many frames might indicate a fast-paced action scene or dialogue between characters. Fourth, graphic novels require readers to consider new ways of reading text, moving beyond the linear, left to right, format typical of many genres. This skill, known as hypertextuality, enables readers to take multiple pathways through the text, at various times reading the text vertically, horizontally, in a circular pattern, or from the bottom-up. Often, graphic novels offer multiple ways to read the text, empowering the reader with the freedom and decision-making capability to decide how to move through the story in the most meaningful way (Cromer \& Clark, 2007).

In addition to these four skills, graphic novels also require readers to toggle between multiple perspectives. As dialogue is typically written in first-person speech bubbles, each character within a graphic novel can use the "I" voice, as opposed to picture books which typically tell stories through one perspective or voice (Hammersberg, 2001). Indeed, this idea of multiplicity is important for students seeking to make sense of graphic novels, as these texts ask readers to juggle "multiple sources of information to draw on, many possible interpretations, and many choices for interacting within the text" (Hassett \& Schieble, 2007, p. 67). Even the reader's own perspective is valued in graphic novels, as evidenced by the author providing many paths through the text, ultimately leaving the power to make meaning of the story in the hands of the reader.

Beyond integrating these literacy elements, what makes graphic novels compelling for the social studies educator? For one, many graphic novels address complex social and historical themes. Frey and Noys (2002) assert "the form has actually been the site for some sustained and sophisticated engagements with the problems of representing historical events" (p. 255). Indeed, authors of graphic novels have not veered away from controversial social issues in their texts. Some of the most well-read and often-discussed graphic novels include Maus: A Survivor's 
Tale (Spiegelman, 1986) about the Holocaust, The Complete Persepolis (Satrapi, 2007) about a young girl in the Irani Revolution, Deogratias: A tale of Rwanda (Stassen, 2006) about the Rwandan genocide, The 9/11 Report: A Graphic Adaptation (Jacobson and Colon, 2006) about the events of September 11, 2001, Pride of Baghdad (Vaughan, 2008) about the American bombing of a zoo in Iraq, and People's History of the American Empire (Zinn, Konopacki, \& Buhle, 2008).

These texts differ from typical social studies textbooks or other historical texts in that 'the graphic novel is a site where 'history' itself, or representations of history, are put into play: interrogated, challenged, and even undermined" (Frey and Noys, 2002, p. 258). Rather than simply providing the reader with historical information or "telling" history, Frey and Noys (2002) argue that the graphic novel format offers "a testing place to probe the limits of history and historiography, whether that be 'traditional', 'modernist' or 'postmodernist'” (p. 259). This idea of "testing" or "playing" with history is unique to the graphic novel format and might be particularly compelling to young readers who feel disconnected by the typical way of representing history as impersonal and fixed. When history is open to interpretation, as it is in graphic novels, readers can be a part of the history-making process, asking questions, analyzing information, and making decisions. Students become active and informed historians, rather than simply passive recipients of history.

Further, graphic novels have the unique capacity to tell multi-layered social studies stories that encourage the reader to consider new and multiple perspectives. These perspectives are typically delivered to readers through the eyes of highlypersonalized characters, depicted in both illustrations and text. Whether fictionalized or not, such characters offer compelling and dynamic entrances points for readers to begin to interpret history for themselves, a far cry from the typically distant and dry representation of history found in social studies text books (Baron \& Levstik, 2004). Barton and Levstik (2004) assert that recognizing the perspectives of others, particularly those in history, is an important component of developing historical empathy and learning to care about people, places, and events in history and today.

\section{Theoretical Lens}

This study utilizes the theoretical lens of critical stance as proposed by Lewison, Leland, and Harste (2008). Building upon ideas of critical literacy (Lewison, Flint, \& Van Sluys, 2002; Luke \& Freebody, 1997; Janks, 2000) and participatory social action (Oakes \& Rogers, 2006), critical stance is a way of thinking and being that is essential to the democratic process. Critical stance is defined by four interrelated dimensions: conscious engagement, trying on alternative states of being, responsibility to inquire, and engaging in reflexivity. The first dimension, conscious engagement, refers to an "ongoing cycle of reflection, deliberation, inquiry, and action" in one's own thoughts, but also in the classroom and community (Heffernan \& Lewison, 2009, p. 19). The second dimension of critical stance entails trying on new and alternative ways of being. This requires a degree of risk-taking and playing 
with new discourses and identities. When students try on alternative ways of being, they have to examine their own positionality within situations and understand the multilayered, multimediated nature of power, history, and literacies (Heffernan \& Lewison, 2009). The third dimension, responsibility to inquiry, encourages an attitude of questioning, problem-posing, and investigation. Students are encouraged to inquire about the nature of knowledge and power, as well as consider history and social issues from "multiple and contradictory viewpoints" (Heffernan \& Lewison, 2009 , p. 20). The final component of the critical stance framework is reflexivity, in which students think critically about their own complicity in maintaining the status quo and reflect on alternative ways of teaching, learning, and being.

The critical stance lens is helpful to this study for several reasons. First, it provides an important link between the fields of literacy and social studies. Engaging students in reading and writing graphic novels on social issues is inherently a cross-curricular, integrated activity. Second, young people with a strong critical stance are capable of critiquing, questioning, and engaging in the civic process, a major goal of social studies education. Therefore, helping youth develop and take a critical stance when engaging with texts such as graphic novels is an important aspect of social studies education.

\section{Methods of Inquiry}

\section{The Texts}

The impetus for this study arose from my discovery of two excellent, though very different, children's books written about the same topic, the true story of Alia Muhammad Baker, the chief librarian of the Central Library in Basra, Iraq. In 2003, in the face of oncoming war, Baker became concerned that her library, and the irreplaceable stories and histories held within it, would be destroyed. After unsuccessfully appealing to the Iraqi government for a safe place to protect the books, Baker decided to save the books herself, sneaking volumes home with her every night. As the war inched closer to Basra, Baker asked her neighbors for help in saving the books and together they risked their lives to smuggle over 30,000 books to safety. Nine days later, the library was burned to the ground and the rest of the collection was lost. Under her guidance, a new library was constructed in 2004 and Basra was reinstated as chief librarian.

The story of Baker's courage and commitment to saving the books of Iraq is told in two different children's books. The Librarian of Basra: A True Story from Iraq by Jeannette Winter is a picture book geared toward younger readers. The book features brightly-colored, simplistic illustrations with one or two sentences of accompanying text on each page. The text offers few details about the historical context of the war in Iraq, focusing instead on Baker's courage in saving the books of her nation and her hopes for peace. Alia's Mission: Saving the Books of Iraq by Mark Alan Stamaty tells Baker's story through the graphic novel genre. Each page consists of a series of frames containing hand-drawn, black and white images and short amounts of text, often written in dialogue bubbles. The first page of this text features a flying, talking book introducing Baker as a "real-life superhero;" this caricatured 
book goes on to narrate the rest of the story, appearing again to conclude the book in its final pages. Unlike Winter's picture book, Stamaty's text contextualizes Baker's story within the war and offers a distinct perspective on Saddam Hussein. For example, the talking book sets up the story by stating, "the year is 2003. Iraq is a trouble nation ruled by a cruel dictator, Saddam Hussein, who is hated and feared by most of his people." The book is geared toward a slightly older reader than Winter's picture book, appealing perhaps to the upper elementary/middle school audience.

Though different in their approaches and content, both books tell Baker's fascinating story in a compelling and engaging way, offering young readers a unique perspective on the war in Iraq. After reading each text myself, I was curious how students would react and make meaning of the two different versions of the story. Would students prefer one format over the other? What would students take away from each text to help them understand this complicated social studies story? Moreover, how does engagement with these two texts help students understand the Iraq War specifically and the concept of war more generally? My desire to explore these questions led to the creation of this case study, which I conducted with a class of third grade students.

\section{The Study}

The study began with a discussion about what students already knew about the war in Iraq. Next, students were introduced to Baker's story and the two texts. Students then listened as I read aloud The Librarian of Basra, the picture book by Winter. I read each page as I showed students the illustrations, scanning the book across the room to ensure that all students could see the images. Next, I read aloud Alia's Mission, the graphic novel by Stamaty. To ensure that students could see the detail within each frame and read the text and images simultaneously, I chose to project this book on a large screen, zooming in and out with a projector to capture the detail of each image/text frame. After listening to both texts, I engaged students in a class discussion about the two versions of the story. Students were asked to share their thoughts on the two formats, as well as reflect on what they learned about Baker as a historical figure and role model for civic action, about the Iraq War, and about war in general through these two books. Finally, students were given the opportunity to retell Baker's story in their own words. Given plain white paper and open-ended instructions, students were free to retell the story however they saw fit, drawing from the formats of the two books or creating a new format for sharing the story. After students finished their retellings, the class reconvened to share their stories and explain why they chose to tell their story as they did. Students reflected on how retelling the story in their own words offered a unique perspective on the two books and helped them better understand Baker's actions and the Iraq War. 


\section{Participants and Setting}

This study was conducted in one third grade classroom at a public school located within a large school district on the urban fringe of a major Midwestern city. Seventy-nine percent of students at this school were identified as white, $7 \%$ as Hispanic, $7 \%$ as multiracial, $5 \%$ as Black, and $2 \%$ as Asian. More than a third of the students (38\%) qualified for free or reduced lunch. The school consistently scored well on state standardized tests, with $85 \%$ of students passing in 2008-2009, nearly $15 \%$ higher than the state average. The participating classroom was composed of 22 students, 14 females and 8 males, and was taught by an African American male teacher. For three months prior to this study, I worked closely with these students and the teacher on an extensive research project on a related topic. As such, I was quite familiar with the class and was treated as a respected teacher and researcher at the time of this study.

\section{Data Sources and Analysis}

This qualitative case study utilized a range of data sources. First, I took extensive field notes during my time teaching and observing in this classroom. These field notes were supplemented and strengthened by audio recordings made of during the lessons. Recordings were transcribed and combined with my field notes to create a "thick record" of the classroom experience during this case study (Carspecken, 1996, p. 49). This thick record was further supplemented by photographs taken throughout the study depicting various elements of the lessons and student work. Additionally, I collected and photocopied the students' written retellings. Finally, I conducted short, informal interviews with approximately ten students, asking them to orally share their retelling and explain their thinking and decision-making process with me. By using a wide range of methods, I aimed to more fully capture the experience of participants and in turn increase the fruitfulness of my findings.

The thick records and interview transcripts were coded in order to identify emerging themes. I utilized a Grounded Theory Approach to coding, as developed by Glaser and Strauss (1967) and Strauss and Corbin (1990), to identify codes that are internal or grounded in the data, emerging from the participants' experiences. Grounded theory allows the researcher to identify implicit ideas that participants hold about their lives and bring these often unspoken theories of meaning to the surface. I analyzed the written documents and photographs in a similar manner, asking questions about meaning and representation. The answers to these questions helped me identify codes and eventually categories and themes which supported and complicated the themes that emerged from the other sources.

\section{Findings}

In this section, I share findings related to three main themes. First, students expressed great interest and enthusiasm for the graphic novel genre, particularly in comparison to the picture book, despite their lack of previous knowledge and experience with the format. Second, engaging with this graphic novel helped the students understand the reality of the war, the actions of a unique active citizen, and 
an Iraqi perspective. Finally, students exhibited an implicit understanding of the key features of graphic novels in their retellings of the story of Alia Baker. In particular, students showcased intertextuality, visual literacy, and the ability to tell stories from multiple perspectives, including their own, in their retellings. Each of these themes will be explored in detail in the following sections.

\section{“Cool! It's a graphic novel!"}

Students were instantly drawn in by Stamaty's graphic novel, Alia's Mission. As soon as I announced we would be reading a graphic novel, I heard several students proclaim "yes!" and "cool!" Despite this enthusiasm, only a few students, all boys, indicated that they had ever read a graphic novel before and nobody could recall reading one as part of a school assignment or curriculum. I projected the book onto a large screen and immediately upon opening the first page of the text, students started laughing and cheering in response to the talking, walking book character that Stamaty uses to narrate the story and introduce readers to Baker, who he proclaims as a real-life superhero. This element of fantasy was quite captivating to students, who had no trouble switching between this fictional character and the true story presented in the book. During my reading of the book, students asked me to stop several times to zoom in on certain panels, read speech bubbles, ask questions, and provide extra time for them to closely examine the images. When the author dramatically fills the page with the scene of the library burning down, students audibly gasped in horror, clearly understanding the gravity of the situation.

Students also listened intently as I read the picture book, The Librarian of Basra, however they did not show the same enthusiasm or interest in the story as they did while reading the graphic novel. Even though this version was more colorful and shorter, students seemed less captivated by the story. They asked no clarifying questions nor did they make any connections with the text; it was as though they were reading a book that was completely separate from their own lives. Perhaps this is because they are quite familiar with picture books, whereas the graphic novel was decidedly different, and thus more exciting, than books they typically read in school.

In discussions afterward about the two books, students overwhelmingly noted that they preferred the graphic novel over the picture book. Several students mentioned that the pictures and text in the graphic novel were more specific and detailed, providing helpful information that complicated the story. Interestingly, I was initially concerned that Stamaty's graphic novel would be too detailed for third grade students, as he contextualizes Baker's story within the war in complex ways that Winter's more simplistic picture book does not. However, this level of detail seems to be exactly what drew students into the story; they appreciated knowing specific facts and information, particularly when this detail was presented in an engaging manner. Sean ${ }^{4}$ explained, "I don't really like picture books because they don't tell a lot of words, but graphic novels have a lot of pictures and words." Wyatt

\footnotetext{
${ }^{4}$ All of the names in this paper are pseudonyms.
} 
further indicated that he learned more by reading the graphic novel because "instead of just having one picture you can put a whole bunch more details and stuff."

\section{"Who would want to blow up a library?"}

Prior to reading either of these stories, I asked students to share with me what they already knew about Iraq and the war taking place there. Comments ranged from vague ideas about what is happening there- "they are having something related to a war there"-to more specific statements, such as "there is lots of soldiers fighting in Iraq." Mitch indicated that Iraq made him think of his mom's boyfriend, who is currently serving in the military there. Destiny said that when she hears the word Iraq, she thinks of the word "destroy," explaining that "like Iraq, like it messed up everything." Another student explained that soldiers are fighting because "they are trying to protect us, like the Iraqians and us, because we took their land and they want it back." Overall, students seemed unsure what to think about Iraq and were hesitant to even venture a guess, perhaps a sign that very little teaching or discussion about the war in Iraq is happening in their classroom or at home. The little background knowledge they did possess revolved around American soldiers going to fight in Iraq and an overall impression that the United States was fighting against the Iraqis.

After reading the two books, students expressed surprise over several facets of the war. Wyatt indicated that "I didn't know that they blew up a library." He goes on to share that he thought wars happened out in the desert and away from ordinary people, not so close to places that normal people use, like libraries. Nora further questioned, with great exasperation, "who would want to blow up a library?" Likewise, others were surprised that people's houses were destroyed during war. Emily noted "whenever we have wars, we destroy people's homes and some of their most precious things," a salient insight into the Iraq War, but also the consequences of war more broadly. Further, Mitch was amazed at how commonplace it seemed for buildings to be blown up in Iraq and the government's apparent disinterest in helping stop the destruction. He said, "I learned that people in Iraq don't really care that they are getting bombed. They are used to the buildings being bombed. The government didn't want to help save the library." Students also expressed dismay that looting occurred after buildings were destroyed, as Stamaty described people running into the remains of the library to steal rugs and pencil sharpeners.

After reading the two books, students revealed an understanding of a completely new side of the war, an Iraqi perspective. Previously, their limited knowledge about the war seemed to center on the American position, particularly the point-of-view of American soldiers fighting in the war. The story of Alia Muhammad Baker, in contrast, offers a fresh perspective on the war, offering a glimpse into ordinary life in Iraq through the eyes of an unlikely hero, a courageous and civically-minded elderly Iraqi woman. One student was impressed that "she is very old and she saves all these books at that age," while another proclaimed her a real-life hero who "saved the history of her country." Thinking about the war 
through the eyes of Baker was both surprising and compelling for students, who knew little about life in Iraq and previously thought the only heroes in the war were the American soldiers. As such, engaging with the graphic novel helped students visualize the realities of war and understand multiple perspectives on it, particularly the experiences of the Iraqi people.

\section{In Their Own Words}

After reading and discussing the two texts, students were asked to retell the story in their own words and pictures. With minimal, open-ended instructions and blank, white paper as a canvas, students had the freedom to choose any format they wanted to retell the tale of Alia Baker. Of the twenty-two participating students, twelve chose to retell the story in a graphic novel format, two created more traditional picture books, seven wrote text-only stories, and one student used images and stand-alone words to tell the story.

In this section I will share some of the most interesting features of the student retellings. In particular, I will look closely at the retellings of students who utilized the graphic novel format. Although students had limited prior exposure to this format, many students exhibited an implicit understanding of the key features of graphic novels, including intertextuality, visual literacy, and the ability to tell stories from multiple perspectives, including their own. I will also examine the retellings of students who utilized formats other than the graphic novel and share some of the students' explanations for how they made decisions regarding which format best fit their retelling.

Intertextuality. First, these students played with the idea of intertextuality, the co-dependency of text and images in graphic novels. Sean (Figure 1) created a graphic novel that requires readers to closely examine the images and text simultaneously. He only writes text in the form of speech bubbles, providing no background information or text outside of the framed image. Several of his panels have no words at all; instead he uses images to show action and move the storyline forward. Similarly, Amanda (Figure 2) uses images to complete thoughts she begins in words. For example, she writes, "And it starts like this..." on the top of a framed image of Baker driving to work, allowing the image to serve as the remainder of her sentence. It would be impossible for the reader to understand Amanda's story by examining the pictures or words on their own, but together they read as a singular text. 


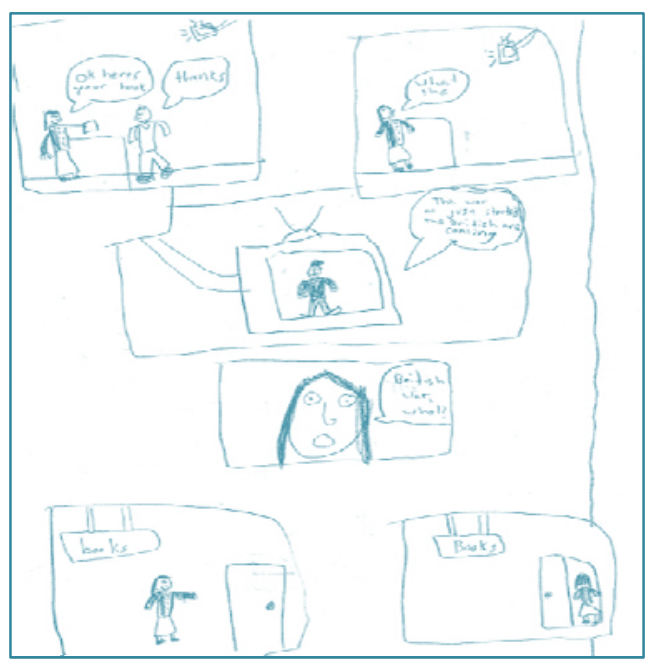

Figure 1

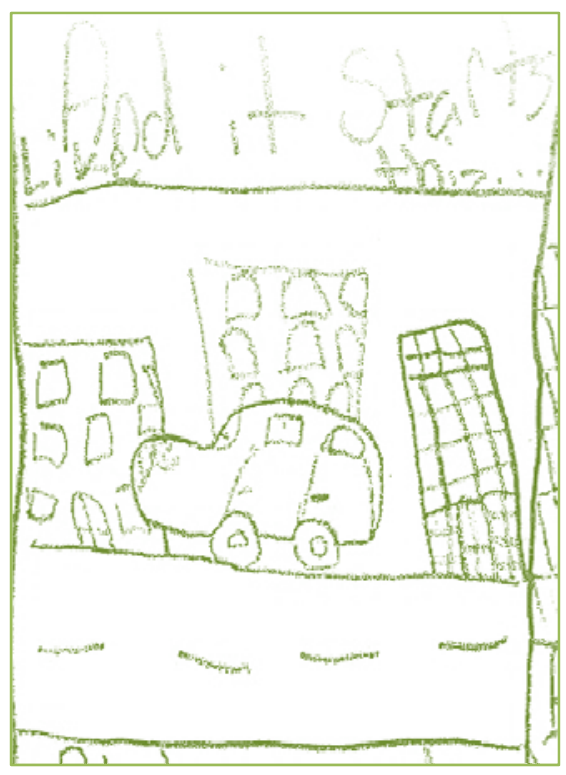

Figure 2

Visual Literacy. Students also played with the idea of visual literacy. Jasper (Figure 3) varied the size of his panels depending on the importance and type of information contained within them. For example, one page of his book contains 4 frames detailing the transfer of the books from the library to the restaurant. The four frames are crowded together and give the reader a sense of action, as if the efforts to save the books are happening quickly and at a frantic pace. Later, Jasper uses one large panel (Figure 4), the same size as the four described above, to depict the burning of the library, adding drama and a pause to the most climactic moment in the book. By varying the frames in this way, Jasper controls the pace of the plot for the reader and shows an understanding of the relative importance of various moments in the story. Other students also displayed an understanding of visual literacy skills when they used images to display emotions and tell important parts of the story without using words. For example, in one panel of her story Amelia (Figure 5) writes "Alia and her friends took the books so they won't get on fire." The accompanying image in this panel shows two women carrying stacks of books. One women has a large tear running down her face while the other has a dialogue bubble drawn from her mouth, showing that she is yelling "Hurry up!." In decoding Amelia's image, the reader understands that moving the books out of the library was a sad and scary experience for Baker and her friends, who felt pressured to move the books as quickly as possible. Yet this urgency and emotion does not come through in Amelia's rather vague sentence. It is only through reading the image in relation to the words that the full meaning of Amelia's text is revealed. 


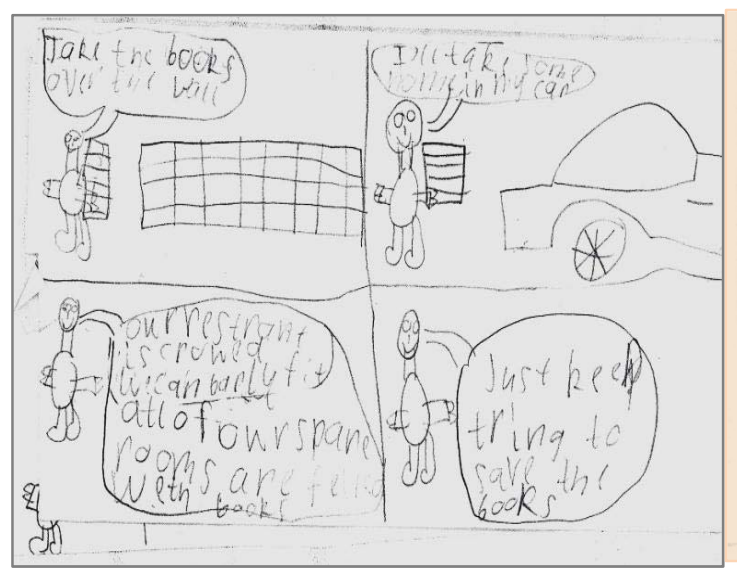

Figure 3

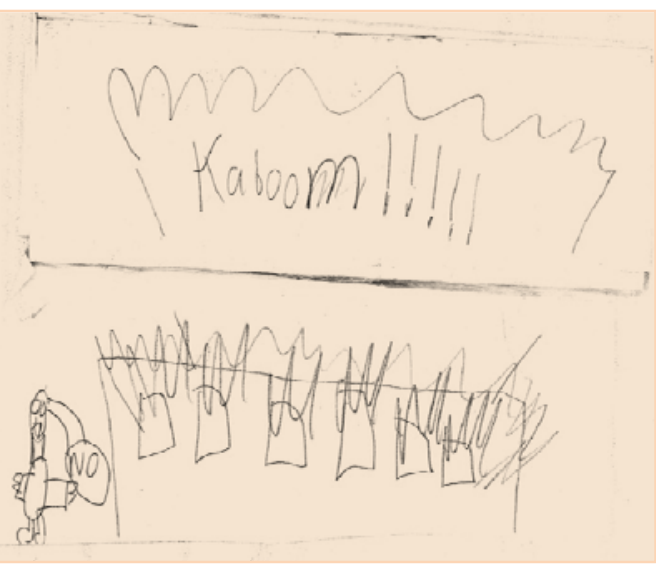

Figure 4

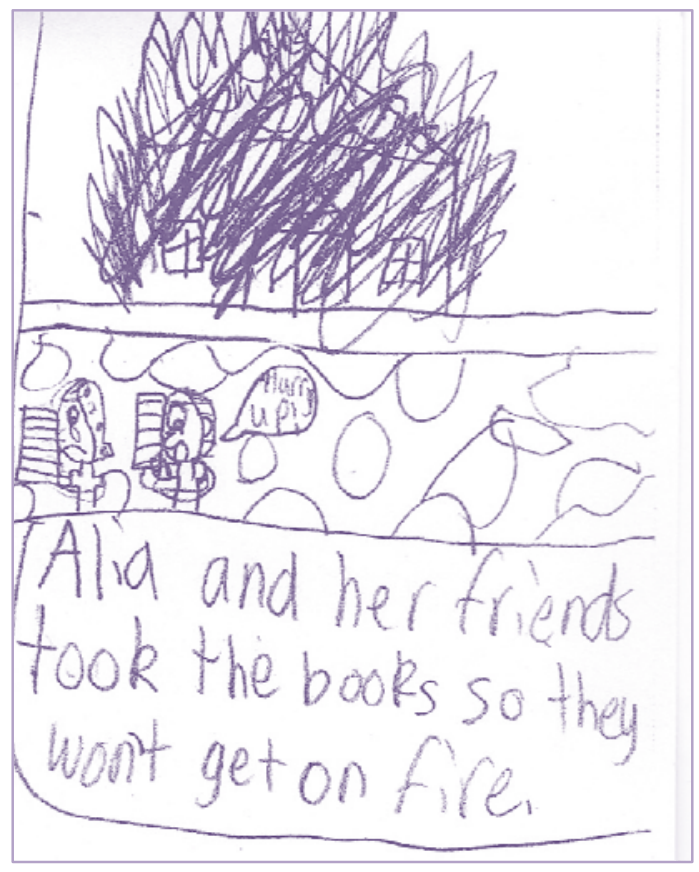

Figure 5

Multiple Perspectives. Students who chose to retell the story through the graphic novel format also displayed an understanding that graphic novels provide unique opportunities to share multiple perspectives. Nine of the twelve students wrote at least some of their text in speech bubbles, forcing the reader to switch between multiple speakers and perspectives. Unlike picture books, where the speaker is often identified with the "he/she said" phrase and the speech act is placed in quotation marks, these students used speech bubbles to show who was speaking and provide multiple points-of-view on the story. For example, Amanda (Figure 6) drew a panel in her book depicting two people in conversation. At the top of the panel, she writes "And people start saying rumors that might come true." Beneath this text, one character exclaims, through a speech bubble, "Oh no people might die" 
and the other responds "Will my family survive?" Through using the speech bubbles in this way, Amanda provides readers with a glimpse into the thoughts and feelings of people in Basra at the time of the war, generating a more complete understanding than if she had simply told the story from one perspective. Beyond speech bubbles, several students actually created a new character to narrate or introduce their story, adding a fictional element to this true story. Indeed four students followed the lead of Stamaty, the author of Alia's Mission, in introducing a talking, walking book to help tell the story. Madison (Figure 7) begins her retelling with an image of a smiling book stating "The year was 2003" while Allyiay's cover depicts a book with a peace sign on front declaring "Read this book!."

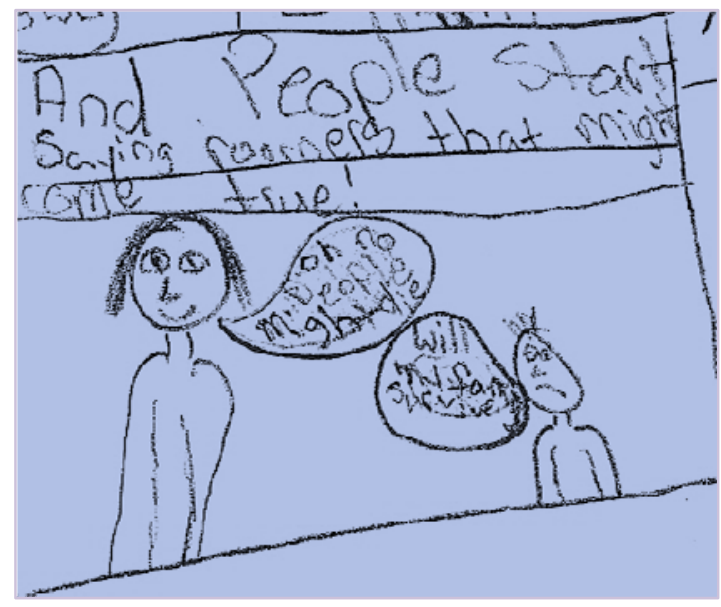

Figure 6

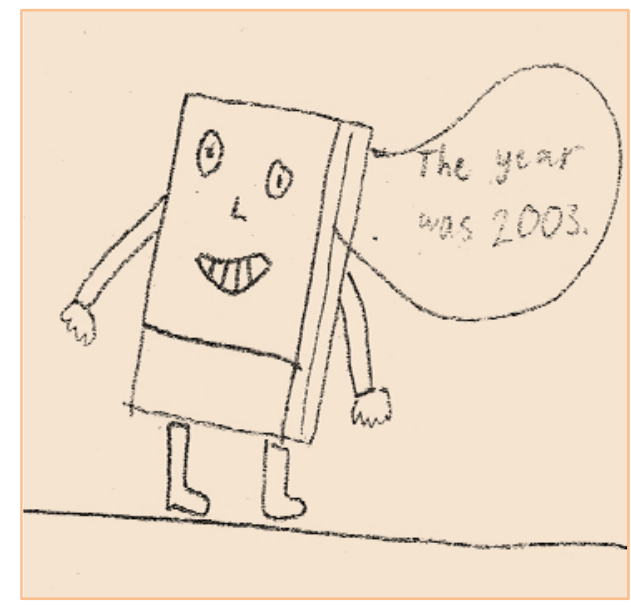

Figure 7

New Perspectives. Perhaps most interestingly, many students included a new perspective in the text, their own. Students embellished stories, changed facts, and reworked the ending of the story, adding their own unique perspective to Baker's story just as the authors of the two books did. Many students displayed an urge to conclude their books on a positive note, even if this positivity was not accurate to the factual details of the story. For example, Maya finishes her story by writing " 6 months later there was a new library. Even more kids came than before." Indeed, there was not a new library six months later, nor were students provided any information about attendance at the new library. Similarly, Rebecca writes "she lived happily ever after in her new library!" at the conclusion of her retelling, a statement that vastly oversimplifies the hardship Baker endured, including suffering a stroke on the day of the fire, in order to save and eventually rebuild the library. Like Maya and Rebecca, Henry seems determined to put a positive spin on the story, titling his book "Alia's Worst to Best Day Ever!" In his retelling, the fire department comes to the rescue of the library and Alia is happy because the library "was harmed a little," leaving "the books still good to read!" This retelling glosses over all of the angst and fear Baker feels about losing the books in the library and oversimplifies the story to such a point where it is simply inaccurate, for the library was burned to 
the ground and many of the books went with it. It is hard to imagine Baker proclaiming the burning of the library to be her "best day ever," as Henry declares.

Other formats. Of course, not all of the students utilized the graphic novel format to retell Baker's story. Seven students chose to use mainly text to retell their story. Several of these students wrote lengthy pages of text, adding a great amount of detail from the original books into their retellings, while others wrote only a few sentences, simplifying the story significantly. Without using images, Charlie turned to other visual techniques, such as using all capital letters and exclamation points, to signify important moments in the story, as in "she saw a sign that said war TOMORROW!!" Likewise, Claire dramatized the climactic moment of the book when she wrote, "soon the war came closer and closer and KABO0M! The library was on fire!" Three of the students who wrote text-based books began their stories with the phrase "one day..." and concluded their retellings by writing "The End," drawing from traditional story-telling techniques as though Baker's story was fictional.

Student Rationale. After completing their retellings, students were asked to explain why and how they choose to retell the story. One student exclaimed that he chose to use pictures and text to share his story because, "I think that pictures alone wouldn't give a good description of what happened because...if you just showed pictures of a war, they might think the story was about a war, not about saving a library." Emily elected to use a graphic novel format because, "I think I can tell the story better using the images and the short words." Similarly, Maya noted that it "would be boring to have one big picture and just a couple of words. I wouldn't be able to fit the whole story like that.... If I just used words, I wouldn't be able to tell the whole story." Jasper also settled on the graphic novel because he found it useful to tell the story through words and images, though he originally wanted to create a wordless book. "At first I wanted to just do pictures, but then I realized I couldn't really explain the story in pictures alone so I needed to use some words too," he explained. Several students who chose to use mainly text in their retellings indicated that they did not like to draw or did not feel like drawing that day.

\section{Implications for Elementary Social Studies}

Though this case study was limited in its scope, it provides valuable insights to elementary educators about the power and potential of using graphic novels to teach social studies. First, students in this class made it abundantly clear that they enjoy reading graphic novels, often more so than they do a traditional picture book. The graphic novel we read, Alia's Mission, offered immense details in the text and images, resulting in a longer, more complicated story than the picture book version. Ironically, this complexity made me initially leery to share the graphic novel with this class of third-graders, who I feared would get confused or bored by the nuanced plot. Instead, it is precisely this level of detail that engaged students with the graphic novel; several students even expressed disappointment over the fact that the picture book version glossed over so many facets of the story, such as Baker's stroke after the library burns down. More than simply enjoying the graphic novel version of the story, students also showed a remarkable ability to read the visual and textual 
components of the book as a singular text. They were entranced by the black and white images in Stamaty's book and asked repeatedly for extra time to examine the images and read the accompanying speech bubbles. Whereas they passively listened to my reading of the picture book, they wanted to linger inside the pages of the graphic novel, reveling in the intricacies of the images.

This level of student engagement suggests that elementary educators need not shy away from graphic novels for fear that they are too complex or detailed, but rather utilize them in the curriculum for exactly these reasons, providing elementary students with the in-depth information they crave through a genre that is compelling for young people. Whereas social studies text books can also provide detailed information about historical or socio-cultural events, such texts are typically quite dry to read, with long paragraphs full of facts and few illustrations. Conversely, graphic novels can present the same type of information in a more interesting way, offering multiple perspectives on events, personal insights into social studies stories, and powerful illustrations that propel the story forward. Picture books can also do this, and certainly many excellent texts do, but graphic novels have a tendency to be more detailed, lengthy, and nuanced than the typical children's picture book, offering great possibilities to tell social studies stories in complicated, yet accessible, ways.

Secondly, this case study suggests the power of having students reinterpret and retell social studies stories in their own words. Rather than simply discussing and analyzing the two texts, students were encouraged to do something with Baker's story, creating a new version-their own. This turned a typically passive classroom exercise, listening to a book read aloud, into a more active one, in which students were reconstructing the story and taking on the role of authors and illustrators. Students were given much freedom in choosing how to best retell the story of Alia Baker; they needed to make key decisions about what content to include and what to leave out, as well as what format-graphic novel, picture book, text only, or an original style-would be most appropriate for their retelling. "Figuring out what to say, what to depict, and how these modes should be interrelated in their books are all important tasks for the child," assert Pappas and Varelas (2009, p. 210), who further state that the task of creating multimodal texts can reveal underlying content knowledge that often goes unidentified when teachers emphasize one mode, usually writing, exclusively. "In a nutshell, concentrating only on written text clearly does not paint the 'whole picture'" (Pappas and Varelas, 2009, p. 210).

What was particularly interesting about the students' retellings in this case study was that so many of the students utilized the graphic novel format to share their stories. Even though the students had little exposure and had received minimal teaching about this format, they still found the graphic novel compelling enough to try out for themselves, a strong indication of student interest in this realm of writing. Imagine the possibilities for student learning if indeed this sort of communication did become an area of teacher emphasis. As Hammerberg (2001) argues, "instruction can take place on the conceptual level of textual design and 
ever-shifting perspectives (e.g. hypertext). This kind of instruction will rely on techniques that transform the abstract into a different kind of concrete: a textual form that represents the imaginative ranges and perspectives of students" (p. 214). Beyond this sort of language arts curricular reinvention, social studies instruction could also be reinterpreted to incorporate the many lessons of graphic novels. For instance, students could use the texts as starting points to grapple with multiple perspectives on social issues, as models for their own multimodal writing, and as sites to explore their own voices as authors and illustrators of social stories.

Finally, it became increasingly evident during this case study that engagement with Baker's story through reading the two texts and participating in the retelling exercise helped students develop a critical stance (Lewison, Leland, \& Harste, 2008). In this case study, students practiced conscious engagement by making decisions about how to respond to the story and being cognizant of the power of their choices as authors and illustrators. Students played with alternative states of being when they sought to understand the multimodal nature of the books they were reading and creating, as well as when they were taking risks in their own retellings, trying out new and different ways to share their voices. A responsibility to inquire was exhibited when students asked questions about both the content of the story (i.e. "who would want to blow up a library?") and about the format for their retellings. Students also exhibited this responsibility to inquire when they questioned the viewpoints of the authors of the two texts, particularly when they considered why each author chose to include or exclude certain pieces of information, and considered the perspectives of Iraqi citizens and American soldiers in the stories.

Why does the development of a critical stance matter? Lewison, Leland, and Harste (2008) assert that ascertaining a critical stance is crucial to an individual's civic growth and essential to a community's democratic development. Young people with a strong critical stance are better equipped to engage with, question, and challenge the civic process, a major goal of social studies education. Moreover, students who possess a critical stance can imagine alternative ways of being and acting that challenge systems of injustice and the status quo, instead taking risks and trying out new discourses. Of course, the development of a critical stance is an enormous goal and one that must be shared over the course of a student's education-the students in this case study surely did not develop a critical stance simply by partaking in this short project. However, projects like this one do help students nurture their critical stance, providing opportunities to practice new discourses and try skills necessary for this type of critical engagement.

\section{Conclusion}

This case study provided third-grade students the opportunity to read, write, and re-write history using the graphic novel format. Through exploring the story of Alia Baker, students shared high levels of interest in graphic novels, exhibited new knowledge and perspectives on the Iraq War and active citizenship in general, and utilized key features of graphic novels to tell complex and multilayered social stories 
from their own perspective. Engaging with graphic novels helped students better comprehend both the content of the lesson, the realities of the Iraq War and civic commitment of one Iraqi woman, and the nature of historical narratives. In their retellings, students showed an understanding that history is open to interpretation, that there are multiple, valid perspectives on every issue, and that the viewpoints of young people matter, including their own.

The success of this case study raises questions about how we as educators can utilize graphic novels, as well as other forms of alternative and out-of-school literacies, like blogs, podcasts, online games, web pages, videos, and social networking, to similarly motivate young people to engage in the civic process and develop a critical stance. Picture an elementary classroom in which students learned about social and historical issues through these types of literacies. How different such a classroom would look and feel than the typical social studies classroom, where students learn a staid version of history from a textbook and literacy means simply reading books. Imagine a class where these literacies were nurtured, rather than marginalized, brought into the mainstream of both the literacy and social studies curricula as essential elements to teach content and promote student engagement, civic development, and critical stance. It is not implausible to think that in such classrooms the voices of more students would be welcomed, the interests of diverse populations would be considered, and the disconnection between learningat-school and learning-at-home would be minimized. This case study is but a small start—surely these ideas merit further exploration.

\section{References}

Barton, K. C., \& Levstik, L. S. (2004). Teaching history for the common good. Mahwah, NJ: Lawrence Erlbaum.

Carspecken, P. F. (1996). Critical ethnography in educational research: A theoretical and practical guide. New York: Routledge.

Cromer, M., \& Clark, P. (2007). Getting graphic with the past: Graphic novels and the teaching of history. Theory and Research in Social Education, 35(4), 574-591.

Frey, H., \& Noys, B. (2002). Editorial. Rethinking History, 6(3), 255-260.

Glazer, B. G., \& Strauss, A. L. (1967). The discovery of grounded theory: Strategies for qualitative research. New York: Aldine.

Gorman, M. (2008). Graphic novels rule! The latest and greatest comics for young kids. School Library Journal, March, 42-47.

Hassett, D., \& Schieble, M. (2007). Finding space and time for the visual in K-12 literacy instruction. English Journal, 97(1), 62-68.

Hammerberg, D. (2001). Reading and writing "hypertextually": Children's literature, technology, and early writing instruction. Language Arts, 78(3), 207-216. 
Heffernan, L., \& Lewison, M. (2009). Keep your eyes on the prize: critical stance in the middle school classroom. Voices from the Middle, 17(2), 19-27.

Jacobson, S., \& Colon, E. (2006). The 9/11 report: A graphic adaptation. New York: Hill and Wang.

Janks, H. (2000). Domination, access, diversity, and design: A synthesis for critical literacy education. Educational Review, 52, 15-30.

Lewison, M., Flint, A. S., \& Van Sluys, K. (2002). Taking on critical literacy: The journey of newcomers and novices. Language Arts, 79, 382-392.

Lewison, M., Leland, C., \& Harste, J. (2008). Creating critical classrooms: K-8 reading and writing with an edge. New York: Lawrence Erlbaum.

Luke, A., \& Freebody, P. (1997). Shaping the social practices for reading. In S. Muspratt, A. Luke \& P. Freebody (Eds.), Constructing critical literacies (pp. 185-223). Cresskill, NJ: Hampton Press.

Lyga, A. (2006). Graphic novels for (really) young readers. School Library Journal, March, 56- 61.

Oakes, J., \& Rogers, J. (2006). Learning power: Organizing for education and justice. New York: Teachers College Press.

Pappas, C., \& Varelas, M. (2009). Multimodal books in science-literacy units: Language and visual images for meaning making. Language Arts, 86(3), 201211.

Satrapi, M. (2007) The complete Persepolis. New York: Pantheon.

Spiegelman, A. (1986). Maus: A survivor's tale. New York: Pantheon.

Stamaty, M. A. (2004). Alia's mission: Saving the books of Iraq. New York: Knopf.

Stassen, J. P. (2006). Deogratias: A tale of Rwanda. New York: First Second.

Strauss, A., \& Corbin, J. (1990). Basics of qualitative research: Grounded theory procedures and techniques. London: Sage.

Vaughan, B. K. (2008). The pride of Baghdad. New York: Vertigo.

Winter, J. (2005). The librarian of Basra: A true story from Iraq. Orlando: Harcourt.

Zinn, H., Konopackin, M., \& Buhle, P. (2008). A people's history of American empire: A graphic adaptation. New York: Henry Holt. 


\title{
Standard Written Academic English: A Critical Appraisal
}

\author{
Laura (Violeta) Colombo
}

\begin{abstract}
Science today is mainly communicated through standard written academic English (SWAE). In this paper, I apply the postulations of Gramsci, Bourdieu and Canagarajah to show how domination structures are reproduced in scientific communication worldwide. I argue that these structures do not allow nondominant epistemologies and ways of producing and communicating science to participate in the international arena. I apply a critical lens to interpret each one of the terms present in SWAE. I propose that a critical appraisal of each one of these terms is the first step towards a more democratic conceptualization of science communication where the standards are not only seen as a means of innocuous communication but also as ideologically charged fictitious universals. It is my claim that understanding the arbitrary nature of these universals and the influence that language has on knowledge construction will give space to nondominant ways of producing and communicating knowledge.
\end{abstract}

\section{Standard Written Academic English: A Critical Appraisal}

It is widely known that in today's world science is mainly communicated through writing. Writing plays a major role in academic communities as a way of producing and legitimizing knowledge (Bourdieu, 1986). In addition, many scholars agree that English has become the "language of science" (Canagarajah, 2002b; Curry \& Lillis, 2004; Čmejrková, 1996; Hyland, 2006, Martín-Martín, 2003; Mauranen, 1996; Pennycook, 2001; Reichelt, 2001; Swales \& Feak, 1994; among others) at an international level. Therefore, in order to participate in the international sphere, scholars are expected to use standard written academic English (SWAE ${ }^{5}$ ). If we take into account that SWAE is the main means through which academic discourse is spread, not only nationally but also internationally, the analysis of SWAE becomes imperative to acknowledge the reproduction of social inequalities. This paper proposes a critical appraisal of what the term SWAE implies and how each one of its components and the meanings tied to them are rooted in domination structures present in the current ways of communicating science.

\footnotetext{
5 I would like to apologize to the reader for not following in this paper the same order in which each word appears in the acronym. However, clarity in the presentation of my argument seemed to be more important in this case.
} 


\section{Method}

In this paper I offer a critical analysis of what the use of SWAE implies. In order to do this, I first apply Gramsci's postulations to analyze the hegemonic prominence of writing among other communicative means for academic and scientific 6 communication. Second, I utilize Bourdieu's ideas to explore the term academic and to analyze the structures of domination that are present in the national and international scientific fields due to the use of SWAE. Third, I draw on Canagarajah's claims to consider what is standard in SWAE and how this is related to a monolithic view of language. Finally, I propose that for SWAE to allow a more democratic participation in the international scientific field all these issues should be acknowledged.

\section{Why written academic language?}

In this section I apply the framework offered by Antonio Gramsci to propose that writing is a major component in the current hegemonic modes of communication of science and knowledge. I first briefly explain the concepts of structure and superstructure in economic systems, according to traditional Marxism. Second, I present Gramsci's claims about the importance of the superstructure. Finally, I explain the role of writing in the current hegemonic modes of communication of science.

In today's society, scientific activity is mostly communicated through written language (Ventola \& Mauranen, 1996). Writing plays a major role not only as a means for communicating science but also as an artifact that defines worldwide scientific work as such (Buta \& Sued, 2005). Scientific work is mainly situated in academic institutions which, in Marxist terms, are part of the superstructure, the ideological terrain.

In traditional Marxism, economic systems could be defined as having a base or structure, and a superstructure. The base is constituted by the material conditions of a specific time: forces of production, relations of production and the modes of production of a specific economic system. These are the elements on which Karl Marx mainly centered his economic analysis. On the other hand, the superstructure is defined as false ideology or "mere illusions" (Forgacs, 1988, p. 196) that endorse the interests of the dominant group. In traditional Marxism, therefore, the base (or structure) determines the superstructure. Figure 1 illustrates this.

\footnotetext{
${ }^{6}$ In this paper I use the words "science" and "scientific" not only to refer to what is related to the commonly called "sciences" in US academia. Because it goes beyond the focus of this paper, I leave aside the dichotomy between sciences and humanities, and include both in the categories of "science" and "scientific."
} 


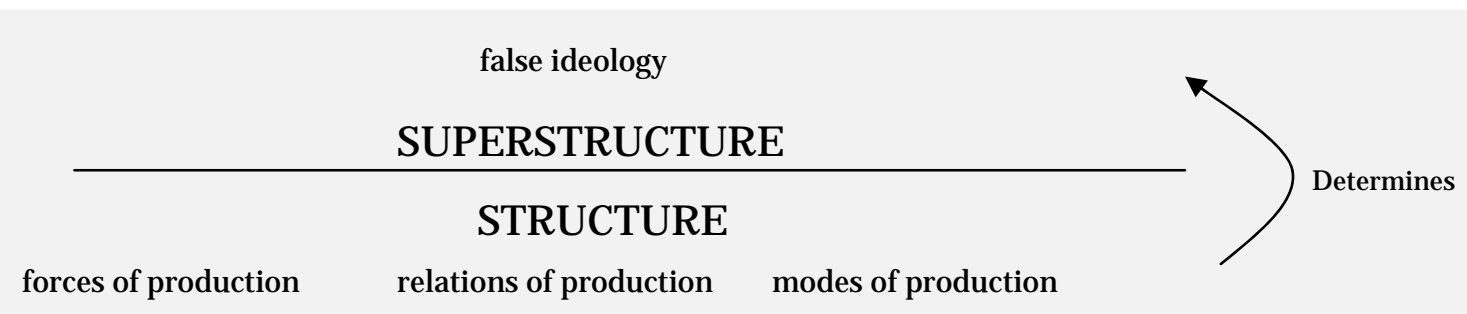

Figure 1. Elements of and relationships between structure and superstructure in traditional Marxism

Contrary to traditional Marxists, Gramsci saw the superstructure as a much more complex phenomenon, as more than an "immediate expression of the structure" (Forgacs, 1988, p. 190). In search of an answer and a practical application that would promote social change, the author opened new directions for Marxist discussions by claiming that base and superstructure are interconnected, although not deterministically. According to Forgacs (1988), Gramsci maintained that there existed "a reciprocity between structure and superstructures, a reciprocity which is nothing other than the real dialectical process" (Forgacs, 1988, p. 193). Therefore, not only do changes in the base determine changes in the superstructure, but changes in the "ideological terrain" (Forgacs, 1988, p. 190) can also generate changes in the structure.

In his analysis of the "sphere of the complex superstructure" (Forgacs, 1988, p. 189), Gramsci further explores the "ideological terrain," frequently forgotten by previous thinkers, and he classifies institutions as either coercive or noncoercive. Coercive institutions are associated with what the author names "political society" and domination, since they exercise direct coercion on individuals. Noncoercive institutions are related to the civil society and are associated with the concept of hegemony. While hegemony and domination are both forms of control, domination is the "direct physical coercion by police and armed forces" and hegemony is the "ideological control and more crucially, consent" (Burke, 1999, online). This is the ideological control of the dominant class along with the consent of the dominated class. According to Burke (1999), hegemony for Gramsci "meant the permeation throughout society of an entire system of values, attitudes, beliefs and morality that has the effect of supporting the status quo in power relations. Hegemony in this sense might be defined as an 'organising principle' that is diffused by the process of socialisation into every area of daily life" (Burke, 1999, online). These principles go unnoticed, and thus reinforce those discourses that keep in power those already in power. Figure 2 illustrates Gramsci's stand on the relationship between structure and superstructure and the different elements that compose both of them. 


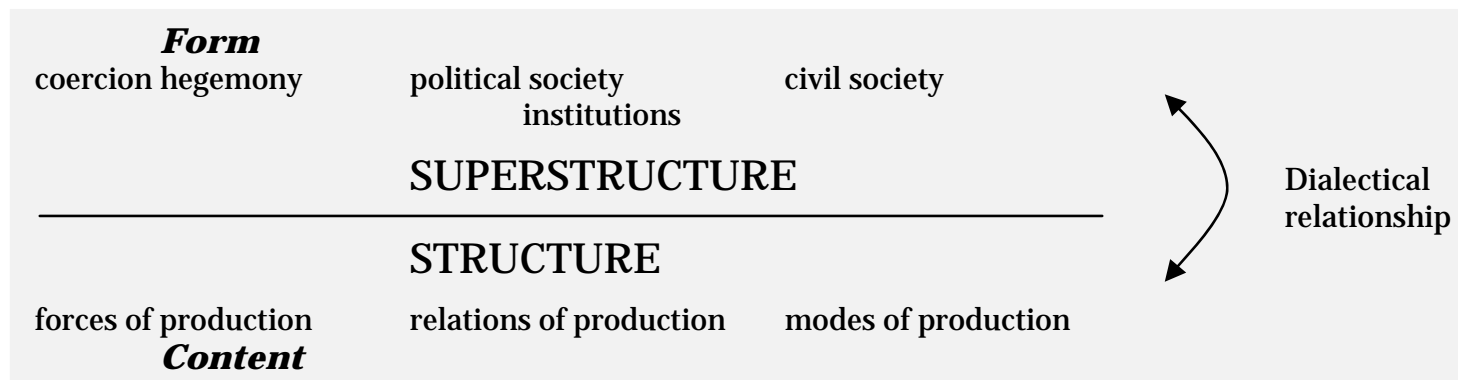

Figure 2. Elements of and relationships between structure and superstructure in Gramci's writings

As part of the superstructure, academic institutions are noncoercive institutions that contribute to the hegemony of the dominant groups in society. In Gramsci's terms, the superstructure has a dialectical relationship with the structural conditions. The structural conditions in capitalism, then, define the specific modes of production of science and knowledge in a capitalist society. Current structural conditions of scientific work in academia are highly linked to legitimized modes of scientific production, within which writing plays a major role in validating research findings when these are communicated to the scientific community.

The current legitimized modes of scientific production, according to Canagarajah (2002b), are still linked to the tradition of scientific positivism despite the appearance of recent orientations that link writing with knowledge construction (i.e., a post-Enlightment orientation to knowledge construction). In the scientific positivist tradition, "knowledge is supposed to precede the writing of it in textsand therefore stand free of factors of language and communication" (Canagarajah, 2002 b, p. 59). This separation of the context of "production" and communication of knowledge leads to a reification of writing that sets the publication of scientific articles (with their exchange and use values) as an imperative for being recognized as an expert in any worldwide scientific field. It is along this line that Buta and Sued (2005) affirm that "la función del artículo científico ... consiste en algo más que la comunicación de un nuevo conocimiento. Originada en los reclamos por la propiedad intelectual de las contribuciones, se construye además como instrumento de medición de la productividad del científico como trabajador, índice de pertenencia a un determinado campo científico"7 (p. 3).

Therefore, despite the variations that may exist in local material conditions influencing the production of knowledge, researchers worldwide feel the imperative to publish. This imperative reinforces those standardized modes of labor imposed by the publication market and further reinforced by world-wide gate-keeping

\footnotetext{
7 "The function of scientific articles ... goes beyond the communication of new knowledge. With its origin in the intellectual claim implied in [Originating in claims on the intellectual property of] the contributions, [this function] is also constituted as an instrument to measure the productivity of the researcher as worker, a measure of membership in a specific scientific field." (The translation is mine).
} 
mechanisms (for a more detailed discussion see Curry \& Lillis, 2004) that endorse a manufactured consent held by the hegemonic power of the ruling class in capitalism.

The materialization of this hegemonic power in science can be found in the prevalence of writing as the preferred and legitimized mode of communicating science worldwide. It is in this sense that the relationship between structure and superstructure reinforces the hegemony in the economic system, since writing as the legitimized mode of communication of science reinforces and defines the scientific activity as such following the tradition of scientific positivism.

Nevertheless, if we take into account Gramsci's stance on the reciprocal character of the relationship between structure and superstructure, there is a greater possibility of social change if the forces of change operate not only on the structure, but also on the superstructure. Therefore, change can be generated by a "war of position" or by a "war of movement." The war of position is held in the terrain of the civil society, which is "a site of consent, hegemony, direction," while the war of movement is "a frontal assault on the state" or political society, "which is a site of coercion, dictatorship, domination" (Forgacs, 1988, p. 224). Gramsci, then, envisions a real opportunity for change associated not only with material conditions but also with an "ideological struggle" (Forgacs, 1988, p. 223). This ideological struggle is the struggle for counter-hegemony that is waged through the war of position in which hegemony is challenged and there is a struggle to forge new consent around counter-hegemonic ideas. The following figure shows in bold those areas where intellectuals could play a major role and start acting as forces for social change.

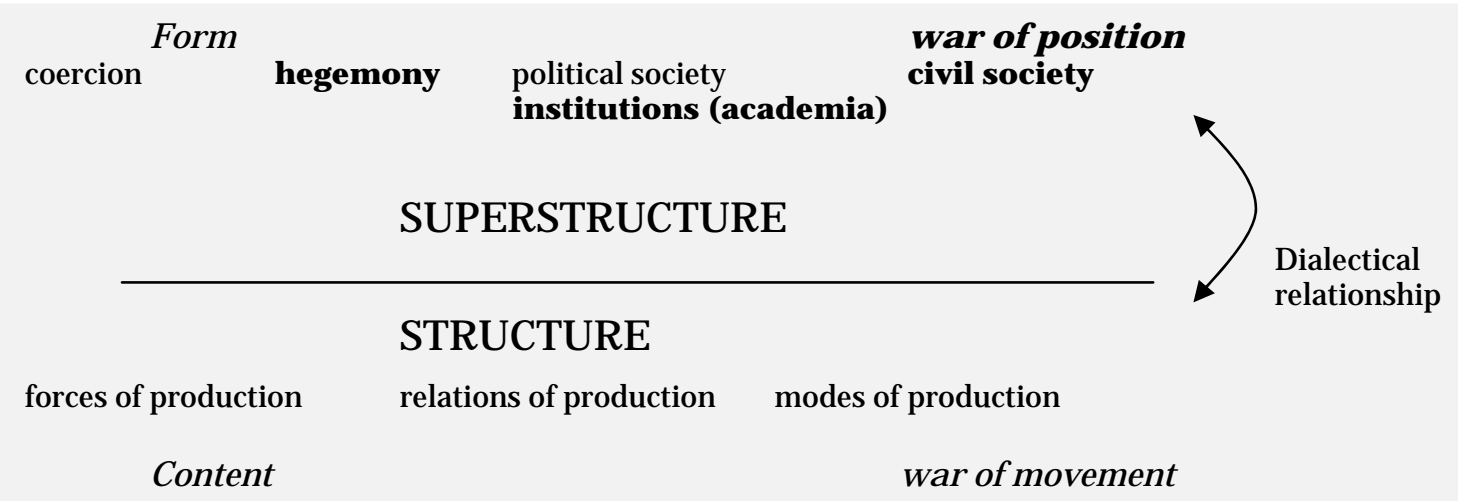

Figure 3. Positioning of the counter-hegemonic discourses in the superstructure (see bolded words)

In the war of position, then, counter-hegemonic discourses would be defying the dominant hegemonic discourses in different areas in the superstructure. In the case of academic writing, a war of position against the absolute prominence of written language to communicate science could start in the territory of academic institutions. This counter-hegemonic movement could propose other ways of communicating science that do not rely heavily on written language, but that also draw on other communicative means such as oral or visual communication. 
For example, Canagarajah (1996) reports that in nondominant academic cultures the communication of science "is more significantly taking place in face-toface oral interactions rather than in print" (p. 458). As will be shown in following sections, these differences in the ways in which knowledge is communicated also influence the way knowledge is produced. Wysocki (2004) also acknowledges how the visual is still pretty much absent "in the circulation of academic and other 'serious' writing" (p. 14). The author proposes that it should be acknowledged how the "different technologies of production-of writing, of photograph, and so onhave the status and position-building weights and possibilities they do because of how they fit within the broad but contingent material practices and structures in which we all live" (p. 23). In this way, both authors voice the fact that the means and materiality through which knowledge is communicated are not neutral; rather they are related to social practices and material realities present in academia.

If different modes were more frequently used for communicating science (for example, the oral and visual modes mentioned), they would permeate the superstructure, and along with them, different epistemologies and methodologies ${ }^{8}$ (born in places where the material conditions for the production of knowledge step aside from the dominant capitalist paradigm) would start having validity in the academic field. In addition, new modes of communicating science could appear thanks to the aid of current technological advances. For example, an oral modality supported by computer-mediated communication could open the door to a more dialogical style since the deferred nature of writing would be replaced by synchronic communication.

Regardless of the materialization that these new modes take (oral, visual, face-to-face, computer-mediated, etc.), what they share in common is that they need to gain space in academia in order to constitute counter-hegemonic forces that lead to social change. However, what is academia? And what is academic about the writing it produces? What do we call academic writing? The following section explores the use of the term "academic" in SWAE, drawing on Bourdieu's postulations.

\section{What is academic about academic language? Writing in academia and the accumulation of symbolic capital}

In the previous section it was shown how the communication of academic knowledge is linked to the written mode, conceptualized as the preferred mode to "communicate" and validate scientific knowledge in the current economic system. In this section, I apply Bourdieu's postulations to explore the role of "academic" discourse in today's world and how it relates to issues of hegemony and power.

As proposed in the previous section and according to Gramsci, the interplay between current structural and superstructural conditions sets writing as the preferred and legitimized mode of communicating science. Academic institutions,

\footnotetext{
${ }^{8}$ In regards to methodologies, Marxist feminist studies have shown that there exists a hegemony of the scientific method associated with the hard sciences (see Sprague, 1997).
} 
which are noncoercive institutions, therefore generate a hegemonic discourse where writing is established as the appropriate mode of communicating the academic discourse. But how is this hegemony materialized? How do these processes existing in the superstructure reinforce domination? And who is the dominated and who is the dominator in academic writing?

According to Swartz (1997), what distinguishes Bourdieu from Marxists is that he looks "into the black box of cultural processes and institutions rather than relegating them to the abstract conceptualization of superstructure" (p. 66). Bourdieu asserts that the reproduction of social inequalities is not only based on material conditions. Dominant groups in society do not only draw on material forms of capital, but also on cultural, social and symbolic resources that "help to maintain and enhance their positions in the social order" (Swartz, 1997, p. 73).

Bourdieu (1986) defines symbolic capital as "economic or political capital that is disavowed, misrecognized and thereby recognized, hence legitimate" (p. 132). Symbolic capital confers symbolic power, "a legitimating power that elicits the consent of both the dominant and the dominated" (Swartz, 1997, p. 89). Gained through symbolic struggle, symbolic power is achieved and maintained by means of symbolic violence, which is "the imposition of a cultural arbitrary by an arbitrary power" (Bourdieu \& Passeron, 1998, p. 5). The arbitrary power is constituted by a dominant class or class fraction in society that imposes a cultural arbitrary, a "definition of the social world that is best suited to their interests" (Bourdieu, 1991, p. 167). One major component of symbolic capital, symbolic power, and symbolic violence, is the "misrecognition" of their arbitrary character that brings with it the naturalization of the "selection of meanings" (Bourdieu \& Passeron, 1998, p. 8) pertaining to the dominant class. Symbolic violence, thus, facilitates the reproduction of the social order and power relations by naturalizing and conferring legitimacy on the cultural arbitrary imposed by the dominant group. According to Swartz (1997), “[m]isrecognition is tied to Bourdieu's strong claim that all actions are interested. The logic of self-interest underlying all practices-particularly those in the cultural domain-is misrecognized as a logic of 'disinterest'” (p. 90). It is by being embedded in this logic of disinterest that "activities and resources gain in symbolic power, or legitimacy" (p. 90).

Worldwide in academia, written scientific discourse is embedded with a great amount of symbolic and cultural capital that confers upon this discourse an equally great amount of symbolic power. According to Bourdieu (1991), academic discourse is a worldwide legitimate discourse that won its legitimacy "through an arbitrary relativization of the dominant usage, which is socially recognized as legitimate, and not only by those who are dominant" (p. 53). The fact that academic written discourse is broadly recognized as legitimate not only in academia but also in society in general, makes it hegemonic according to Gramsci's postulates. This hegemony is not only related to a preferred mode of communication (written) but also to a preferred variety within each language.

According to Bourdieu, academic written discourse embodies a prestigious variety of language, with a great amount of linguistic capital. This prestigious variety 
of language is nothing less than an arbitrary linguistic competence endowed with linguistic capital through a legitimating process that does not take place in isolation, but is part of the cultural field, which contains the linguistic market. The linguistic market is what endows this arbitrary written variety of language with linguistic capital, and the educational system plays a central role in the "reproduction of the market without which the social value of the linguistic competence, its capacity to function as linguistic capital, would cease to exist" (Bourdieu, 1991, p. 57).

Academic discourse, then, is a code that is "imposed and inculcated as the principle of the production and evaluation of speech" (Bourdieu, 1991, p. 61). Therefore, academic written discourse is not only constituted by a legitimate language but it also helps to constitute the legitimate language. Structuring structure, structured structure, and instrument of domination, academic discourse is a symbolic instrument.

First, as a structuring structure, academic written language is an "instrument for knowing and constructing the objective world" (Bourdieu, 1991, p. 165). It is through academic writing that scientific knowledge is constructed and communicated, and reality objectified. As a structuring structure, academic language allows the construction and communication of scientific knowledge (objectivity) that is based on the agreement between the members of the academia (subjects).

Second, as a structured structure, academic written language is a structured system that allows science to be communicated. In this sense, academic language can be conceptualized as a "pre-constructed object" (Bourdieu, 1991, p. 44) that merely allows communicating an objective meaning, in this case, scientific facts.

Third, as an instrument of domination, academic language is a source of power because it produces the "instrument of production, such as rhetorical devices, genres, legitimate styles and manners and, more generally, all the formulations destined to be 'authoritative'." Therefore, academic language "confers to those who engage in it a power over language and thereby over the ordinary users of language, as well as over their capital" (Bourdieu, 1991, p. 58). It is for this reason that academic discourse "gives to those who hold it, or who appear to hold it, a monopoly of the legitimate viewpoint, of self-fulfilling prophecy" (Bourdieu, 1988, p. 28).

Finally, these three characteristics that constitute academic discourse as a symbolic instrument do not exclude each other but constantly interact. In order to be considered as such, academic discourse has to "take into account the state of representations of scientificity and the norms to be respected in practice in order to produce scientific effect and thereby acquire symbolic efficacity and the social profits associated with conformity to scientific appearances" (Bourdieu, 1988, p. 29). Consequently, the three elements interact since academic discourse is a structured structure ("norms to be respected in practice") that has a structuring function ("scientific effect") that serves as an instrument of domination ("symbolic efficacity"). 
If we take into account the fact that writing is one of the main vehicles through which academic discourse is spread, not only nationally but internationally in today's world, the analysis of academic writing as a symbolic instrument becomes an imperative. In it we can recognize an ideal arena for the reproduction of social inequalities not only at national or local level, but also at a global level.

The way science is currently being communicated internationally establishes the research paper as the main genre of publication (Swales, 1990) and English as the legitimate language variety (Curry \& Lillis, 2004). Therefore, in the international scientific arena, an arbitrary power establishes a cultural arbitrary: SWAE as the legitimate international science language, and research paper as the preferred genre to communicate knowledge. This cultural arbitrary finds its materialization in the fact that an overwhelming number of the most renowned international academic journals publish research papers written in English (for a more detailed discussion see Canagarajah, 1996, pp. 440-441).

Therefore, the international sphere constituted mainly by academic journals can be seen as what I call "international scientific field": an international publication market oriented towards "knowledge-manufacturing" practices that are nothing less than misrecognized symbolic capital. On the other hand, there also exists what I call "national scientific fields." National scientific fields are constituted by local publication markets and writing practices that are relatively autonomous. The international sphere and the local sphere are related and, as glocalisation theories propose, each local sphere enacts the "socio-spatial power choreographies" (Swyngedouw, 2004, p. 26) in a particular way.

According to Canagarajah (1996), in those countries that belong to what Wallerstein calls the "periphery," the knowledge-construction process is different, and scholars "might develop [their] own intellectual agenda and academic cultureone that is not necessarily in step with the other circles in the discipline" (p. 443). Due to geopolitical realities related to "the prestige of the mainstream journals" mostly published in English, and "the dominance of center academic communities" (Canagarajah, 1996, p. 443), the differences between the national scientific and the international scientific fields are more noticeable in those countries that belong to the periphery. Therefore, even if we consider disciplinary fields as the thread that unites scholars internationally, national scientific fields can be seen as relatively autonomous from international scientific fields.

Despite the differences that can be drawn between the international and the national scientific fields, in Bourdieu's terms, they have something in common: each of them is a power structure in which there are different positions linked by power or domination relations. Positions are defined by capital (symbolic and economic). The kinds of capitals, the kinds of assets that are valued may vary across fields. And within fields, power results from the differences in capital among positions and agents therein that struggle to obtain and preserve capital.

In addition, the international and national fields are interwoven and related. However, since the international scientific field in each discipline rises dominant 
over the national scientific fields, the relationships between the international and national fields are not based on equality but on power differentials. In this way, the mechanisms of domination that are present in each field are replicated in a higher scale in the relationships established between the international and the national fields.

An example of these mechanisms of domination is when non-Englishspeaking scholars need to publish in SWAE. When acting in the international scientific field, these multilingual scholars seem to be dispossessed of cultural and symbolic capital since what is valued in their national scientific field is not necessarily valued in the international one. Sometimes this dispossession of cultural and symbolic capital is rooted in the lack of "legitimate" linguistic competence: SWAE. This lack, in the international scientific field, constitutes an "objective dispossession of the dominated classes," related to the "monopoly of the legitimated use of the legitimated language" (Bourdieu, 1991, p. 59), the prestige variety of SWAE as the language of science. In this way, each field determines the relative positions and dispositions of the agents that "struggle for control over valued resources" (Swartz, 1997, p. 122).

Non-English-speaking scholars, then, despite possessing symbolic and cultural capital that assigns them certain positions and dispositions in their national academic fields, lack the legitimate competence of the arbitrary language of science and "are de facto excluded from the social domains in which this competence is required, or are condemned to silence" (Bourdieu, 1991, p. 55). The international academic field, therefore, "leaves them 'speechless', 'tongue-tied', 'at a loss for words', as if they were suddenly dispossessed of their own language" (Bourdieu, 1991, p. 52). In order to avoid this and to be able to participate in the field struggle, non-English-speaking scholars should acquire a new "habitus" that would enable them to adapt and produce appropriate texts written in SWAE to gain capital in the international scientific field.

Habitus is defined by Bourdieu and Passeron (1998) as "the product of internalization of the principles of a cultural arbitrary capable of perpetuating itself after PA [pedagogic action] has ceased and thereby of perpetuating in practices the principles of the internalized arbitrary" (p. 31). Thus, there is a "symbolic violence" executed on non-English-speaking scholars when they are required to acquire those ways of expression legitimized by the dominant group. In Bourdieu's terms, these scholars, in order to enter the field, must show a "tacit acceptance of the rules of the game" (Swartz, 1997, p. 125). They must learn those "strategies" that allow them to accumulate symbolic capital. This implies the acquisition of the "mastery of the laws of the functioning of the field" (Bourdieu, 1986, p. 132) in order to succeed.

According to Mahar, Harker and Wilkes (1990), "competence and mastery of the game are analogous to a person's habitus and possession of capital as they exist within the field" (p. 7). So when non-English-speaking scholars master the standards of academic written English, they have incorporated the dominant societal representations as habitus. 
Despite the change of material conditions in the last few decades characterized by the increasing interchange between different academic communities and reflected in the growing number of international journals and conferences all over the globe, the rules of communication of science tend to preserve within them the structure of domination associated with a cultural arbitrary: SWAE. Therefore, SWAE is a symbolic instrument, a structuring structure that leads us to construct and apprehend reality according to a certain cultural arbitrary. SWAE as the "language of science," then, is not an innocuous instrument of communication that offers a common ground for interaction between the international and national scientific fields. On the contrary, it is a symbolic instrument that contributes to the preservation and reproduction of the structures of domination. These structures of domination can mute not only dominated voices, but also other epistemologies and ways of approaching social reality.

However, we can still pose the following questions: How are "competence and mastery of the game" defined in the international field? What exactly is "standard" written English in the international field? In the following section, I draw on Canagarajah's claims to problematize this term.

\section{What is standard in SWAE?}

The term "standard" is related to what is called a "monolithic" view of language. A monolithic view of language is one that points to a set of established norms or standards and to an "appropriate" use of them. It is based on the assumption that there is an ideal speaker and an ideal way of speaking, together with an ideal writer and an ideal way of writing. The ideal speaker or writer in this monolithic view of language would be an expert user, a "native" speaker or writer, who would be able to use the language according to the norms, in the correct way, and therefore, communication would be achieved through the innocuous means of a standard language.

In his writings, Canagarajah (1996, 1999, 2002a, 2002b, 2002c) contests the previous conceptualization of language, claiming that things are not that simple. Languages are not monolithic. Languages are living entities, constantly changing, and there are many varieties functioning in the real world. English, in Canagarajah's writings, becomes "Englishes" since even what it is considered "standard" English is nothing but a variety that, thanks to power dynamics, started to be seen as a universal. A fictitious universal, a fiction based on the monolithic view of language and power differentials. This universal, according to the author, is fictitious because it is just a variety that, due to politico-economic factors, became legitimized by the dominant factions of society. This correlates to the concept of cultural arbitrary proposed by Bourdieu and to the concept of hegemony proposed by Gramsci.

In academic writing, this universal, arbitrariness, or hegemony is embodied in the use of SWAE as the "language of science". Furthermore, the fictitious universal quality of SWAE is reinforced by the fact that this variety is not attached to any geographical or political boundary, since there is no country associated with it. Therefore, the monolithic view of language sets SWAE as a neutral and ideology-free 
means that allows international scientific communication. In this way, a good academic writer is a person who can enter conversations in the field because $\mathrm{s} / \mathrm{he}$ possesses the disciplinary knowledge and the ability to transmit it in SWAE. In Bourdieu's (1986) terms, an ideal writer is the one that masters "the laws of functioning in the field" (p. 132). That is, an ideal academic writer, writing in ideal SWAE.

However, what happens if this monolithic view of language is abandoned and communication is conceptualized in a more complex way? What happens if it is acknowledged that English is not a mere ideology-free system acquired by the people in order to communicate with each other? What happens if the connection between discursive practices, material conditions, and knowledge production is recognized? Opening the door to these "what ifs" is what Canagarajah (2002a, $2002 \mathrm{~b}$ ) proposes when he advocates a critical stance in scientific publication practices and English language teaching. The following section elaborates on these arguments.

\section{Abandoning a monolithic definition of SWAE}

Abandoning the monolithic view of language implies conceptualizing languages as ideologically loaded, epistemologically charged, and context-bounded. The previous does not mean that communication is unachievable, but that we should demand and value other kinds of competencies from scholars writing for an international audience. These competencies are those that multilingual speakers and writers in many parts of the world apply in their everyday life.

According to Canagarajah (2006a), multilingual speakers and writers possess communicative competence that is valuable in these globalized times since they are used to moving across and merging linguistic boundaries. In multilingual communities, then, there exists more awareness that the other's language and language variety may be different from one's own. Thus, when communicating, people make more efforts to develop competence in the other's language or language variety without considering their own as the universal one (Canagarajah, 2006a). These real discursive practices have heterogeneity as the norm and not the exception, and constantly defy the monolithic view of language. It is along these lines that Canagarajah (2006b) states that

"[t]o be really proficient in English in the postmodern world, one has to be multidialectal. Not only must we possess a repertoire of codes from the English language, we must also learn to use it in combination with other world languages. Gone are the days in which we could focus on a singular target language. These concerns gain importance as we begin to question the distinctions native/nonnative and standard/nonstandard and give due recognition to speakers of WEs [World Englishes]" (p. 26).

Proficiency in today's world is not linked to the mere mastering of standards and rules but to being able to shuttle and negotiate between languages and codes, especially when dealing with multilingual contexts such as the international 
scientific field. This anti-monolithic view of language should be the one informing scientific international communication practices where SWAE is used. This would lead to a completely different definition of "competence and mastery of the game" in Bourdieu's terms, a definition informed by a critical appraisal of how SWAE is defined.

The previous view of language is related to what has been called "English as lingua franca." Hyland (2006) explains that the term refers to

A variety of English which does not assume adherence to all anglo communication conventions and where traditional native-speakerness holds no advantages. Here academic users of English are no less proficient than native speakers of that language and they are not aspiring to speak a standard English variety. What matters is clarity and comprehensibility and L1 [first language] English speakers may need to adjust their language to new norms of international academic communication. (p. 29)

However, the author also warns the reader about conceptualizing English in a monolithic way and perceiving it as a "culture-free language" (Hyland, 2006, p. 29). In fact, the absolute opposite conception of SWAE is necessary in the international scientific field for English to be able to function as a real lingua franca, allowing a more democratic way of communicating science. The critical appraisal of SWAE offered here is what I consider to be the necessary first step towards a view of language that goes beyond this "culture-free" conception.

\section{Conclusion}

In the previous sections, I brought into consideration the structures of domination that underlay each one of the words that compose the term SWAE. I first showed how scientific communication relies on the hegemony of the written mode. The interplay between current structural and superstructural conditions set written communication as the preferred way of not only communicating science but also of validating the scientific work of authors in the current economic system. I claimed that there is a possibility for counter-hegemonic movements in academia: the use of modes of communicating science that go beyond writing would validate different scientific epistemologies and methodologies.

Second, I demonstrated that academic discourse is a structured structure ("norms to be respected in practice") that has a structuring function ("scientific effect") and that serves as an instrument of domination ("symbolic efficacity"). Thus, academic language is an arbitrarily legitimated prestigious variety, and mechanisms of domination are present in the international and national scientific fields in regards to the use of SWAE. I also claimed that these structures of domination can mute not only other forms of communication but also the construction of science, if they are not acknowledged.

Third, I explained how the previous domination structures are related to a monolithic view of language which imposes the standard in SWAE as a fictitious 
universal. This fictitious universal conceals the fact that SWAE it is just a legitimized variety. I proposed that for English to become a real lingua franca, it should be regarded as ideologically loaded, epistemologically charged, and context-bounded. In this way, scholars writing for an international audience should be able to move across and merge linguistic boundaries, having heterogeneity as the norm and not the exception.

It is my belief that the recognition of the hegemony of the written mode, the structure of domination associated with a cultural arbitrary, and the fictitious universal of a monolithic view of language is the first step towards a more democratic conceptualization of scientific communication. This democratic way of communicating science should: 1) acknowledge the intrinsic connection between different modes of communicating science and knowledge-construction practices, and open the door to nonhegemonic modes of communication; 2) recognize the power structures that operate in the national and international scientific fields; 3 ) envision academic discourse as a social construction and recognize that even disciplinary fields are constructed ${ }^{9}$ and thus are open for change; 3 ) dismantle the monolithic view of language and go beyond the native/non-native or standard/nonstandard categories, defying the hegemonic aspect of SWAE in order to allow real growth and communication in science.

The critical appraisal of SWAE offered in this paper disentangled the power structures present in the current modes of construction and communication of scientific knowledge. This, I believe, is the first step for achieving more democratic practices when communicating science. Science communication and production should give place to many still unheard voices. This would not only benefit those who have not been heard yet, but it would also promote a more democratic production and spread of scientific knowledge.

\section{References}

Bourdieu, P. (1986). The production of belief: Contribution to an economy of symbolic goods. (R. Nice, Trans.). In R. Collons et al. (Eds.), Media, culture and society (pp. 131-163). London: Sage.

Bourdieu, P. (1988). Homo academicus. (P. Collier, Trans.). Palo Alto, CA: Stanford University Press.

Bourdieu, P. (1991). Language and symbolic power. (G. Raymond \& M. Adamson, Trans.). Cambridge, MA: Harvard University Press.

Bourdieu, P., \& Passeron, J. C. (1998). Reproduction in education, society and culture (2nd. ed.). (R. Nice, Trans.). London: Sage.

\footnotetext{
${ }_{9}^{9}$ In this regard, Lenoir (1993) offers an interesting description of disciplinary and research programs as discursive productions.
} 
Burke, B. $(1999,2005)$ Antonio Gramsci, schooling and education. In The encyclopedia of informal education. Retrieved from http://www.infed.org/thinkers/et-gram.htm

Buta, J., \& Sued, G. (2005, August). Publicaciones científicas en internet: Relaciones entre lo local y lo global. Symposium conducted by Sociedad Argentina de Informática e Investigación, Rosario, Argentina.

Canagarajah, S. (1996). "Nondiscursive" requirements in academic publishing, material resources of periphery scholars, and the politics of knowledge production. Written Communication, 13(4), 435-472.

Canagarajah, S. (1999). Resisting linguistic imperialism in English teaching. New York: Oxford University Press.

Canagarajah, S. (2002a). Critical academic writing and multilingual students. Ann Arbor: University of Michigan Press.

Canagarajah, S. (2002b). A geopolitics of academic writing. Pittsburgh, PA: University of Pittsburgh Press.

Canagarajah, S. (2002c). Multilingual writers and the academic community: Towards a critical relationship. Journal of English for Academic Purposes, 1, 29-44.

Canagarajah, S. (2006a). The place of world Englishes in composition: Pluralization continued. College Composition and Communication, 57(4), 586-619.

Canagarajah, S. (2006b). TESOL at forty: What are the issues? TESOL Quarterly 40(1), 9-34.

Čmejrková, S. (1996). Academic writing in Czech and English. In E. Ventola \& A. Mauranen (Eds.), Academic writing: Intercultural and textual issues (pp. 137152). Philadelphia: John Benjamins.

Curry, M. J., \& Lillis, T. (2004). Multilingual scholars and the imperative to publish in English: Negotiating interests, demands, and rewards. TESOL Quarterly, 38(4), 663-688.

Forgacs, D. (Ed.). (1988). The Gramsci reader: Selected writings 1916-1935. New York: New York University Press.

Hyland, K. (2006). English for academic purposes: An advanced resource book. New York: Routledge.

Lenoir, T. (1993). The discipline of nature and the nature of disciplines. In E. MesserDavidow, D. Shumway \& D. Sylvan (Eds.), Knowledges: Historical and critical studies in disciplinarity. Charlottesville: University Press of Virginia.

Mahar, C., Harker, R., \& Wilkes, C. (1990). An introduction to the work of Pierre Bourdieu. New York: Saint Martins. 
Martín-Martín, P. (2003). A genre analysis of English and Spanish research paper abstracts in experimental social sciences. English for Specific Purposes, 22, 2543.

Mauranen, A. (1996). Discourse competence: Evidence from thematic development in native and non-native texts. In E. Ventola \& A. Mauranen (Eds.), Academic writing: Intercultural and textual issues (pp. 195-230). Philadelphia: John Benjamins.

Pennycook, A. (2001). English in the world/The world in English. In A. Burns \& C. Coffin (Eds.), Analysing English in a global context: A reader (pp. 78-92). New York: Routledge.

Reichelt, M. (2001). A critical review of foreign language writing research on pedagogical approaches. The Modern Language Journal, 85(4), 578-598.

Sprague, J. (1997). Holy men and big guns: The Can[n] on in social theory. Gender and Society, 11(1), 88-107.

Swales, J. (1990). Genre analysis: English in academic and research settings. Cambridge, MA: Cambridge University Press.

Swales, J., \& Feak, C. (2003). Academic writing for graduate students: Essential tasks and skills (3rd ed.). Ann Arbor: University of Michigan Press.

Swartz, D. (1997). Culture and power: The sociology of Pierre Bourdieu. Chicago: The University of Chicago Press.

Swyngedouw, E. (2004). Globalisation or 'glocalisation'? Networks, territories and rescaling. Cambridge Review of International Affairs, 17(1), 25-48.

Ventola, E., \& Mauranen, A. (Eds.). (1996). Academic writing: Intercultural and textual issues. Philadelphia: John Benjamins.

Wysocki, A. F. (2004). Opening new media to writing: Openings and justifications. In A. F. Wysocki, J. Johnson-Eilola, C. Selfe \& J. Sirc (Eds.), Writing new media: Theory and applications for expanding the teaching of composition. Logan: Utah State University Press. 


\title{
A Skype-Buddy Model for Blended Learning
}

\author{
Carmen E. Macharaschwili \\ Linda Skidmore Coggin
}

\begin{abstract}
Online learning in higher education allows distance-education students to complete degree requirements in virtual environments. Universities are challenged with providing quality education experiences for these students and meeting the students' needs for engagement and challenge within a collaborative framework. This study proposes how Voice over Internet Protocol (VoIP) could be used to provide face-to-face participation in a traditional classroom using a unique "Skype-buddy" system. In this project we examined the experiences related to the satisfaction, benefits, challenges, and surprises of each of the participants (Skype buddies, professors, and other students in the class) in two doctoral seminars.
\end{abstract}

\section{A Skype-Buddy Model for Blended Learning}

Online learning is common in higher education, allowing distance-education students to complete degree requirements in virtual environments. Universities are challenged with providing quality education experiences for these students and meeting the students' need for engagement and challenge within a collaborative framework. With the ever-changing landscape of computer-mediated communication tools, this study proposes how Voice over Internet Protocol (VoIP) could be used to provide face-to-face participation in a traditional classroom.

Some educators have responded to this issue with what is termed a blended learning environment. Garrison and Kanuka (2004) define blended learning as "the thoughtful integration of classroom face-to-face learning experiences with online learning experiences" (p. 96). There are many forms of blended learning that include the combination of face-to face (traditional classroom) and asynchronous (text based, Internet) environments. In this project we propose a new concept of blended learning: that of virtual face-to-face with the use of Skype technology in the classroom.

Skype is a form of VoIP/video (Voice Over Internet Protocol with video) software that allows for video and voice calls to be made over the Internet. In addition to voice and video functions, Skype also has a synchronous chat function. This form of software simulates the face-to-face environment of a traditional classroom while still allowing a student to participate at a distance. 
Though various forms of this type of environment have been used, this study is unique in the method of applying a "Skype-buddy" system. The distance student (online) is paired with a proxy student (in the traditional face-to-face classroom) who is responsible for adjusting the camera, volume, and computer to allow for full participation by the distance student. In this project the researchers participated in a Skype-buddy model in two doctoral seminars and examined the experiences related to the satisfaction, benefits, challenges, and surprises of each of the participants.

Our main research questions are:

1. How does using Skype in a blended learning environment shape participants' (distance student and proxy student) engagement in the (online and traditional) classroom?

2. What are the satisfactions, benefits, challenges, and surprises for other students and instructors in a traditional classroom when Skype is used to include a distance student in full class and small group work in the classroom?

\section{Review of the Literature}

A good deal of research has been done on distance education in general. Roblyer and Wiencke (2004) found that the degree of interaction among participants in distance education classes contributes to both student achievement and satisfaction. Our research builds upon this finding. Specifically, we examined a virtual version of blended learning as a means to increase interaction among the distance learner, professor, and classmates.

Garrison \& Cleveland-Innes (2005) examined the effect of interaction and its impact on student satisfaction and found that interaction needs to be structured and systematic for online education. In addition, in order to create a community of inquiry where interaction is meaningful and sustained and ideas are shared, this community must include various forms of interaction to include interaction among content, instructors and students. The various forms of interaction included in this blended learning study include the use of Skype video conferencing, the Skype chat function, an online asynchronous environment through the use of the online course environment, phone calls, and face-to-face conversations among the students, professor and other classmates.

Few studies have reported the use of VoIP to allow virtual participation in a traditional classroom. Samsonov and Harris (2010) conducted a pilot study with three homebound students to determine if Skype technology could be effectively used to allow active participation in the traditional classroom. Skype was successful in providing access, but a limitation was the motivation of the homebound student to use the technology and participate during class time. Another study reported by Newman (2007) looked at using current VoIP technology to add synchronous voice communication to an online course in response to the finding that many students of online courses were dissatisfied with the lack of personal interaction with the instructor. Students were presented with instructional material for the use of the 
Skype application, and instructors were available to students via the VoIP technology. Students were enthusiastic about the Skype application and found it easy to use, but like those in the previous study cited (Samsonov \& Harris, 2010) did not or rarely took advantage of the opportunity to use the VoIP to connect with the instructor.

Our study addresses these limitations by pairing two students. This model extends the paradigm to go beyond the teacher-controlled environment and include the distance learner as a participant in regular classroom activities through the VoIP and the partner student. In the Samsonov and Harris study, the "camera view" was set on the white board used for instruction. In the seminar used for this study, PowerPoint presentations by the instructor and other materials handed out were available online for the distance learner to access during class time. The purpose of this design is to hold students more accountable by being in control of making the connecting call, controlling the camera "view," and communicating through the chat feature during class to enhance the experience. Thus, the students are not only responsible for their own participation, but to each other as well.

The emotional and experiential aspects of learning in blended learning settings were reported by two research studies that inform our work. Blau \& Caspi (2008) examined the differences between audio conferencing (using Skype with an audio-only component) and traditional face-to-face learning. They found that while learning was the same in both groups, the emotional-experiential aspects favored face-to-face communication. Significant differences in favor of face-to-face communication were found in the emotional-experiential aspects of learning: amount of students' attention and interest, learning satisfaction, and enjoyment from the interaction with tutor or peers. Supporting these findings, Ryobe (2009) reported that $100 \%$ of the video chat students' free comments were positive in his study in 2007 and 2008, compared to $90 \%$ of voice chat groups in 2006. Furthermore, it was found that the students involved in the video chats achieved better performance and motivation.

The Skype-Buddy project adds dimension to the notion of an "interaction equation" (Roblyer \& Weincke, 2004, p. 2). An interaction equation is defined as "a created environment in which social and instructional messages are exchanged among entities of a course and in which messages are both carried and influenced by the activities and technology resources" (Roblyer \& Weincke, 2004, p. 5). Our research adds to the "interaction equation" by creating the partnering relationship that provides virtual entrance into the interaction of the traditional classroom through Skype and real time chat to facilitate interaction among participants.

\section{Methods}

\section{Settings and Context}

This research took place in two doctoral seminars offered in a large university in the Midwestern region of the United States. The primary class (blended learning class) offered access to both online and traditional classroom students. The class, Electronic Language and Literacy Learning, consisted of fifteen weekly three-hour 
traditional class meetings for on-campus students. An online component provided access to four distance-education students who attended two to three class meetings for face-to-face presentations and attended the rest of the class sessions in an online forum format. The other seminar, focused on issues in language education, was a face-to-face, on-campus doctoral seminar that met weekly in a traditional classroom environment.

\section{Participants}

The primary participants in this study are two doctoral students (participant researchers) enrolled in both doctoral seminar classes. Author 1, Carmen, participated in the blended learning class as a "distance learner" taking advantage of the online option and commuted 200 miles to participate in the traditional class seminar once a week. Linda, Author 2, is a traditional student who attended both doctoral seminars as a traditional on-campus student. These students acted as Skype buddies during the semester. Other participants are the twenty-three students (19 traditional students and 4 distance students) also enrolled in the same doctoral seminars and two professors that teach the seminars.

\section{Description of Process}

Beginning on the third class meeting of the 15-week semester a "Skype-buddy" partnership was initiated. In the blended learning class, Linda began "Skyping" Carmen into class. Linda brought her personal laptop and external microphone to class, and used Skype software to allow Carmen to listen and participate in class lectures, whole group and small group discussions as a "virtual" student on the computer. During small group discussions, the computer "Carmen" was moved to form the small group meeting. For large group learning, the computer was placed on a table or desk and oriented toward the primary speaker for the class whether it was the professor, a guest speaker, or a student. The screen was adjusted so that the classroom's projected large screen with slides was visible to Carmen via the laptop camera. During each class meeting Carmen and Linda also used the chat feature of Skype to communicate during the Skyped session.

This virtual participation continued for all remaining class periods (12) in the blended learning class except on one occasion when Carmen physically attended the class to give a presentation. With the use of Skype's screen-sharing function, Carmen was even able to present to the class from a distance on two occasions. The laptop with the virtual student was connected to the class projector and displayed for the class during the presentation with the use of the screen share option on the Skype software.

A similar protocol was used in the traditional class to allow Carmen to virtually attend the class. Linda, as the Skype buddy, accessed the traditional class via Skype for Carmen during two additional class meetings. During the traditional seminar class format, Carmen, as a virtual student, had access to both large and small group discussions. 


\section{Data Collection}

How does using Skype in a blended learning environment shape participants' (distance student and proxy student) engagement in the classroom (virtual and traditional)? To address this primary research question, the researcher-participants collected the following data.

\section{Journal Entries}

Skype Buddies kept a journal of field notes during and after each class session when Skype was used. Participants addressed, but were not limited to, recording perceptions of satisfactions, benefits, challenges, and surprises that were encountered with equipment, physical arrangements and any other observations about the learning environment.

\section{Chat Records}

Skype Buddies used the chat feature available through Skype software for additional communication. This chat was used to record perceptions of ease of use, engagement in class activities, and any problems that were encountered with equipment or physical arrangements during the class session using Skype. All chat records generated during class sessions were archived through Skype software.

\section{Classroom Observation and Recording}

Two class meetings were audiorecorded and one of these class small group sessions was transcribed with observational field notes. This recording provided a record of student and instructor interaction with the virtual student in the classroom. These recordings helped to triangulate data from anecdotal and chat records to include another view of specific interactions of participants during class sessions.

Journal entries, chat records, and small group observation and transcription were analyzed and coded using inductive and comparative methods to uncover common themes related to the participants' engagement and learning in the classrooms reflecting satisfactions, benefits, challenges and surprises. Using these methods in two different classrooms strengthens the validity of the data. A qualitative case study to describe the experiences and perspectives of the distance student and traditional student will be used to answer the first research question.

In addition to classroom recordings, interviews and a survey were used to address the second research question to identify satisfactions, benefits, challenges, and surprises for other students and instructors in a traditional classroom when Skype was used to include a distance student in full class and small group work in the classroom.

\section{Interviews}

Semistructured interviews were conducted with the two professors of the seminars, one distance learner from the hybrid learning class, and two traditional students (one from each class where Skype Buddy was in place) after six weeks of using 
Skype in the classroom. Students were selected who had interacted with Carmen as a virtual student in a small group and large group setting. These interviews were analyzed and coded using inductive and comparative methods to find common themes related to the satisfactions, benefits, challenges, and surprises for other students and the instructors in a traditional classroom when Skype was used to include a distance student in the classroom.

\section{Survey}

Students in both classrooms were asked to voluntarily complete an online survey regarding their views of the perceived benefits and challenges related to the use of Skype to include a virtual student in the classroom activities. Survey questions were based on the Classroom Community Scale (Rovai, 2002). This survey was offered online and included twenty-three questions using a 5-point Likert scale with two additional open-ended questions. (Appendix A). This survey was used to determine other class members' views of the benefits and challenges resulting from the use of Skype in the classroom.

\section{Triangulation of data}

A qualitative case study approach is used to describe the experience of Skype Buddies. Comparison of the field notes of Skype Buddies, online chat between buddies during Skype sessions, class session audiorecording, professor and student interviews, and student surveys provided for triangulation of the data. Furthermore, the use of the Skype Buddy system in two separate doctoral seminars allowed for further analysis of the data. Finally, researcher-participants exchanged field notes, independently coded field notes and chat records, and met to compare findings. Definitions were generated to define emerging themes and inter-rater agreement was reached through modification and clarification of category definitions, and some items were discussed and recoded as a result of the inter-rater definition agreements.

\section{Results}

\section{Chat Session}

Chat sessions were coded separately and results yielded similar coding categories by each researcher-participant. Though there were minor differences in how each researcher defined categories, the category topics were similar. For example, Carmen coded certain entries as "emotions" and Linda coded the same or similar entries as "personal." As a result, definitions were established; Table 1 provides definitions, examples, and frequency of categories that resulted through discussion and comparison of samples in the chat sessions. 


\begin{tabular}{|c|c|c|c|c|}
\hline Category & Definition & Count & $\%$ & Examples \\
\hline Technological & $\begin{array}{l}\text { Functioning, adjustment, or } \\
\text { observations regarding the use } \\
\text { and placement of the different } \\
\text { technologies, i.e. computer, } \\
\text { microphone, camera, power } \\
\text { point, internet connection, etc. }\end{array}$ & 115 & 31 & $\begin{array}{l}\text { [10/13/10 4:09:07 PM] } \\
\text { Linda: I made you bigger I } \\
\text { never thought of that!? } \\
\\
\text { [9/15/10 4:12:54 PM] } \\
\text { Carmen: Can you move the } \\
\text { camera more on him? }\end{array}$ \\
\hline Personal & $\begin{array}{l}\text { Personal comments not directly } \\
\text { related to class content like } \\
\text { thoughts or feelings regarding } \\
\text { environment or personal } \\
\text { schedules. }\end{array}$ & 94 & 26 & $\begin{array}{l}\text { [9/15/10 4:12:54 PM] } \\
\text { Carmen: I have to go in } \\
\text { about } 20 \text { minutes if not } \\
\text { sooner--babysitter issues! } \\
\text { My hubby called and can't } \\
\text { take the kids to soccer }\end{array}$ \\
\hline Information & $\begin{array}{l}\text { Data that informs distance } \\
\text { student of what is occurring by } \\
\text { proxy student, includes } \\
\text { questions from distance student } \\
\text { for clarification or comments } \\
\text { that the proxy student believed } \\
\text { would aid distance students in } \\
\text { understanding }\end{array}$ & 112 & 30 & $\begin{array}{l}\text { [9/15/10 4:12:54 PM] } \\
\text { Carmen: I can't hear her at } \\
\text { all } \\
\text { [9/15/10 5:12:58 PM] } \\
\text { Linda: she said keep } \\
\text { traditional literacy }\end{array}$ \\
\hline Participation & $\begin{array}{l}\text { Comments and questions } \\
\text { directly related to in-class } \\
\text { subject matter, comments from } \\
\text { distance students directly to } \\
\text { proxy student, to small groups } \\
\text { in-class, and to whole class or to } \\
\text { professor }\end{array}$ & 28 & 8 & $\begin{array}{l}\text { [9/15/10 5:12:58 PM] } \\
\text { Linda: What are other } \\
\text { interesting points or } \\
\text { questions } \\
\text { [10/4/10 4:23:12 PM] } \\
\text { Carmen: teacher as learner } \\
\text { rather than all-out authority } \\
\text { figure }\end{array}$ \\
\hline Project & $\begin{array}{l}\text { Discussion between the distance } \\
\text { and proxy student directly } \\
\text { related to the research project, } \\
\text { not tied to technology or class } \\
\text { but rather to the research } \\
\text { process }\end{array}$ & 21 & 6 & $\begin{array}{l}\text { [9/27/10 5:38:18 PM] } \\
\text { Carmen: approach to } \\
\text { collecting the data--yes! I } \\
\text { would be nodding in class! } \\
\text { [9/27/10 5:38:28 PM] } \\
\text { Linda: think of all the } \\
\text { messaging on this Skype } \\
\text { [9/27/10 5:38:47 PM] } \\
\text { Carmen: I KNOW...there is } \\
\text { another aspect to our study } \\
\text { to make it unique! }\end{array}$ \\
\hline
\end{tabular}

Table 1. Examples and Definitions of Chat Session Coding

Differences in the results for the traditional seminar class, where Skype was used in only two classes, were noted related to visual and audio constraints. The classroom configuration made it more difficult to set up the personal computer so that the distance student could see and hear the whole class presentations. As a result, the information category was significantly increased because the proxy student felt the need to narrate the class via the chat function because she perceived that the distance student was not able to see and hear what was going on in the 
classroom. The results for this category without the traditional class would have been fourteen percent if the second class had not been included in chat coding analysis.

\begin{tabular}{|c|c|c|c|c|c|}
\hline \multirow[b]{2}{*}{ Category } & \multirow[b]{2}{*}{ Definition } & \multicolumn{2}{|c|}{ Distance Student } & \multicolumn{2}{|c|}{ Proxy Student } \\
\hline & & Field Note & Explanation & Field Note & Explanation \\
\hline Satisfaction & $\begin{array}{l}\text {-personal } \\
\text { satisfaction } \\
\text {-closely tied } \\
\text { to emotion } \\
\text {-how the } \\
\text { participant } \\
\text { feels about } \\
\text { the } \\
\text { experience. } \\
\text { Example: } \\
\text { relationship } \\
\text { building and } \\
\text { personal } \\
\text { connection. }\end{array}$ & $\begin{array}{l}\text { YAY I felt like } \\
\text { I was } \\
\text { contributing } \\
\text { to the class! }\end{array}$ & $\begin{array}{l}\text { Acknowledged } \\
\text { as class } \\
\text { participant, } \\
\text { able to gain } \\
\text { and } \\
\text { contribute }\end{array}$ & $\begin{array}{l}\text { "Do you carry } \\
\text { her around } \\
\text { everywhere?" }\end{array}$ & $\begin{array}{l}\text { Another classmate } \\
\text { is perceiving the } \\
\text { "buddies" as } \\
\text { inseparable-an } \\
\text { interesting } \\
\text { perception from } \\
\text { which the proxy } \\
\text { student gained a } \\
\text { sense of } \\
\text { satisfaction }\end{array}$ \\
\hline Benefits & $\begin{array}{l}\text {-closely tied } \\
\text { to learning or } \\
\text { increase in } \\
\text { knowledge } \\
\text { Example: } \\
\text { contribution } \\
\text { to learning } \\
\text { and to class. }\end{array}$ & $\begin{array}{l}\text { I got to hear } \\
\text { [the } \\
\text { professor's] } \\
\text { anecdotal } \\
\text { input from } \\
\text { his } \\
\text { experience } \\
\text { and } \\
\text { knowledge-- } \\
\text { like the } \\
\text { survey done } \\
\text { in Canada } \\
\text { for example }\end{array}$ & $\begin{array}{l}\text { Information } \\
\text { gained from } \\
\text { Skype that I } \\
\text { couldn't get in } \\
\text { a purely } \\
\text { online } \\
\text { environment. }\end{array}$ & $\begin{array}{l}\text { I don't have } \\
\text { time for my } \\
\text { mind to wander } \\
\text { because I don't } \\
\text { just think about } \\
\text { how I am } \\
\text { receiving } \\
\text { information. I } \\
\text { think how } \\
\text { Carmen might } \\
\text { be 'seeing'. }\end{array}$ & $\begin{array}{l}\text { An expression of } \\
\text { heightened } \\
\text { awareness of } \\
\text { what is taking } \\
\text { place in class as } \\
\text { attributed to the } \\
\text { responsibility to } \\
\text { the distance } \\
\text { student. }\end{array}$ \\
\hline Challenges & $\begin{array}{l}\text {-closely tied } \\
\text { to the actual } \\
\text { use of the } \\
\text { hardware } \\
\text { and software. } \\
\text { Example: } \\
\text { equipment } \\
\text { and } \\
\text { connection } \\
\text { issues and } \\
\text { distractions } \\
\text { related to } \\
\text { such issues. }\end{array}$ & $\begin{array}{l}\text { Dog } \\
\text { barking- } \\
\text { can't hear }\end{array}$ & $\begin{array}{l}\text { Distractions } \\
\text { that come } \\
\text { with being at } \\
\text { home instead } \\
\text { of the real } \\
\text { classroom }\end{array}$ & $\begin{array}{l}\text { "It is still } \\
\text { difficult to chat, } \\
\text { I wish the } \\
\text { camera was on } \\
\text { the back of the } \\
\text { laptop!!!" }\end{array}$ & $\begin{array}{l}\text { Expression of } \\
\text { frustrations due } \\
\text { to set-up of } \\
\text { technology }\end{array}$ \\
\hline Surprises & $\begin{array}{l}\text {-unexpected } \\
\text { results of the } \\
\text { use of the } \\
\text { VoIP } \\
\text { technology }\end{array}$ & $\begin{array}{l}\text { Without } \\
\text { Linda, I } \\
\text { didn't feel as } \\
\text { if I was } \\
\text { interacting. }\end{array}$ & $\begin{array}{l}\text { Emotional } \\
\text { connection }\end{array}$ & $\begin{array}{l}\text { "It was really } \\
\text { just like } \\
\text { another person } \\
\text { being there }\end{array}$ & $\begin{array}{l}\text { Reference to a } \\
\text { small group } \\
\text { discussion in } \\
\text { which distance } \\
\text { student }\end{array}$ \\
\hline
\end{tabular}




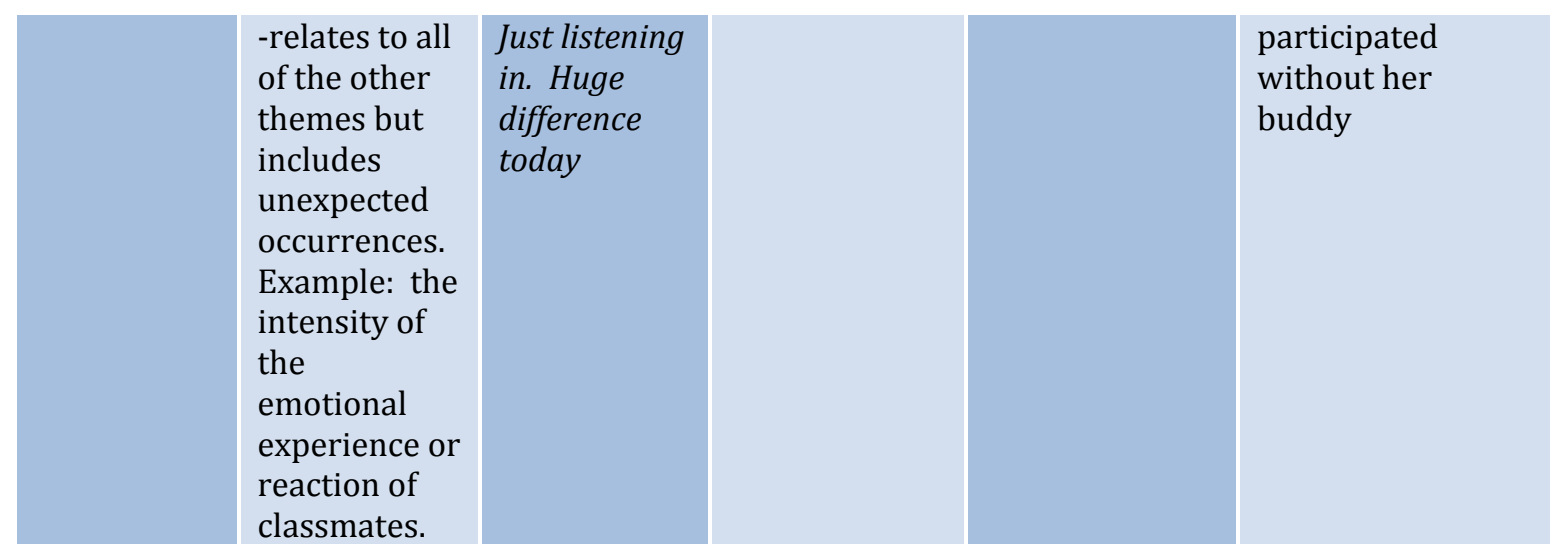

Table 2 Examples of and Definitions of Field Note Coding

From the chat results, it is clear that most of the chat function was used to resolve technical difficulties and share basic information to clarify what was happening in the classroom (approximately 60\% for both classes, approximately $45 \%$ for blended learning class). Personal comments that were not related to the class were the second most frequent chat category (30\%). Actual participation and discussion of the researcher participant was minimal (only 14\%). It is necessary to look at this data in conjunction with the field notes in order to analyze the "whole picture."

The field notes corroborate the data derived from the analysis of the chat notes. Both the distance and the proxy student benefited and were surprised by the level of personal connection that took place between them and with other class participants. This opportunity for personal connection is evidenced by the fact that $30 \%$ of the chat comments were of a personal nature and this personal connection was also noted in the field notes.

The research-participants noted their biggest challenges were technical issues. Thirty-one percent of the chat comments were about technical adjustments; in fact, 16/22 chat notes coded as challenges in the first 5 class periods were about physical placement of equipment. These technological issues did not interfere with the personal connection. The day that the distance student felt most "distant" was the day that there were no technological issues, but rather, little interaction with the proxy student.

The virtual face-to-face connection and chat conversation permitted through the software was an important piece in the distance student's perception of participation. The adjustment of hardware and placement of the computer were directly related to participation. Throughout the field notes there were comments about classmates touching the mouse pad to make sure the computer didn't sleep, making sure the microphone was placed correctly, and moving the Skype window so that the distance student could be seen. Through these actions, many people in the class were able to interact with the Skype buddies. Table 3 provides examples that show how the combination of participation opportunities and challenging 
technological issues produced surprising benefits for both the proxy and the distance student.

\begin{tabular}{|c|c|c|}
\hline Category & Example & Explanation \\
\hline Personal & $\begin{array}{l}\text { (Linda 10/27/10) Carmen's daughter was } \\
\text { "entertaining" Tara's daughter who was in class by } \\
\text { holding up a phone and making noises- it was } \\
\text { really funny. It was also nice to actually see her } \\
\text { daughter on Skype. } \\
\text { (Linda10/4/10) People were saying "hi" to Carmen } \\
\text { when came in. } \\
\text { (Carmen 11/3/10) Interesting that after we talked } \\
\text { about how attentive Linda is last week-I did not } \\
\text { feel that way today. Weird feeling, almost like she } \\
\text { was mad or something. Without Linda, I didn't feel } \\
\text { as if I was interacting. Just listening in. Huge } \\
\text { difference today. No [technological] glitches } \\
\text { whatsoever today though }\end{array}$ & $\begin{array}{l}\text { A personal connection } \\
\text { was made among } \\
\text { classmates in an informal } \\
\text { discussion that had } \\
\text { nothing to do with class } \\
\text { Acknowledgement of } \\
\text { distance student as part } \\
\text { of the classroom } \\
\text { community } \\
\text { Evidence of the } \\
\text { importance of personal } \\
\text { connection even when the } \\
\text { technology was working } \\
\text { correctly. }\end{array}$ \\
\hline Technological & $\begin{array}{l}\text { (Carmen 9/22/10) Couldn't hear the other group } \\
\text { until they moved the mic and then confused me } \\
\text { when I couldn't see for a minute. } \\
\text { (Linda 10/27/10) I thought this would be a better } \\
\text { place for the microphone because Carmen has said } \\
\text { she can't hear these girls }\end{array}$ & $\begin{array}{l}\text { These examples give } \\
\text { evidence of the } \\
\text { frustration caused by } \\
\text { technical issues and the } \\
\text { adjustments necessary to } \\
\text { improve the quality of the } \\
\text { interaction }\end{array}$ \\
\hline Information & $\begin{array}{l}\text { [10/6/10 4:49:58 PM] Carmen: My questions: how } \\
\text { do I access the climate change CWR? How will } \\
\text { teachers access the new system? Will you charge? } \\
\text { Free? How is it marketed? } \\
\text { [10/6/10 4:49:59 PM] Linda: do you want me to } \\
\text { ask } \\
\text { [10/6/10 4:50:14 PM] Carmen: yes please or let } \\
\text { him know i have a question }\end{array}$ & $\begin{array}{l}\text { These are examples of } \\
\text { how the use of the use of } \\
\text { the proxy student acting } \\
\text { as an "interpreter" and } \\
\text { the chat function being } \\
\text { used to communicate } \\
\text { basic class information. }\end{array}$ \\
\hline $\begin{array}{l}\text { Project } \\
\text { Participation }\end{array}$ & $\begin{array}{l}\text { (Carmen 10/13/10) I was able to participate in full } \\
\text { group discussion, with [Professor] calling on me. } \\
\text { (Linda 9/22/10) It was really just like another } \\
\text { person being there (ref. to small group discussion) } \\
\text { (Linda 9/22/10) Carmen presented to class for her } \\
\text { group and I could feel everyone closing in- I } \\
\text { thought it was good- they were including the cyber } \\
\text { person in the group. }\end{array}$ & $\begin{array}{l}\text { The expressions of both } \\
\text { students are those of } \\
\text { satisfaction in making a } \\
\text { virtual situation "feel" } \\
\text { real. The recognition of } \\
\text { the distance learner as } \\
\text { being a person } \\
\text { participating in a real- } \\
\text { time discussion is } \\
\text { evident. }\end{array}$ \\
\hline
\end{tabular}

Table 3. Participation Opportunities and Technological Issues 
As shown in the examples above, the researcher-participants perceived that despite frustrations, more learning was taking place as a result of the opportunities afforded by the Skype technology. For the distance student this is obvious. The faceto-face interaction provided through the software gave opportunities for immediate feedback that would not be possible in an online session. Surprisingly, the benefits extended to the proxy student as well. The responsibility for monitoring the distance student's participation forced the proxy student to attend to the class in a different way. These perceived benefits are evident in the chat and field notes of the researcher participants. For example, "I do think I change the way I listen then because I'm not thinking about can she hear or see, are there cues she is missing by not being here? I am listening more for content. When I'm on my own, my mind wanders to other things. That doesn't happen when I am responsible for Skype." (Linda, field notes October 4, 2010). "It helps me to immediately be able to talk [chat] to you." (Carmen chat notes, September 22, 2010).

Interviews with professors and students and anecdotal evidence from chat messages and personal field notes yielded several themes related to other students' and instructors' satisfaction, benefits, challenges, and surprises when the SkypeBuddy system was used in the classrooms. Three main themes emerged in the analysis of this data:

- Access

- Connections/Relationship

- Distraction (as related to use of VoIP Technology in the classroom by Skype buddies)

The primary theme salient in all data sources was access. Three kinds of access can be identified in the interview transcripts and notes; 1) access to graduate work, 2) access to traditional "class" by online participation, and 3) access to class as a "virtual" student through the use of technology. Online classes and our study of a "virtual student" provided access to graduate work for students who may have limited access to a traditional onsite class. Professor A said, "Our graduate program, especially for doctoral students, hasn't been able to employ everybody. So we've got lots more people, in fact about a quarter of our class, as a matter of fact, who have to be full time employees someplace else" (Professor A interview, November 2010). Each student interviewed expressed that Carmen was able to get the "full benefit of class without physically having to sit in class" and "still learn" (M interview, November 2010).

Access in this study was also interpreted as allowing flexibility. One of the professors commented that technology allows students to be in more than one place at a time- "Someone who's traveling or someone who cannot be there [in class] for a particular reason but who could be there in a computer just for the class" (Professor B interview, November 2010)—and identified this as an alternative way to attend class. This was the case in the traditional doctoral seminar that Carmen attended on campus but Skype allowed her to still "attend" class when she had other commitments that prevented her from making the long drive to campus. 
The Skype Buddy distance student, by virtual participation, has access to the same knowledge and opportunities afforded onsite students in the traditional classroom community. Carmen was aware that she had access to class presentations by other students and frequent guest speakers that were not available to students attending only online. In field notes she commented: "How will the distance students receive access to these presentations? Another huge loss? "(Carmen's field notes, October 6, 2010). Another online student, noted that

When I look at the way you [Linda] and Carmen have created this environment for Carmen and although she's had to leave early she still gets the benefit of the conversation that happens in that face-to-face class and I'm not getting that benefit. That's a choice that I made, I chose to take this class [as an online student] but if I had the opportunity to Skype in I think that that conversation that happens inside those four walls would be really important and enlighten me quite a bit. (Student M interview, November 2010)

Carmen's participation in small groups was another way this partnership allowed access to class sharing, but it was noted by another student that she had "trouble knowing how to relate to a virtual presence" (student S interview, November, 2010). In the transcription of a small group class interaction that involved the virtual student, an observation was made (observation notes and transcription of small group interaction on September 29, 2010) that one group member was looking at Linda and pointing to the computer where Carmen's image was, and said, "I can't hear that" (pointing to the computer screen and looking at Linda). It is interesting he says "that" instead of referring to Carmen as a person. The same incident was referenced by Carmen in her field notes, "student (name) doesn't seem to be catching what I'm saying" (Carmen field notes, September 29, 2010). Both of these traditional students later commented in interviews that "after it (Carmen "Skyped" into class) happened a couple of times, however, it felt like she was really in the classroom and seemed very natural" (student S interview, November, 2010).

One professor indicated that the virtual participation allowed by Skype somewhat addressed concerns he had about online classes in higher education. He could "see" the virtual student participating in small group discussion and hear her spontaneous comments and her "think[ing] on her feet," which enhanced his view of her. A distance student, who also teaches an online class, said "[my] class is one where I think we need to have some conversations among us rather than just us having the conversation in the forum because so much is lost in just textual language. So yeah, I think that Skype would help a lot with that" (student M interview, November 2010). A traditional student who is in both classes noted, "we can listen to the participant's voice and we can share his or her opinion" (student C interview, November 2010). These are benefits for all students and instructors.

The second theme extends the idea of the benefits of this community to allow for connections with others as a result of technology. In an interview, Professor A 
proposed the importance of connecting with others who are doing similar work. He viewed technology as a means for students to connect with each other electronically and also with students being able to connect with doctoral committees through technology. Technology opens a wider door for access and participation by a more diverse group of people.

There was also evidence that the presence of a "virtual student" through VoIP technology shaped the sense of community in the classroom. This theme is woven in all of the data collection. Professor B said:

For me it became a very, not to sound romanticizing, (kind of laughing) but it came like a very communal thing. Through your computer you can come, you know, can I be in your computer and can we share? (She was saying these like she was pretending to be the person asking these questions to another). So you know it worked out really well I think and I think everybody was like giving their best try to include Carmen in their conversation. So I thought that was very nice. (Professor B interview, November 2010)

In field notes we noted when other students were "helping with the microphone, moving it around when other people were talking" (Linda field notes, September 29, 2010). When small groups met and the Skype Buddy was not in the group, the other students took care of "virtual Carmen." In one small group time, "I (Linda) noticed a very shy girl (I don't think I've ever heard her talk in class) was moving the computer so Carmen could see and this happened more than once" (Linda field notes, September 22, 2010). The first time Carmen informally presented her small group's discussion it was noted in field notes that "Carmen presented to class for her group and I could feel everyone closing in-I thought it was goodthey were including the cyber person in the group" (Linda field notes, September 22, 2010).

Other students in interviews also noted personal connections. A student in the traditional class that Carmen physically attended for most of the meetings stated, "I don't know if she would have felt like such a part of our community if we had only known her in a virtual way" (student S interview, November, 2010). But students in the class that Carmen attended 12/15 of the class meetings as a virtual student felt, "that's why Skype is impressive. If I could see other people I could be more motivated... I think seeing others seems to be important actually" (student C interview, November, 2010). A student who participates in class as an online student (and has attended 2-3 classes to give presentations) said she "felt very disconnected and I think Skype could have helped with that" (student M interview, November 2010).

The idea of problems and distractions created by the VoIP technology use was also a theme in interviews, chat, and notes. Professor B compares the virtual student to a second language learner in the classroom and some of the distractions as "translating" what is going on in the room. The technology as "an irritant and annoyance" when it doesn't work was considered "no different than other kinds of 
distractions like somebody in the hallway" (Professor A interview, November 2010). While Professor B lauded the "improvised nature" of what we were doing, she also mentions several times the need for more technical support and procedures for further implementation of the concept of using VoIP in the traditional classroom (Professor B interview, 2010).

Distraction was often related to audio. The distraction noted by a student in the traditional class related to being able to hear Carmen. She noted, "with a more developed sound system to accommodate the Skyping student, we could feel like the virtual student was really sitting in our class" (student S interview, November 2010). The professors voiced the same concern at times and two of those times were related to the buddy's "human error" - the computer sound was muted (Linda field notes, 11/3/10). This problem was alleviated during presentations when the "virtual student" laptop was connected to the classroom audio system.

The problems and distractions related to technology are no different than other "distractions" in a typical classroom. Seventy-five percent of classmates who completed the online survey about our use of Skype disagreed (4) and strongly disagreed (8) that the use of Skype was a distraction in the classroom. Considering the limitations and possible distractions caused by the technology, "the positives outweigh the negatives by far" (Professor A interview, November 2010). He sums up his feeling on these by saying, "I like the richness of reality intruding".

\section{Discussion}

In a Skype-Buddy Model for Blended Learning, researcher-participants add to the growing body of knowledge surrounding blended learning environments. This study confirms the research done by Roblyer \& Wienke (2004), Garrison \& ClevelandInnes (2005), and Blau \& Caspi (2008) that the degree of interaction provided to a student in a distance-learning environment contributes to student achievement and satisfaction. Both researcher-participants found that the Skype-Buddy system confirmed the benefit of face-to-face communication, even virtually, and contributed to the emotional-experiential aspects of learning: amount of students' attention and interest, learning satisfaction, and enjoyment from the interaction with tutor or peers (Blau \& Caspi, 2008).

The Skype-Buddy partnership changed class engagement for both participants. The proxy student noted a change in class participation in her field notes. "That is when I realized how I notice what is going on in the class in a different way. I don't have as much time for my mind to wander" (Linda field notes, September 27, 2010). The distance student made similar comments that despite the challenges posed by the use of the technology, learning satisfaction was evident. "I'm noticing that even with all of this mess today (referring to distractions at home), I'm probably still getting a lot more out of this than if I were online. ...I can't imagine how those who cannot participate in class are getting half of what I'm getting right now at this moment" (Carmen field notes, September 27, 2010). This fact is further evidenced in the interview with the distance student that was not able to participate in the Skype Buddy model. 
An important outcome of this study is the protocol that was developed to use this technology and the "buddy" design (Appendix B). Another essential aspect to this design is the importance of selecting participant "buddies" and the motivation and amenability of the students and professors involved in the classroom. The protocol outlines the steps for implementing the Skype Buddy design and is a beginning step toward successful implementation. According to Curtis \& Lawson (2001), Martyn (2003), and many others (Bonk \& Graham, 2006; Zhao et al. 2005; Means et al. 2009) the design and implementation of a blended learning environment is essential to success.

Samsonov \& Harris (2010) and Newman (2007) observed that student motivation and student interaction with the professor were also essential factors. Our study confirmed these observations and allows for these interactions in the suggested protocol. Statements from the chat and field notes confirm the responsibility that the proxy student must demonstrate to ensure the opportunity for learning and satisfaction of the distance student.

I was trying to get [Professor A's] attention by waving and then I had to shout out and apologize that I couldn't get their attention and Linda apologized-interesting that she felt responsible, but I didn't even try to "chat" or get her attention because I didn't want to disturb her and have her turn the computer around. It seems we are hyper aware of each other-she feels responsible for my learning (she's said this). (Carmen field notes September 15, 2010)

It seems that even with the challenges involved in conducting a blended learning experience with the VoIP buddy approach, all participants were open to the model and believed that the benefits outweighed the challenges. The importance of this benefit is illustrated by Professor A's comment outlining some of these benefits.

The central thing in most of the work I do has to do with access, has to do with giving people access to knowledge, access to information, access to new opportunities and I think it opens up a wider door for access, for both the kinds of people who can participate in graduate work and for them to be able to have access to what's going on here (referring to the physical university setting) and that's, that's a good. It's an unqualified good. And any efforts to keep that from happening I couldn't see that they would be protecting anything and they would be detrimental. (Professor A interview, November 2010)

Finally, the enjoyment gained from interaction among participants was evidenced in the informal interactions that occurred. Conversations between the "virtual" classmate and onsite class members about favorite books or family interactions during class "breaks" were frequent and allowed a personal connection to occur among students outside of the Skype-Buddy relationship. Most guest speakers stopped to speak to the Skype Buddies after their presentations, perhaps out of sheer curiosity, but again, an opportunity for informal personal interaction 
was achieved. This was further evidenced by survey results in which all participants were asked if they would be willing to participate in a class in a Skype-Buddy situation. The majority agreed that they would be willing to try the model (81\%). In fact, this was evidenced weeks after the conclusion of this study when the researchers continued the practice in the next semester, along with three more "Skype Buddy" teams within the class. Furthermore, through informal conversations, researchers learned that several other classes in the program are using the Skype Buddy Protocol. It is clear that the means for further investigation of this tool is available.

\section{Limitations}

Though clearly this study proved successful for participants, it is limited by the fact that it was a first-time exploratory study conducted by a very small group. Furthermore, the main body of evidence comes from the researcher-participants themselves, who are clearly biased in favor of the novelty of this idea. The professor of the class in which most Skyping took place had the idea to allow for the distance students to participate this way, so this class was particularly supportive of the experiment. In order to confirm the findings of this study, it is essential that future research be conducted using this approach to blended learning.

\section{Implications for Future Research}

For further research, the protocol developed as a result of this study (Appendix B) should be tested and measured. More research is needed on the "fractured space" (Lankshear \& Knoble, 2007) created by having a virtual student in class. Implications for harnessing the energy that the digital generation puts into the use of tools such as VoIP technology calls for this study to be replicated in larger and more diverse populations.

This study utilized the participatory and collaborative nature of new technologies in a "fractured space" (distinctively new cyberspace that coexists with physical space). Lankshear \& Knoble (2007) refer to this social phenomenon as "fracturing of space" that is accompanied by a new mindset. As illustrated by this study, VoIP provided another way of attending class. This coexistence of a traditional and virtual student in the traditional space of an on-campus classroom is possible. More research is needed to determine if this new way of participating in education is indeed a new way of accessing knowledge that is not only enhanced but transformed by interactive technology and empowered learners.

\section{Conclusion}

Will future students (the digital generation) embrace this model of a virtual face-toface student and "buddy" with the use of VoIP technology in the classroom as another multitasking, fractured space, social reality? Is it possible that it might even enable teachers and students to navigate "fractured space" in a beneficial way? Instead of a distraction for their students, can teachers engage the digital learner by forcing them to be responsible to their virtual peer? It is unknown whether offering 
flexibility for the virtual student and a different form of class participation for the proxy student is a new way of providing flexible access to knowledge, more rigorous intellectual participation, and a satisfying social learning component as a different "ethos" (Lankshear \& Knoble, 2007) that allows a new view of distance learning.

\section{References}

Blau, I., \& Caspi, A. (2008). Do media richness and visual anonymity influence learning? A comparative study using SkypeTM. In Y. Eshet, A. Caspi \& N. Geri (Eds.), Proceedings of the Chais Conference on Instructional Technologies Research 2008: Learning in the technological era (pp. 18-25). Ra'anana, Israel: Open University of Israel. Retrieved from http://telempub.openu.ac.il/users/chais/2008/noon/4 2.pdf

Bonk, C., \& Graham, C. (Eds.). (2006). Handbook of blended learning environments. San Francisco: Pfeiffer.

Curtis, D. D., \& Lawson, M. J. (2001). Exploring collaborative online learning. Journal of Asynchronous Learning Networks, 5(1), 21-34.

Garrison, D. R., \& Cleveland-Innes, M. (2005). Facilitating cognitive presence in online learning: Interaction is not enough. The American Journal of Distance Learning, 19(30), 133-148.

Garrison, D. R., \& Kanuka, H. (2004). Blended learning: Uncovering its transformative potential in higher education. Internet and Higher Education, 7, 95-105.

Lankshear, C., \& Knobel, M. (2007). Sampling 'the new' in new literacies. In M. Knobel \& C. Lankshear (Eds.), The new literacies sampler (pp. 1-24). New York: Peter Lang.

Martyn, M. (2003). The hybrid online model: Good practice. Educause Quarterly, 26(1),18-23.

Means, B., Toyama, Y., Murphy, R., Bakia, M., \& Jones, K. (2009). Evaluation of evidence-based practices in online learning: A meta-analysis and review of online learning studies. US Department of Education, Office of Planning, Evaluation, and Policy Development, Policy and Program Studies Service Center for Technology in Learning. Retrieved from www.ed.gov/about/offices/list/opepd/ppss/reports.html

Newman, J. (2007). Using VoIP technology for online course in higher education. In R. Carlsen et al. (Eds.), Proceedings of Society for Information Technology \& Teacher Education International Conference (pp. 444-447). Chesapeake, VA: AACE.

Roblyer, M. D., \& Wiencke, W. R. (2004). Exploring the interaction equation: Validating a rubric to assess and encourage interaction in distance courses. The Journal of Asynchronous Learning Networks, 8(4), 25-37. 
Rovai, A. P. (2002). Development of an instrument to measure classroom community. Internet and Higher Education, 5(3), 197 - 211.

Ryobe, I. (2009). The effects of Skype-based video chats with volunteer Filipino English teachers (II): Discovering the superiority of video chat. Kyoto: Kyoto Sangyo University, Center for General Education.

Samsonov, P., \& Harris, S. (2010). Leading a horse to water: Connecting home-bound students to their classrooms using skype technology. Society for Information Technology \& Teacher Education International Conference Annual (pp. 34743479). San Antonio: Association for Advancement of Computing in Education.

Zhao, Y., Lei, J., Lai, B., \& Tan, H. (2005). What makes the difference? A practical analysis of research on the effectiveness of distance education. Teachers College Record, 107, 1836-1884.

\section{Appendix A}

Please answer the questions based on Classroom Community Scale (Rovai 2002). Answer Strongly Agree, Agree, Neutral, Disagree or Strongly Disagree on the drop down menu. Do not spend too much time on any one statement, but give the response that seems to describe how you feel. Please respond to all items. If you neither agree nor disagree with a statement or are uncertain, or if the statement doesn't apply to you, please mark Neutral.

1. I feel that students in this course care about each other.

2. I feel that I am encouraged to ask questions.

3. I feel connected to others in this course.

4. I feel that it is hard to get help when I have a question.

5. I do not feel a spirit of community.

6. I feel that I receive timely feedback.

7. I feel that this course is like a family.

8. I feel uneasy exposing gaps in my understanding.

9. I feel isolated in this course.

10. I feel reluctant to speak openly.

11. I trust others in this course.

12. I trust others in this course.

13. I feel that this course results in only modest learning.

14. I feel that I can rely on others in this course.

15. I feel that other students do not help me learn.

16. I feel that other students do not help me learn.

17. I feel that I am given ample opportunities to learn.

18. I feel uncertain about others in this course.

19. I feel uncertain about others in this course.

20. I feel that my educational needs are not being met.

21. I feel confident that others will support me.

22. I feel that this course does not promote a desire to learn.

23. How frequently do you use Skype?

24. Skype in the classroom was distracting to the students in the classroom.

25. Please add any other comments to aid us in researching the use of Skype in the classroom.

26. Please record some comments about your experiences with Skype in the classroom. 


\section{Appendix B-Buddy Protocol}

Hardware:

- Laptop computer

- Internet connection

- Web camera

- External microphone

- Modem/Wireless or High Speed Internet Connection

- External Speakers (Optional)

VoIP Software: (Skype, Google Video, etc.)

Use:

- Set up VoIP accounts, exchange user names and permissions

- Test how make and receive calls, activate video feature

- Access to chat function

- Use of File Share

- Make sure the Skype-Buddies use the same software and updated versions

Optimal Classroom Configuration:

- Table for laptop set up, near electrical outlet

- U shape or seating arrangement that allows for close proximity for whole class discussion

- Clear view to presenter/slides if applicable

- Location of microphone can be adjusted for group

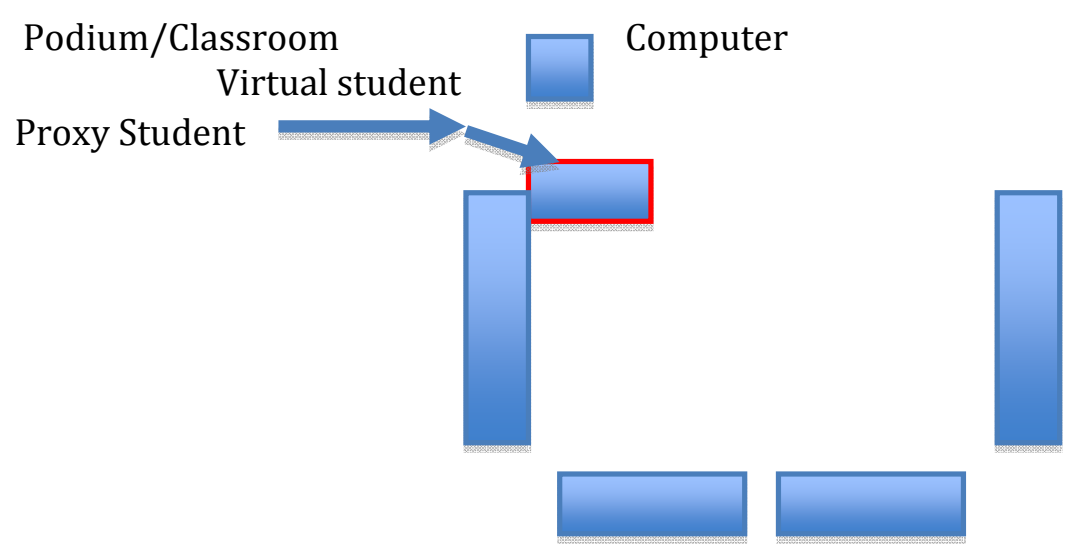

Proxy student might sit with virtual student positioned so that proxy student can "see" virtual student and notice chat box. If an external web camera is used experiment with placement on "back" of laptop screen so the proxy student can still use computer screen facing proxy student. Microphone can be placed on table near virtual student (whole class) or within small group for discussion.

Proxy Student:

1. Arrive in class in time to set up beforehand- choose seat that allows for full view of presentation area.

2. Plug computer into outlet- VoIP takes energy!

3. Plug in external microphone and place it where needed. (For example, close to "soft spoken" classmates or near presentation area if teacher or student presenter).

4. Best to sit so that computer screen can be viewed from "the side" so camera can see class or presentation area and you can see the chat. 
5. Call distance student when ready-- call can be muted so that it doesn't "ring" if class has started. Just don't forget to change mute so virtual student can be heard. Be sure to signal to distance student and check chat function to be sure that everything is working properly.

6. Size of "virtual student" can be enlarged by dragging lower right corner or choosing view full screen.

7. Chat feature of Skype can be accessed and is useful to monitor needed adjustments without disturbing class.

8. Laptop can be moved to accommodate small group interactions. The Skype buddies don't have to be in the same group! Other students will help.

Distance Student:

1. Be ready to answer call when distance student calls.

2. Confirm that VoIP is working properly, signal to classmate to indicate that it is okay or use chat function to indicate if you cannot see or hear well.

3. Use the mute to avoid feedback or background noise-Turn off mute when you would like to speak.

4. Be an active participant-be proactive in communicating with others. Use a combination of chat and voice to indicate where to turn the camera, if you want to contribute to whole or small group discussion, if you can't see, let your "buddy" know. Clear communication is the only way your buddy can help.

Instructor:

1. Announce to class that "virtual" student will participate in class-awareness is key and will minimize distraction.

2. Make handouts and power points and links (YouTube, etc.) used in class available in resources on OnCourse for virtual student to access during class. Ask students who are presenting to do so as well.

3. Speak to virtual student during class, elicit their responses when appropriate.

4. Ensure optimum classroom configuration for Skype buddy when possible.

Other Students: Other traditional classroom students should be invited to interact with the Skype buddies by both engaging the virtual student in discussion, and by helping the proxy student with hardware and software adjustments as needed. 


\title{
Looking for Children Left Behind: American Language Policies in a Multilingual World
}

\author{
Suparna Bose
}

\begin{abstract}
This article discusses ramifications of the Census 2010 reports, a substantial increase in language-minority populations, and an atmosphere of mistrust towards bilingual and bidialectal people felt by mainstream society in America. It also examines the process of assimilation, immersion, and silencing of immigrant/minority cultures, resulting in the loss of their identity. The pejorative effects of this can be observed in the lower self-esteem, lower grades and continuing school dropout rates of languageminority children today. By looking at models of bilingual or multilingual countries, the article also highlights that lawmakers and communities recognize the cultural histories of bilingual/multilingual learners and acknowledge the benefits of bilingualism. It goes on to recommend ways to increase the marketability of future American citizens, both monolingual and bilingual, in an era of globalization and plurality of the English language.
\end{abstract}

\section{Introduction}

The Census 2010 reports showed some noteworthy changes in the population distribution of different ethnicities in the United States, and an unprecedented growth in the minority population. Between 2000 and 2010, the Hispanic population grew by 43 percent-rising from 35.3 million in 2000, when this group made up 13 percent of the total population, to 50.5 million. The Asian population also increased by 43 percent between 2000 and 2010, moving up from about 4 percent of the total population in 2000 to about 5 percent in 2010. The Native Hawaiian and Other Pacific Islander population, the smallest major race group, also grew substantially between 2000 and 2010, increasing by more than one third. This population numbered 398,835 in 2000 , rising to 540,013 in 2010 , with its proportion of the total population changing from 0.1 percent to 0.2 percent. An 18 percent growth in the American Indian and Alaskan Native population occurred between 2000 and 2010. This population, also relatively small numerically, maintained its proportion of the total population between decennial censuses $(0.9$ percent) while growing from 2.5 million to 2.9 million. The Black population rose from 34.7 million in 2000 to 38.9 million in 2010, increasing 12 percent between 2000 and 2010. The White population increased from 211.5 million in 2000 to 223.6 million in 2010, an increase of 5.7 percent; it was the only major race group to experience a decrease in its proportion of the total population. 
Also, a separate segment in the 2010 Census, entitled 'Geographic Distribution of the Minority Population' recorded that over one third of the US population reported their race and ethnicity as something other than non-Hispanic White. This group, referred to as the "minority" population for this report, increased from 86.9 million to 111.9 million between 2000 and 2010, representing a growth of 29 percent over the decade. Moreover, a comparative study (see Figure 1) of the present total population of the USA with that of its projected population in 2050 would show that numerically the "minority" population was set to overtake the non-Hispanic White segment. Data for Figure 1 was taken from Table 4 "Projections of the Population by Sex, Race, and Hispanic origin for the United States: 2010 to 2050" (NP 2008-T4) (United States Census Bureau, Population Division, 2008).

\begin{tabular}{|lll|}
\hline Population by Race alone & $\mathbf{2 0 1 0}$ (Actual) & $\mathbf{2 0 5 0}$ (Projected) \\
\hline White & 246,630 & 324,800 \\
\hline Non-Hispanic White & 200,853 & 203,347 \\
\hline Black & 39,909 & 56,944 \\
\hline $\begin{array}{l}\text { American Indian and Alaskan Native } \\
\text { American }\end{array}$ & 3,188 & 5,462 \\
\hline Asian & 14,415 & 34,399 \\
\hline Native Hawaiian and Pacific Islander & 592 & 1,134 \\
\hline Hispanic, belonging to any race & 49,726 & 132,792
\end{tabular}

Figure 1. Comparison of the Distribution of the US Population by Race Alone, in 2010 and 2050.

When observed together with the results of the 2010 American Community Survey 1-Year Estimates, "Language Spoken at Home by Population 5 Years and Older" (United States Census Bureau Factfinder), some intriguing facts come to light. English continued to be the most prevalent language spoken in the US by $79.4 \%$ of the people (only speaking English), compared to $20.6 \%$ speaking languages other than English. $12.8 \%$ of the population spoke Spanish or Spanish Creole, $3.7 \%$ spoke other Indo-European languages, $3.2 \%$ spoke Asian and Pacific Island languages and $0.9 \%$ spoke other languages. As the numbers of "minority" speakers (in Spanish, Spanish Creole, other Indo-European, Asian and Pacific Island languages) increase, as shown in Figure 1, there would be a significant and concomitant rise in the population of bilinguals in this country, noted in Figures 2 and 3 below (data from US Census Bureau, Population Division, 2008). 


\section{US Population 2010}

- Bilingual/Bidialectal $\quad$ Monolingual

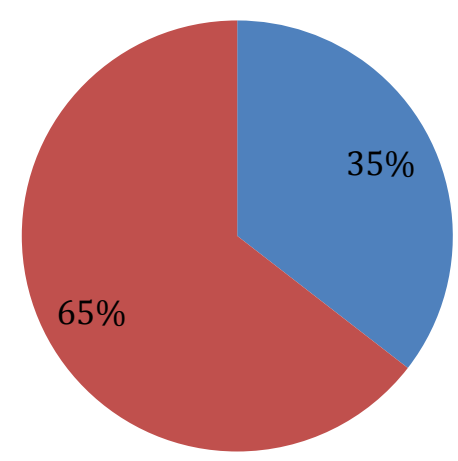

Figure 2. Distribution of Monolingual and Bilingual/Bidialectal Population in the US in 2010

\section{US Population 2050}

- Bilingual/Bidialectal $\quad$ Monolingual

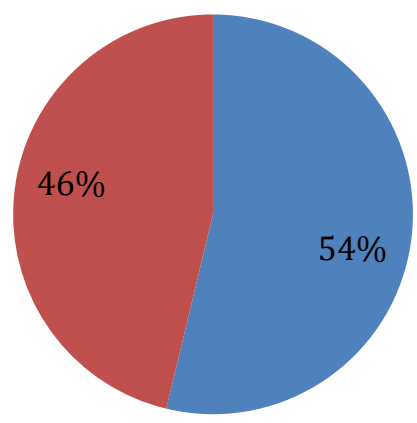

Figure 3. Distribution of Monolingual and Bilingual/Bidialectal Population in the US in 2050 


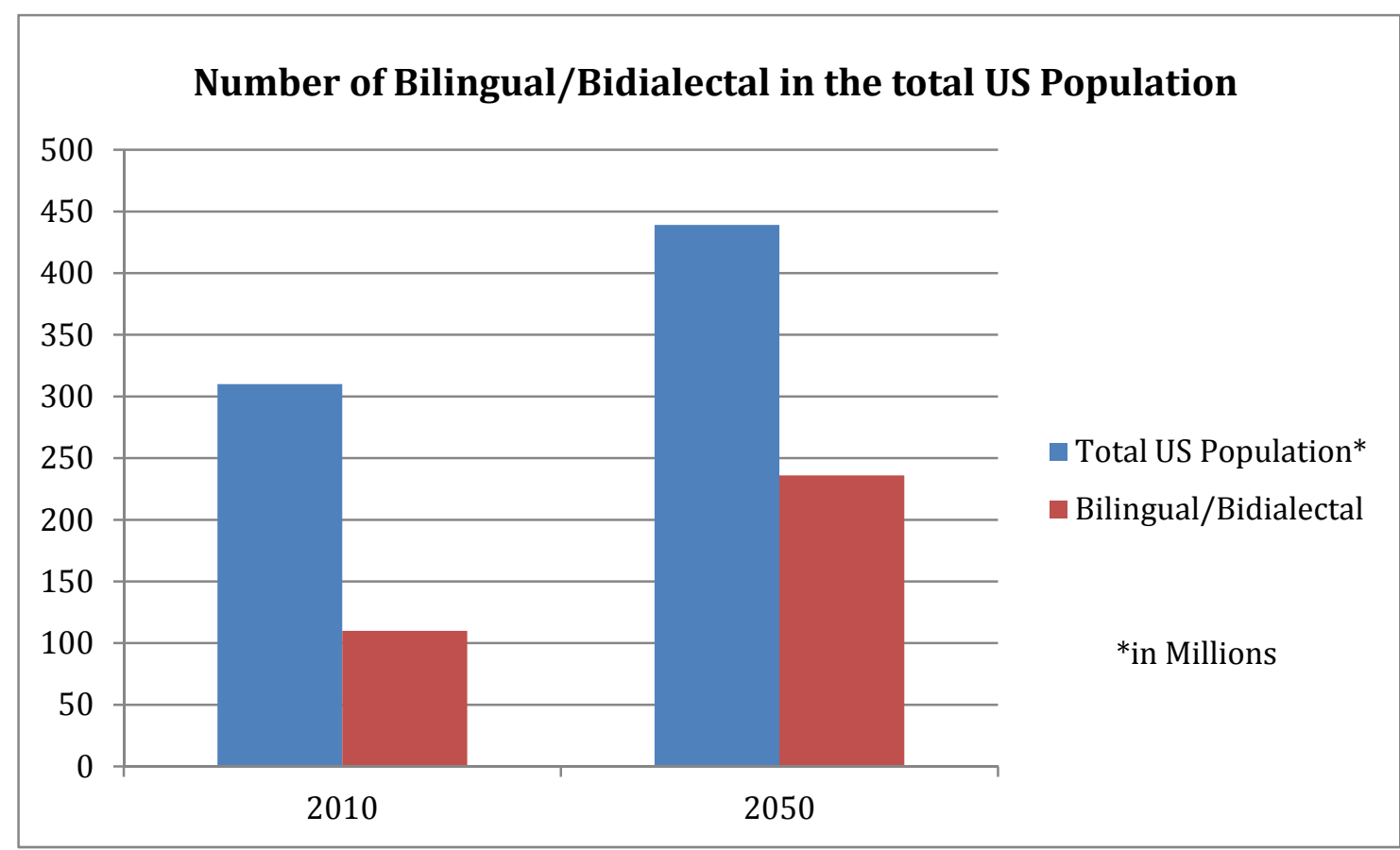

Figure 4. A Comparison of Numbers of Bilinguals/Bidialectals in the US in 2010 and 2050.

The changing demographics of the future must be matched with an accommodating education policy, not a one-size-fits-all type. In this context, this article will define some basic terms-“bilingual", "bidialectal", "voluntary and involuntary immigrants", "minorities"— that will play a vital role in the arguments put forward.

\section{Bilingualism, Bidialectalism and Immigration}

This article will use the term "bilingual" or "bilingual speaker" following Colin Baker's (1993) definition of "bilingualism as a group or societal possession" (p. 4) and will refer both to 1) "voluntary immigrants" speaking languages different from English like, Spanish, Portuguese, French, German, Dutch, Chinese, Korean, Japanese, Vietnamese, Arabic, etc.; and 2) "involuntary immigrants" through a process of colonization and/or annexation, speaking dialectal varieties of English like AfricanAmerican English Vernacular (AAEV), Hawaiian Creole English (HCE) or Chicano English as following John U. Ogbu's (1999) definition of "voluntary" and "involuntary" immigrants (p. 153).

The term "Minorities" had been defined as 1) voluntary immigrants who moved to the US in search of better opportunities in life, for example, immigrants from Asia, Africa, Central or South America; and 2) involuntary immigrants or nonimmigrants who were made a part of the US against their will through annexation, colonization or slavery, for example, the native Americans and Alaskans, the early Mexicans of the Southwest, native Hawaiians, Puerto Ricans and African-Americans. Many of these groups, as bilinguals and/or bidialectals, experience a sense of marginalization stemming from their immigration (whether voluntary or involuntary) and reinforced by their loss of identity (Ogbu, 1999). 
LOOKING FOR CHILDREN LEFT BEHIND PAGE | 165

\section{Loss of Identity and Self and Social Marginalization in Bilinguals and Bidialectals}

Before the twentieth century, instead of encouraging language diversity, the American government adopted a policy of "quick assimilation into English" (Nieto, 2009 , p. 61) when dealing with immigrant language-minority populations to ensure easier governance, using English and Anglicization as a unifying force. That resulted in a loss of identity among the immigrant or language-minority speakers; their forced Anglicization in immersion-type schooling; and finally, frustration of the bilingual students in abandoning their own language and learning the new language. The bilingual speaker was left with a feeling of ambivalence "toward one's own native language, the value of one's cultural background, and, ultimately, the value of oneself" (Nieto, 2009, p. 61).

It could be argued that the place of language in the cultural life of each social group was interdependent with the habits and values of behavior shared among members of that group (Heath, 1996). Hence, when one's native language was taken away and another language was imposed, the collective identity of the colonized/immigrant/minority-language group took a beating. The result of this ambivalence could be observed in the studies of many researchers. It became a devaluation of the "self" by virtue of which the colonizer's or majority-language group's language was imposed on the colonized or the minority speakers until the latter found the language of the former to be superior: "Blacks found White speakers of SAE to be more attractive, kind, and articulate. In fact, Black participants were much harsher critics of BE than were Whites" (Billings, 2000, pp. 74-77).

Language might become an even greater source of collective disgrace, "a collective shame we African-Americans have internalized about our very beings" (Delpit, 2002, p. 35). However, this feeling was not limited to African-Americans alone. It was shared by other minority communities as well. Victoria-Maria Macdonald (2004) quoted the 1969 manifesto "El Plan de Santa Barbara" to describe the Mexican-American: "The Mexican-American is a person who lacks respect for his culture and ethnic heritage. Unsure of himself, he seeks assimilation as a way out of his 'degraded' social status"' (p. 260).

This collective sense of lowliness, degradation, shame and inferiority, coexisting with the silencing of immigrant or minority languages, did not improve the immigrant or minority student's facility in English. Instead, its pejorative effect could be observed in the school dropout rates and lower grades of such students. Recent research has shown that the Asian-American community, stereotypically regarded as a model minority group because of their success and upward social mobility, had its share of school dropouts (Lew, 2004; Min, 1996). Moreover, such minority speakers tended to associate successful members of their community with whiteness, and their own low socioeconomic status with other minorities of color with a similar social status (Lew, 2004).

However, merely assimilating by learning to speak English was not enough. Mastering Standard American English (SAE) was the key. Ogbu (1999) had 
described that in a bidialectal speech community, one dialect ranked higher than the other on political grounds. This argument could be extended to include the bilingual speech communities as well, who spoke distinctively different dialects of English. This article would like to connect that standpoint with the "unquestioned association between so-called good English and good character" (Spiecher and Bielanski, 2000, p. 158) and explain how the practice of Standard Ideology "justifie[d] discriminatory practices in the schools, the workplace and society" and "privilege[d] certain usages and stigmatize[d] the others, adversely affect[ing] the lives of those who use stigmatized forms" (p. 157). Social mobility was inextricably linked with the use of SAE, the language of the mainstream or the majority, the language associated with whiteness. The bidialectal and the bilingual speaker have been excluded by virtue of the languages and dialects that they spoke. The same tool for assimilation that alienated them from their language now became a stigma of otherness.

The paradox of this situation lay rooted in the past, in the inconsistent language policies of the last couple of centuries. Analyzing historical events, one can discern two contradictory influences having contributed to this uncertainty. Throughout its history, the government has imposed English on voluntary and involuntary immigrants alike. On the other hand, democratic and libertarian ideals and a welcoming immigration policy have emphasized the freedoms of the individual and the model of America as the land of dreams and opportunity. The key to future educational reform lies in charting a middle path between these divergent stances.

\section{History of the Dominance of English in the US}

\section{Annexation Policies of the Nineteenth Century}

The American government imposed the use of English among Native Americans and inhabitants of the Southwest territories, as well as on the African-Americans who were slaves. Then it also used different strategies to increase the influx of Englishspeaking people into the Southwestern states. In some areas, the Spanish-speaking zones were split. In others, statehood was deferred until there were sufficient numbers of English speakers in the state. California gained statehood in 1850; Nevada in 1864; Colorado in 1876; Utah in 1896; New Mexico and Arizona in 1908 (Nieto, 2009, p. 62).

\section{Legislations, the First World War and the Rise of American Nationalism}

The Nationality Act of Texas (1906) stipulated English to be the only language taught in schools and highlighted the necessity for all immigrants to speak English to "start the process of their naturalization." In 1917 the Burnett Act required all new immigrants to pass a literacy test and barred immigration from Asia (exceptions being Japan and the Philippines). Simultaneously, the First World War brought in its wake unprecedented anti-German sentiments and nationalizing tendencies, leading towards monolingualism, with English being called the "one language in this country" by President Roosevelt (Nieto, 2009, p. 62). 
Significantly, the movement against bilingualism started peaking from the 1980 s to the present. Prominent examples include the Reagan administration's campaign against bilingual education; Senator S. I. Hayakawa's attempt (1981) to introduce a constitutional amendment aimed at adopting English as the official language of the US and his subsequent founding of "US English"; the rise of the English Only movement; the House of Representatives passing a similar bill in 1996 but failing to secure a majority in the Senate; California's Proposition 227 of 1998 ending bilingual programs throughout the state; and the No Child Left Behind Act of 2002 (Crawford, 2000, pp. 4-30; Donahue, 1995, pp. 112-141; Nieto, 2009; Ovando, 2003). Notably, the No Child Left Behind Act (NCLB) eliminated all references to bilingual education and imposed a testing system that relied on English-only instruction.

\section{Legacies of the Past}

In spite of the past history of forced assimilation of minority communities, America could not have been characterized as the land of dreams and opportunity and a haven for immigrants if some remarkable events had not happened. The democratic ideals of the American constitution, the abolition of slavery, the supremacy of the judiciary, and some remarkable legislation have all made America the democracy it was.

\section{Landmark Legislation}

Laws like Meyer v. Nebraska (1923), Farrington v. Tokushige (1927), and Mo Hok Ke Lok Po v. Stainbeck (1949) affirmed the rights of language-minority communities in the early and mid-twentieth century. However, the crowning glory of all legislations was the case of Brown v. the Board of Education of Topeka, which advocated desegregation in schools. This ruling paved the way for the AfricanAmerican community in their struggle for civil rights. It culminated in the passage of the Civil Rights act of 1964, Title VI of which proved to be a cornerstone for bilingual education in the US. The 1974 Lau v. Nichols ruling, the 1975 Lau Remedies, and the 1981 Castañeda v. Pickard are other landmark decisions that have served the needs and rights of language-minority students in the US (Nieto, 2009, pp. 63-4; Ovando, 2003, pp. 9-10).

\section{The First Two-way Bilingual School}

The Cuban Revolution of 1959 resulted in the arrival of a flood of exiled Cubans in Florida. Subsequently, a two-way bilingual program at Coral Way Elementary School in Florida was successfully established in 1963, with the help of federal assistance, the local teaching community, and the families. The previously existing bilingual schools were mostly catering to European immigrant populations. Thus, public and private schools teaching German had been established in Pennsylvania, Maryland, Ohio, Indiana, Illinois, Missouri, Nebraska, Colorado, and Oregon. Swedish, Norwegian, and Danish were taught in schools in Wisconsin, Illinois, Minnesota, Iowa, North and South Dakota, Nebraska, and Washington. Dutch was taught in 
Michigan, Polish and Italian in Wisconsin, Czech in Texas, French in Louisiana, and Spanish in the Southwest (Ovando, 2003).

\section{Increase in Numbers of Minority Communities in 1960-70}

The period of 1960 to 1970 saw a considerable increase in numbers of minority communities. The Immigration and Nationality Act of 1965 abolished the nationalorigin quotas and opened the way for a surge in immigration. It established annual visa caps for immigrants from Eastern and Western Hemisphere countries and preference categories based on family relationships and job skills.

Paradoxically, the wave against bilingual education reached its climax when modern-day research in bilingual education was pointing out all its advantages and immigration from Latin American and Asian countries was on the rise. Nieto (2009) and Ovando (2003) referred to the work of Krashen, Crawford, Greene, Hakuta, Padilla and Macedo, as opposed to the anti-bilingual arguments proffered by Keith Baker and Adrien de Kanter in this regard. This article will now explore the stances of opposition towards bilingualism and its associations with un-Americanism, as its detractors claim.

\section{Being Bilingual and Un-American}

In the era of Standard Ideology or monolingualism in the USA, being bidialectal or bilingual would not only affect social mobility, but would also reinforce the connection between English acquisition and loyalty. President Theodore Roosevelt emphasized the connection in 1926:

We have room for but one language in this country and that is the English language, for we intend to see that the crucible turns out our people as Americans, of American nationality, and not as dwellers in a polyglot boarding house. (quoted in Nieto, p. 62)

The ideology of English monolingualism in the US and its link with American identity could be perceived as a reaction against the large-scale immigration from the post-World War I era. A similar wave of immigration and the increase in minority populations as seen in the 2010 US Census reports has again been fomenting an atmosphere of mistrust against bilingualism among monolingual English speakers.

Bilingual speakers have been accused of being "disinclined to learn English or acquire literacy in English because of their loyalty to their native languages and cultures" (Wiley, 1996, p. 15). Such stigma and prejudices attached to languageminority or immigrant groups could actually prove counterproductive in the process of assimilation, as numerous investigations have shown. A study by Portes and Rumbaut (2006) of over 5000 second-generation children of immigrants including Asians and Chicanos found that children who experienced racial and ethnic discrimination were significantly less likely to identify as "American" (in Lee \& Suarez, 2009). The non-immigrant minorities also tended to construct an 
oppositional collective identity after being forced into their minority status (Ogbu, 1999; Porter \& Washington, 1993). The children of plantation workers in Hawaii felt uncomfortable using Standard English because it was associated with the European American oligarchy (Tamura, 1996, pp. 439-440). Thus, the forced use of the language of the majority culture often did not have the desired outcome.

Moreover, the myth that bilingualism negated American values was denounced by the Arizona High Court in its ruling on Yniguez v. Arizonans for Official English, 1995:

In our diverse and pluralistic society, the importance of establishing common bonds and a common language between citizens is clear. Equally important, however, is the American tradition of tolerance, a tradition that recognizes a critical difference between encouraging the use of English and repressing other languages... Freedom of speech is the foundation of our democratic process... By restricting the free communication of ideas between elected officials and the people they serve, article XXVIII threatens the very survival of our democratic society. (quoted in Crawford, 2000, p. 43)

A close analysis of the key terms used in the court ruling-diverse, pluralistic, common bonds, democratic society, the American tradition of tolerance, freedom of speech, free communication of ideas - show that bilingualism and Americanization need not be mutually exclusive notions. An American citizen could be bilingual and yet still American.

With notions of these legacies in mind, this article will go on to examine the implications of the 2010 Census reports to explore how an atmosphere of mistrust towards language-minority communities has marginalized the learners.

\section{Analyzing the Educational Attainments of Different Ethnic Groups}

A study of other available data from the Census Reports, namely, the American Community Survey and the Statistical Abstracts regarding the languages spoken by different communities of the American people, their educational attainments and dropout rates showed that the population growth of some of the minority communities was not commensurate with the growth of their educational achievements. The Hispanic population had, for example, grown by $43 \%$ between 2000 and 2010. However, the educational attainment of the community had not grown commensurately. Compared to other minority groups, the number of Hispanic high school and college graduates lagged behind (see Figures $5 \& 7$ below), and their number of high school dropouts had not decreased proportionately (see Figure 9 below). Also, even among Hispanics, the Mexican-American community seemed to be lagging behind the most, with the lowest numbers of high school and college graduates (see Figures $6 \& 8$ below). The number of Black students graduating from high school had improved drastically, from $31.4 \%$ in 1970 to $84.1 \%$ in 2009 (see Figure 6 below). However, the number of college graduates from the Black community had not improved likewise; it still ranked quite low (see Figure 8 
below). The number of high school dropouts in the Black community, though, had dropped considerably (see Figure 9 below).

The number of high school dropouts among White students was $11.3 \%$ in 1980 , decreasing to $6.5 \%$ in 2008; among Black students, $16.0 \%$ in 1980, dropping to $8.6 \%$; and among Hispanic students, $29.5 \%$ in 1980 , declining to $15.0 \%$ in 2008 . Among the Hispanic students of age 16-17 years (see Figure 10 below), the numbers have decreased considerably from $16.6 \%$ in 1980 to $3.1 \%$ in 2008 . However, among $18-21$ year-olds, it is still an issue: from $40.3 \%$ in 1980 to $20.0 \%$ in 2008 . Similarly among 22-24 year-olds, the numbers of dropouts have gone down from $40.6 \%$ in 1980 to $25.4 \%$ in 2008 (all figures come from the United States Census Bureau Statistical Abstracts of the United States, Tables 225 and 268, 2011).

\section{Observations}

1) The number of high school and college graduates was lowest among the Hispanic ethnic group.

2) The Mexican-American community was by far the lowest, in educational attainment, among the Hispanics.

3) The number of college graduates among Blacks was still quite low.

4) The number of high school dropouts among Blacks and Hispanics (16-17 years of age) dropped considerably.

5) Hispanic youths (18-24 years of age) were more likely to drop out of school than their younger counterparts.

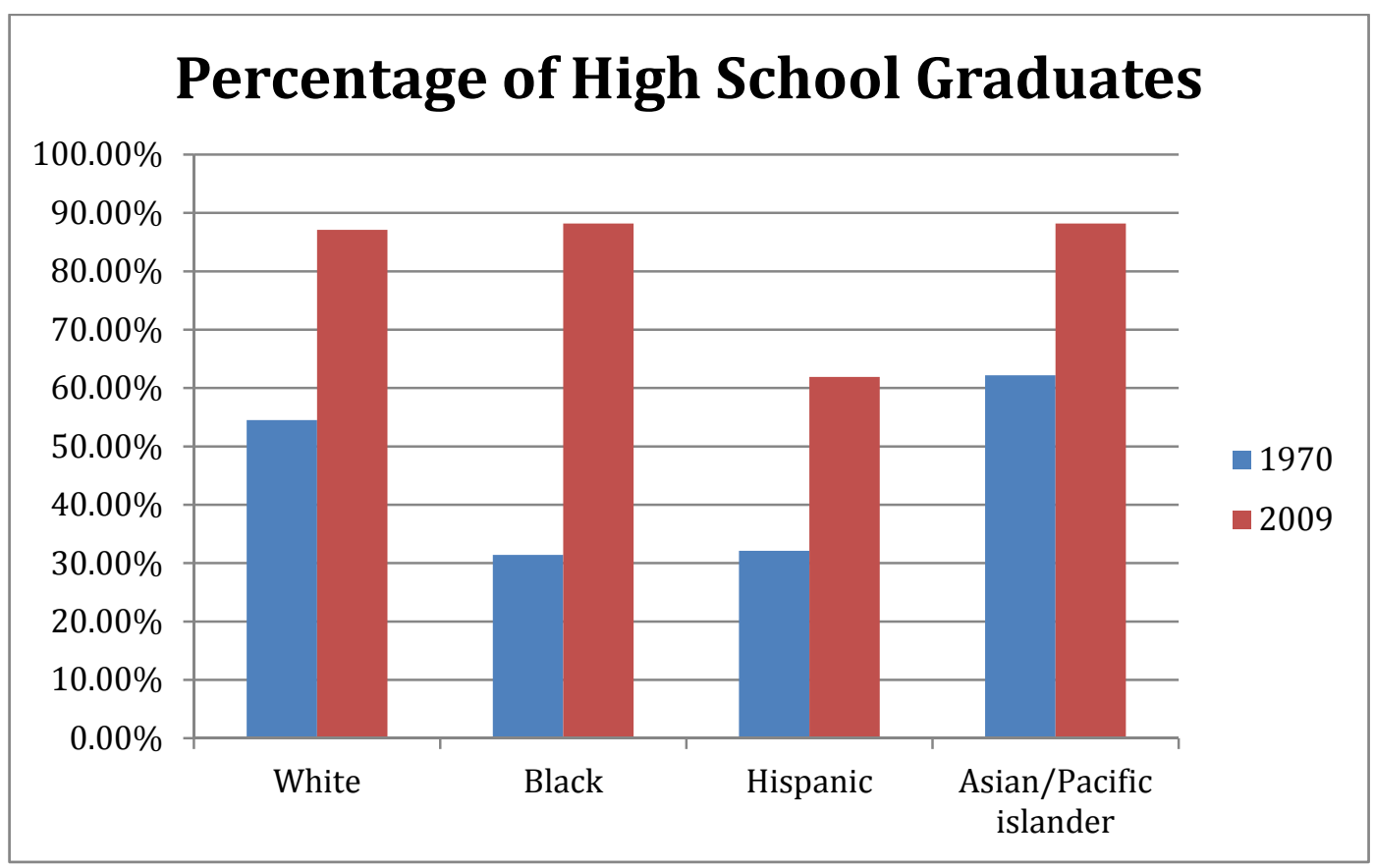

Figure 5. Percentage of High School Graduates, 1970 and 2009 


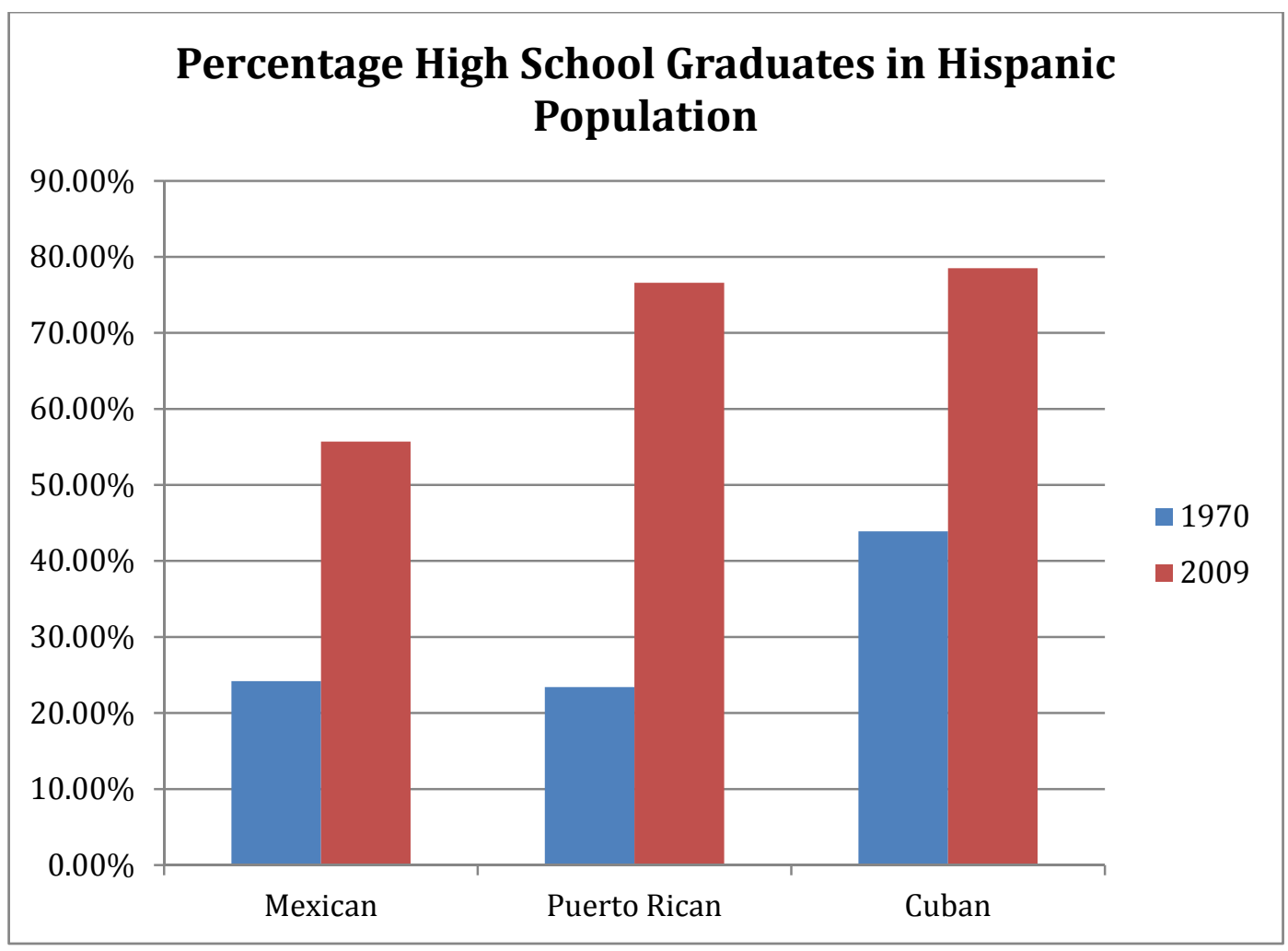

Figure 6. Percentage of High School Graduates in Hispanic Population, 1970 and 2009

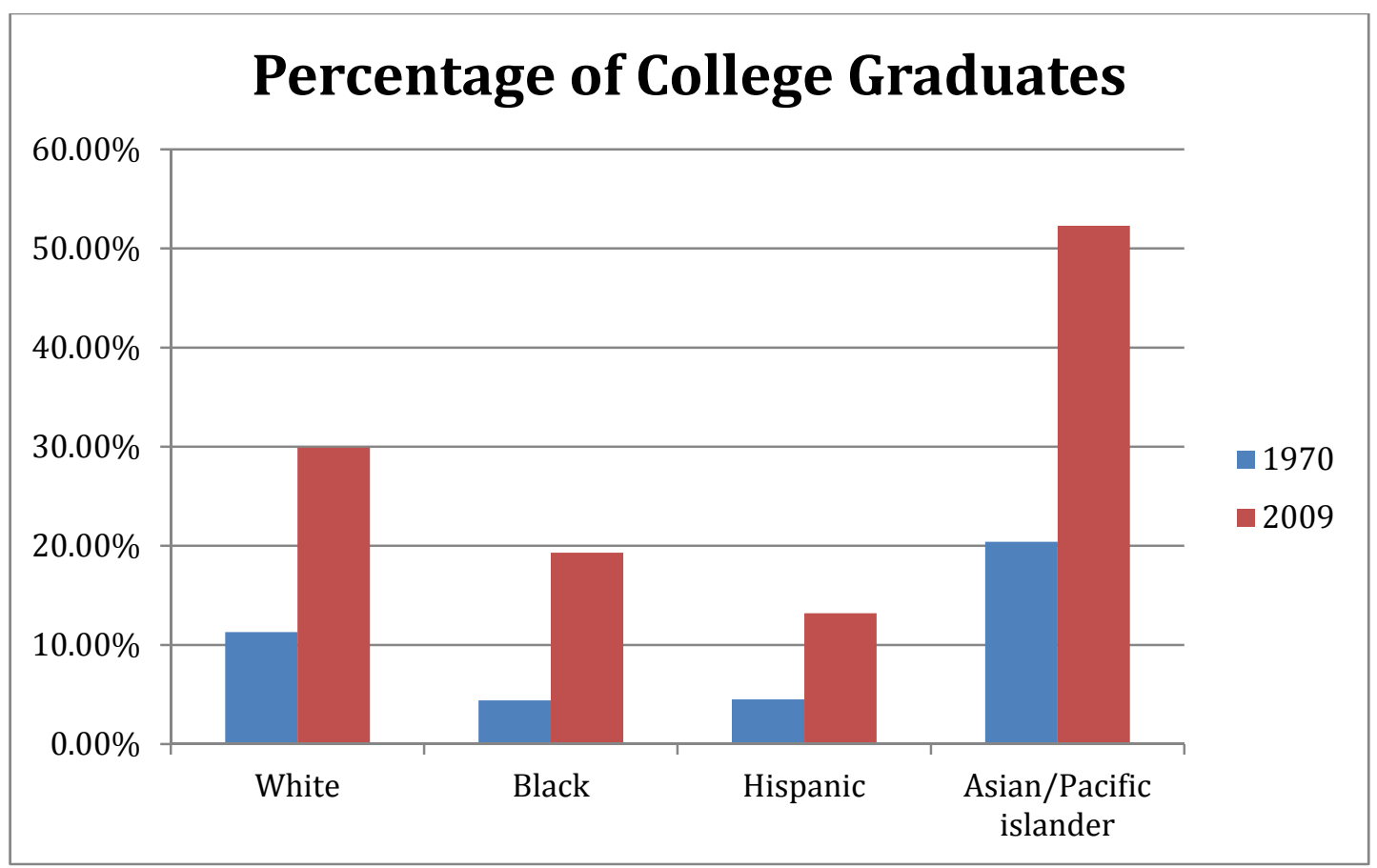

Figure 7. Percentage of College Graduates in US, 1970 to 2009 


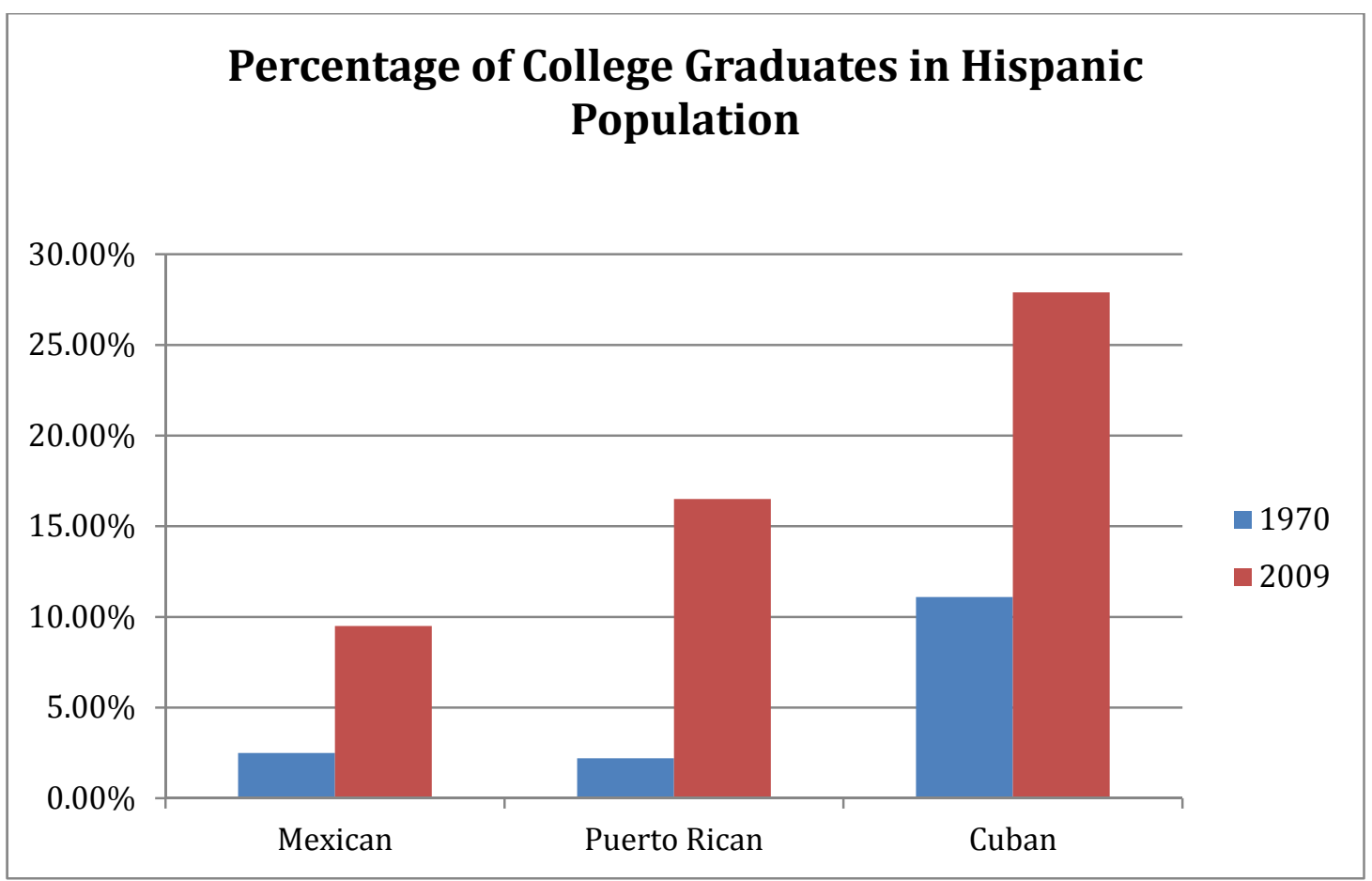

Figure 8. Percentage of College Graduates in Hispanic Population, 1970 and 2009

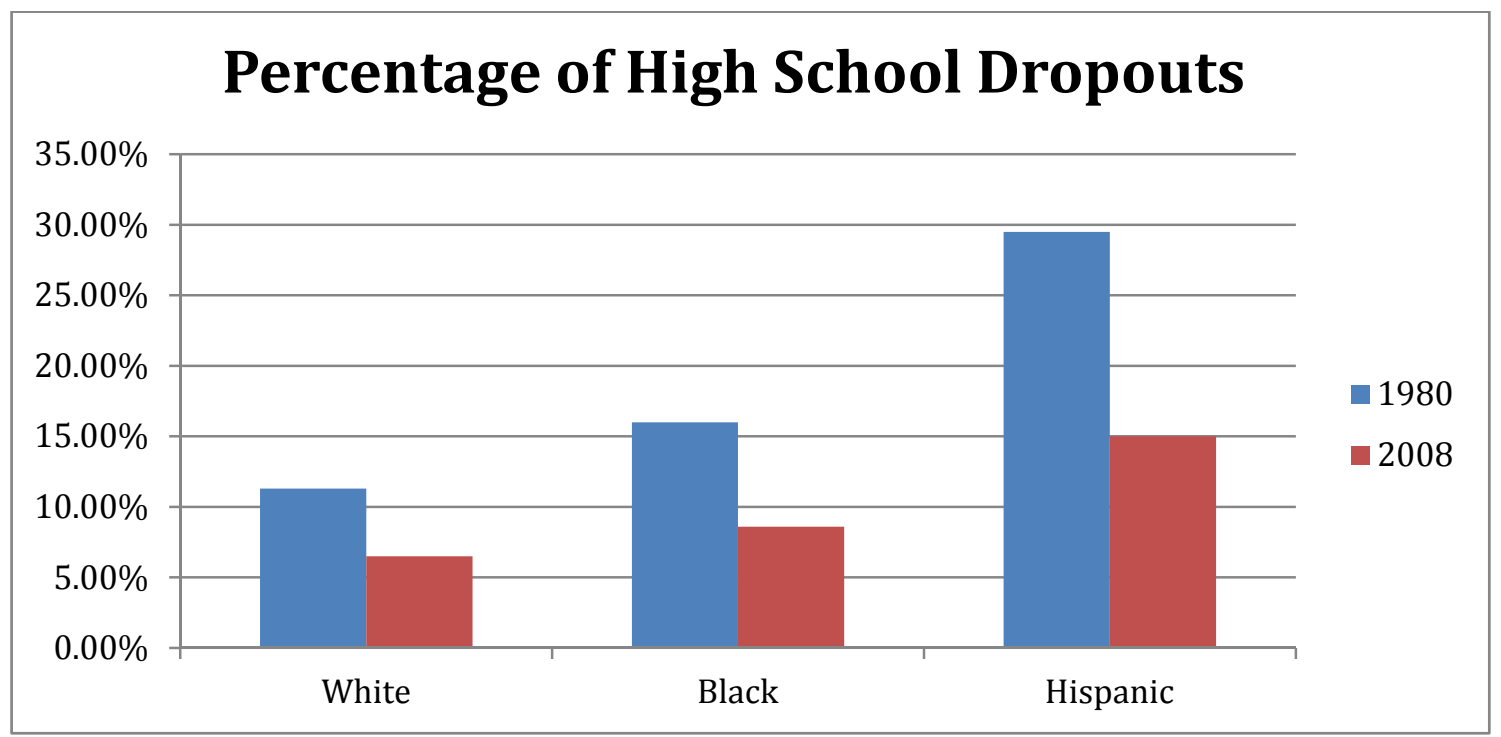

Figure 9. Percentage of High School Dropouts by Age, 1970 and 2009 


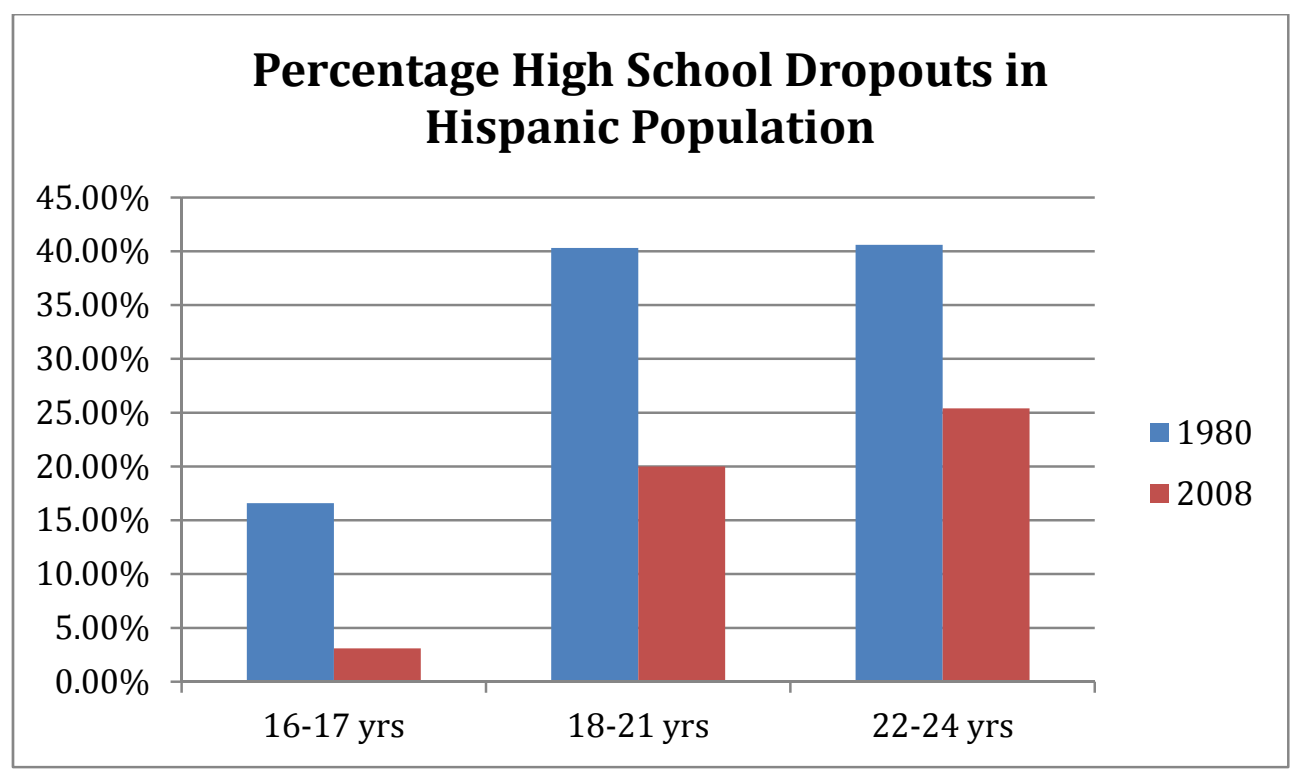

Figure 10. Percentage of High School Dropouts in Hispanic Population by Age, 1980 and 2008

\section{Attitudes Towards Bilingualism Need to Change}

From these figures, it is apparent that steps have to be taken to improve the language learning of bilinguals (and by extension bidialectals) in this changing demographic scenario. Otherwise, a sizeable part of the American population will be lacking in English proficiency.

The first way this could be done is by improving self-esteem among bilinguals (and by extension, bidialectals) by highlighting achievements of their home languages and cultures in schools. Delpit (2002) used the example of Africa to reinforce this point:

Those of us who teach must first make our students recognize their potential brilliance. When we know the real history of Africa - the Egyptian wonders of technology and mathematics, the astronomical genius of the Mali Dogon, the libraries of Timbuktu - then we can teach our children that if they do not feel they are brilliant, then it is only because they do not know whence they came. (p. 46)

Many elementary schools in the USA already study the history of the Native American people. Similar curricula could also be done with Asian and Central and South American cultures.

Secondly, the administration could help by granting proper status to the previously marginalized minority languages, as happened in Hawaii. The US Department of Education's Office of Bilingual Education and Minority Languages Affairs included Hawai'i Creole English as a language qualifying for federal funding under Title VII of the Elementary and Secondary Education Act. As a result, the Hawai'i State Department of Education's office of Bilingual/Multicultural Projects 
applied for and received funding in 1984-1989 for Project Holopono, aimed at selected elementary students, and in 1989-1993 for Project Akamai, aimed at selected high school students. Recognition by the government opened up new avenues and unlocked funds to revive a dying language (Tamura, 1996).

Moreover, for those who believe that English is losing its place of prominence in the US and that other languages are taking over, recent studies show otherwise. According to the results of the Language Spoken at Home survey done by the 2010 American Community Survey 1-Year Estimates, English continues to be the most prevalent language spoken in the US, spoken by $79.4 \%$ of the total population (speaking only English), compared to $20.6 \%$ speaking languages other than English.

Further, the monolingual communities have to be made aware of how bilingualism (learning a foreign language, in this case) could become an asset in an era of globalization. Learning another foreign language would give monolingual English speakers an edge and marketability in getting jobs in different parts of the world.

\section{English as a Tool of Global Communication in an Expanding World Order}

Instead of becoming defunct, as the English-only and English First advocates would like to believe, English has, in fact, become the dominant world language and the language of global communication. Kachru (1996) stated that "English is now the major instrument of initiating large-scale bilingualism around the world-being a bilingual now essentially means knowing English and using English as an additional language, as a language of wider communication" (p. 138).

Educational policymakers should therefore realize that it is time to return to the tolerant language policies of earlier days (Ovando, 2003). The handout of the 1999 National Association for Bilingual Education Conference highlighted that bilingual education could not be considered an isolated education program. It had to be re-embedded "in the larger frameworks of quality education and access for language-minority communities, promoting bilingualism for all (and foreign language policy), and ending the divisive tracking of children of different languages and skin colors and national backgrounds to different futures" (quoted in Ovando, 2003, p. 17).

The expanding world order can be discerned in Kachru's model of the "Three Concentric Circles." The figure is made up of the Inner Circle countries: UK, USA, Canada, Australia and New Zealand; the Outer Circle countries: Bangladesh, Ghana, India, Jamaica, Kenya, Malaysia, Nigeria, Pakistan, Philippines, Singapore, Sri Lanka, Tanzania and Zambia; and the Expanding Circle countries: China, Egypt, Israel, Japan, Korea, Nepal, Saudi Arabia, Taiwan, USSR and Zimbabwe (Kachru, 1996). Bhatt (2001) explains that the Outer Circle represents the spread of English in nonnative contexts, where it has been institutionalized as an additional language, with an estimated 150-300 million speakers. The Expanding Circle, with a steady increase in the number of speakers and functional domains, includes nations where English is used primarily as a foreign language, with an estimated 100-1,000 million 
speakers. Hence, the Outer and Expanding Circle countries could provide excellent employment opportunities.

\section{Models of Bilingual or Multilingual Countries: India and Singapore}

According to the United States Library of Congress, Federal Research Division and the Government of India portal, there are 22 different languages recognized by the Constitution of India, with Hindi as the official language. Article 343(3) empowers the Parliament to provide by law for continued use of English for official purposes. Hence, all the states have their own vernacular language, Hindi as the official language and English as another official language.

For some Indians, especially in the non-Hindi-speaking states in southern India, English is often the only language of communication with people from other parts of India. In most public schools, the medium of instruction is the state vernacular language, and English is taught as a second language. In private schools, the medium of instruction is English, and students have to study another vernacular language as well. Moreover, Hindi, the official language, is usually introduced in the curriculum around Grade 5/6/7, depending upon the state (Assam Education Department Rules and Orders; Maharashtra Board of Secondary Education, 2012; West Bengal Board of Secondary Education, 2010 Central Board of Secondary Education, Curriculum 2010; Indian Certificate of Secondary Education, Regulations).

According to the constitution of Singapore, Malay, Mandarin, Tamil and English were the four official languages in Singapore. The national language was the Malay language. The medium of instruction in all schools, public or private, was English. From Grade 1, English, accompanied by any other official language, was taught (Ministry of Education, Singapore, 2011).

\section{Problems Faced By India and Singapore}

These multilingual countries have also had their difficulties while implementing their language policies. In India, the dilemma had surfaced with the growth of a privileged class of learners from English-medium schools $10 \%$ of the total number of Indian schools, usually private schools), as opposed to the vernacular-medium free or subsidized schools run by the government (equivalent to the US public schools). Though the official language in India is Hindi, the makers of language policy in India had not been able to make all government schools adopt Hindi as the common medium, because of continued resistance from non-Hindi-speaking states. Thus, English continued to be an additional official language and the fluent English speaker enjoyed social mobility and socioeconomic status (Annamalai, 2005; Pattanayak, 1990, 1991).

In Singapore, the Speak Good English Movement guided by the ruling political leadership encouraged the use of Standard English in daily life, to counter the colloquial Singaporean English, known as 'Singlish'. Also, proficiency in English was associated with social prestige, mobility and economic status (Rappa \& Wee, 2006; Rubdy, 2005). Recent research has also pointed out that activities between 
different ethnic groups in public school classrooms did not result in similar multiethnic interaction during recess or playtime (Lee et al., 2004).

\section{How to Solve These Issues in an American Context}

1) The Indian public schools are paid for or subsidized by the government and hence often lack the infrastructure, facilities, or funds to employ English teachers with adequate qualifications. American public schools, on the contrary, benefit from municipal taxes, enjoy better funding and resources and are better staffed. Moreover, the Indian language scenario is complicated by the sheer number and variety of languages and dialects spoken in states, in contrast to the US.

2) The Singaporean identity was constructed on an "ideology of pragmatism" (Lai, 1995, p. 184) united with a rigid "CMIO (Chinese-Malay-Indian-Others)" brand of multiracialism, which equated each ethnic group in the city-state with a particular language, religion and culture, closely supervised by the government (Lai, 1995, p. 179; Clammer, 1998). American policymakers need to adopt a pragmatic point of view as well, in the realm of language. However, the concept of government supervision would have to be replaced by local administrative supervision, which matches the American federal principle.

\section{Recommendations in the Areas of Policy-making, Methodology and Curriculum}

1) Introduction of foreign languages at elementary school level is necessary and could go hand in hand with providing bilingual education for the languageminority groups. The choice of language could be made preferably by looking at demographics and language needs of school districts. After consultation with and feedback from the families of the students, such choices will also improve and expand the future career choices of monolingual students as well as preserve the cultural identity of the bilingual ones. Also, the introduction of an additional language at the elementary school level would mean the creation of more teaching jobs.

2) Recognizing "pluricentricity" of the English language, or "Englishes," as Bhatt (2001) termed them, might salvage the situation. Spanish could be declared a second official language, in states where a sizeable part of the population is Spanish-speaking. English dialects like AAEV, HCE, Chicano English and others should be given their proper status in the language world order, to make amends for years of marginalization. In this context, it is pertinent to look at the National Council of Teachers of English's (NCTE) language resolution of 1974 entitled "Students' Right to Their Own Language": "We know that American English is pluralistic. We know that our students can and do function in a growing multiplicity of language situations which require different dialects, changing interconnections of dialects, and dynamic uses of language" (p. 14).

3) In such a scenario, training both old and new teachers to deal with multi-ethnic or multicultural classrooms is of prime importance. A number of researchers 
have highlighted the teacher's role in this context. Spiecher and Bielanski (2000), recognizing Standard English as the language of social mobility and the discrimination resulting from it, zeroed in on the figure of the teacher in their quest to "combat the ubiquitous linguicism in [the] school system, [the] offices and society" with the help of the Prototype Theory applied to language usage. According to them, more research was needed on the dialects used by teachers in actual classrooms. The teacher's dialect "affect[s] his/her understanding of the students and their dialects, and ... affect[s] [their] ability to learn." Also, the educational community must be aware of "differences in the form and function of spoken and written language, of the way in which pupils' gender, social class, and ethnic group may affect the way they speak... and of the social attitudes toward linguistic diversity" (pp. 154-156, 164-165). Campano (2007) spoke about a "second classroom' that ran in tandem with and sometimes counter to the mandated curriculum." He visualized a "more horizontal model, [where] the classroom is conceptualized as a space of shared inquiry and the diversity of the student population as an epistemic advantage, rather than a hindrance" (p. 4).

4) Openness of teachers to learning new things about themselves as well as their learners was also significant. Heath (1996) discussed the teachers she was teaching in a graduate course and where they themselves became learners and their attitudes changed. Goodman's (2006) depiction of Doreen Noone Wheeler, the European-American teacher and her journey of misconception towards actual knowledge about the language competence of her student Jasmine, showed how teachers also need to keep on learning. Doreen selected Jasmine as the focal point of research, as her perception was that Jasmine always spoke AAEV and never used code switching, and this was affecting her education. However, as she started audiotaping Jasmine's class conversations and compared it with her writing samples, she realized that Jasmine was aware of the differences between formal and informal English spoken in different contexts, and this revelation influenced her attitude towards learners of other speech communities later. The NCTE's 1974 language resolution also underscored this issue.

5) Teachers need to ratify their book knowledge of language by living as minority speakers. They should be wholly immersed in a dialect group other than their own. Although such an opportunity may be difficult for some to obtain, less definitive experience may be obtained by listening to tapes and records, as well as interviewing sympathetic speakers who use minority dialects (NCTE, 1974).

6) Involving and enlisting help from immigrant communities in language classes could help in creating a comfortable, relaxed and productive learning environment. Delpit (2002) referred to Krashen's depiction of the "affective filter" operating when the affective conditions are not optimal, when the students are not motivated, or are overanxious. Therefore, the classroom should be made comfortable for all learners. Using the image of America as a melting pot of different immigrant nations, schools could celebrate a World Culture Day, where learners could trace and share their family history. Tracing one's 
genealogy is a prevalent practice in many countries, as the numbers of burgeoning websites can attest. Moreover, it would make a number of students think about where their ancestors came from-Europe, Mexico, South America or Asia. That would probably give them a distinctly different perspective if they thought of themselves as immigrants. Parents could chip in by bringing in food items characteristic of their region. Such events, followed by map pointing and "meaningful in-class discussions" (Lee et al, 2004, p. 133) could develop the imagination of students and increase awareness of other cultures. These attempts might seem superficial but they often make immigrant cultures seems less exotic and more mundane. For example, after tasting an Indian onion pakora, a non-Indian would recognize it as a variation of a Burger King onion ring and a piece of tandoori chicken as a spicy chicken wing. However, to cement in the knowledge of diversity with the notion of assimilation, age-old American values like loving your family, responsibility to your family, respect for other people, freedom of speech, and freedom of religion should be highlighted. Enlisting the help of the minority/immigrant learners' families and communities could help make the classroom more comfortable for such learners and acquaints learners coming from mainstream families with other cultures.

7) Spreading awareness among monolingual families in school districts regarding the benefits of bilingualism and of learning a second language from an early age is necessary. Highlighting the importance of an increasing need to improve one's language skills in the job market, especially in the context of the rising economic power of China, India, Brazil and other Latin American countries, and the continued deployment of troops in the Middle East and Southeast Asia, is required.

8) Using ESL/ELL strategies for dialectal English (AAEV, HCE, Chicano English) speakers and use of home language as part of the school curriculum are avenues that could be followed successfully. Use of language experience stories of the learners and of real-life situations could make the classroom a comfortable learning zone. Heffernan \& Lewison (2005) depicted the desegregation happening in a school lunchroom (pp. 25-34), where the children learned how to practice desegregation in reality. Using strategies that the learners understand and identify with-hairstyle, fashion, music, football, soccer, baseball, moviescould make learning more interesting and learner-appropriate. Also, as Chanda the teacher said in Goodman (2006), children's home language was part of being "themselves" (p. 150), and incorporating it in a classroom would be useful as well as meaningful. The 60 schools in the Los Angeles school district that have started a program called "Academic English Mastery," whereby the AAEV speakers could differentiate between AAEV and SAE without feeling degraded (PS 100, Watts, Los Angeles, CA), have clearly started following this path.

9) For bilinguals, the testing system should have translated versions in their native language.

Billings' (2005) strategy of highlighting the differences between the Black and White communities and then progressing towards further research to eradicate 
differences, could be expanded to include other ethnically and linguistically different groups in contemporary United States. He remarked that the way "to eliminate differences between the races is to first illuminate these differences ... some may argue that the separation of races for the purpose of the study only widens the divide, [but] this research can bring cultures together through explaining how Whites and Blacks [are] cognitively and behaviorally different. Once research demonstrates the ways in which the races differ, future research can begin to pinpoint why these differences exist" (p. 80).

The inherently pluralistic fabric of American society would benefit from taking a close look at the similarities and differences that characterize different ethnicities instead of stereotyping and categorizing them. Nieto-Phillips (2005) wrote:

The popular imagination is fed by two seemingly contradictory stereotypes: the wholesome, light-skinned Hispanic who believes in tradition, family, and the American Dream; and the lawbreaking, desperate, dark-skinned day laborer who will stop at nothing to enter the US even at great peril. Like the White and Black legends, these stereotypes can be found on the opposite sides of the same ideological coin...Hispanophilia...and Hispanophobia. (p. 253)

\section{Conclusion}

Taking into account the developing notion of association of monolingualism with Americanism (and of bilingualism with un-Americanism or anti-Americanism), this article explores the psyche of the language-minority student in an atmosphere of marginalization and mistrust prevailing in mainstream society. The 2010 reports of the US Census Bureau, meanwhile, highlight significant changes in the minority population of the country. With the help of other available data from the American Community Survey and the Statistical Abstracts regarding the languages spoken by different communities of American people, their educational attainments and dropout rates, it is observed that the population growth of some of the minority communities is not commensurate with the growth of their educational achievements.

The article underscores the need to change attitudes prevailing in society regarding bilingualism and bilingual speakers. Acknowledging the proper status of the minority languages and dialects and restoring the self-confidence of the minority learners would be a step in the right direction. Also, making the country aware of the advantages of bilingualism in a globalized world and making bilingual education a part of mainstream education (by introducing a foreign language) could alleviate feelings of resentment in monolingual communities. Moreover, the continuing and ever-widening hegemony of English throughout US and the world is an undisputed fact, and that should satisfy those who are worried that English will lose its prominence. A multicultural and multiethnic US should also learn from models of other multicultural and successfully multilingual countries like India and Singapore. 
The article recommends major policy, methodology, and curriculum changes:

1) The introduction of a foreign language at the elementary school level for monolingual speakers, which would go hand in hand with ongoing bilingual education programs for the language-minority groups. The choice could be made by consulting the demographics and language needs of school districts.

2) Recognition should be given to the plurality of the English language, and other dialectical forms of English should be used in the classroom.

3) The need to train teachers in handling multicultural classes; the role of teachers as learners, comprehending immigrant or minority cultures.

4) Enlisting help from immigrant and minority communities to make the classroom a relaxed space conducive to learning.

5) Using home language and language experience stories of the learners as texts in the class.

All communities must be aware of their respective language and ethnic differences, and also of the universal human values and the longstanding American values common to each of them. And for the lawmakers and policymakers, sweeping dust under the carpet by following soft options, marginalizing bilingual education by concentrating on short-term, politically-motivated gains is not useful any more. American traditions of plurality and democracy, of equal opportunity for all, must not be forgotten. Disguised discourses of race, language and power have to be brought out in the open. Until then, the future of this diverse land of dreams and opportunity will continue to drift and flounder.

\section{Recommendations for Further Research}

The changing demographic scenario in the US as shown in the Census report demands a new way of viewing bilingualism and bidialectalism. Bilingualism is now inextricably linked with globalization. Instead of perpetuating the history of marginalizing the language-minority groups by promoting English immersion classes, American society-and educational policymakers in particular-need to take a new look at the resources of growing bilingual and bidialectal communities and reform the existing education system. However, some issues remain unexplored and could therefore form the basis of future research:

1) The continuing dropout rate among minority students in the US, its link with their socioeconomic status, and the students' feelings of alienation across ethnicities; how their families could help them, with proper guidance from schools.

2) The use of ELL strategies in helping bidialectal students, instead of remedial classes.

3) The future of Singaporean English faced with the hegemony of SE. 
4) The future of the Indian education system: is the discrepancy between the English speakers and vernacular speakers widening? And what could be its implications?

\section{References}

Annamalai, E. (2005). Nation-building in a globalised world: Language choice and education in India. In Angel M. Y. Lin \& Peter W. Martin (Eds.), Decolonisation, globalisation: Language-in-education policy and practice. Clevedon, UK: Multilingual Matters.

Assam Education Department, Rules and Orders. Retrieved from http://aasc.nic.in/

Baker, C. (1993). Foundations of bilingual education and bilingualism. Clevedon, UK: Multilingual Matters.

Bhatt, R. M. (2001). World Englishes. Annual Review of Anthropology, 30, 527-550. doi: http://www.jstor.org/stable/3069227

Billings, A. C. (2000). Beyond the Ebonics debate: Attitudes about Black and Standard American English. Journal of Black Studies, 36(1), 68-81.

Campano, G. (2007). Immigrant students and literacy: Reading, writing, and remembering. New York: Teachers College Press.

Central Board of Secondary Education, India. (2012). Retrieved from http://cbse.nic.in/

Clammer, J. R. (1998). Race and state in independent Singapore, 1965-1990: The cultural politics of pluralism in a multiethnic society. Aldershot, UK: Ashgate.

Crawford, J. (2000). Anatomy of the English-only movement. In J. Crawford (Ed.), At war with diversity: US language policy in an age of anxiety (pp. 4-30). Clevedon, UK: Multilingual Matters.

Delpit, L. (2002). The skin that we speak. New York: New Press.

Donahue, T. S. (1995). American language policy and compensatory opinion. In J. W. Tollefson (Ed.), Power and inequality in language education (pp. 112-141). Cambridge: Cambridge University Press.

Goodman, K. S. (1992). I didn’t found whole language. The Reading Teacher, 46(3), 188-199.

Government of India portal (2011). Retrieved from http://india.gov.in/

Heath, S. B. (1996). Ways with words: Language, life, and work in communities and classrooms. Cambridge: Cambridge University Press.

Heffernan, L., \& Lewison, M. (2005). What's lunch got to do with it? Critical literacy and the discourse of the lunchroom. Language Arts, 83(2), 25-35.

Indian Certificate of Secondary Education (2011). Retrieved from http://www.icseindia.org 
Kachru, B. B. (1996). World Englishes: Agony and ecstasy. Journal of Aesthetic Education, 30(2), 135-55. Doi: http://www.jstor.org/stable/3333196

Lai, A. E. (1995). Meanings of multiethnicity: A case study of ethnicity and ethnic relations in Singapore. Oxford: Oxford University Press.

Lee, J. S., \& Suarez, D. (2009). A synthesis of the roles of heritage language in the lives of children of immigrants: What educators need to know. In T. G. Wiley, J. S. Lee \& R. W. Rumberger (Eds.), The education of language minority immigrants in the United States. Clevedon, UK: Multilingual Matters.

Lee, C., Cherian, M., Ismail, R., Ng, M., Sim, J., \& Chee, M. F. (2004). Children's experiences of multiracial relationships in informal primary school settings. In A. E. Lai (Ed.), Beyond rituals and riots: Ethnic pluralism and social cohesion in Singapore (pp. 114-145). Singapore: Eastern Universities Press.

Lew, J. (2004) The "other" story of model minorities: Korean American high school dropouts in an urban context. Anthropology \& Education Quarterly, 35(3), 303-323.

Macdonald, V. M. (2004). Latino education in the United States: A narrated history from 1513-2000. New York: Palgrave Macmillan.

Maharashtra Board of Secondary Education, State Curriculum Framework (2012). Retrieved from: http://www.msbshse.ac.in/newsite/newhome.html

Min, P. G. (1996). Caught in the middle: Korean communities in New York. Berkeley, CA: University of California Press.

Ministry of Education, Singapore (2011). Retrieved from http://www.moe.gov.sg/education/

National Council of Teachers of English (NCTE). Retrieved from http://www.ncte.org

Nieto, D. (2009). A brief history of bilingual education in the United States. Perspectives on Urban Education, Spring, 61-84.

Nieto-Philips, J. M. (2005). Afterword. In J. M. Nieto-Philips \& C. Schmidt-Nowara (Eds.), Interpreting Spanish colonialism: Empires, nations, and legends (pp. 249-256). Albuquerque: University of New Mexico Press.

Ogbu, J. U. (1999). Beyond language: Ebonics, proper English and identity in a Black American speech community. American Educational Research Journal, 36(2), 147-184.

Ovando, C. (2003). Bilingual education in the United States: Historical development and current issues. Bilingual Research Journal, 27(1), 1-24.

Park, I., \& Kim, J. (2007). Enculturation of Korean American adolescents within familial and cultural contexts: The mediating role of ethnic identity. Family Relations, 56(4), 403-412.

Pattanayak, D. P. (1991). Language, education and culture. Mysore, India: Central Institute of Indian Languages. 
Pattanayak, D. P. (Ed.). (1990). Multilingualism in India. Clevedon, UK: Multilingual Matters.

Porter, J. R., \& Washington, R. E. (1993). Minority identity and self-esteem. Annual Review of Sociology, Vol. 19, 139-161.

PS 100 in Watts, Los Angeles, California. (Video clip.) Retrieved from http://www.youtube.com/watch?v=h31qVYi70HE

Rappa, A. L., \& Wee, L. (2006). Language policy and modernity in Southeast Asia: Malaysia, the Philippines, Singapore, and Thailand. New York: Springer.

Rubdy, R. (2005). Remaking Singapore for the new age: Official ideology and the realities of practice in language-in-education. In A. Lin \& P. Martin (Eds.), Decolonisation, globalisation: Language-in-education policy and practice. Clevedon, UK: Multilingual Matters.

Spiecher, B. L., \& Bielanski, J. R. (2000). Critical thoughts on teaching Standard English. Curriculum Inquiry, 30(2), 147-169.

Tamura, E. H. (1996). Power, status, and Hawai'i Creole English: An example of linguistic intolerance in American history. The Pacific Historical Review, 65(3), 431-454. Retrieved from http://www.jstor.org/stable/3640023

United States Census Bureau Factfinder (2010). S1601, Language spoken at home by population 5 years and older, American community survey 1-year estimates. Retrieved from http://factfinder.census.gov/

United States Census Bureau, Population Division (2010). Table 4, Projections of the Population by Sex, Race, and Hispanic origin for the United States, 2010 to 2050 (NP 2008-T4). Overview of Race and Hispanic Origin: 2010. Release date: 2008. Retrieved from http://www.census.gov/

United States Census Bureau Statistical Abstract on Education (2011a). Table 225, Educational Attainment by Race and Hispanic Origin, 1970 to 2009. Retrieved from http://www.census.gov/

United States Census Bureau Statistical Abstract on Education (2011b). Table 268, High School Dropouts by Age, Race and Hispanic Origin: 1980 to 2008. Retrieved from http://www.census.gov/

United States Library of Congress, Federal Research Division. Country Profile: India. Retrieved from http://lcweb2.loc.gov/frd/cs/profiles/India.pdf

West Bengal Board of Secondary Education. (2010). Retrieved from file: http://wbbse.org/

Wiley T. G. (1996). Literacy and language diversity in the United States. Washington, DC: Center for Applied Linguistics. 


\title{
Literacy Programs for Incarcerated Youth in the United States
}

\author{
Diana Brace
}

\begin{abstract}
Incarcerated youth in the United States face many barriers to literacy learning. This paper collects and analyzes research on literacy programs in juvenile correctional facilities. The review of literature reveals a troubled institution lacking resources and clear solutions. Few articles deeply consider students' cultures, literacy identities, and voices. This discovery suggests that new approaches to research of incarcerated youth's literacy learning are needed. The paper calls for research that investigates and observes how literacy identities of incarcerated youth can be utilized to increase literacy learning both within and outside the correctional facility. The author further suggests that this goal could best be achieved by considering the theoretical frameworks of Bakhtin, Freire, and Peck, Flower, and Higgins.
\end{abstract}

\section{Introduction}

Incarcerated youth in the United States face many barriers to literacy learning. Yet research shows that participating in educational programs during incarceration reduces recidivism rates (Rozalski, Deignan, \& Engel, 2008). This literature review seeks to investigate the state of literacy education within juvenile educational facilities. While this review focuses on juvenile justice facilities in the United States, it could inform those working and researching in other educational settings where a diverse and marginalized population is not receiving adequate literacy instruction. These settings include adult correctional facilities and struggling urban and rural classrooms throughout the United States. The main research questions for this review of literature were broad: What do literacy programs in juvenile justice facilities look like? What kinds of instruction are effective? Why or why not? And how do cultural and institutional issues affect literacy learning in juvenile correctional facilities?

\section{Theoretical Frameworks}

The paper's perspective on literacy is informed by several theories, including Bakhtin (1994), Freire (2001), and Peck, Flower, and Higgins' (2001) “community literacy." These theories all promote critical literacy, and Freire (2001) and Peck et al. (2001) explicitly link learning literacy with creating social change.

Freire believes literacy is a critical tool of liberation for the oppressed to gain agency. Freire (2001) states: "[T]o acquire literacy is more than to psychologically 
and mechanically dominate reading and writing techniques. It is to dominate these techniques in terms of consciousness; to understand what one reads and to write what one understands; it is to communicate graphically" (p. 622). His overall philosophy, seeing literacy as a tool for liberation, condemns rote learning and teacher-centered classrooms. It encourages a culture of inquiry and critical thinking that asserts "an attitude of creation and re-creation, a self-transformation producing a stance of intervention in one's context" (p. 622). Freire (2001) wants students to "achieve critical consciousness so that they can teach themselves to read and write" (p. 627). His insistence on student agency in literacy learning is important in that it shifts power from the teacher to the student, calling for educators to be "partners of the students" (Freire, 2010, p. 75).

Peck et al. (2001) bring to light another crucial aspect in forging social change through literacy learning: forming new discourses through social practices. They refer to this "search for an alternative discourse" as "community literacy" (p. 575). The concept is grounded in problem-based learning, meaning students use literacy to solve a problem that affects them and their community. Under this view, students meet with other stakeholders in the community-some of whom are in direct conflict with the students' views-in order to resolve an issue they find problematic. By asking students to confront discourses that directly oppose their own, students are forced to "go beyond mere conversation to the delicate exploration of difference and conflict and toward the construction of a negotiated meaning" (p. 578). These conversations can result in "hybrid texts and discourses" (p. 580), meaning that the two discourses clash and recombine by the power of the conversation participants, creating a new discourse. Thus, the students' voices are legitimized, and they are active in constructing the change that they are seeking. Subsequently, when the students create a "hybrid text" by publishing, as exemplified in Peck et al., a newsletter that contained practical action steps alongside raps and commentary, they perpetuate the conversation into a different time and place, hopefully leading to further understanding and resolution. It also can further legitimize the shared discourse and maintain a respectful relationship between students and administration that was not there before the "hybrid discourse" emerged. This will hopefully lead to continued work toward goals bridging once hostile communication gaps within a community.

Students' conversations with community stakeholders in the research of Peck et al. (2001) demonstrate a strong resemblance to Bakhtin's theory of heteroglossia. Through conflict between the "outer forces and inner voices" (Peck et al., p. 581), or as Bakhtin would describe it, the struggle between the centripetal (dominant discourse) and centrifugal (stratifying, personal discourses) forces, discourse participants can "reveal ever newer ways to mean" (Bakhtin, 1994, p. 79). Just as community literacy guides students toward critical literacy by prompting them to consider their audience and the context of their audience's response, so does Bakhtin (1994) describe the dialogic between the speaker and listener: "[The speaker's] orientation toward the listener is an orientation toward a specific conceptual horizon, toward the specific world of the listener" (p. 76). This is a perspective grounded in the generative nature of social interaction. Peck et al. 
(2001) use this perspective to promote the creation of new discourses that can work toward social change within communities.

\section{Findings in the Literature}

A thorough search of scholarly online journals produced few results directly examining the effectiveness of literacy programs within juvenile correctional facilities. Several articles found echoed the fact that there is a dearth of research specifically addressing literacy instruction in juvenile correctional facilities (Foley, 2001; Krezmien \& Mulcahy, 2008; Mulcahy, Krezmien, Leone, Houchins, \& Baltodano, 2008; Rogers-Adkinson, Melloy, Stuart, Fletcher, \& Rinaldi, 2008). The majority of articles found were literature reviews or descriptive of research and data. Most of the literature also cited a 1997 study from The Center on Crime, Communities, and Culture, which claimed that helping students gain educational skills is one of the greatest ways to prevent future recidivism (Drakeford, 2002; Leone, Krezmien, Mason, \& Meisel, 2005; Malmgren \& Leone, 2000; Morrison \& Epps, 2002).

Findings from the literature are best categorized by instructional and systemic factors affecting literacy instruction. Throughout the literature instructional methods, materials, and the instructors using them are discussed. Further described are the student populations within United States juvenile correctional facilities. Systemic factors touched upon include structural culture and policy.

\section{Instruction}

Methods \& Materials. Most articles agree that a focus on remediation and drill and practice techniques are outdated and ineffective for the majority of students within juvenile correctional facilities. Foley (2001), Morrison \& Epps (2002), and RogersAdkinson et al. (2008) all noted an emphasis on tutoring and direct instruction. One study (Malmgren \& Leone, 2000) used a range of instructional techniques and materials (these are described in further detail below). Several other articles suggested implementing a variety of practices (Collier \& Thomas, 2001; Morrison \& Epps, 2002; Rogers-Adkinson et al., 2008). Both Collier and Thomas (2001) and Morrison and Epps (2002) focus on engaging in culturally relevant texts and literacy practices with incarcerated students. Rogers-Adkinson et al. (2008) describe several "key components of reading intervention" that include offering texts that are "culturally sensitive, meaningful to youth, highly engaging, and inclusive and respectful” (p. 207). This article also mentions the successful impact of Collaborative Strategic Reading (CSR) on comprehension for students with reading disabilities, second language learners, and struggling readers (p. 206). CSR groups students by literacy levels to help each other employ meta-cognitive reading strategies.

Additionally, the Corrective Reading series is used frequently in studies validating the effectiveness of direct instruction with incarcerated teenagers (Drakeford, 2002; Malmgren \& Leone, 2000; Mulcahy et al., 2008) This program is a commercial, scripted instructional reading model published by McGraw-Hill and 
developed by Science Research Associates (Rogers-Atkinson et al., 2008). It contains two strands, decoding and comprehension, and provides materials for four reading levels (Corrective Reading website). Drakeford (2002) used Corrective Reading and achieved positive results in his eight week study of reading students in a correctional facility in Maryland that houses male and females aged 12 through 21. He utilized a single-subject multiple baseline study using the program and a sample size of six (two groups of three) students who were all African American males with low reading scores and a mean age of 17 . Students gained in oral reading fluency scores, grade level placements, and claimed an improved attitude toward reading. Malmgren and Leone (2000) used the Corrective Reading curriculum in combination with whole language approaches and teacher read-alouds. The researchers designed a six-week study using pre-tests and post-tests for teenagers in a juvenile detention facility. The study found significant gains in reading rate, accuracy, and rate and accuracy combined, though no significant gains were found in reading comprehension. The researchers also cited a loss of almost $50 \%$ of their original sample size, ending with 45 African-American male participants, averaging 17 years of age. Mulcahy and her colleagues (2008) stated in their study that "[t]he instructors had difficulty maintaining participant involvement with the Corrective Reading series," citing "student disdain" for the Corrective Reading portions of the program (p.249). This led Mulcahy et al. (2008) to find and develop their own instructional materials that included age-appropriate texts for students reading at a lower level and activity sheets to accompany Read Naturally passages (p.243). They further suggest that researchers continue to "develop curriculum materials and assessments appropriate for this population of youth" (p.244).

\section{Students \& Instructors}

Diversity of student population. The achievement gap found in public schools between minorities and Caucasian students is similarly evident in correctional facility education programs (Rogers-Adkinson et al., 2008). There is a pronounced over-representation of minorities, particularly African-American males, within juvenile correctional facilities (Leone et al., 2005; Morrison \& Epps, 2002). Leone et al. (2005) provided some staggering statistics:

The long-standing pattern of disproportionate arrest and incarceration of minority juveniles is a disturbing national problem (Poe-Yamagata \& Jones, 2000). Over-representation is especially pronounced for African-American youth who constitute $14 \%$ of the overall population ages 10 to 17 but $40 \%$ of all incarcerated juveniles nationally and are 5 times more likely to be incarcerated than Caucasian youth (Sickmund, 2004). Latino and Native American youth are 2.5 times more likely to be incarcerated than Caucasian youth (Poe-Yamagata \& Jones, 2000). (pp. 91-92)

Leone et al. (2005) follow these statistics with a call for more "culturally relevant curriculum" (p. 92), though they never explicitly state what such a curriculum would look like. 
There is also an over-representation of students with emotional disturbance (Malmgren \& Leone, 2000), as well as behavioral and learning disabilities (Foley, 2001; Krezmien et al., 2008; Morrison \& Epps, 2002; Rogers-Adkinson et al., 2008). Some states have reported that between $60 \%$ to $70 \%$ of incarcerated youth receive special education services (Leone et al., 2005, p. 91).

Collier and Thomas (2001) address the English language learner population within US correctional facilities, advising educators to transplant research-based English as a second language instructional practices into the correctional facility setting. They advocate bilingual education, teaching the second language through content, and teaching literacy in the student's primary language. They further address emotional and sociocultural needs of learners.

In their 2006 literature review, Harris, Baltodano, Artiles, and Rutherford detail the lack of research integrating culture into instruction, as well as the "absence of cultural considerations when teaching and evaluating incarcerated youth" (p. 761). Like Collier and Thomas (2001), Harris et al. (2006) urge those educating the diverse population of incarcerated youth to recognize "youth's sociocultural contexts of literacy" (p. 753)-an important factor when providing authentic and meaningful literacy practices to these students that "may not perceive school literacy to be a valuable skill" (p. 753).

Here may be an appropriate time to expand on the disconnect between "school literacy" - one often reiterated in juvenile correctional facility classrooms as noted in the literature review of Harris and her colleagues (2006)-and the literacies of the ethnically diverse population of students most often found in these facilities. The "school-to-prison-pipeline" is a term used to describe why there is the previously described over-representation of minorities in juvenile correctional facilities and prisons. Winn and Behizadeh (2011) provide a concise summary of the school to prison pipeline literature. They delve into literacy as a civil right, and how this right has been denied to many students in poor, urban, predominantly minority populated areas. The authors note that a "focus on basic skills, remediation, and overzealous test preparation" are the problems faced by classrooms populated by students of color (p. 150). They go on to chide the irony of No Child Left Behindmeant to close the achievement gap, when in actuality, NCLB is only widening the gap by implementing a decreasingly rigorous curriculum meant only to prepare students for high-stakes testing, not critical thinking (p. 152). Such curriculum has been criticized for its "subordination of knowledge and identity historically experienced by marginalized groups" (Lipman, 2008 as cited in Winn \& Behizadeh, 2011, p. 152). The curriculum described brings to mind Freire's notion of "banking education", in which the oppressed are merely fed knowledge by their teacher rather than engaged in critical and empowered thinking. It is this sort of "banking"type schooling that the authors' claim promotes high dropout rates that can lead to incarceration-i.e., the school-to-prison pipeline. As mentioned above, research has found that this type of remediation and drill and skill curriculum is prevalent in juvenile correctional facility classrooms in the United States. 
Instructors. Many articles noted a scarcity of highly qualified or certified instructors in juvenile correctional facilities. Instructors may lack knowledge of reading instruction best practices. Several articles reported staff with low selfefficacy, low morale, and a reluctance to cooperate with researchers (Drakeford, 2002; Krezmien \& Mulcahy, 2008; Malmgren \& Leone, 2000; Mulcahy et al., 2008. More on correctional facility culture below.) Leone et al. (2005) also found that instructors can feel isolated from professional development opportunities and the educational community in general (p. 94). At the same time, it may be difficult for instructors to form relationships with students due to the correctional environment (Rogers-Adkinson et al., 2008; Taymans \& Corley, 2001). This disconnect in turn affects students, because Rogers-Adkinson et al. (2008) note that students within correctional facilities may value and consider their relationships with educators important to their future success. Suggestions from Taymans and Corley (2001) for improved relationships between instructional and correctional staff at adult facilities are mentioned below in the broader context of correctional culture and systemic issues.

\section{Correctional Culture \& Systemic Issues}

Although the purpose of much of the literature was to discuss incarcerated youth's academic struggles, many studies briefly touched on contextual factors that affect how those strategies are successful or not successful in the classroom. According to the research, collaboration between all stakeholders, from sheriff to correctional officer, from social worker to teacher, is imperative in providing as much consistency as possible to enable student learning (Drakeford, 2002; Leone et al., 2005; Taymans \& Corley, 2001). Several articles mentioned disagreements between correctional officers and educators, as well as correctional officers and researchers (Drakeford, 2002; Leone et al., 2005; Mulcahy et al., 2008). Leone et al. (2005) state: "[C]orrections and education personnel working within the same juvenile facility may have conflicting perspectives about whether punishment and control or rehabilitation and treatment should be the governing principles for youth incarceration" (p. 93). Drakeford (2002) explicitly addresses the need to change "institutional culture" (p. 143) in order to incentivize educational improvement. One way this could be done is through increased communication between staff and students which in turn can increase staff's awareness of the incarcerated youth's situations, as further described below by Taymans and Corley (2001).

Due to the high percentage of students with learning disabilities, Taymans and Corley (2001) also note the need for all correctional facility personnel to have an awareness and "understanding of learning disabilities, their manifestations, and their consequences" (p. 74). Through this awareness, the correctional culture may become more receptive to issues faced by inmates with learning disabilities, and work to provide educational opportunities to these inmates. While the authors discuss learning disabilities in particular, one could see how educating correctional officers and staff about other aspects of the youth's lives and cultures could prove beneficial to both the youth and those working in the correctional facilities. 
On a broader structural level, Taymans and Corley (2001) sought to provide suggestions for systemic reform within educational programs for correctional facilities. Their article solely discussed US adult correctional facilities, reiterating the need for further exploration into the culture of juvenile correctional facilities in the United States. They focused on collaboration, setting shared goals, gathering resources and funds, providing adequate professional development to improve instruction, and assessing whether these reforms have achieved better learning for inmates with learning disabilities.

Overall, Mulcahy et al. (2008) highlight the role of law and policy in the problem of educating incarcerated youth: "[T]he absence of policy guidelines for education and special education services in juvenile corrections highlights a situation in which a marginalized group of children may be denied the right to an education that is afforded to their peers in public schools" (p. 240).

\section{Research Analysis \& Implications \\ Lack of Cultural and Critical Perspectives on Literacy}

While many articles acknowledge the diversity and common over-representation of minorities within juvenile correctional facilities, few provide substantial practical suggestions. This may be due in part to the quantitative design of the research, as well as the focus on special education instruction. The focus appears to be on the methods of instruction taught in the classroom, and not the knowledge the students bring to the classroom. This apparent disregard in the literature of researching-or clearly defining-culturally responsive instruction is problematic.

While Drakeford (2002) and Malmgren and Leone (2000) had some success with certain direct instruction materials, there is little other evidence to suggest direct instruction will consistently work within a correctional facility. Does direct instruction work on its own? (Malmgren and Leone (2000) used whole language approaches and teacher read-alouds along with the Corrective Reading direct instruction materials.) What other instructional methods can supplement direct instruction in order to provide students with greater access to the texts?

Collier and Thomas (2001) engage the reader in a perspective that values students' voices, knowledge, and cultural backgrounds. Yet, they do not fully integrate the implications of their theories and practice for English language learners so they can be applied to students within the correctional setting. Instead, the authors advocate for the transference of best practices for ESL students into correctional facilities. This transfer is appropriate to an extent, but it fails to consider a multitude of other factors that exist within a correctional facility that may not be addressed through what are considered best practices in a different setting.

How can research connect the instructional methods research found in several studies with the more sociocultural and anthropological perspective Collier and Thomas (2001) took? As mentioned above, Rogers-Adkinson et al. (2008) offer ideas for differentiated instruction with cultural background and student engagement in mind. These ideas-especially providing students with a variety of 
texts they may connect to and opportunities for collaborative group learning-are a great start. But none of these proposed strategies have been fully researched within a correctional facility. How effective would they be?

While Drakeford (2002) and Malmgren and Leone (2000) focus on special education instruction in a treatment study design, they rightfully seek to address the need for intensive, time-sensitive reading instruction for adjudicated youth (youth being detained until formal sentencing). This can be a time when little educational progress is made due to the uncertainty of the youths' situations. Thus, research on intense intervention that can be implemented when possible during this flux period is needed.

\section{Problems in Correctional Culture and Systemic Issues}

Throughout the literature on correctional education, there are cries for collaboration and a shared goal of putting rehabilitation first. If correctional educators are in conflict with facility administration or officers, student learning can be pushed aside. Things are further complicated when researchers are brought into the facility. How do you balance the focused interest of researchers attempting to improve literacy practices, with the broader interests of the correctional personnel on site every day?

Underlying many of these systemic problems-philosophical conflicts between staff and educators, a lack of qualified educators, as well as inconsistent student attendance and high student turnover rates-are policies and laws over which the educator has little influence. While more difficult to change, it is important to acknowledge and understand the effect that state and federal policy and law have on how incarcerated youth are treated and educated. Even though inmates under 21 are required by law under the Elementary and Secondary Education Act to be offered educational services within correctional facilities (Foley, 2001), students are not receiving high quality educational services. This has resulted in numerous lawsuits and investigations at the state and local levels to bring juvenile correctional facility educational programs in sync with federal law (Mulcahy et al., 2008). How can these broader institutional issues be addressed in research? How can these issues be addressed within the literacy classroom where we find those most affected by these policies and laws - the inmates?

Taymans and Corley (2001) rightfully address the importance of obtaining and maintaining sources of funding and materials by corralling stakeholders and community organizations to, in a way, "sponsor" literacy. Taking these "sponsors of literacy" (Brandt, 2001) into account is worthwhile when researching the cultural and systemic-or the more global-details of literacy learning within a juvenile correctional facility. What materials are in the classroom? Who is providing these materials? What resources are missing and why? How does the lack of resources affect incarcerated youth's motivation to learn? 


\section{Issues in Research Methodology}

As mentioned above, the majority of research in this area is descriptive data analysis, with two quantitative, empirical studies using a treatment research design. The difficulty in administering valid quantitative studies is admitted within a few of articles themselves. Mulcahy et al. (2008) stated that the level of quantitative research now valued "may not be possible in all juvenile corrections facilities because of the highly volatile nature of the settings" (p. 250). Krezmien and Mulcahy (2008) noted "the absence of an emphasis on intensive empirically validated reading programs in juvenile corrections settings contrasts with the current push from the No Child Left Behind Act of 2001 (2002) to implement systematic and scientifically based reading programs" (pp. 221-222). Yet perhaps because of this push, researchers continue to suggest further quantitative methods rather than mixed methods or qualitative research. Peck et al. (2001) call for mixed methods within community literacy that I believe applies well to the need to expand research options within juvenile correctional facility literacy programs: "But a robust community literacy must embrace multiple kinds of inquiry-from systematic analyses to personal reflections in which both community and university people develop an awareness of the practices they bring and the ways they might be adapted" (p. 586).

Mulcahy et al. (2008) discussed the challenges facing reading researchers wanting to design valid quantitative studies within juvenile correctional facilities. These challenges include: difficulties collaborating with administrators, decreasing sample size due to release dates, inadequate materials and instructional settings, as well as sporadic student schedules. The article also noted that reading researchers must yield to research from the special education field because of the lack of research within youth correctional facilities (p. 241).

Due to the difficulties that have arisen within these quantitative studies, perhaps researchers should consider different methods. Morrison and Epps (2002) supplemented their data analysis and instructional suggestions with case studies. Exploring incarcerated youths' literacy through ethnographic research would prove beneficial in understanding the literacies that they carry with them into the correctional education setting, and what literacies they will leave that setting with. By critically investigating and observing the literacies of incarcerated youth, we may better "make use of the students' linguistic and cultural knowledge to bridge to new knowledge" (Collier \& Thomas, 2001, p. 68).

Again, many researchers tout statistics and surveys to depict the dilapidated state of the United States' juvenile justice educational system. They detail the overrepresentation of minorities and students with disabilities. It should be noted that these are issues often faced in adult correctional facilities and disadvantaged urban and rural classrooms in the United States, as well. These are incredibly important to acknowledge, but it is time to move beyond reporting and time to start using what we know to look for new ways to attend to the problems entrenched in juvenile justice facilities. 


\section{Implications for the Correctional Classroom}

The students within correctional facilities have very little power. They are told where they go, what they do, and when. There is a crucial place for literacy learning within this environment that, while not overlooked, hasn't been considered to the extent it should. While incarcerated youth may not have the typical academic literacy skills valued by our society, they carry literacies into the facility. Through the proposed theories, they could be able to leave with additional literaciesconstructed from their own literacies.

Due to the diversity within a youth correctional facility, an instructional theory or framework must be one that can be applied to a heterogeneous group of students who have different cultures, languages, literacy abilities, and experiences. One must also note the unique educational environment found in correctional facilities-one of limited freedoms and resources for students. Adolescents are often suspicious of authority-imagine students who must deal with coercive adults nearly every day while incarcerated. With these challenges in mind, Bakhtin (1994), Freire (2001), and Peck et al. (2001) provide glimpses into applicable theoretical frameworks.

Bakhtin (1994) provides a basis for understanding that language is constantly evolving through conversations with others and with ourselves. His notion of heteroglossia also pertains to incarcerated youth as they struggle against a dominant discourse of which they are not a part. By making students aware of the dominant discourse in a way that highlights this struggle, rather than asking them to assimilate to the discourse, students may come away with new meaning.

Freire (2001) and Peck et al. (2001) describe a "process"-there is a visible framework for implementation. Freire's process and "community literacy" are structures that can be adapted and also work toward social change.

It would be interesting to see how Freire's (2001) process of teaching basic literacy through culturally relative generative words-words that come from the learners' culture and experiences from which literacy instruction can be built upon -would work within a correctional facility. Freire's process has been shown to work in an astonishingly short amount of time (p. 627). Freire wants students to "achieve critical consciousness so that they can teach themselves to read and write" (p. 627). This is imperative when considering that educators within juvenile correctional facilities often have students for only a brief period of time. There is an urgency to motivate and teach students how to teach themselves.

As mentioned above, students within correctional facilities have very little power. Whether or not their crimes warrant this loss of power is not the issuethey are there, and have the right to an education. With this context in mind, one can see how the framework of community literacy (Peck et al., 2001) could act as a mediation tool between student inmates, correctional officers, and facility administration. If an open, intercultural dialogue can be established between a literacy class of incarcerated youth and correctional officers, students can not only increase literacy skills in an authentic manner, but also work toward improving 
structural problems using that literacy. Critical thinking skills developed through the community literacy framework can be used outside of the classroom. Perhaps most importantly, the framework allows students to have agency in their learning, hopefully demonstrating to the incarcerated youth the power their voices have to challenge the dominant discourse, construct new meaning, and solve problems.

One can see how these theories express themselves in creating new studentled discourses with The Insight Project, part of a New York City Alternative to Incarceration Program that includes students who are involved in the criminal justice system (Vasudevan, Stageman, Jay, Rodriguez, Fernandez, \& Dattatreyan, 2010). Here students engage in storytelling, improvisation, and dramatic performances. As the improvisations turned to scripts and rehearsed lines, students began to critically view the characters they had created, considering multiple perspectives pushed by critical dialogue with their teacher. Thus, rehearsals "became spaces for the youth to re-imagine the script they would perform on stage, as well as spaces within which to rehearse and re-script their own life narratives" (p. 62). They create new discourses and identities through literacy practices. After performances, students engaged in talkbacks, where audience members would ask the students questions. The talkbacks provided another venue for generating new discourses, allowing students "to portray themselves outside of the stereotypes and familiar expectations of posturing that followed them across contexts" (p. 63). This harkens to Bakhtin's notion of pushing against the dominant discourse with unique literacies, as well as the generation of new meaning through the dialogic between speaker and listener.

They are also, in a sense, engaging in community literacy as they work with teachers and other stakeholders to create a new discourse in the form of a play for a community audience. In facing questions during talkbacks, the students may dialogue with those who may not agree with or understand their narrative. This pushes students to again create new discourses as they work to answer the audience's questions in a meaningful way. Furthermore, these talkbacks place the students in the role of teacher-consistent with Freire's theories of student agency-the audience learning from the Insight Project participants' experience. One participant of the program is provided further authority and agency over the discourse by being named a coauthor on the article.

In addition to providing open spaces for students to author themselves, the program takes the Freirian notion of generative themes mentioned above. Each script begins with the words created during student improvisation, thus plays are built upon the cultural knowledge and experiences of the students-not of the teachers.

As Vasudevan and her coauthors (2010) note, while "institutions of education and justice are often characterized as sites of oppression, there are hopeful and generative possibilities for imaginative education within the institutional walls" (p. 64). If students are provided the space to demonstrate agency and create new discourses they may leave incarceration with new literacies that can better solve problems and lead an effort toward social change. 


\section{Potential Problems}

Freire's (2001) focus on basic literacy is certainly applicable to the number of incarcerated youth who are illiterate. Has Freire's process been attempted within the United States? If so, has it been effective? Even though the particular process of using generative words to build literacy may not be applicable to adolescents in youth correctional centers, his notion of "appropriating the mechanism critically... to produce..."(p. 625) could be translated to certain genres of writing and speaking. Vasudevan et al.'s (2010) work shows how his theories could be applied to writing and speaking, and further thought and research should investigate the possibilities of The Insight's Project's approach with detained youth.

The community literacy approach also contains some limitations. We are unsure of the literacy levels of the participants involved, but from the writing examples, it is evident that the students are writing above the fourth grade level [what is considered the average level of reading for incarcerated youth (Drakeford, 2002; Foley, 2001; Malmgren \& Leone, 2000)]. While students do not necessarily need to be reading at grade level in order to think critically, if the community literacy framework were to be implemented, educators may need to supplement instruction in reading and writing for students struggling or with learning disabilities. The framework could provide the authentic motivation for struggling students to work toward improving their basic skills.

Bakhtin (1994), Freire (2001), and Peck et al. (2001) all battle with issues of power and dominance within speech genres, discourses, and literacy learning. These power struggles can be exacerbated in the emotional environment of a correctional facility. The reason why educators may be hesitant in initiating intercultural conversations that look critically at power in the classroom is aptly put by Peck et al. (2001): "The agenda of integrating cultural practices draws us into a value-laden tangle of decisions about power" (p. 574). Building enough trust between educator and students to navigate through this uncomfortable "tangle of decisions about power" within intercultural dialogue may be the greatest challenge to literacy educators in correctional facilities. The community literacy framework offers needed practical solutions, but without the initial push for intercultural dialogue from all stakeholders, the entire framework is inapplicable. How easily could this framework fall apart with a sudden shift in power or loss of trust? And what correctional facility would believe in an instructional plan that gave power to the inmates they are attempting to keep under control? This question returns us to the fundamental conflict in philosophies noted in Leone et al. (2005): "punishment and control or rehabilitation and treatment" (p. 93).

\section{Conclusion and Further Directions}

It is obvious from the research that more needs to be done to promote a passion for inquiry among incarcerated youth. Unfortunately, the institutional barriers are daunting, and the diversity of the population within these correctional facilities can make instructional planning more difficult. What is missing from most of this research is the promotion of agency in the learner, the need to "nourish the critical 
spirit" (Freire, 2001, p. 628), so that students may leave incarceration with a renewed sense of confidence in their voice and ability as a learner.

As we attempt to look closer to the local cultural context of each student, we also need to investigate the variety of external, global factors. Like the public school system, the correctional education system is diverse-not only in student population, but in facility offerings and conditions. They include youth and adult populations, state and federal facilities, cultures of rehabilitation and cultures of punishment. It's my hope that the theories and research in this literature review can potentially guide educators and researchers throughout the diverse criminal justice system, as well as lower-socioeconomic public school classrooms. Additionally, researchers should consider the dominant discourse that pushes against the call for improved literacy education for inmates. What are current public opinions of the juvenile justice system and how best to handle the issue? Is there any political will? While we've seen growing concern on the federal level from the Department of Education in regards to preventing high school dropout, does this translate to aid and research for incarcerated youth? Is the level of support real or rhetorical? The entanglement of correctional education with politics and law makes the search and implementation of solutions that much more difficult at the same time the need for solutions becomes more urgent.

\section{References}

Bakhtin, M. M. (1994). The dialogic imagination. (Trans. M. Holmquist \& C. Emerson.) In P. Morris (Ed.), The Bakhtin reader: Selected writings of Bakhtin, Medvedev, Voloshinov (pp. 74-80). London: Edward Arnold. (Original work published in 1935).

Brandt, D. (2001). Sponsors of literacy. In E. Cushman, E. R. Kintgen, B. M. Kroll \& M. Rose (Eds.), Literacy: A critical sourcebook (pp. 555-571). Boston: Bedford/ St. Martin's.

Collier, V. P., \& Thomas, W. P. (2001). Educating linguistically and culturally diverse students in correctional settings. Journal of Correctional Education, 52(2), 6873.

Corrective Reading. (n.d.). Retrieved from http://www.mcgrawhill.co.uk/sra/correctivereading.htm

Drakeford, W. (2002). The impact of an intensive program to increase the literacy skills of youth confined to juvenile corrections. Journal of Correctional Education, 53(4), 139-143.

Foley, R. M. (2001). Academic characteristics of incarcerated youth and correctional educational programs: A literature review. Journal of Emotional and Behavioral Disorders, 9(4), 248-259. 
Freire, P. (2001). The adult literacy process as cultural action for freedom and education and conscientização. In E. Cushman, E. R. Kintgen, B. M. Kroll \& M. Rose (Eds.), Literacy: A critical sourcebook (pp. 616-628). Boston: Bedford/St. Martin's.

Harris, P. J., Baltodano, H. M., Artiles, A. J., \& Rutherford, R. B. (2006). Integration of culture in reading studies for youth in corrections: A literature review. Education and Treatment of Children, 29(4), 749-778.

Krezmien, M. P., \& Mulcahy, C. A. (2008). Literacy and delinquency: Current status of reading interventions with detained and incarcerated youth. Reading \& Writing Quarterly, 24, 219-238.

Leone, P. E., Krezmien, M., Mason, L., \& Meisel, S. M. (2005). Organizing and delivering empirically based literacy instruction to incarcerated youth. Exceptionality, 13(2), 89-102.

Malmgren, K. W., \& Leone, P. E. (2000). Effects of a short-term auxiliary reading program on the reading skills of incarcerated youth. The Education and Treatment of Children, 23(3), 239-247.

Morrison, H. R., \& Epps, B. D. (2002). Warehousing or rehabilitation? Public schooling in the juvenile justice system. Journal of Negro Education, 71(3), 218-232.

Mulcahy, C. A., Krezmien, M. P., Leone, P. E., Houchins, D. E., \& Baltodano, H. (2008). Lessons learned: Barriers and solutions for conducting reading investigations in juvenile corrections settings. Reading \& Writing Quarterly, $24,239-252$.

Peck, W.C., Flower, L., \& Higgins, L. (2001). Community literacy. In E. Cushman, E. R. Kintgen, B.M. Kroll \& M. Rose (Eds.), Literacy: A critical sourcebook (pp. 572587). Boston: Bedford/St. Martin's.

Rogers-Adkinson, D., Melloy, K., Stuart, S., Fletcher, L., \& Rinaldi, C. (2008). Reading and written language competency of incarcerated youth. Reading \& Writing Quarterly, 24, 197-218.

Rozalski, M., Deignan, M., \& Engel, S. (2008). The world of juvenile justice according to the numbers. Reading \& Writing Quarterly, 24, 143-147.

Taymans, J. M. \& Corley, M. (2001). Enhancing services to inmates with learning disabilities: Systemic reform of prison literacy programs. Journal of Correctional Education, 52(2), 74-78.

Vasudevan, L., Stageman, D., Jay, J., Rodriguez, K., Fernandez, E., \& Dattatreyan, E. G. (2010). Authoring new narratives with youth at the intersection of the arts and justice. Perspectives on Urban Education, 7(1), 54-64.

Winn M. T., \& Behizadeh, N. (2011). The right to be literate: Literacy, education, and the school-to-prison pipeline. Review of Research in Education, 35, 147-173. 


\section{ENGLISH AS A SECOND AND FOREIGN LANGUAGE}




\title{
Strategy-Based Reading Instruction Utilizing the CALLA Model in an ESL/EFL Context
}

\author{
Young-Mee Suh
}

\begin{abstract}
This paper describes four English reading instruction approaches which are primarily used in ESL/EFL reading classes: Experience-Text-Relationship, the Reciprocal Teaching Approach, Transactional Strategy Instruction, and the Cognitive Academic Language Learning Approach. Each reading approach is based on reading strategy instruction, and students are considered active learners in these paradigms. The CALLA model in particular puts emphasis on both language and content development while teaching strategies explicitly. Considering that the CALLA model is based on promotion of language and content at the same time, it can be a desirable instructional model in ESL/EFL reading classes. Targeting postsecondary school students whose English reading proficiency levels are in between intermediate and high-intermediate, this paper illustrates each stage of the CALLA instructional model and provides a sample lesson plan. ESL/EFL teachers may utilize the demonstration or the lesson plan in a real teaching situation to help learners be successful ESL/EFL readers while increasing their content knowledge and language proficiency.
\end{abstract}

\section{Introduction}

There has been much research emerging concerning effective ways of teaching English reading comprehension to L1 learners using strategy-based reading instruction (Dole, Duffy, \& Pearson, 1991; Kusiak, 2001). The L1 strategy-based reading studies have shown that students' comprehension abilities improve when they are taught to use comprehension strategies. Recently, to enhance students' comprehension in reading English texts, L1 researchers have focused on implementing multiple strategies in the classroom. They suggested that teachers should teach varied strategies or combinations of them rather than focusing on a given strategy exclusively (Alfassi, 1998; Vaughn \& Klingner 1999).

Interestingly enough, however, there have been relatively few studies on effective reading strategy training for second language students. Research in the field of L2 reading instruction has not addressed strategic engagement with texts, and consequently, many ESL learners struggle with reading, especially in the context of university content courses (Nist \& Diehl, 1990). More studies on strategy-based reading instruction in $\mathrm{L} 2$ contexts need to be done to see whether success in L1 
contexts in terms of strategy-based reading instruction can be replicated in L2 contexts.

In this paper, I will describe the Cognitive Academic Language Learning Approach (CALLA) in Chamot and O'Malley (1997) as a way of teaching strategybased reading to ESL/EFL learners. I will also illustrate how to teach reading to ESL/EFL readers utilizing the CALLA approach. For this purpose, I will first introduce and compare the four main L2 reading approaches; that is, ExperienceText-Relationship (ETR), the Reciprocal Teaching Approach (RTA), Transactional Strategy Instruction (TSI), and the Cognitive Academic Language Learning Approach (CALLA). I will focus on the CALLA method, describing it in detail and offering a lesson plan as an illustration of how this approach can be applied in the classroom. I focus especially on CALLA because students are able to learn how to use strategies to enhance content knowledge, L2 reading, and other skills at the same time. ESL/EFL teachers will be able to utilize this lesson plan in their reading classes to help ESL/EFL learners bolster their reading proficiency at the grade school level.

\section{Literature Review}

As in L1 reading instruction, approaches to ESL reading instruction have shifted from the drill-based practice models to more cognitively based comprehension models. Much research has focused on effective combined reading strategies within the L1 context (Baker, 2002; Brown, 2002; Duke \& Pearson, 2002; Pressley, 2002a, 2002b; Trabasso \& Bouchard, 2002). Trabasso and Bouchard (2002) identified individual reading strategies which have important influences on L1 reading comprehension. Duke and Pearson (2002) reviewed effective instructional strategies in L1 reading comprehension. Baker (2002), Brown (2002), and Pressley (2002a, 2002b) found that instruction of multiple strategy use is more effective than individual strategy instruction.

Compared to L1 reading strategy research, however, there is relatively little L2 research on strategic reading instruction, especially in EFL contexts. More research needs to be done within the field of L2 reading instruction in order "to develop strategic engagement with texts to help ESL students promote reading comprehension skills" (Grabe, 2004, p. 55).

Recently, in the EFL context, there have been a few studies on teaching reading strategies in English reading programs. More specifically, several studies investigated the effectiveness of explicit English reading strategy instruction on the positive improvement of Korean college students' reading ability of English texts (Kim, 2006; Lee, 2007; Park, 1996; Song, 1998). For example, Song (1998) taught college students reading strategies with newspaper articles in English. The students were trained to self-report on how they read the articles. The strategy training showed that the students enhanced their ability to understand readings in English, and their reading speed to find out what happened in the story became faster. Lee (2007) taught six reading strategies to college students and found that students' attitudes toward strategy training became more positive after practicing with familiar grammar-related activities. 


\section{Instructional Approaches}

According to Grabe (2004), in L1 reading research, 10 approaches-KWL (Know, Want to know, Learned), ETR (Experience-Text-Relate), QAR (Question-AnswerResponse), DR-TA (Directed Reading and Thinking Activities), Reciprocal Teaching, CSR (Collaborative Strategic Reading), Direct Explanation, Questioning the Author, TSI (Transactional Strategies Instruction), and CORI (Concept-Oriented Reading Instruction-are commonly taught as effective reading strategies. In this paper, among the ten reading instruction approaches, only four reading strategy approaches-ETR, RTA, TSI, and the CALLA-were reviewed for reading comprehension strategy instruction in ESL/EFL contexts. The first one is the ETR approach.

\section{Experience-Text-Relationship Approach}

According to Lawrence (2007), the ETR approach was originally associated with Kathrin $\mathrm{Au}$. Young Hawaiian children were instructed with the ETR approach and were found to comprehend better than those children who were not $(\mathrm{Au}, 1977)$. The ETR model aims to activate students' prior knowledge and experiences to enhance both reading motivation and comprehension. It has three basic ingredients: (1) experience, (2) text, and (3) relationship. The first step is the experience part. The teacher encourages students to discuss their experiences or background knowledge related to the story or topic of the study. By asking the learners discussion questions about the story, a motivating reading environment can be created. Next, the teacher tells the learners to read the text and asks them comprehension questions to check their understanding of the text. Finally, the teacher relates what learners discussed to their prior knowledge. Carrell, Pharis, and Liberto (1989) used this model to teach bilingual university students, and the results showed that the students trained in the ETR model improved their comprehension of TOEFL passages the most of all the groups tested. They were also able to make semantic maps with no scaffolding after being trained with this approach.

\section{Reciprocal Teaching Approach}

The RTA was originally proposed by Palinscar and Brown $(1984,1986)$ based on a cognitive-constructivist theory of reading. In the RTA, the reader is expected to use his or her prior knowledge to comprehend the text, under the assumption that reading is a meaning-making process. The role of the teacher within this model is to scaffold the students by modeling reading strategies including generating questions, clarifying text, summarizing and making predictions. More specifically, the teacher summarizes the passage first. Then the teacher generates questions about the passage. Next, the teacher predicts the following passage. Finally, the teacher clarifies the key points showing "critical evaluation of the passage in terms of consistency and compatibility with prior knowledge and common sense" (Song, 1998, p.45).

The teacher is primarily responsible for the initial instruction, but the responsibility is gradually transferred to the students. The students are often 
divided into groups, and each group discusses the text including summarizing, asking questions, clarifying misunderstandings, and generating predictions. Song (1998) investigated this model in an EFL context in Korea, and the results showed that the students who had the lowest comprehension scores initially improved the most after receiving instruction using this technique. Padron (1992) examined the effects of reciprocal teaching combined with the Question-Answer-Relationships approach in Hispanic bilingual elementary school students. Students instructed using the reciprocal teaching approach were shown to use more strategies, including summarizing and self-generated questions, which were positively related to reading achievement.

\section{Transactional Strategy Instruction}

According to Allen (2003), Michael Pressley is considered the designer of TSI. Similar to the RTA, the TSI model is based on a constructivist point of view. Teachers of TSI believe that "learners who construct their own knowledge of subject areas rather than being taught such knowledge have a greater ownership of the material" (Allen, 2003, p. 326). With this assumption, the TSI teacher usually starts his or her lesson by explaining strategies that will be used in the class. Then the teacher models the strategies by thinking aloud. After the teacher's modeling, students are encouraged to take turns practicing the strategies presented. If necessary, the teacher can intervene in peer group discussions and talk to students directly about their reading strategy problems while helping them construct an understanding of the strategies and the ways to use them. Following this procedure, students are able to acquire a deep, personal understanding of the strategies on their own.

Unlike studies of the RTA, research into the effectiveness of the TSI model tends to be long-term since the model is based on long-term instruction. Consequently, the studies are often in the form of ethnographies, ethnographic interviews, long-term case studies, and analyses of classroom discourse (Pressley \& Warton-McDonald, 1997). Both the RTA and the TSI model subscribe to a similar teaching protocol: (1) summarizing, (2) generating and answering questions, (3) making predictions, and (4) clarifying the unclear parts. People who use the TSI model try to find how questions, including how comprehension strategies are related to other subject areas and how students forge meaning out of potentially ambiguous text types (Allen, 2003).

Collin (1991) showed an improvement in standardized measures of comprehension after students were taught comprehension strategies in the TSI model. Notably, Brown, Pressley, Van Meter, and Schuder (1996) showed that the students who were taught in the TSI model interpreted the texts in a richer and more diverse way, understood more of the content of the lessons, and exhibited a higher retention rate for the material that they learned. 


\section{The Cognitive Academic Language Learning Approach}

CALLA was originally developed by Anna Chamot and Michael O'Malley in 1987 based upon cognitive learning (Lawrence, 2007). The CALLA model is designed to enable ESL students to develop their language skills within content area subjects while implementing effective strategies. In other words, it aims to promote ESL students' academic achievement while at the same time improving their language skills. Under the premise that learning is an active and dynamic process, the model assumes that (1) active learners are productive learners, (2) strategies can be learned, (3) academic content learning is more effective with strategy use, and (4) learning reading strategies can transfer to new learning (Lawrence, 2007). Like RTA and TSI, CALLA is based on constructivism and cognitive theory. Allen (2003) suggested that "learning new information requires mental processing through organizing the information, elaborating it, and linking it with existing knowledge" (p. 329).

According to Chamot and O'Malley (1997), the CALLA model consists of three components: (1) topics from the major content subjects, (2) the development of academic language skills, and (3) explicit instruction in learning strategies for both content and language acquisition. More specifically, this model incorporates actual topics that students will encounter in grade-level classrooms. The content areas should be introduced gradually so as not to overwhelm students with both language and content. Chamot and O'Malley (1997) suggested that "the first content subject introduced should either have extensive contextual supports for learning or reduced language demands" (p. 10).

CALLA is not only used for reading strategy instruction but also for development of all four language skills (that is, speaking, listening, reading and writing). The skills are taught using the academic subject matter with the purpose of developing academic language skills. In addition to this, students learn important concepts and skills such as analyzing, evaluating, justifying, and persuading by using academic language.

In terms of learning strategy instruction, teachers are expected to teach cognitive, social/affective, and metacognitive strategies. Chamot and O'Malley (1996) suggested that the strategies should be taught explicitly by the teacher; thus scaffolding is an important aspect of teaching strategies within this model. Allen (2003) claimed that "students develop effective learning behaviors by watching teachers and other experts as they perform learning tasks. Then by practicing these behaviors with support until they are able to do them alone, students can internalize them" (p. 330). To summarize, the CALLA model is based on cognitive theory and integrates academic language development, content area instruction, and explicit instruction in learning reading strategies.

The three components of the CALLA model are realized in a five-stage instructional sequence: (1) preparation, (2) presentation, (3) practice, (4) evaluation, and (5) expansion. First, the teacher poses questions to students in order to elicit their background knowledge and strategies in the preparation stage. 
Second, the teacher presents new strategies, concepts, and language through modeling in the presentation stage. The teacher is encouraged to use lots of visuals and demonstrations. Third, students use the strategies they learn from modeling and apply the strategies more effectively with new tasks in the practice stage. They verbalize and describe their efforts to apply strategies with learning activities, often working with classmates in a collaborative manner. In the fourth stage students raise their metacognitive awareness of what they achieved and assess their learning process. Finally, in the expansion stage, the students relate what they learned to their culture and transfer strategies they learn to the outside world. The following figure demonstrates each stage (Chamot \& Robbins, 2005, pp. 11-13):

- Identify objectives.

\section{Preparation}

- Elicit students' prior knowledge.

- Develop vocabulary.

- Provide motivation.

\section{Presentation}

- Present new information in varied ways.

- Model processes explicitly.

- Explain learning strategies.

- Discuss connections to students' prior knowledge.

\section{Practice}

- Use hands-on/inquiry-based activities.

- Provide different cooperative learning structures.

- Use authentic content tasks.

- Ask students to use learning strategies.

\section{Self-evaluation}

- Students reflect on their own learning.

- Students evaluate themselves.

- Students assess their own strategy use. 


\section{Expansion}

- Students apply information to their own lives.

- Students make connections between language and content.

- Students relate information to first language knowledge.

- Parents contribute to learning.

Figure 1. CALLA instructional sequence: Five recursive phases

The teacher's objectives in the CALLA model are to activate background knowledge, to explain and model the target strategies, to prompt use of strategies and give feedback, to assess students' strategies, and to support transfer and application of strategies. Corresponding to the teacher's aims, students participate in discussions, apply strategies with guidance, self-assess strategies, use strategies independently, and transfer strategies to new tasks.

A series of studies have been conducted using the CALLA model in the field of language-learning strategies for ESL/EFL students in academic settings (Chamot, 1993; Chamot \& O'Malley, 1987; O'Malley \& Chamot, 1990; Rasekh \& Ranjbary, 2003). For example, Chamot and O'Malley (1987) trained bilingual secondary students and showed that CALLA positively affected metacognitive strategy use. Rasekh and Ranjbary (2003) trained bilingual university students and showed that CALLA positively affected vocabulary scores. In short, the results of the studies have shown that student performance in content, language, and use of learning strategies tends to improve after receiving instruction using the CALLA method.

\section{Strategy-Based Reading Instruction in the CALLA Model}

Among the instructional models previously described, the CALLA instructional model was selected in this paper in order to illustrate strategy-based reading instruction. Since the CALLA instruction promotes both language and content development in explicit instruction of learning strategies, it is most appropriate to the lesson topic of this illustration: raising awareness of important AfricanAmerican figures in modern history. I chose this topic since negative stereotypes and prejudiced points of view regarding African-Americans still persist in the present day. By dealing with this topic in class, teachers are not only able to promote a balanced and tolerant mind set towards African-Americans but also able to bolster students' content knowledge and academic language skills. More specifically, this strategy-based lesson plan follows the CALLA instructional plan (see Appendix A). This lesson is on the topic of an important African-American woman, Oprah Winfrey. Prior to the delivery of this lesson plan, students will be asked to do some research about important African-American figures in history on their own. The lesson plan is designed for postsecondary students whose English reading proficiency levels are between intermediate and high-intermediate. 


\section{A Lesson Plan: Oprah Winfrey}

A. General Overview

- Time needed: 50 minutes

- Grade/Language Level: Intermediate English proficiency level

B. Standards

1) Content Objective

- Collaborating with their classmates, students will be able to read and understand a passage about Oprah Winfrey.

2) Strategy Objectives

- Students will be able to use the title of the textbook to predict what they will learn.

- Students will be able to guess the meaning of new words using context and their background knowledge.

- Students will be able to practice such reading strategies as skimming and summarizing.

3) Language Objectives

- Students will be able to practice listening, speaking, reading, and writing to improve their understanding of the story in English.

- Students will be able to participate in pair, group, and whole-class discussions to express their ideas in English.

C. Materials

1) Textbook story: “Beating the odds." In Wegmann, B., \& Knezevic, M. (2002), Mosaic 1 reading, $4^{\text {th }}$ ed. New York: McGraw-Hill.

2) Oprah Winfrey show. ([2005]). The Oprah Winfrey Show: 20th Anniversary Collection. Hollywood: Paramount Pictures.

3) Slide projector / Cassette tape / Cassette tape player

4) Inquiry chart (Appendix B)

5) Reference list of Oprah Winfrey (Appendix C)

6) Checklist for CALLA lesson objectives (Appendix D)

D. Procedures

1) Preparation

- Warm-up (5 minutes): The teacher will ask students whether they recognize Oprah Winfrey in a picture in their book. The teacher tells the students she is one of the richest female entertainers in the world and has fought against discrimination. The teacher asks the students to name other African-American heroes. The teacher draws a clustering graph on the board with the word "African-Americans" in the center of the graph and puts key words in the graph based on students' answers. The teacher briefly summarizes the history 
of African-Americans in the United States including discrimination, prejudice, segregation, and the Civil Rights movement in the 1960s and 1970s. The teacher asks students to think about what the title tells them about Oprah Winfrey's life. [Predicting + Graphic organizer + Brainstorming + Selfassessment of prior knowledge]

- Watching Oprah show (5 minutes): Students will watch a video clip of the Oprah show. After watching it, students will be asked what they feel and what they learn about her. The teacher tells the class that millions of domestic viewers in the United States watch the Oprah TV talk show each week. The teacher also informs them that Oprah has influence in other areas such as social awareness, publishing, film, philanthropy, and education. [Active listening for getting information of the topic]

2) Presentation (6 minutes)

- The teacher plays a tape of the passage and students listen to understand the text. Then the teacher models a reading of the first paragraph using the think-aloud technique in order to demonstrate how to predict vocabulary meanings, how to summarize, and how to skim the passage to get information. [Listening strategy for getting the main idea of the passage + Modeling in think-aloud technique]

3) Practice

- Contextualizing vocabulary (5 minutes): The teacher distributes a word list to students. The teacher asks students to answer questions on the words in the textbook. The teacher encourages them to use their intuition, knowledge of word structure, and inferences. The teacher goes over the answers in class. [Selecting the appropriate words for the given context]

- Jigsaw (15 minutes): The teacher organizes the class into groups of four, and each group focuses on two or three paragraphs. Each group summarizes each of their paragraphs in English and helps each other if there are unfamiliar sentence structures or words. The teacher helps students if there is a question. After the time is up, each group rotates so that new groups are formed to share what they discussed in their previous group in English. [Summarizing + Reciprocal teaching + Practicing speaking in the target language + Cooperating to complete tasks]

- Identifying positive and negative points (12 minutes): The teacher tells students that the article describes not only positive influences but also negative influences in the early life of Oprah Winfrey. The teacher asks students to work with a partner to make two lists: the people, places, and events that positively influenced Oprah and the people, places, and events that negatively influenced her. The teacher models first how to do this activity by showing an example. After the time is up, students compare their list with the lists of others. [Modeling + Scanning + Making a chart + Cooperating to complete tasks] 
4) Expansion: Homework and wrap-up (2 minutes)

- The teacher assigns students homework: vocabulary recall list from the textbook and Inquiry Chart (see Appendix B). The teacher models how to fill out the columns of the chart. For the following class, the teacher asks students to research recent events in Oprah's life by using reliable sources (see Appendix C).

5) Evaluation

- Students will assess their own learning by doing the vocabulary recall list and inquiry chart for homework. Students will also do peer-to-peer evaluation by sharing their ideas or opinions of their strategy use. The teacher assesses his or her lesson plan by checking the checklist for CALLA lesson objectives (see Appendix D). The teacher also assesses students' understanding of the lesson using the objectives as follows:

- Language objective: Do the students participate by expressing their feelings or opinions with regards to the teachers' questions? Do the students speak English as much as possible? Do the students help one another in pair and group activities? Do the students actively listen to the text and to others' opinions?

- Strategy objective: Do the students make educated guesses about the meaning of unfamiliar words? Do the students actively participate in listening, graph clustering, summarizing, and skimming? How helpful was watching the teacher complete the think-aloud demonstration in helping students figure out how to apply the reading strategies to their own work? Was using the chart useful in extracting and organizing information from the passage? What technique proved to be the most helpful in aiding students to comprehend the reading?

\section{Conclusion}

Despite the growing demand for quality reading instruction in the English as a Foreign/Second Language context and despite the mounting body of literature on first-language reading strategy use, there appears to be a sizable gap in research on effective reading strategies for EFL and ESL learners. Due to this lack of pertinent research, there has yet to appear an agreed-upon set of guidelines for teaching reading strategies in the EFL and ESL contexts. Therefore, the aim of this paper is to provide a model for how one might incorporate strategic reading instruction into classrooms. Among the four different strategy-based reading models, I described the CALLA model in detail since it is especially focused on promoting content knowledge and language skills. Using the CALLA teaching protocol as well as the sample lesson plan described in this paper, teachers will be able to implement strategies for reading instruction in their own classrooms. They will also be able to adjust or expand on the model and demonstration by adding their ideas and experiences while instructing reading strategies in their classrooms. 
One limitation of this paper is that the lesson plan presented here has not been implemented in a real EFL classroom. For this reason, it is necessary to conduct follow-up studies that utilize the CALLA model in a real setting. In doing so, it would be possible to see whether or not the lesson presented in this study is actually helpful in authentic EFL classes. Such research would also allow for a more in-depth assessment of teachers' feeling towards and experiences with teaching in this manner.

\section{References}

$\mathrm{Au}, \mathrm{K} . \mathrm{H}$. (1977). Cognitive training and reading achievement. Paper presented at the annual meeting of the Association for the Advancement of Behavior Therapy. Atlanta, GA.

Alfassi, M. (1998). Reading for meaning: The efficacy of reciprocal teaching in fostering reading comprehension in high school students in remedial reading classes. American Educational Research Journal, 35(2), 309-332.

Allen, S. (2003). An analytic comparison of three models of reading strategy instruction. IRAL, 41, 319-338.

Baker, L. (2002). Metacognition in comprehension instruction. In C. Block \& M. Pressley (Eds.), Comprehension instruction: Research-based best practices (pp. 77-95). New York: Guilford Press.

Brown, R. (2002). Straddling two worlds: Self-directed comprehension instruction for middle schoolers. In C. Block \& M. Pressley (Eds.), Comprehension instruction: Research-based best practices (pp. 337-350). New York: Guilford Press.

Brown, R., Pressley, M., Van Meter, P., \& Schuder, T. (1996). A quasi-experimental validation of transactional strategy instruction with low-achieving secondgrade readers. Journal of Educational Psychology, 88, 18-37.

Carrell, P. L., Pharis, B. G., \& Liberto, J. C. (1989). Metacognitive strategy training for ESL reading. TESOL Quarterly, 23, 647-678.

Chamot, A. U. (1993). Student responses to learning strategy instruction in the foreign language classroom. Foreign Language Annals, 26, 308-321.

Chamot, A., \& O'Malley, M. (1987). The cognitive academic language learning approach: A bridge to the mainstream. TESOL Quarterly, 21, 227-249.

Chamot, A., \& O'Malley, M. (1996). The cognitive academic language learning approach: A model for linguistically diverse classrooms. The Elementary School Journal, 96, 259-273.

Chamot, A., \& O'Malley, M. (1997). The CALLA handbook: Implementing the cognitive academic language learning approach. New York: Addison-Wesley. 
Chamot, A., \& Robbins, J. (2005). The CALLA model: Strategies for ELL student success. Paper presented at the workshop for region 10 New York City Board of Education. New York, NY.

Collin, C. (1991). Reading instruction that increases thinking abilities. Journal of Reading, 34, 510-516.

Dole, J. A., Duffy, G. G., \& Pearson, P. D. (1991). Moving from the old to the new: Research on reading comprehension instruction. Review of Educational Research, 61(2), 239-264.

Duke, N., \& Pearson, P. D. (2002). Effective practices for developing reading comprehension. In A. Farstrup \& S. Samuels (Eds.), What research has to say about reading instruction (3 ${ }^{\text {rd }}$ ed., pp. 205-242). Newark, DE: International Reading Association.

Grabe, W. (2004). Research on teaching reading. Annual Review of Applied Linguistics, 24, 44-69.

Kim, H-O. (2006). Changes in learner beliefs and strategy use through strategybased instruction. Foreign Languages Education, 13(4), 193-217.

Kusiak, M. (2001). The effect of metacognitive strategy training on reading comprehension and metacognitive knowledge. EUROSLA Yearbook, 1(1), 255274.

Lawrence, L. J. (2007). Cognitive and metacognitive reading strategies revisited: Implications for instruction. The Reading Matrix, 7(3), 55-71.

Lee, K. R. (2007). Self-confidence fostering activities: Scaffolds for EFL learners' reading strategies. English Language Teaching, 19(4), 27-50.

Nist, S. L., \& Diehl, W. (1990). Instructor's guide: Developing textbook thinking $\left(^{\text {nd }}\right.$ ed.). Lexington, MA: Heath.

O'Malley, J. M., \& Chamot, A. U. (1990). Learning strategies in second language acquisition. New York: Cambridge University Press.

Oprah Winfrey show. ([2005]). The Oprah Winfrey show: 20th anniversary collection. Hollywood, CA: Paramount Pictures.

Padron, Y. N. (1992). The effect of strategy instruction on bilingual students' cognitive strategy use in reading. Bilingual Research Journal, 16(3\&4), 35-51.

Palinscar, A., \& Brown, A. (1984). Reciprocal teaching of comprehension-fostering and comprehension monitoring activities. Cognition and Instruction, 1, 117175.

Palinscar, A., \& Brown, A. (1986). Interactive teaching to promote independent learning from text. The Reading Teacher, 39(8), 771-777. 
Park, Y. Y. (1996). Self-regulated strategy training in second language reading: Its effects on reading comprehension, strategy use, reading attitudes, and learning styles of university ESL students. Foreign Languages Education, 2(1), 59-80.

Pressley, M. (2002a). Comprehension strategy instruction: A turn-of-the-centurystatus report. In C. Block \& M. Pressley (Eds.), Comprehension instruction: Research-based best practices (pp. 11-27). New York: Guilford Press.

Pressley, M. (2002b). Metacognition and self-regulated instruction. In A. Farstrup \& S. Samuels (Eds.), What research has to say about reading instruction ( $3^{\text {rd }}$ ed., pp. 291-309). Newark, DE: International Reading Association.

Pressley, M., \& Warton-McDonald, R. (1997). Skilled comprehension and its development through instruction. School Psychology Review, 26(3), 448-466.

Rasekh, Z., \& Ranjbary, R. (2003). Metacognitive strategy training for vocabulary learning, TESL-EJ, 7(2), 1-18.

Song, M. J. (1998). Teaching reading strategies in an ongoing EFL university reading classroom. Asian Journal of English Language Teaching, 8, 41-54.

Trabasso, T., \& Bouchard, E. (2002). Teaching readers how to comprehend text strategically. In C. Collins \& M. Pressley (Eds.), Comprehension instruction: Research-based best practices (pp. 176-200). New York: Guilford Press.

Wegmann, B., \& Knezevic, M. (2002). Mosaic 1 reading (4th ed.). New York: McGrawHill.

Vaughn, S., \& Klingner, J. K. (1999). Teaching reading comprehension through collaborative strategic reading. Intervention in School and Clinic, 34(5), 284292.

\section{Appendix A. The CALLA Handbook, Table 5.3}

\section{CALLA Instructional Plan}

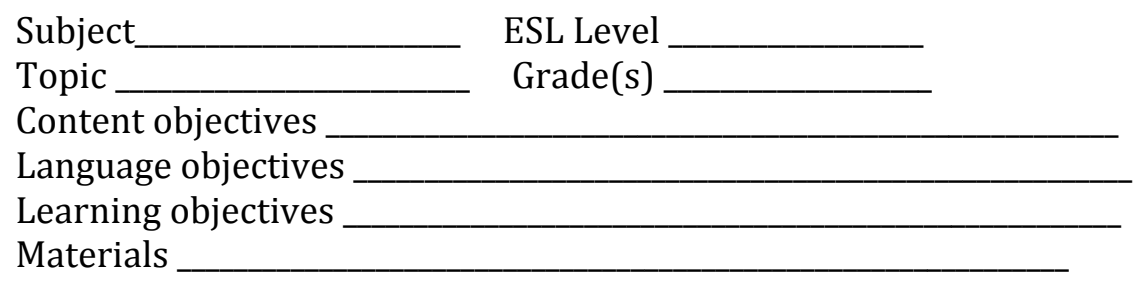

\section{Procedures}

1. Preparation: How will you find out what your students already know about the topic?

2. Presentation: How will you present and explain the topic?

3. Practice: What cooperative learning activities will provide meaningful practice?

4. Evaluation: How will students assess their own learning?

5. Expansion: What thinking-skills discussion questions are appropriate? How will students apply what they have learned in the unit to new situations? 


\section{Appendix B. Inquiry Chart}

\begin{tabular}{|l|l|l|}
\hline What do you KNOW? & What do you WANT to find out? & What did you LEARN? \\
$\begin{array}{lll}\text { - Oprah is an African- } \\
\text { American. }\end{array}$ & $\begin{array}{l}\text { - The civil war } \\
\text { - The civil rights era }\end{array}$ & - She was a very smart girl. \\
\hline
\end{tabular}

\section{Appendix C. Useful Resources of Oprah Winfrey}

[Books]

Cooper, I. (2007). Oprah Winfrey. New York: Penguin Group.

Holland, G. (2001). Oprah Winfrey. Chicago: Heinemann Library.

Mara, W. (2005). Oprah Winfrey. New York: Children's Press.

Corliss, R. (1998). Bewitching Beloved. Time. [New York : Time Inc.].

[DVDs]

Spielberg, Stephen (Director). The Color purple. (1997 [1985]). Burbank, CA: Warner Home Video.

Demme, Jonathan (Director). Beloved. (1999). Hollywood, CA: Touchstone Home Video.

Oprah Winfrey show. (2005). The Oprah Winfrey show: 20th anniversary collection.

Hollywood, CA: Paramount Pictures.

[WWW Resources]

http://www.gale.com/free resources/bhm/bio/winfrey o.htm

http://www.oprah.com/about/press/about press bio.jhtml

http://en.wikipedia.org/wiki/Oprah Winfrey

\section{Appendix D. The CALLA Handbook, Table 7.7}

\section{Checklist for CALLA Lesson Objectives}

1. Objectives stated for content, language, and learning strategies

2. Content selected is essential for grade level(s) and is aligned with state framework/local curriculum

3. Activities are included that develop vocabulary, listening, reading, speaking, and writing

4. One or two learning strategies directly taught and/or practiced

5. Language somewhat simplified, but not tightly controlled for grammatical structures or vocabulary

6. Students' prior knowledge elicited in Preparation phase

7. Context provided through visuals, graphic organizers, manipulatives, realia, hands-on, etc.

8. Cooperative learning activity and active practice with new information presented included in lesson

9. Self-evaluation activity included in lesson

10. Higher-level questions posed during lesson

11. Real-life applications of content addressed through activity and/or discussion 


\title{
The Challenges of Teaching and Learning English Literature in L2 Context: The Case of Junior Secondary Schools in Botswana
}

\author{
Deborah Adeninhun Adeyemi
}

\begin{abstract}
Various Botswana policy documents (Republic of Botswana, 1977, 1994, 2002) and Vision 2016 (1997) have advocated for an enlightened and well-informed society and the provision of a ten-year basic education as a fundamental human right of her citizens. It is against this background that this paper discusses the importance of English Literature in the Junior Secondary School (JSS) curriculum and examines the challenges faced by teachers and students in the teaching/learning process that can hamper the achievement of the country's educational and social goals. Two Form One classes were chosen in two schools in Gaborone, the capital of Botswana, for this study. The 35 students in each of the two classes (totaling 70 students) and their 2 teachers were used in the study by adopting simple qualitative and quantitative descriptions. The study showed that the major difficulties faced by the teachers include lack of interest/enthusiasm for learning the subject by the students, as well as their lack of basic background in English, among others. Other problems on the part of the students include difficulty in understanding and difficult vocabulary/language in texts. As a result, pertinent recommendations were made for improved teacher practices and strategies.
\end{abstract}

\section{Introduction}

In Botswana, the provision of quality basic education is viewed as a fundamental human right. Basic education in this context aims at fostering intellectual growth and creativity, enabling every citizen to achieve their full potential and prepare them for life in the 21st Century-The Curriculum Blueprint (Republic of Botswana, 2002).

Various policy documents, such as the National Commission on Education (Republic of Botswana, 1977), Revised National Policy on Education (RNPE; Republic of Botswana, 1994) and Vision 2016 (Republic of Botswana, 1997) stress the building of a nation enviable to the global community through the education of its citizens. It is the view that literature education is important to the achievement of the nation's educational and social goals. To this end, the study of literature in both English and Setswana (the national language) become useful tools in the achievement of the outlined goals. 


\section{Background to the Study}

English literature is used at the junior secondary level in Botswana to teach literacy in the English language. A part of the junior secondary English syllabus states that the study of literature will enable pupils gain further practice in the key areas of the four language skills of listening, speaking, reading and writing (Republic of Botswana, 2008), consolidating these skills in interesting and communicative ways to enrich learners' day-to-day language learning and use. It is also hoped that the study of literature at this level will encourage learners to develop a culture of reading which will help them have access to information on a wide variety of topics, and thereby become informed and educated as stated in Vision 2016.

It is important to emphasize that the teaching and learning of literature at the junior secondary level through works of fiction, drama and poetry serve many purposes. Various government education policy documents mentioned earlier, and the development document tagged Vision 2016, favor the teaching of literature as a component of the English language. Again, it is indicated in the junior secondary English language syllabus (Republic of Botswana, 2008) that the syllabus embraces two integrated components, language and literature, which are seen to be complementary. It is believed that the integration of literature with language will help learners reinforce their knowledge and use of the English language.

Furthermore, some of the specific aims of the ten-year basic education program which relate to the teaching of literature in Botswana schools include the following:

- Acquire knowledge and understanding of society, appreciation of culture including languages, traditions, songs, ceremonies, customs, social norms and a sense of citizenship.

- Acquire a good knowledge and practice of moral standards.

- Develop their own special interests, talents and skills, whether these are dexterity, physical strength, intellectual ability, and/or artistic gifts.

- Develop critical thinking and problem solving ability. (Republic of Botswana, 2002: iii)

For example, the values of the appreciation of language, culture, traditions, songs, moral standards in family and community life, developing intellectual and other talents, critical thinking and problem solving abilities are core values that the teaching of literature inculcates. As an example, literature books such as Things Fall Apart, The Amaryllis, The Play of Goggle Eyes, and anthologies in The Rain Song recommended as texts at the junior secondary level in Botswana illustrate stories, poems and plays that emphasize personal, moral and social values of traditional and contemporary African and global issues. The activities inherent in the teaching of the subject are capable of teaching values clarification and enhancing communication and language development of students in English. Also, the intellectual skills involved will enable students to comprehend language in other content areas of the school curriculum.

Finally, the identified national and educational objectives outlined in this discussion cannot be achieved without addressing the challenges that both teachers 
and students encounter in the teaching and learning process that impacts negatively on students' performance in English literature. To this end, this study attempts to elucidate the challenges that may hinder effective pedagogy in the subject and proffer some measures for improvement.

\section{Problem Statement}

It is established that literature teaching and learning at the junior secondary level is helpful to students in the language learning process. This is because of the personal involvement it fosters in readers, and the rich context it provides for the language learning process. It is also believed that literature teaching and learning enables students to gain familiarity with many features of the written and spoken language, especially in the second language (L2) learning (Republic of Botswana, 2008) context for the promotion of literacy. Also of importance is one of the pillars of Vision 2016, which articulates that Batswana (the people of Botswana) will be "educated and informed by the year 2016." The hindrance to achieving this and other educational and social goals of Botswana is the poor performance of students in literature at the junior secondary level.

Again, the 2004 Junior Certificate (Republic of Botswana, 2004) examiner's report notes in some sections that a considerable number of students did not understand some questions in the English literature paper before rushing to answer them and thereby, lost points. Furthermore, the 2008 JC report observes that some candidates were ill prepared for the Literature Paper 3 which required students to:

- Explain

- Describe

- Show feelings

- Express opinions

- Demonstrate understanding of literary aspects. (Republic of Botswana, 2008)

Furthermore, the experience of this author as a teacher at the junior secondary level for about one and a half decades, persistent student difficulties with the subject, coupled with the noted dissatisfaction of teachers with the teaching of literature, informed this study. It is hoped that the findings will help to alleviate the challenges encountered by both the teachers and students in the teaching and learning of English literature.

\section{Objectives of Paper}

1. To examine the rationale for the teaching of English Literature at the junior secondary school level in Botswana;

2. To identify the challenges/problems of the teaching and learning of English Literature at the junior secondary school level; and

3. To discuss the implications for teacher practices and strategies. 


\section{Rationale for Teaching English Literature in Botswana Schools}

The seven pillars of the famous government document Vision 2016 (Republic of Botswana, 1997) states that by the year 2016, Botswana would become:

- An educated and informed nation;

- A prosperous, productive and innovative nation;

- A compassionate, just and caring nation;

- A safe and secure nation;

- An open, democratic and accountable nation;

- A moral and tolerant nation; and

- A united and proud nation. (Republic of Botswana, 1997)

The seven pillars of Vision 2016 above are value-laden and intimately relate to moral and intellectual education. For citizens of Botswana to be well educated, and informed, compassionate, just, caring, moral and tolerant, the teaching and learning of literature both in Setswana (the national language) and English (the official language) must undoubtedly be part of the curriculum. This is because the teaching of literature has the identified academic and value-laden objectives that can contribute to the realization of the country's visionary goals. This view is further supported by DeRouche and Williams (2001) who articulate:

The two major purposes of school are cognitive-academic development and character education. Together they prepare students for the world of work, for lifelong learning, and for citizenship. (p. 8)

Furthermore, it is recognized that both academic and moral development is a great challenge for all people. It is not a surprise that Gibbons in one of the Forewords in Brooks (2001) asked some questions: "what do we, as a society, want of young people as they walk across the stage and receive their diplomas...? What do we want them to walk away with and be able to do?" He answers:

Yes, we want them to be able to write, calculate, and read, but we also want them to resolve conflicts in a peaceful manner, care about what happens to others, exercise self-discipline, show respect for others, be honest and truthful, and have confidence in themselves and others. The list of characteristics goes on and on. In short, we want to help students develop their character as well as their academic skills. (p. 9)

Moreover, it is believed that literature in both English and Setswana helps to establish the values of appreciating the world, developing a positive self-image, and understanding the connection between all people all over the world. There is no doubt that in the present global setting which stresses the interdependence of nations and communities, the ability to communicate effectively, build an understanding of cultures of the world, acquire new information, respond to the 
needs and demands of society and the workplace, and for peaceful coexistence, is important. Botswana equally shares all these ideals, and they are reflected in the nation's basic education and social goals. The assumption is that the goal of an educated and informed nation, in addition to other goals, can be achieved through literature education in the junior secondary schools. This paper will, however, focus on the teaching and learning of English literature in the second language (L2) context.

\section{Methodology}

Participants

Seventy (70) Form One students in two different schools and their two (2) English language teachers in the two junior secondary schools in Gaborone, the capital city of Botswana, were used as subjects of this study. The two schools as indicated were purposely chosen because of their nearness to the investigator's workplace and the convenience afforded by the two schools in data collection. The teachers had seven and eight years teaching experience respectively. They were judged to be in a position to furnish the information required by the investigator. There were thirtyfive (35) students in each of the two deliberately selected classes, making a total of seventy (70) students between the ages of thirteen and fifteen (13-15) years.

\section{Method of Data Collection}

An open-ended semistructured interview questionnaire was designed to interview the two teachers on a one-on-one basis as follows (see Appendix A):

1. What is your area of specialization?

2. How long have you been teaching English Literature?

3. What are the attitudes of your students to the teaching of the subject (literature)?

4. Do you like teaching English Literature to your students? Why?

5. What are the difficulties you experience with the teaching of the subject, starting with the major problems?

6. What do you perceive as the reasons for those problems?

7. How can the difficulties you have identified be remedied?

The seventy Form One students chosen were given questionnaires requiring them to respond to a few open-ended questions as stated below (see Appendix B):

a) Class:

b) Age:

c) Male or Female

1. I like studying English Literature because of these reasons:

2. I do not like studying English Literature because of these reasons:

3. List what you think are the problems you have with the learning of English Literature:

The method of data collection was very simple. Each of the two teachers helped to distribute the questionnaires. The two teachers were interviewed orally. 
The study was done with the students during their literature learning period of forty minutes in each of the two schools on different days of the week. The teachers were interviewed on their free afternoon in the week of the study.

In reporting the responses of the teachers and the students, simple qualitative and quantitative descriptions were employed. This was to ensure a greater degree of reliability and validity. It is believed that there are advantages in the multimethod approach, as it attempts to explain more fully the richness and complexity of human behavior by studying it from more than one view point; that is, by making use of both quantitative and qualitative data (Cohen, Manion and Morrison, 2005). The challenges faced by the teachers and students were as reported below.

\section{Analysis of Data}

The interviews with the teachers were done over a period of one hour each and tape-recorded in addition to notes taken during the interview. The responses were coded and examined for recurrent themes/categories. The recurrent themes were identified for discussion.

\section{Findings (Interview with Teachers)}

The two teachers interviewed, A and B, held post-graduate degrees in education and have seven and eight years of teaching experience respectively, as stated earlier. Even though the two teachers said that they enjoyed teaching literature, they went on to express reservations.

In the one-on-one discussions with the teachers during the interview, they identified the following challenges in order of importance:

1. The negative attitudes of students/general lack of interest;

2. Problems of reading, comprehension and writing in English (this is common to the majority of students);

3. Students' inability to comprehend what they read. Even though they (the students) are able to pronounce the words, they lack understanding;

4. Inadequate materials to teach as students sometimes have to share books to read;

5. Copying of written homework;

6. Content of prescribed materials/books being above or not within the students' experience;

7. Students' lack of good background in English at the primary level and having to learn literature in junior secondary school;

8. Problems of mixed ability teaching.

\section{Discussion of Findings}

Judging from various responses, the challenges faced by teachers and students in literature education might jeopardize the achievement of educational and social 
goals of literature teaching and learning in Botswana junior secondary schools. Some of the findings pertaining to teachers indicate the following:

Teacher attitude: Attitudinal issues are part of the problems facing the teaching and learning of English literature in schools. Even though the two teachers interviewed said they were not averse to teaching English literature, they adopted a defeatist tone when they said they were usually discouraged about teaching literature to their students. In the interviews with the teachers on this, some responses indicate:

- I get discouraged by students who are admitted to secondary level who have not passed well and are unable to read or respond to questions.

- Some students have difficulties with reading to start with, and to request them to read a text for interpretation becomes a problem. Where am I supposed to start from?

In addition, there are instances of negative attitudes from the teachers towards the teaching of some aspects of literature, such as poetry or drama, as they consider them boring and uninteresting. Aspects of the interview that indicate this trend are as follows:

- Students have a negative attitude towards poetry. Maybe this is a result of the approach we have been using to teach them, always asking them to identify figures of speech, which they find difficult, and students' lack of understanding.

- The low achievers and mediocre achievers would always struggle to grasp concepts with complex texts and literature genres, e.g., poetry.

Negative attitudes/vibes about teaching particular aspects of literature to students can easily be picked up by students. If teachers lack enthusiasm themselves, it is doubtful if they can help their students to develop any interest in the subject.

Students' lack of interest and negative attitudes to literature: This may be due to several factors, including those related to the teacher such as methodology/approach, difficult vocabulary/text, and lack of understanding of students' difficulties. For instance, this was picked up from students in their responses as to why they do not like studying literature:

- Literature often has difficult vocabulary

- Literature can be confusing

- Literature often has long stories and I don't understand most English words

- Literature deals with a lot of poems and I am not good at poetry

- The poetry aspect is most difficult for me

- It takes a long time to finish reading and at times I forget what the reading is about by the time I finish reading 
It is important for teachers to articulate or diagnose their students' learning problems adequately. Students' lack of interest may stem from many factors, including difficult vocabulary, difficult texts, teaching methodology, and so on. For example, one of the teachers cited lack of reading culture as a cause of students' lack of interest. What students indicated as their challenges were more than a mere inability to read as suggested by the teachers. The responses students gave suggested implications for choice of literature materials as well as methodology issues.

Students' problems of reading, comprehension and writing: Some teachers assume erroneously that the ability to read translates to literature comprehension ability. Reading is an aid and not an end to literature ability. This is further illustrated by the teacher who said that students can read out loud (pronounce/recognize) the words but are unable to comprehend. Effective literature teaching goes beyond mere reading of an interesting novel or story. Helping students comprehend literature demands that teachers be skillful at teaching it. This is because in addition to reading, students should be able to comprehend, enjoy, and respond to what they read. Finally, it is assumed that reading is an important factor that enhances writing in developing literacy skills.

Provision of resources: The allusion to the unsuitability of resources that have difficult language or contents that are far removed from the students' immediate social contexts can contribute to ineffective literature instruction. During the teacher interviews, a teacher commented that most often they are not consulted before books are recommended for students by the Ministry of Education and Skills Development (the government body that provides textbooks and other learning materials to schools). On this, a teacher comments:

- One of the problems is lack of resources such as textbooks. There is sometimes a 1-to-3 ratio in book use by students.

- I think one of the big challenges is the lack of teacher input in the book selection process for students.

In addition, it is noted that the provision of inadequate textbooks for students can be a major stumbling block to effective literature instruction.

Copying of homework: This is not a surprising development judging from the students' lack of understanding and perceptions of literature learning. If a particular subject is boring, difficult and confusing to students to start with, it is doubtful if they can do homework successfully in it. Thus, students resort to copying from one another.

Students' lack of good background in English: Several authors, such as Akyel and Yacin (1990) and Widdowson (1975), note that L2 learners find literature learning difficult because of the challenge of teaching literary texts to learners who have an inadequate background in the basic mechanics of the English language. This is evident in the teachers' complaints about the poor English background of student intakes from the primary schools. Also, Widdowson (1975) notes that the 
interpretive procedures in literature may lead the L2 learner to become confused and overloaded even at the best of times. This view probably explains some of the difficulties of the lack of understanding that the teachers noted in their students. This perception is further reinforced by a student respondent who in frustration said:

- I don't like literature because it is boring and confusing.

Mixed ability teaching: One of the teachers in this study was having difficulties with mixed ability teaching, which should not be the case. A mixed ability class should not be a challenge that would prevent teachers from effective instruction delivery. The teacher education program should prepare them to deal with such situations. Besides, presently, the average Botswana public school classroom is mixed ability in nature, and this situation informs the inclusion of mixed ability/multicultural education in the teacher preparation program of the University of Botswana. Also, this development makes it imperative for both inservice and pre-service teachers to have knowledge of mixed ability teaching.

\section{Findings (Students)}

As stated earlier, 70 students participated in this investigation. A few of them (18 or approximately 25\%) indicated that they enjoy learning literature because it is enjoyable and it involves stories that they love. However, the main focus of this paper is on the challenges faced by the majority of students (approximately 75\%), who indicated that they do not enjoy learning literature. The main themes of their responses as tallied in rank order, absolute numbers, and percentages are as follows in descending order:

1. The difficulty of understanding literature $-49(94 \%)$;

2. Difficult vocabulary - $39(75 \%)$;

3. Literature has difficult poetry aspects $-36(69 \%)$;

4. Too lengthy stories/novels, which make them lose sight of what the story was about by the time they finished reading it -34 (65\%);

5. It is boring and confusing- $32(62 \%)$;

6. Too much note taking - 26 (50\%);

7. English literature is difficult to pass, as they usually get very poor grades in tests and examinations - 21 (40\%); and

8. Requires too much thinking, which some of them find difficult to do - 14 (30\%)

\section{Discussion of Findings (Students)}

Difficulty in understanding: Some of the findings tend to indicate generally that the learners find literature difficult. Forty-nine students representing $94 \%$ of the fiftytwo (52) students having difficulty with literature cited difficulty in understanding English literature. This agrees with the views of such authors as Akyel and Yacin (1990) and Widdowson (1975), who note that L2 learners find literature learning difficult. On the same issue, another challenge to students is the difficulty in teaching creative use of language by teachers who are themselves L2 speakers of the 
language (Adeyemi, 2008) and as a result might have proficiency problems themselves. Furthermore, from the previous observations and experience of this writer, some teachers who dislike some aspects of literature such as poetry and drama usually are selective in the aspects they teach or where they are taught, and they unconsciously infect their students with the negative attitudes they unwittingly display. Thus, many of the students complained about the learning of poetry:

- I don't like literature because it uses unfamiliar words, especially in poems

- I hate poetry because the language is difficult to understand

- Literature is hard and has many poems that I don't understand.

Difficult vocabulary: According to thirty-nine students or seventy-five percent of them, unsuitable English literature books that have difficult language contribute to students' lack of interest as well as failure in the subject. This was evident by the students' frustration at learning literature because according to them, English literature is difficult to understand and has difficult vocabulary. Unfamiliar settings and cultural differences in some literature materials compound the difficulties students experience.

Difficult poetry aspects: Some teachers tend to be selective in teaching aspects of literature they enjoy, such as stories and novels, and shy away from those they consider challenging, such as poetry and other creative aspects of the English language. This probably explains the peculiar problems the students were having. Thirty-six students or sixty-nine percent of them alluded to this challenge. In addition, there are instances of general observations that many teachers skip some aspects of literature teaching such as poetry or drama because it is boring and uninteresting to them. Adeyemi (2008) notes that creative aspects of L2 language learning has been accorded very little importance both at the primary and secondary levels, which has negatively impacted students' reading and writing skills development.

Too lengthy stories/novels: Thirty-four or sixty-five percent of the students have problems with the length of their stories and novels. This situation is closely related to the use of unsuitable materials in the teaching of literature. Material selection and use should consider students' reading level, interest, familiar/authentic contents and appropriate teaching strategies. Materials should not be too lengthy or inadequate for students; otherwise they lose sight of the plot or the whole essence of the reading exercise.

Boring and confusing literature: Twenty-four students or forty-six percent said they find literature boring and confusing. This view of the learning of literature by students may be closely related to the teaching methodologies adopted by teachers. This may indicate a need for teachers to vary their approaches and methodologies for teaching the subject. There are very many interesting ways of teaching literature so that it includes activities that integrate language skills with other personal response activities such as role-play, debates, discussions, group/pair work and other problem solving and interpretive techniques in learning. 
Too much note taking: This can be explained as a fall out from teacher strategies, as twenty-six or fifty percent of the students consider it as a challenge to their learning. The teaching of literature should involve the use of varying strategies and approaches to reflect the new thinking in literature education which integrates language skills and reader-response strategies to minimize note- taking and enhance understanding and personal response in literature, as already alluded to earlier.

Literature is difficult to pass: Another complaint by twenty-one or forty percent of the students indicates that literature is difficult to pass on tests and examinations. The complaint that literature is difficult to pass as a result of poor grades in traditional tests and examinations may be linked to students' reading comprehension and writing skills. A possible reason may also be linked to unsuitable teaching resources as well as poor teaching strategies. Some of the remedies already indicated for teaching strategies and improved resources for teaching the subject can also help to improve learning.

English literature requires too much thinking: Fourteen or thirty percent of the students have problems with critical thinking skills that literature learning involves. This situation may be related to the poor English language background of the students, reflected in poor reading and comprehension skills, poor speaking and writing skills, and materials that are above the students' level of understanding. This also calls for appropriate diagnosis/understanding of students' learning difficulties in order for teachers to remediate them. Diagnosis and remediation of reading disabilities in students is an important area that needs to be addressed by teachers at the onset of the course. In the present order, much is taken for granted. There is no indication of reading diagnosis being done to screen students to determine their reading levels or readiness for the type of skill needed to tackle the learning of English literature at the junior level. Teachers just take it for granted that all students are at the same level, without due consideration of students' interests and abilities. This is a wholesale approach in teaching that needs to be reviewed in the Botswana public education system.

In view of the challenges faced by teachers and students in the teaching and learning of English literature at the junior secondary level in Botswana, the following implications are discussed.

\section{Implications for Teacher Practices and Strategies}

Some of the implications for in-service and pre-service education of teachers in connection with literature teaching are discussed below.

Exposure to approaches and strategies for teaching literature: There is a need for teacher educators to expose teachers to the different approaches available to enhance the teaching of literature taking into consideration the particular needs of their students. New orientations in literature teaching and learning involve the application of transactional theories (Karolides, 1997; Cadorath \& Harris, 1998) and integrated approaches (Carter \& Nash, 1990). 
These views to literature teaching and learning are informed by the consideration of the role of the readers, acknowledgement of the readers' prior knowledge in the reading act, and the readers' ability to interact with the text in creating meaning, and not just the writers' interpretation or meaning alone. The integrated approach theories submit that particular needs of the students concerned can be factored into the strategies to address language needs as well as individual response mechanisms. I support both views, considering L2 language learning difficulties as well as the enabling environment provided by the response strategies.

Mixed ability teaching skills: Many teachers are having difficulties meeting the needs of the diverse students in their classrooms. Even experienced teachers discover that they may not be adequately prepared to teach their students (Rassol and Curtis, 2004). This is because of the continuing challenges teachers are often confronted with in day-to-day classroom situations such as problems of students' backgrounds, multiethnic orientations, cultural backgrounds, language backgrounds, students with special needs, and so on. The education of teachers must include multicultural teaching to ensure effectiveness of teachers in the mixed ability classrooms.

Courses on materials development and evaluation: This should be an important course in teacher education. It is important in language teaching as well as in other content areas, as it would enable student teachers as well as practicing teachers to function effectively in their roles of providing and recommending useful and relevant resources for teaching literature and other subjects. When teachers are called in to help review and recommend resources for instruction, they should be empowered to do this to solve the problems of resource materials development and procurement.

Strategies for teaching literature: Strategies for teaching literature are many and varied and should include any of the three characteristics believed to be important in teaching L2 learners: that language learning be integrated (Snow and Brinton, 1988); that students be given access to problem-solving and critical thinking activities in non-threatening, cooperative contexts to foster higher order thinking (Moll \& Diaz, 1987) which include critical thinking strategies; and that learning activities be mediated or scaffolded so as to build background and promote learning (Rasool \& Curtis, 2004).

\section{Conclusion}

As students are prepared for living in the twenty-first century, it is important to help them learn the strategies and skills that will let them function effectively in all aspects of their lives. This calls for the use of effective strategies that will enhance learning and help students develop effective skills and abilities needed for the individuals to become more critical and effective communicators, as well as functional citizens of their communities and the world. Perhaps the most important factor in guiding learners to read, enjoy and learn from literature is the teacher's own attitude. If teachers show interest, read widely, and are enthusiastic about 
literature, they will communicate their own enjoyment to many of their learners. In addition, teachers must be willing to take chances and plan interactive activities that will personally involve learners. They must also be accommodating of students' responses to literature in diverse ways in order to motivate and appreciate their students' contributions in the learning process and thereby help to achieve the educational and social goals of teaching literature in the schools in Botswana and elsewhere with similar challenges.

\section{References}

Adeyemi, D. A. (2008). Approaches to teaching English composition writing at junior secondary schools in Botswana. Unpublished doctoral dissertation, University of South Africa, Pretoria.

Achebe, C. (2002). Things fall apart. Oxford: Macmillan.

Akyel, A., \& Yalcin, E. (1990). Literature in the EFL class: a study of goal-achievement incongruence. ELT Journal, 44(3), 174-180.

Brooks, D. L. (2001). Readings and activities for character education. Peterborough, NH: Cobblestone.

Cadorath, J., \& Harris, S. (1998). Unplanned classroom language and teacher training. ELT Journal, 52(3), 188.

Carter, R., \& Nash, W. (1990). Seeing through language. Oxford: Blackwell.

Cohen, L., Manion, L., \& Morrison, K. (2005). Research methods in education. New York: RoutledgeFalmer.

DeRoche E., \& Williams, M. (2001). Foreword. In D. L. Brooks, Readings and activities for character education. Peterborough, $\mathrm{NH}$ : Cobblestone.

Fine, A. (1995). The play of goggle eyes. Oxford: Heinemann.

Karolides, N. J. (1997). Reading process: Transactional theory in action. In N. J. Karolides (Ed.), Reader-response in elementary classrooms: Quest and discovery (pp. 3-28). Mahwah, NJ: Lawrence Erlbaum.

Moll, L. C., \& Diaz, S. (1987). Change as the goal of educational research. Anthropology and Education Quarterly, 18, 300-311.

Rasool, J. A., \& Curtis, A. C. (2004). Multicultural education in middle and secondary classrooms: Meeting the challenge of diversity and change. Belmont, CA: Thomson Wadsworth.

Republic of Botswana. (2008). Junior Certificate Examination: Principal Examiner's Report - Paper 3. Gaborone, Botswana: Government Printers.

Republic of Botswana. (2008). Three-Year Junior Secondary English Syllabus. Gaborone, Botswana: Department of Curriculum and Evaluation. 
Republic of Botswana. (2004). Junior Certificate Examination: Principal Examiner's Report - Paper 2. Gaborone, Botswana: Government Printers.

Republic of Botswana. (2002). Curriculum Blueprint: Ten Year Basic Education Programme. Gaborone, Botswana: Government Printers.

Republic of Botswana. (1997) Long Term Vision for Botswana, Vision 2001: Towards Prosperity for All. Gaborone, Botswana: Government Printers.

Republic of Botswana. (1994). Revised National Policy on Education (RNPE). Gaborone, Botswana: Government Printers.

Republic of Botswana. (1977). National Policy on Education. Gaborone, Botswana: Government Printer.

Snow, M. A., \& Brinton, D. M. (1988). Content-based language instruction: Investigating the effectiveness of the adjunct model. TESOL Quarterly, 22, 553-574.

Widdowson, H. (1975). Stylistics and the teaching of literature. London: Longman.

\section{Appendix A}

1. What is your area of specialization?

2. How long have you been teaching English Literature?

3. What are the attitudes of your students to the teaching of the subject (literature)?

4. Do you like teaching English Literature to your students? Why?

5. What are the difficulties you experience with the teaching of the subject starting with the major problems?

6. What do you perceive as the reasons for those problems?

7. How can the difficulties you have identified be remedied?

\section{Appendix B}

a) Class:

b) Age:

c) Male or Female

1. I like studying English Literature because of these reasons:

2. I do not like studying English Literature because of these reasons:

3. List what you think are the problems you have with the learning of English Literature: 


\title{
The Effectiveness of Correcting Grammatical Errors in Writing Classes: An EFL Teacher's Perspective
}

\author{
Hye-Kyung Kim
}

\begin{abstract}
The role of grammar instruction to help students reduce errors in L2 writing is under debate: Truscott $(1996,1999,2007)$ claims that error correction is largely ineffective and harmful, whereas Ferris $(1997,1999,2004)$ argues that students need feedback on their grammatical errors. Grammar correction is considered to be one of the most important forms of feedback. This paper examines the role of grammar correction in L2 writing on the basis of these controversies and discusses some pedagogical implications of error correction for teaching writing, with particular reference to my own experience of teaching EFL writing classes in South Korea.
\end{abstract}

\section{Introduction 1}

In L2 writing, the role of grammar instruction as a way of decreasing the number of errors has been hotly debated. In particular, Truscott $(1996,1999,2007)$ claims that error correction is largely ineffective and harmful, whereas Ferris (1997, 1999, 2004) argues that students require feedback on their grammatical errors. My experiences teaching English as a foreign language (EFL) writing at the college level both introduced me to the issue of whether or not to correct grammatical errors and led to my position, which is that grammar and spelling correction is one of the most important forms of feedback, though the type and role of feedback will differ according to students' proficiency.

When I taught English composition for beginners in South Korea, students sought a great deal of support in grammar instruction. Many advanced English language learners (ELLs) still valued supplemental grammar instruction to help build their editing skills, though most of them had good control of sentence-level grammar. Therefore, my pedagogical goals were to help students write effectively by teaching them rules and applications in a basic English composition course and by letting them read as many passages as possible in an advanced English composition course. I led a grammar-based writing class for the basic course, and a reading-based writing class for the advanced course. In the latter course, I employed reading as a way for students to practice elaborating on ideas in writing but also helped students build editing skills through feedback on grammar issues.

${ }^{1}$ I would like to express my gratitude to Dr. Sharon Pugh for her valuable comments on early drafts of this paper. 
In this paper, I will present some teaching ideas related to the following research question based on my experience as an EFL teacher: if it is true that ELLs really want and benefit from feedback on their grammatical errors, what is the most effective way to teach EFL writing and to promote students' development of grammatical knowledge? In order to answer this guiding question, the role of grammar correction in L2 written texts will be thoroughly examined on the basis of the controversies that surround this issue. My teaching experience of English composition in South Korea will also be provided as supporting evidence. Finally, some pedagogical implications of error correction in teaching writing will be discussed, especially with respect to my own experience of teaching EFL writing classes in South Korea. However, because this is a literature review, I will not focus on concrete classroom examples but rather on underlying principles in order to establish a foundation for my future research.

\section{Controversies over Error Correction}

Scholars take different positions on the subject of error correction. While some discourage error correction, others see value in it. Still others take a middle ground and support error correction in certain circumstances, but not in others. Truscott $(1996,1999,2007)$ has consistently claimed that error correction is harmful and should be abandoned, emphasizing that the fact that students clearly request grammar correction does not imply that teachers should provide it for them. Even if benefits from error correction actually exist, Truscott (2007) still concludes that the harmful effects on students' writing ability are greater. He argues that students who receive no error correction have more positive attitudes toward writing than those who receive error feedback (see also Hillocks, 1986), so even though students without error correction are not better writers, their better attitudes encourage them to write more, resulting in more opportunities to improve their performance than students with error correction.

Polio, Fleck, and Leder (1998) agree with Truscott's position, finding that students who receive error correction are not any better at writing accurate texts than those who do not receive any error feedback. In other words, their study shows that error correction does not help learners make improvements in their grammar and word choice. Fazio's (2001) research shows no significant change in students' accuracy in spelling as a consequence of error correction. Similarly, in a study of twenty-five Dutch high school seniors learning L2 French, Dekeyser (1993) reported that error correction has no positive effect on L2 grammar knowledge.

In contrast to Truscott, Polio, and his colleagues, Fazio, and Dekeyser, a body of research provides evidence that students who receive error feedback from teachers improve the accuracy and overall quality of their writing over time. Ferris (1999) critiqued Truscott's claim that grammar correction should be abandoned, supporting error correction in L2 writing classes through her own previous research findings and teaching experiences. She encouraged language teachers to listen to ELLs and to consider their needs before deciding what and how to provide feedback on error correction. Earlier Ferris (1997) found that summary comments 
on grammar, longer comments (e.g., 16-25 words), ${ }^{2}$ and text-specific comments led to positive changes and improvement in the quality of students' papers. Ferris and Hedgcock (1998) have also argued that grammar and editing feedback can be helpful to most students in improving the accuracy of their writing. Moreover, a study by Bitchener, Young, and Cameron (2005) demonstrates that a combination of written and conference feedback can help upper-intermediate L2 writers improve the accuracy of grammatical features, such as the past simple tense and the definite article.

Similarly, Fathman and Walley (1990) claimed that feedback from teachers that focuses on grammatical errors as well as content is effective in improving student writing. According to these scholars, when teachers underlined grammatical errors found in the writing, students showed significant improvement in grammatical accuracy, and encouraging or suggesting comments were also helpful in improving the content of their writing. Fathman and Whalley (1990) found that if grammatical errors are underlined in addition to general comments on content, students can significantly improve both grammar and content in their writing. Ferris and Roberts (2001) found that the group who received feedback significantly outperformed the no-feedback group on a self-editing task. ${ }^{3}$

Earlier, Krashen (1982) pointed out that too much error correction has little effect on language acquisition. In keeping with his basic theoretical stance, he asserted that errors should be corrected when the goal is learning rather than acquisition, but not in every case. ${ }^{4} \mathrm{He}$ emphasized that not all grammatical errors need to be corrected and that there should be no error correction in informal conversation, so as not to interfere with communication. Krashen did allow for error correction on written texts and grammar exercises under the following conditions: (a) when rules are learnable; (b) under Monitor use; ${ }^{5}$ and (c) when students are “Monitor-users" (p. 119).

Rather than a choice between correcting or not correcting errors, emphasis is generally on the most effective ways to provide such feedback. In particular, Kroll (2001) has warned that teachers should not allow the presence of language problems to change a writing course to a grammar course and that errors should be dealt with at an appropriate stage of writing. For example, teachers' correction of grammatical errors on first drafts can have negative effects on students' writing by

\footnotetext{
2 Ferris (1997) mentioned that longer comments can be more helpful in revising students' writing because they give more explicit feedback.

${ }^{3}$ However, Ferris and Roberts (2001) concluded that less explicit feedback helps students self-edit.

${ }^{4}$ Krashen claims that language acquisition differs from language learning, and that the two have no interface. Language acquisition is defined as the "subconscious process" of using the language through communication, whereas language learning is defined as "conscious knowledge" of a second language attained through formal instruction of the language's grammars or rules (Krashen, 1982, p. 10). Hence, grammar instruction helps language learning, but not acquisition.

${ }^{5}$ According to Krashen (1982), the consciously learned language acts as a "Monitor" (p. 15). The Monitor detects errors to correct incorrect utterances. For example, a language learner begins an utterance and the Monitor edits the utterance.
} 
drawing their attention away from other necessary revisions. Additionally, Weaver (1996) has pointed out that if students cannot draw on their grammatical knowledge when they need to edit, and if they do not have enough time to edit their writing carefully, the formal study of grammar might not transfer naturally to students' writing. Keeping such caveats in mind but without losing sight of the importance of promoting students' development of grammatical knowledge, in the following section, I will discuss a balanced approach to the teaching of EFL writing with a focus on my experience in South Korea.

\section{Considerations for Teaching EFL Writing Courses in South Korea}

A growing body of research has focused on error correction in English as second language (ESL) contexts in which teachers provide error correction in students' L2 writing. English teachers face different challenges in EFL contexts, but the differences between teaching in ESL and EFL contexts are not adequately considered in English language teaching. Thus, we need to reconsider how the suggestions researchers have made on error correction are applicable to EFL contexts.

The issue of grammar correction presented itself in my own experience as an EFL writing teacher at a university in South Korea. When I was asked to teach a basic English composition course and an advanced English composition course simultaneously, I decided to teach a grammar-based writing class for the basic English composition course and a reading-based writing class for the advanced English composition course. My teaching goals were to help students engage in writing effectively by teaching them basic grammar in a basic English composition course and by exposing them to various reading texts in an advanced English composition course.

My pedagogy for the advanced English composition course can be supported by both theoretical claims and empirical studies that demonstrate significant correlations between reading and writing. Kern (2000) has claimed that reading and writing are "not singular, unitary constructs, but rather culture-, context-, and taskdependent constructs" (p. 63). Bossone and Troyka (1976) also reported significantly positive effects on writing ability on students' expository writing in English composition courses that integrate reading instruction and writing instruction. Likewise, Eckhoff's (1983) study found that children's writing included grammatical features found in their reading texts, suggesting that children may learn about language structures by being exposed to written texts, which may have a positive impact on their writing. Bélanger (1987) also mentioned that there is a link between reading achievement and writing performance and that skilled writers are usually able readers. A study by Elley and Mangubhai (1983) investigated the effect of systematic exposure to a rich variety of highly engaging illustrated story books on the general L2 language proficiency of elementary school children in the Fuji islands. They concluded that pleasure reading in L2 positively influences L2 writing in conditions where children strive for meaning and receive sufficient support for greater exposure to print in high-interest contexts. Moreover, Janopoulos (1986) 
found a significant positive correlation between reading and writing in L2 and that proficiency levels for L2 reading and writing are closely related, especially in adult learners. He concluded that the amount of pleasure reading in L2 may be a reliable predictor of L2 writing proficiency.

On the other hand, regarding my experience as an EFL teacher in the basic English composition course, I expected that students would need to know about grammar in order to comprehend texts and to write accurately. Even now, I still believe that students need to develop their grammatical accuracy and that teaching grammar can make students better readers and writers (Hinkel, 2002). Some research points out the value of form-focused over non-form-focused instruction to improve learners' accuracy (Larsen-Freeman, 1995). Larsen-Freeman (1997) has further argued that grammar should be seen as a rational, dynamic system that is composed of structures characterized by the three dimensions of form, meaning, and use, rather than as a static system of arbitrary rules.

In my basic English composition class, I began by trying to understand students' needs for grammar instruction, which depended on their level of English proficiency and the extent of their prior exposure to English. Since most of my students were freshmen and many of them lacked confidence in academic writing, I focused mainly on very basic sentence patterns, including important sentence-level grammar such as tenses and word form (e.g., subject-verb agreement, verbpreposition agreement, and articles). In fact, my students felt that the appropriate use of English tenses was one of the most difficult aspects of English grammar.

At the beginning of the semester, I faced the risk of my basic writing course transforming into a grammar course, but I tried to make grammar instruction in my class appropriately simple and narrowly-focused while following my original course schedule (Ferris \& Hedgecock, 2005). As Ellis (1993) has suggested, I viewed grammar teaching as consciousness-raising rather than as the practice of accurate production. I asked students to write various patterns, from sentences to paragraphs to short essays, on given topics, based on the grammar instruction they learned in class. I did not have any difficulty providing linguistic explanations of English grammar because I had studied it in depth for many years. However, a big problem with my class was that it was too large to give students individual feedback on their writing assignments at various stages of the writing process.

Particularly at the beginning, giving my students grammatical error-focused feedback on every single assignment was difficult because they made many mistakes with basic grammar and word choice. Although Robb, Ross, and Shortreed (1986) have pointed out that such direct feedback is not directly related to the improvement of students' overall ability to write accurately, I was afraid that I could not help students systematically reduce the amount of grammatical errors in the time available (Ferris \& Hedgecock, 2005).

Fortunately, my advanced English composition course was much smaller and was composed of students who had a higher level of English proficiency. Most were juniors and seniors. As the course progressed, I exposed my students to sufficient 
reading in class or homework assignments ranging from simple passages to long complex texts. My strategy for the advanced composition class was related to Ruddell's (2005) definition of writing as "the act of constructing meaning while transacting with text" (p. 39). In other words, writers make meaning by combining prior knowledge, previous experience, and information emerging from new texts.

I also believed that reading in the EFL classroom could function as an appropriate input for the acquisition of writing skills. This belief comes from the claim that better L1 writers read more than poorer L1 writers, which shows a correlation between reading achievement and writing ability (Ryan, 1977; Krashen, 1984). Ryan (1977) reported that the parents of good writers frequently read to them as children and that these parents read more themselves (cited in Krashen, 1984). That study supports Krashen's (1984 \& 1993) later claim that reading, especially when it is voluntary and pleasurable, contributes to the development of many aspects of writing ability. Eisterhold (1990) also affirmed that effective writing teachers are sensitive to the relationship between reading and writing.

Even in an advanced English composition course, I touched on problematic aspects of English grammar such as definite/indefinite articles and prepositions, which I perceived to be among the hardest parts of English grammar for Korean students to fully acquire. Generally, most of my students had good control of sentence-level grammar, but many students liked such supplemental grammar instruction to build their editing skills. ${ }^{6}$ It seemed to be true that learning particular grammatical distinctions requires a great deal of time even for the most skilled learners.

I tried to give students individual feedback on their writing on a regular basis. My students in the advanced English composition class still made some minor mistakes in sentence structures and word choice, but their writing skills were good or sometimes excellent. In retrospect, I regret that I did not know how to introduce self-editing strategies and peer-editing workshops at that time, which could have been helpful in improving more advanced student writing (Ferris \& Hedgecock, 2005).

Overall, looking back on my English composition courses as an EFL teacher, I tried to provide students with tools for their continued growth as writers and for the successful fulfillment of their future academic writing through systematic grammar instruction (see Kroll, 2001). Compared to the beginning of the semester, many of my students in the basic and advanced composition classes came to feel more confident in academic writing through constant grammar instruction and extensive reading.

\footnotetext{
${ }^{6}$ In general, it is argued that beginners need more grammar instruction than advanced learners. As Ellis (1984) mentions, however, it can be argued that grammar instruction better equips advanced learners because complex knowledge of the target language cannot be picked up after the occurrence of fossilization.
} 
However, teaching the advanced course was much more difficult than teaching the basic course because teaching appropriate word choice and natural connections between paragraphs was more challenging. Highly proficient English learners still wanted to learn more about advanced grammar, but at times it was difficult for me to touch on subtle grammar points that usually require a native speakers' intuition to understand completely. In this regard, in order to effectively teach English writing courses to more than upper-intermediate students, EFL teachers need to make an effort to achieve high proficiency in English.

\section{Pedagogical Implications for EFL Writing Classes}

From my teaching experience in South Korea, I learned that emphasis on comprehensible input (Krashen, 1982) is more relevant to advanced than to beginning learners, who prefer the support of explicit grammar instruction. Advanced students are ready to develop vocabulary and writing style through extensive reading (Krashen, 1993) along with opportunities to refine their knowledge of English grammar. Also, they are aware that grammatical accuracy plays a crucial role in evaluations of EFL students' writing (Hinkel 2002). As I experienced in my basic English composition class, overt instruction in grammar is important, especially for beginning-level learners because it can increase learners' exposure to language structure. However, when EFL writing teachers want to provide grammar instruction for students' writing, they should remember that (a) writing classes are not grammar classes; (b) explicit instruction should be based on an awareness of students' needs; and (c) effective grammar instruction includes short and narrowly-focused activities (Ferris \& Fedgecock, 2005). Moreover, teachers should always remind students that grammatical errors are common in the writing process and discourage students from associating those errors with the quality of the writing.

Many teachers are not comfortable with allowing errors in the classroom, but meaningful errors are beneficial for students because they can learn language transfer or interruption through the repetitive patterns in their errors. ${ }^{7}$ In this case, correction is meaningful because students can learn why they make errors in specific contexts. When deciding whether to correct errors, EFL teachers should consider their goals and objectives for their students. If their goal is to create fluency and to help students feel comfortable speaking or writing, then teachers must be careful not to over-correct. If teachers point out too many errors, they may make students feel self-conscious and they may shut down. This is especially true when it comes to spelling. If teachers start covering the paper in red ink due to spelling mistakes, then students may become more fearful of writing and may stop trying new words or writing altogether. This greatly hinders development.

On the basis of my discussion in this paper, I can thus conclude that the most effective way of handling grammatical errors in helping EFL students develop their writing skills may be an inductive approach (see also Richard-Amato, 2003):

\footnotetext{
${ }^{7}$ Language transfer or interruption can occur when EFL writers apply knowledge from their native language to English.
} 
teachers can help students identify errors by underlining or circling words or phrases in which problems occur and students can identify their grammatical errors through their own grammatical knowledge. I agree with Frodesen's (2001) suggestions that, (a) indirect correction of errors should be provided; (b) teachers should focus on the errors that need the most attention rather than on all errors in writing; (c) teachers should consider many student variables, such as metalinguistic knowledge and proficiency level, and the instructional situation; and (d) teachers can give feedback on errors in early drafts as well as in later stages of the writing process or in the last draft, according to students' needs and desires. In other words, teachers should help writers develop their linguistic knowledge, including grammatical systems, to convey ideas appropriately and meaningfully to readers. Because feedback on grammatical errors may become more difficult as linguistic complexity increases, it is important for EFL teachers to continue strengthening their own language resources for helping students.

Teachers' feedback, such as error correction in students' writing, is a very important issue in EFL settings because grammar correction represents one of the most crucial forms of feedback. If students are not given any feedback opportunities in a writing class, they have little reason to be there. Most EFL students are very interested in improving their writing skills. As I learned from my writing classes, it is desirable that a writing curriculum in EFL settings includes some grammar instruction for beginners as well as for advanced learners, with emphasis on different grammatical elements to help develop their writing abilities. However, the course need not be heavily grammar-oriented. Particularly from a process-based perspective, writing is "essentially learnt, not taught," and teachers should assist students "to express their own meanings through an encouraging and cooperative environment with minimal interference" (Hyland, 2003, p. 18).

Hence, in EFL writing classes, the strategies and processes involved in students' writing as well as the nature of learning should be considered. To do that, EFL teachers need to be cautious in deciding when, how, and which errors should be corrected, depending on the academic needs of the students and the pedagogical goals of the courses. Finally, since teaching in the EFL context is obviously different from teaching in the ESL context, teaching methodology and textbooks for writing classes need to be situated in contextual conditions (Brutt-Griffler \& Samimy, 1999). In other words, EFL writing teachers should focus on students' needs and learning styles appropriate to the EFL context. My hope is to help EFL teachers understand how to teach students to be successful writers and to promote students' development of grammatical knowledge based on my previous experience as an EFL teacher in South Korea. Furthermore, I hope that my ideas of error correction for EFL writing classes can prompt discussion and further study. 


\section{References}

Bélanger, J. (1987). Theory and research into reading and writing connections: A critical review. Reading-Canada-Lecture, 5(1), 10-18.

Bitchener, J., Young, S., \& Cameron, D. (2005). The effect of different types of corrective feedback on ESL student writing. Journal of Second Language Writing, 14, 191-205.

Bossone, R., \& Troyka, L. Q. (1976). A strategy for coping with high school and college remedial English problems. New York: City University of New York, Center for Advanced Study in Education. Retrieved from http://www.eric.ed.gov/ERICDocs/data/ericdocs2sql/content storage 01/00 00019b/80/36/cd/77.pdf

Brutt-Griffler, J., \& Samimy, K. (1999). Revisiting the colonial in the postcolonial: Critical praxis for nonnative-English-speaking Teachers in a TESOL program. TESOL Quarterly, 33, 413-432.

Dekeyser, R. (1993). The effect of error correction on L2 grammar knowledge and oral proficiency. Modern Language Journal, 77, 501-514.

Eckoff, B. (1983). How reading affects children's writing. Language Arts, 60(5), 607616.

Eisterhold, J. C. (1990). Reading-writing connections: Towards a description for second language learners. In B. Kroll (Ed.), Second language writing: research insights for the classroom (pp. 88-101). Cambridge, UK: Cambridge University Press.

Ellis, R. (1984). Can syntax be taught? A study of the effects of formal instruction on the acquisition of WH questions by children. Applied Linguistics, 5(2), 138-155.

Ellis, R. (1993). The structural syllabus and second language acquisition. TESOL Quarterly, 27, 91-113.

Fathman, A. K., \& Whalley E. (1990). Teacher response to student writing: Focus on form versus content. In B. Kroll (Ed.), Second language writing (pp. 178-190). Cambridge, UK: Cambridge University Press.

Fazio, L. L. (2001). The effect of corrections and commentaries on the journal writing accuracy of minority- and majority-language students. Journal of Second Language Writing, 10, 235-249.

Ferris, D. R. (1997). The influence of teacher commentary on student revision. TESOL Quarterly, 31, 315-339.

Ferris, D. R. (1999). The case for grammar correction in L2 writing classes: A response to Truscott (1996). Journal of Second Language Writing, 8, 1-11.

Ferris, D. R. (2004). The "grammar correction" debate in L2 writing: where are we, and where do we go from here? (And what do we do in the meantime...?). Journal of Second Language Writing, 13, 49-62. 
Ferris, D. R., \& Hedgcook, J. (1998). Teaching ESL composition: purpose, process, and practice. Mahwah, NJ: Lawrence Erlbaum.

Ferris, D. R., \& Hedgcook, J. (2005). Teaching ESL composition: purpose, process, and practice ( $2^{\text {nd }}$ ed.) Mahwah, NJ: Lawrence Erlbaum.

Ferris, D. R., \& Roberts, B. (2001). Error feedback in L2 writing classes: How explicit does it need to be? Journal of Second Language Writing, 10, 161-184.

Frodesen, J. (2001). Grammar in writing. In M. Celce-Murcia (Ed.), Teaching English as a second or foreign language (pp. 233-248). Boston: Heinle \& Heinle.

Hillocks, G. (1986). Research on written composition: New directions for teaching. Urbana, IL: ERIC Clearinghouse on Reading and Communication Skills/National Conference on Research in English.

Hinkel, E. (2002). Grammar teaching in writing classes: Tenses and cohesion. In E. Hinkel \& S. Fotos (Eds.), New perspectives on grammar teaching in second language classrooms (pp.181-198). Mahwah, NJ: Lawrence Erlbaum.

Hyland, K. (2003). Genre-based pedagogies: A social response to process. Journal of Second Language Writing, 12, 17-29.

Janopoulos, M. (1986). The relationship of pleasure reading and second language writing proficiency. TESOL Quarterly, 20(4), 763-768.

Kern, R. (2000). Literacy and language teaching. Oxford: Oxford University Press.

Krashen, S. D. (1982). Principles and practice in second language acquisition. New York: Pergamon.

Krashen, S. D. (1984). Writing: Research, theory, and applications. Oxford: Pergamon.

Krashen, S. D. (1993). The power of reading: Insights from the research. Englewood, CO: Libraries Unlimited.

Kroll, B. (2001). Considerations for teaching an ESL/EFL writing course. In M. CelceMurcia (Ed.), Teaching English as a second or foreign language (pp. 219-232). Boston: Heinle \& Heinle.

Larsen-Freeman, D. (1995). On the teaching and learning of grammar: Challenging the myths. In F. R. Eckman, D. Highland, P. W. Lee, J. Mileham, \& R. R. Weber (Eds.), Second language acquisition: Theory and pedagogy (pp. 131-150). Mahwah, NJ: Lawrence Erlbaum.

Larsen-Freeman, D. (1997). Grammar and its teaching: Challenging the myths. Online Resources: ERIC Digest.

Polio, C., Fleck, C., \& Leder, N. (1998). "If I only had more time:" ESL learners' changes in linguistic accuracy on essay revisions. Journal of Second Language Writing, 7, 43-68.

Richard-Amato, P. A. (2003). Making it happen: From interactive to participatory language teaching. Theory and practice. New York: Longman. 
Robb, T., Ross, S., \& Shortreed, I. (1986). Salience of feedback on error and its effect on EFL writing quality. TESOL Quarterly, 20, 83-95.

Ruddell, M. R. (2005). Teaching content reading and writing (4th ed.). Hoboken, NJ: Wiley.

Ryan, J. (1977). Family patterns of reading problems: The family that reads together. In M. Douglas (Ed.), Claremont reading conference: 41st yearbook (pp. 159163). Claremont, CA: Claremont Graduate School.

Truscott, J. (1996). The case against grammar correction in L2 writing classes. Language Learning, 46, 327-369.

Truscott, J. (1999). The case for "the case for grammar correction in L2 writing classes": A response to Ferris. Journal of Second Language Writing, 8, 111-122.

Truscott, J. (2007). The effect of error correction on learners' ability to write accurately. Journal of Second Language Writing, 16, 255-272.

Weaver, C. (1996). Teaching grammar in context. Portsmouth, NH: Boynton/Cook. 


\title{
Undocumented Mexican Immigrants in Adult ESL Classrooms: Some Issues to Consider
}

\author{
Sheri Jordan
}

\begin{abstract}
With anti-immigrant sentiments permeating the media, policy, and public discourse throughout the United States, little room seems to exist for understanding what drives Mexican migrants northward. However, while acknowledging the historical conditions leading to US immigration policy, negative discourses and stereotypes in the American media and public, continuing Mexican migration in spite of great sacrifice, and the choices of individuals to migrate to the US, adult ESL educators need a framework as they encounter these students in the classroom. This framework combines Freire's "pedagogy of the oppressed" with a transformative pedagogy that relinquishes deficit models and invites student knowledge into the classroom.
\end{abstract}

\section{Introduction}

The City/La Ciudad, filmed over a 6-year period by David Riker (1999), offers "a moving tribute to the struggles and hopes of a group of new Latin American immigrants facing the harsh realities of urban America" (DVD case description). Several black and white cameos of the lives of first-generation immigrants to New York City facing daunting odds depict the bleakness of their situations and pose disturbing questions for American viewers watching comfortably from soft living room couches: Why do these immigrating hopefuls make such great sacrifices to live such second-class lives in our urban centers? Why would grown men fight each other for a hard labor job paying 15 cents per brick cleaned, only to see a comrade die tragically when a wall collapses and the boss is nowhere to be seen to assist? Why would a young woman stay in the US for four years, never once going back to Mexico to see her family, choosing to remain instead in cold American urbania for the sake of sending money home? Why would a tuberculous puppeteer spurn the homeless shelters and choose instead to live in his car with his daughter, who cannot get into a school because he has no proof of residential address? The tragedies abound and, from the reports of my own immigrant contacts in California, where the most immigrants and illegal immigrants to this nation flock (Camarota, 2007), this movie depicts la realidad.

I open my paper with this movie not only for dramatic effect, but because I have heard similar stories from Mexican, Latin and South American students and friends. Migration through our southern border is not only a hot topic in the US now, but has been for decades. Teachers need to familiarize themselves with their students' histories and cultures and the sociopolitical context of immigration, 
language, and education policies (Nieto \& Bode, 2008; Menard-Warwick, 2005). This paper seeks to introduce some of this historical and sociopolitical context, as well as to recommend critical pedagogical approaches that tap into adult ESL students' funds of knowledge and move beyond deficit models of immigrant education.

\section{The "Mexican Problem": Anti-Mexican Discourses in the US}

Most Americans are far from sympathetic to the cause of the immigrantparticularly the immigrant from Latin America, more particularly from Mexico, and even more so, the "illegal" immigrant. We hear anti-immigrant complaints that "they are taking over" American cities, particularly in southern states, that they lower the neighborhood's standard of living, and that they raise the cost of healthcare, since nearly $34 \%$ of immigrants, compared with $13 \%$ of native-born Americans, have no medical insurance, which drives up healthcare costs for everyone else (Camarota, 2007). They overcrowd schools- "illegal immigration" was cited as the number one reason for the overcrowding of LA Unified school district schools in a panel discussion of the education situation there in 1996 ("Inalienable Right?")—and purportedly refuse to learn English. These are common reasons for the sentiment "JUST GO HOME" felt by many US citizens who daily rub shoulders with immigrants - particularly Mexicans-and feel that somehow these immigrants are taking something that is not theirs to take from "us hard-working, god-fearing, taxpaying citizens."

This stigmatizing ideology of Discourses (big D, in Gee's 1990 scheme) in US media (and policy) regarding immigrants, particularly Mexican migrants, has become so naturalized in the US that most citizens take its messages as established fact. Migration (particularly from the south) is traditionally framed as a "problem" even by anthropologists, probably in large part because policy-driven research is not neutral (Castles, 2010). Earlier migration research focused on the problem of Mexicans not assimilating, and there has been a return to "neo-assimilationist approaches" in recent literature (Castles, 2010, p. 1571). Huntington (2004) seems to epitomize nationalist anti-Mexican sentiments about "the Mexican problem" (cited in Smith, 2007, p. 1098), with Mexicans invading the US and refusing to assimilate or speak English. Stephen (2007) attributes the "politics of fear" regarding the border (p. 31), or what Schiller, Basch \& Blanc (1995) call a "bunker mentality" (p. 59), to "border defense groups" like the Minutemen (Stephen, 2007, p. 31). The "Mexican problem" appears at all levels of US society, from national and state immigration and language policies to schools and the deficit theory applied to children of immigrants-multiple and interlinked formulations of the "Mexican problem" that I will attempt to touch on here.

Sociological and anthropological literature also makes it clear that antiimmigrant/anti-Mexican rhetoric and policies are nothing new in the US. De Genova (2002) emphasizes the need to examine "how the historical production of the racialized figure of 'the Mexican' as male 'sojourner' has been rendered synonymous with migrant 'illegality'" (436). In the 1920s (as before and after this period, and as with other racialized groups throughout US immigration history), illegal immig- 
ration was seen as "part of an emergent Mexican 'race problem"' (Ngai, 2004, p. 7), and it was believed that "the narrow frame of 'Americanization' could never assimilate Mexicans as full national citizens: by their language, their ethnic particularity, and their perceived racial difference, working-class Mexicans remained indelibly alien" (Schmidt-Camacho, 2008, p. 28). As far back as 1911, the Dillingham US Immigration Commission announced the following:

Because of their [Mexicans'] strong attachment to their native land, low intelligence, illiteracy, migratory life, and the possibility of their residence here being discontinued, few become citizens of the United States [...] While they are not easily assimilated, this is of no very great importance as long as most of them return to their native land. In the case of the Mexican, he is less desirable as a citizen than as a laborer. (quoted in De Genova, 2002, p. 434)

Thus Mexicans became a distinct group of "undesirables" in the US, and it seems that has not changed much, if the current media and policy rhetoric (particularly in California's Proposition 187 and Arizona's new laws, as well as the trend for such laws increasing in other states) is any indication.

US history attests to public policies decrying the legitimacy of Mexican workers within our borders, when in fact labor and immigration policies encouraged migration northward (Coutin, 2003; Wilson, 1999; De Genova, 2002). Wilson (1999) recounts the major policies scapegoating Mexicans and herding them south: "Since the Great Depression of the 1930s, Mexican laborers have been targeted, stereotyped, blamed and subsequently deported in times of economic crisis" (p. 2). The early "Repatriation Program" herded undocumented Mexican laborers back south. Then "Operation Wetback" shipped them out again during the 1950s recession, with such deportations repeated during the next recession in the 1970s. "Operation Jobs" in the 1980s initiated "raids on workplaces employing Mexican immigrants," with the subsequent deportation of both undocumented immigrants and racially profiled US citizens (Wilson, 1999, p. 2).

Farr (2006) notes wryly that "whenever the 'anti-immigrant' climate in the United States grows, each legislative act intended to curb this migration unintentionally increases it" (p. 57). Other sources confirm this claim (Ngai, 2004; Schmidt-Camacho, 2008; Stephen, 2007). De Genova (2002) discusses the "revolving door policy" of employers and US policy, "whereby mass deportations are concurrent with an overall, large-scale, more or less permanent importation of Mexican migrant labor (citing Cockroft 1986) - for a long time INS split statistics on 'deportable aliens' into 'Mexicans and All Others'” (p. 433). In 1973, 99\% of all deported illegals were Mexican (De Genova, 2002). Surely, though they clearly make up a large percentage of the undocumented, they are not $99 \%$ of it-which suggests racial profiling.

Coutin (2003) notes another paradox in US immigration policies that force migrants into "spaces of nonexistence" (p. 172), tolerating their presence while officially denying it. She notes "underlying tensions" (p. 187) identified by Calavita (1994) which explain this contradiction: employers' demand for cheap labor versus 
employees' demands for fair wages; and the political and logistical unfeasibility of fully enforcing anti-immigration laws. Although it is beyond the scope of this paper to solve the decades-long legal debate over immigration, it is important to understand how national and state policies have permeated the public's perception of workers and families migrating from the south. Mass media messages stir up the anti-immigrant frenzy, as well. Wilson (1999) comments that immigrants have become a convenient target of policy and mass media to avoid tackling the fundamental structural problems of capitalism, for which importing cheap labor is integral.

\section{Terminology}

When discussing immigrants, disparate terms, associations and realities tend to be conflated and muddled together. "Immigrant" emphasizes one-way movement into a receiving country from a sending country, when in fact many Mexican workers are "migrants," moving around the continent for seasonal work and eventually returning to their country (De Genova, 2002). As Mexican communities in the US become more established and grow, while keeping close ties with their home communities, they become "transnational," feet solidly placed in at least two localities. "Illegality" emphasizes the commission of a crime by crossing a border without state-sanctioned papers (or overstaying the expiration date on existing papers), while "undocumented" loses some of the volatility of illegality. "Illegal" or "undocumented" immigrants are usually associated with Mexicans, and Latinos are quickly suspected of illegitimate presence in the US (De Genova, 2002). Even discussing "the immigrant" or "migrant laborers" or "Mexican transnationals" errs by essentializing and homogenizing groups with an objectifying label (De Genova, 2002). All of this is to admit that while we are on terminologically and conceptually shaky ground when discussing the "undocumented immigrant," the focus here is to acknowledge but see past the rhetoric to explore what having "undocumented immigrant" students in our adult ESL classrooms may mean. Throughout this paper I will use the term "immigrant," realizing this may not be accurate in all cases, and the terms "undocumented" and "illegal" interchangeably to mirror the public discourses.

\section{Moving Beyond the Stereotypes}

As neighbors and teachers of immigrants with questionable legal status, we need to "stop regarding the oppressed as an abstract category" [in this case, lumping "immigrants" together with insidious stereotypes] "and see them as persons who have been unjustly dealt with, deprived of their voice, cheated in the sale of their labor" (Freire, 2007, p. 50). Many of my students in a non-credit adult ESL program in Southern California sent money to families at home, while others tried to sustain family who had come with them or joined them here-and yet, even while working 9 to 10 or more hours 6 to 7 days a week, they still valued English enough to come to evening classes 2 to 4 nights a week. Like Rafael in "The Progress of Rafael in English and Family Reading: A Case Study" (Lanteigne \& Schwarzer, 1997), who worked long hours and yet devoted time his own and family members' 
development, my students provided counterexamples to the degrading stereotypes floating around in dominant American cultural scripts. I learned that even undocumented immigrants held stable jobs, sometimes with health benefits and union membership, paid car insurance and taxes, and otherwise lived "god-fearing, law-abiding" lives, aside from the minor detail of lacking the proper "papers." This blatant confrontation to common stereotypes begs questions beyond even those raised by La Ciudad: Why are these people considered such a threat to national security? And if we accept that they are "here to stay," why are we as a nation so reticent to provide them with education and other basic services-some would argue "human rights" (Ticktin, 2006)? Thus the issue I wish to address here is complicated, involving a combination of the stigma, oppression and stereotypes imposed upon Mexican immigrants and the "bad press" undocumented immigrants receive, in addition to questions of educational policy and providing access to "illegals," and the dilemma of how best to serve this demographic in adult education (not to mention K-12) programs.

One of the questions I mention above-why these immigrating hopefuls make such great sacrifices to live such second-class lives in our cities-relates closely to the oppressiveness of their situation. In March 2007, one eighth of residents in the US were immigrants, numbering 37.9 million, and almost one third of these immigrants were undocumented (Camarota, 2007). Over half of the 10.3 million immigrants who entered the US since 2000 are supposedly undocumented, and half of Mexican immigrants are "illegal," comprising an estimated 57\% of the undocumented "aliens" in this country (Camarota, 2007). According to this same report by the Center for Immigration Studies in Washington, DC, 28\% of Mexicans live "in poverty," and $60 \%$ live "in or near poverty," compared with $12 \%$ of "all persons" in poverty and $30.5 \%$ of the general population "in or near poverty" (Camarota, 2007). The report attributes this, as well as the greater use of welfare services and smaller payment of taxes proportionally, to the fact that immigrants from Mexico typically come with only a three-year high school education or less and have larger numbers of dependents (Camarota, 2007). These statistics seem to subtly frame the situation with a xenophobic bent, reflecting the xenophobic, antiMexican discourse that permeates our culture. This also relates to much of the stigma Mexican immigrants must face in the stereotype that they are poor, lowering the general standard of living around them, leeching off the American economy. The above report concludes that granting legal status to undocumented immigrants would likely do little good because of their lower educational attainment. Of course, this would seem to lump all immigrants into the same "boat" with the $57 \%$ of Mexican immigrants who have not finished high school (Camarota, 2007). However, this seems like a huge oversimplification of the problem and its solutions. It of course also views the "immigration problem" in abstract terms, not in terms of its human constituents.

Two tightly knotted issues surrounding the "problem" of "undocumented Mexicans in the US" include (1) the claim that there are so many undocumented immigrants in this country that this is harming our country (overcrowded schools, people who can't function in English, etc.), and (2) the question of whether "illegals" 
have any right to education. For children, the latter was addressed by the Supreme Court Plyler v. Doe decision in 1982, which argued that children should not have to pay for "the sins of their parents" and that "equal protection' under the Fourteenth Amendment 'is not confined to the protection of citizens'" (Stewart, 1993, p. 38). The majority opinion stated, "we cannot ignore the significant cost of social costs borne by our Nation when select groups are denied the means to absorb the values and skills upon which our social order rests" (quoted in Stewart, p. 39). This statement acknowledges the sociocultural capital inherent in school-taught literacy that enables people to function in a domain-in this case, in American schools, workplaces, and society in general (Bourdieu; Marsh, 2006; Compton-Lilly, 2007). As Gutierrez \& Orellana (2006) note regarding the "cultural deprivation" theory, "differences are never just difference; they will always be interpreted and ranked according to dominant cultural values and norms" (p. 506), and immigrant children "different" from dominant culture students will thus be stigmatized for life (Stewart, 1993).

However, this Supreme Court ruling has been challenged and overturned in some states. This goes back to issue \#1 above, blaming overcrowding in schools on massive illegal immigration. For instance, in California, "on education alone the state is spending close to $\$ 2$ billion this year to school 380,000 illegal immigrant children," and illegal immigration in this transcript is claimed to be the "No. 1 reason that Los Angeles Unified School District schools are overcrowded" (Kaye, 1996). This claim again reflects the kind of anti-immigrant sentiment that circulates around our society as the power in discourse that Foucault describes (1990/1978), or Gee's (1990) "Discourse." One "solution" proposed to the issue of undocumented children in schools is that parents be pursued and deported (and the children will follow) rather than enforcing immigration laws in schools (Kaye, 1996). Clearly, recent changes in Arizona law and bills in Indiana, as well as other states, are dealing a heavy hand to both the documented and undocumented in those states, further complicating this situation.

Regarding the education of adults, in the 1980s the Carter administration created an amnesty immigration measure-the Immigration Reform \& Control Act (IRCA) - requiring that illegals only take forty hours of ESL to qualify for amnesty (legal residence in the US; Perlmutter, 1999). That measure is no longer in place, although, as in the "don't ask, don't tell" policy in LA public schools, adult schools also have a long tradition of not asking students' legal status. Now, arguments against the education of undocumented adults include the cost, overcrowding of schools, and long wait lists. Arguments for educating "illegals": they are here, and that is the reality. According to one researcher, "English proficiency among immigrants is linked to higher earnings and tax contributions, lower welfare dependency and greater educational and economic advancement in the second generation"-greater economic capital, in Bourdieu's paradigm - "It's not just a cost. [...] There are returns on this investment"' (quoted in Brulliard, 2007). (Although this quote refers to second-generation immigrants, the principle could readily extend to first generation immigrants). Even with hyper-vigilant enforcement, not all of the many illegals who have entered the US since 2000 will be 
caught. What they need-and if we are honest, what we need for them-is that they can be functioning members of society-which in general entails speaking English.

\section{Immigrants in the Adult ESL Classroom}

ESL teachers of adult immigrants tend to see their role as helping students improve traditional literacy skills and improve scores on the CASAS (Comprehensive Adult Student Assessment System) test-which, incidentally, was the primary IRCA indicator that students had achieved the English level needed to get the green card when that policy was in place (Ferguson, 1998). Even the desire to help immigrants assimilate into the new culture can cause symbolic violence to students (Bourdieu, as discussed in Compton-Lilly, 2007)-or, in Freirean terms, this can be a form of "cultural invasion" in which "the oppressed become convinced of their intrinsic inferiority" linguistically, culturally, and so forth (2007, p. 153). Adult ESL teachers-consciously or subconsciously-often frame lessons in terms of assimilation, when in fact they are imposing their own "world view upon" their students (Freire, 2007, p. 160). However, rather than "teaching with the goal of having students register progress on discrete measures," teachers must "desire to speak to students' cultural identities [and] honor the realities of their lives" (Campano, 2007, p. 4). Rather than "brand[ing]" our literacy level students as "'illiterate' or 'subliterate"' (Campano, p. 13), we must come to recognize and value the "life experiences, values, and literate practices" of our students, helping these students to "become more effective agents in their own educational development" (p. 14). In Freirean terms, this means engaging our students in dialog toward transformation (2007/1970).

\section{Critical Pedagogical Approaches: Finding the Right Balance}

This is not to suggest that guiding our students toward this Freirean liberation will be easy, straightforward, or even welcomed. Lytle (1993) notes that teacher research is "risky" (p. 20) "profoundly political" (p. 21), and "entail[s] boundary crossings and power negotiations that raise further issues" (p. 23)-all of which apply to the incorporation of critical pedagogy into the classroom. Traditionally, teachers are "well-intentioned bank clerks" who see themselves-and in fact, whom the students likely see as- "depositing" knowledge into the "banks" of student brains (Feire, 2007, p. 74). However, in Feire's view, this hierarchical pedagogy is "dehumanizing" (p. 75). In the Freirean tradition of pedagogy, teachers no longer hold a hierarchical position in the classroom but use a "friendship strategy" that allows students to question without fear of being demeaned or shut down (Bartlett, 2005, p. 352). However, the "friendship strategy" is not enough-Bartlett (2005) found limitations in this approach in that students still considered teachers their "superiors" outside of the classroom, and "reduced Freire's complex notion of dialog to a more simplistic ideal of egalitarian classroom discussion" (p. 356), which failed to address "the very social critiques Freire advocated" (p. 359).

The additional Freirean principle of and integrating students' experiences into the classroom-clearly related to the Bourdieuan concept of sociocultural capital and recognizing the capital students bring to the classroom (Compton-Lilly, 
2007; Marsh, 2006), rather than viewing students in terms of their "deficits" (Gutierrez \& Orellana, 2006) - was also oversimplified in practice in Bartlett's (2005) study: teachers generalized immigrants, rather than recognizing their vast diversity; they tried to move students to see the world from their perspectiveclearly not what Freire intended when he said, "Revolutionary leaders cannot think without the people, nor for the people, but only with the people" $(2007$, p. 131). Teachers must become "co-investigators" of problems with their students (Freire, 2007, p. 106), "co-authors of the action that both perform upon the world" (p. 180) open to the "cross-pollination of these two sets of experiences that fuels inquiry" (Campano, 2007, p. 112). Even well-meaning programs seeking to help immigrant adults assimilate through counseling and other extracurricular programs (Szelenyi \& Change, 2002) seem to view students from both deficit model and banking perspectives. How to meet these students' real needs without creating symbolic violence/cultural invasion is tricky, but programs do exist which have done so successfully, such as the Nuevos Horizontes program at Triton College (Illinois), which offers "services including citizenship classes, free legal advice on immigration and naturalization policies, tax preparation assistance, parenting workshops, academic counseling, cultural events," and tutoring, in addition to encouraging the cultural contributions of its Hispanic students (Szelenyi \& Chage, 2002).

Teachers in the Bartlett (2005) study faced other dilemmas, such as encountering student knowledge based on folk wisdom or "knowledge" that countered teachers' own "reverence for official, school knowledge" (p. 359). Clearly, making the shift from a traditional, hierarchical pedagogy to a more egalitarian, dialogical, problem-posing pedagogy is not smooth or unproblematic. Lalik and Oliver (2007) discuss the resistance of Oliver's adolescent students to her agendas (such as extending survey questions to include non-heterosexuals and broadening attraction to go beyond mere appearance) and how teacher and students negotiated and compromised on the curriculum. Oliver had to compromise her agenda by letting what was important to her drop when it was repeatedly rejected by the adolescent girls.

Perhaps a more serious problem would be teachers resistant to incorporating a problem-posing pedagogy in favor of the traditional approaches, simply because those are familiar, comfortable, and secure. However, teachers must realize that they are participating in hegemony, "the process by which we learn to embrace enthusiastically a system of beliefs and practices that end up harming us and working to support the interests of others who have power over us" (Brookfield, 2005, p. 94). Educators who sacrifice their time and energy as a reaction to budget cuts may feel a "private moral commitment" to their "vocation," but they are participating in "a mechanism of control and a prop to the maintenance of the exchange economy" (p. 103). As Freire asserted, teaching, then, is no longer a safe, charitable, neutral vocation, but rather entails a political obligation to empowering students. Educators may in fact be enjoying the "emotional dependence" of the "oppressed" (Freire, 2007, p. 66) without even realizing it. 
Part of empowering students through a "dialogical" approach involves helping them place their situation in "historical context" (Freire, 2007, p. 176). In the general US immigration context, immigrants for centuries have always been "denied full acceptance by public and private institutions, whose leaders insisted they learn English, reject past allegiances, and become totally assimilated" (Perlmutter, 1999, p. 213). As far back as 1919, newspaper editorials criticized the insistence of monolingual "Americanizers" that multi-lingual immigrants speak English and only English (Perlmutter, 1999). No doubt to the vexation of Englishonly enthusiasts, the earliest European immigrants to the United States "were from Spain and not from England in 1598" (Jeria, 1999), which would suggest Spanish as the first non-native colonizing language of this country, not English. Anti-Hispanic sentiment is threaded throughout our history, but not (according to one source) when Hispanics were "viewed as useful resources for economic productivity" (Jeria, 1999)-although I would argue that even when they have been purportedly "welcomed" into this country, the stereotypes and stigmas so deeply embedded in the discourse have persisted. According to Jeria (1999), IRCA "marked a high point of anti-Hispanic sentiment," in addition to the English Only movement countering bilingual education: "English language literacy is driven by labor market needs, as defined by politicians, business leaders, and educators" (Jeria, 1999). This would suggest that even if ESL adult educators have the best intentions of helping their students to adapt to the new culture and attain the needed language skills, they are still just cogs in the machine of dominant discourses (Foucault, 1990), dominant hegemony (Brookfield, 2005), and the "false generosity" of the oppressors (Freire, 2007, p. 146). Thus, as Jeria (1999) notes, "The economic exploitation of Hispanics has shaped a good deal of educational practice toward Hispanics as a group."

\section{Seekers of the American Dream and Holders of Funds of Knowledge}

Not only has exploitation historically existed in education, but also in Mexican experiences in this country in general. For immigrants who risk crossing the border without the proper paperwork, there is "the constant threat of apprehension by the INS" (Brooks, et al., 2007) and by supposed "helpers" (often coyotes who charge border crossers exorbitant fees and then exploit them on top of that). Yet many Mexicans, like the generations of immigrants to the US before them, have embraced the American Dream. Many either hear glorious tales of the good life in the US and move here to improve their lives, only to find themselves in harsh labor situations (like the laborers in La Ciudad), or they plan to come only temporarily to fulfill some financial obligation, and then return to Mexico (Brooks, et al., 2007) - contrary to "leeching and staying indefinitely" stereotypes. Overwhelmingly, though, the Mexicans who crossed the border illegally in one study did so to increase "their children's human capital" (Brooks et al., 2007), which I assume to mean their economic and cultural capital in the US. 
Again, as Freire asserts, it is important to see these cases as humans, not as abstractions. In addition, from the perspective of Moll (1994), many Mexican immigrants possess rich "funds of knowledge" (or in Bourdieu's terms, sociocultural "capital") on which to draw. Funds of knowledge "require specific knowledge of strategic importance to households" (Moll, p. 184), which implies that what knowledge and skills families consider important may differ from what educators and policy makers consider important. These skills include complex social networking far beyond what most US citizens may practice in our competitive, individualistic society, and in Mexican society, this would equal economic capital, not just social/cultural (Bourdieu). As teachers, we need to move beyond the tendency to frame our students in terms of deficit-what they lack (mainly, English and possibly related literacy and job skills) - and to recognize and highlight the strengths they bring to the classroom-lifetimes of experiences, rich linguistic resources, strong motivation, and more.

Ethnographic and sociolinguistic studies have highlighted some of these strengths. For instance, Guerra and Farr, 2002 have demonstrated that in spite of the "literacy crisis" that has been decried in the US for some time, long-term ethnographic work in Chicago with the Mexican community has shown "the creativity, resourcefulness, and substantial capacities that ordinary people demonstrate in their everyday uses of written language (p. 96). Their work may represent one of the few in-depth, long-term transnational sociolinguistic ethnographies conducted with Mexicanos outside the US Southwest. Their work clearly extends from Heath's (1983) famous studies of three communities in one town, exploring the differences between home and school literacy practices and the impact on children's success in school-but with a view toward emphasizing the strengths or "funds of knowledge" (following Moll) or "habitus" (following Bourdieu). Farr (2006) also aims to counter stereotypes homogenizing Mexicans into a single culture, studying the dialects and other indexes of the Rancheros.

Critical Social Theory (CST) offers another pedagogical approach that may tap into these funds of knowledge and enable students to overcome the oppression inherent in their situation. Leonardo (2004) describes CST as "cultivat[ing] students' ability to critique institutional as well as conceptual dilemmas, particularly those that lead to domination or oppression," and in so doing it leads to "knowledge transformation," not "knowledge transmission" (p. 11), as in the banking model that Freire rejected. It seeks to help students free themselves from oppression, and as such, may be known as "sociotherapy" (p. 13). This allusion to psychotherapy brings to mind Rollo May's (1972) Power and Innocence: A Search for the Sources of Violence, essentially a text in psychotherapy, which notes that "The passion for experience is an endeavor to include more of the self in the picture [...] One can, and ought, to reflect on experience" (p. 76). This echoes Freire's relentless call for "the people [to] act, as well as reflect, upon the reality to be transformed" (2007, p. 130). As May notes, "Inherent in power-to-be is the need to affirm one's own being" (1972, p. 137), and so again, immigrants reflecting on their own context within the broader historical context of their situation can enact "transformation." As educators, it is our responsibility to guide our students in becoming successful 
"border crossers" not only literally but metaphorically, as "creative thinkers, decision makers, and transformers of their current life situation" (Ball, 2000, p. 166).

\section{References}

Ball, A. (2000). Empowering pedagogies that enhance the learning of multicultural students. Teachers College Record, 102(6), 1006-1034.

Bartlett, L. (2005). Dialogue, knowledge, and teacher-student relations: Freirean pedagogy and theory in practice. Comparative Education Review, 49(3), 344364.

Brookfield, S. (2005). The power of critical theory for adult learning and teaching. New York: Open University Press.

Brooks, A., Womack, D., Varela, L., Madhlangobe, L., Williams, A., Rodriguez, S., \& Garcia, E. (2007). Mexican perspectives on Mexico-US immigration: Implications for adult education in the U.S \& Mexico [electronic version]. Learning in Community: Proceedings of the Joint International Conference of the Adult Education Research Conference (AERC) (48 th National Conference) and the Canadian Association for the Study of Adult Education CASAE)/l'Association Canadienne pour l'Etude de l'Education des Adultes (ACEEA) (26 ${ }^{\text {th }}$ National Conference).

Brulliard, K. (2007, August 1). English instruction touted for immigrants: Fourfold increase in spending urged. Washington Post, p. A18.

Camarota, S. (2007, November). Immigrants in the United States, 2007: A profile of America's foreign-born population. Backgrounder. Washington DC: Center for Immigration Studies.

Campano, G. (2007). Immigrant students and literacy: Reading, writing, and remembering. New York: Teachers College Press.

Castles, S. (2010). Understanding global migration: A social transformation perspective. Journal of Ethnic and Migration Studies, 36(10), 1565-1586.

Compton-Lilly, C. (2007). The complexities of reading capital in two Puerto Rican families. Reading Research Quarterly, 42(1), 72-98.

Coutin, S. B. (2003). Illegality, borderlands, and the space of nonexistence. In R. Perry \& B. Maurer (Eds.), Globalization under construction (pp. 171-202). Minneapolis: University of Minnesota Press.

De Genova, N. (2002). Migrant "illegality" and deportability in everyday life. Annual Review of Anthropology, 31, 419-447.

Farr, M. (2006). Rancheros in Chicagoacán: Language and identity in a transnational community. Austin: University of Texas Press.

Farr, M., \& Guerra, J. (1995). Literacy in the community: A study of Mexicano families in Chicago. Discourse Processes, 19, 7-19. 
Ferguson, P. (1998). The politics of adult ESL literacy: Becoming politically visible. In T. Smoke (Ed.), Adult ESL: Politics, pedagogy, \& participation in classroom \& community programs (pp. 3-15). Mahwah, NJ: Lawrence Erlbaum.

Foucault, M. (1978/1990). The history of sexuality: An introduction (vol. I). New York: Vintage Books.

Freire, P. (2007). Pedagogy of the oppressed. 30 th anniversary ed. New York: Continuum.

Gee, J. P. (1990). Social linguistics and literacies: Ideology in discourses. London: Falmer.

Guerra, J., \& Farr, M. (2002). Writing on the margins: The spiritual and autobiographical discourse of two Mexicanas in Chicago. In G. Hull \& K. Schultz (Eds), School's out! Bridging out-of-school literacies with classroom practice (pp. 96-123). New York: Teachers College/Columbia University.

Gutierrez, K., \& Orellana, M. (2006). The "problem" of English learners: Constructing genres of difference. Research in the Teaching of English, 40(4), 502-507.

Heath, S. (1983). Ways with words: Language, life, and work in communities and classrooms. Cambridge, UK: Cambridge University Press.

Jeria, J. (1999). The quest for visibility in adult education: The Hispanic experience. Directions for Adult and Continuing Education, 82, 49-65.

Kaye, J. (1996, May 27). Inalienable right? [Transcript of panel discussion]. Los Angeles: KCET-TV.

Lanteigne, B., \& Schwarzer, D. (1997). The progress of Rafael in English and family reading: A case study. Journal of Adolescent and Adult Literacy, 41(1): 36-45.

Leonardo, Z. (2004). Critical social theory and transformative knowledge: The functions of criticism in quality education. Educational Researcher, 33(6), 1118.

Lytle, S. (1993). Risky business. The Quarterly, 15(1), 20-23.

Marsh, J. (2006). Popular culture in the literacy curriculum: A Bourdieuan analysis. Reading Research Quarterly, 41(2), 160-174.

Menard-Warwick, J. (2005). Intergenerational trajectories and sociopolitical context: Latina immigrants in adult ESL. TESOL Quarterly, 39(2), 165-185.

Moll, L. (1994). Literacy research in community and classrooms: A sociocultural approach. In R. Ruddell, M. Ruddell \& H. Singer, Theoretical models \& processes of reading (4th ed.). Newark, DE: IRA. Reprinted in L600 Issues in Language Education, Section 8685 coursepack, pp. 197-207.

Ngai, M. (2004). Impossible subjects: Illegal aliens and the making of modern America. Princeton, NJ: Princeton University Press.

Nieto, S., \& Bode, P. (2008). Affirming diversity: The sociopolitical context of multicultural education. New York: Pearson. 
Perlmutter, P. (1999). Legacy of hate: A short history of ethnic, religious, and racial prejudice in America. New York: Sharpe.

Riker, D. (Dir.) (1999). The City/La Ciudad [DVD]. Originally aired on PBS.

Rollo, M. (1972). Power and innocence: A search for the sources of violence. New York: Delta.

Schiller, N., Basch, L., \& Blanc, C. (1995). From immigrant to transmigrant: Theorizing transnational migration. Anthropological Quarterly, 68(1), 48-63.

Schmidt-Camacho, A. (2008). Migrant imaginaries: Latino cultural politics in the US Mexico borderland. New York: New York University Press.

Stephen, L. (2007). Transborder lives: Indigenous Oaxacans in Mexico, California, and Oregon. Durham, NC: Duke University Press.

Stewart, D. (1993). Immigration and education: The crisis and opportunities. New York: Lexington Books.

Szelenyi, K., \& Chang, J. (2002). Educating immigrants: The community college role. Community College Review, 30(2), 55-73.

Ticktin, M. (2006). Where ethics and politics meet: The violence of humanitarianism in France. American Ethnologist, 33(1), 33-49.

Wilson, T.D. (1999). Anti-immigrant sentiment and the process of settlement among Mexican immigrants to the United States: Reflections on the current wave of Mexican bashing. Review of Radical Political Economics, 31(2), 1-26. 


\section{Book Review}

\section{Craig D. Howard}

Language Learning and Teacher Education: A Sociocultural Approach, edited by Margaret Hawkins. Clevedon, UK: Multilingual Matters, 2004, pp. vii + 197, ISBN 185359-763-5.

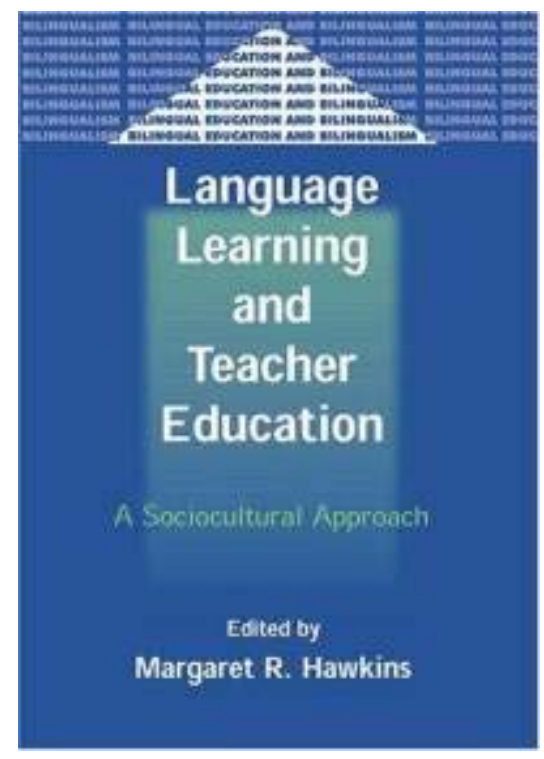

This book is a qualitative look at instructional and meta-instructional cases where pedagogical decisions revolving around modality choices are viewed in terms of social grammars, what Gee calls Discourses. Multimodal learning and social discourses are not fads; they are components of language education we must learn to reckon with if we are to empower communicative learners. The issues that these cases bring up are as prominent today as they were when the book was first published in 2004. More recent research has not replaced the issues, just dealt with progressively more complexity as new media arrive on the scene (Kress, 2010). Hawkins begins, "the role of the teacher [is] as a catalyst to ensure equal educational access and promote social change" (p. 5). This is more assumed than argued; ambitious and socially conscious statements pepper the rest of the book, providing a rational for some curricular decisions. However, what the book really sets out to do is grapple with our role in teaching, not teaching, or teaching versions of social discourses with an expanded option of tools including narratives, computermediated communication (CMC) and student-made visuals. This book accomplishes what it sets out to do; namely, provide examples of different discourses at play, and 
cases where multimodal approaches have been harnessed to provide fora for expression.

The seven chapters of the book are organized into five parts, each part containing one theme. In Chapter 1, Gee lays the ground for the rest of the book by giving a number of examples explicating Social Discourse as language distinct from our less socially informed definitions of what we study when we study language. The book hinges on Gee's distinctions; one cannot appreciate the perspectives in subsequent chapters without reading Chapter 1 . For Gee, socially uninformed views of grammar and syntax challenge for language educators because just grammar and vocabulary do not add up to language proficiency. Gee gives examples such as a teenager who recites the same opinion in different terms to her friends and to her parents, making the grammar of social discourses very clear. This is the logical expansion of communicative language teaching (CLT), getting at the heart of why communicative proficiency does not equal the grammar and syntax as stated in our textbooks (Hymes, 1972).

Gee does not ignore the elephant in the room: Does creating an environment not subservient to the dominant groups' discourse styles do more harm than good if the world outside the classroom still punishes those without dominant discourse proficiency? The rest of the text addresses this question with examples of approaches, and reflections on attempts that did, and did not, play out as authors had expected. Avoiding "reinforce[ing] cultural models that will help students fail" (p. 27) is a theme throughout the book. For example, in Chapter 5, Miller implies that teachers accustomed to making sense of L2 constructions quickly grasp students' intended meanings, but society at large is unlikely to be very understanding. Miller points out that teachers can be too coddling for students who must function in a less linguistically tolerant world. Freeman (Chapter 7) partially resolves the issue in his argument that the content we teach is the social discourse of the groups in power, and the way to bridge that is more sensitive and enlightened teacher education.

The strengths of the book are in the precedent the examples of pedagogical interventions bring to a discussion of social discourse. A hidden gem in Chapter 5 has to be the SLA concepts' chart on page 115, delineating a shift into a Discourse model understanding of SLA. On the whole, these examples and discussions of vignettes make a strong case that, on the syllabus or not, students learn quickly that student/teacher talk is quite different from student/student talk. What learners do not have are outlets for their own expressions and access to the clear, intelligible explanations of the dominant group's social grammars. The content of learning is only partially contained in the curricula we recognize and test. A curious option was presented in chapter 3 , which brings up a paradox within the whole book. Jerri Willett and his student coauthor attempted to remove the dominant discourse altogether, and ended up in a kind of reverse observer's paradox. Removing the dominant discourse helps little when, in the end, the terms of evaluation are the dominant discourse. When the teacher's voice goes unheard, important discourses 
go unheard. As with examples in other chapters, readers may conclude that recognizing the dominant discourse is helpful, but disposing of it is futile.

Where this book fails is in the discussions of multimodality. In a book that discusses multimodal approaches to accessing the discourses learners are most comfortable in, there are no figures, pictures, or examples of student work. I admit, some of the multimodal approaches are narrative and hard to capture without multimedia. While hardly as performance-focused as something like the Rassias Method (Johnston, 1983; Oller, 1993), pictures would really help readers see the methods at work. Stein (Chapter 2) and Beynon (Chapter 6) draw on similar alternative modalities without the help of visuals that would make the text an asset for practitioners. Stein attempts to grant "exchange value" to students' cultural resources by approaching language instruction through "multiple semiotic modes," namely, performed narrative (acting), and taking photographs. The discussion would gain much from a closer look at those pictures and some strategies for teachers to really put them to use.

Margaret Hawkins' examination of bulletin board class discussions exemplifies common weaknesses among the other chapters. She takes a closer look at examples of real learner discourse, but stops short of actually proposing how one might go about teaching the more effective discourses in a mediated setting. She gives up when she concludes these discourses are something we quickly pick up on, but rarely consciously recognize. When many students have excellent language skills, but lack the discourse skills needed to build rapport in mediated environments, why have there been so few attempts to teach these discourses online (Howard, 2011)? This chapter, as well as a number of the others, fails to acknowledge the extreme amount of academic freedom inherent in the different approaches. These approaches identify explorative practices only a tenured faculty member could get away with. Not all of us can turn our classrooms into workshops, include free-flowing narratives, or include open discussions in CMC spaces in an attempt to teach discourses.

This is why language educators should own, or at least read, this text. It is a link between the arguments for communicative language teaching (Canale \& Swain, 1980) and multimodal literacies (Kress, Jewitt, Ogborn \& Tsatsarelis, 2001; Kress, 2010). Particularly the first chapter provides students of language pedagogy with a concise argument for just why it is that these new literacies are important components of language teaching. It is not an easy step for a language teacher to come to terms with the concept that they are not teaching how to conjugate verbs in language $x$, but rather how to create an educated discussant in culture $y$. It is not the wrong tense that will hinder the learners' success; it's saying the wrong thing at the wrong time. This book ties the ideas of multimodal literacy to teaching in a world where correct answers are not provided on a rubric, and the punishment for wrong answers is intangible and severe. 


\section{References}

Canale, M., \& Swain, M. (1980). Theoretical bases of communicative approaches to second language teaching and testing. Applied Linguistics, 1(1), 1-47.

Howard, C. D. (2011). An instructional paradigm for the teaching of computermediated communication. Instructional Science, 39(6), 1-21. doi: $10.1007 / \mathrm{s} 11251-011-9187-0$

Hymes, D. (1972). On communicative competence. In J. B. Pride \& J. Holmes (Eds.), Sociolinguistics (pp. 269-293). Harmondsworth, UK: Penguin.

Johnston, O. W. (1983). Five years with the Rassias Method in German: A follow-up report from the University of Florida. Foreign Language Annals, 16(5), 343351.

Kress, G., Jewitt, C., Ogborn, J., \& Tsatsarelis, C. (2001). Multimodal teaching and learning: The rhetorics of the science classroom. London: Cassell.

Kress, G. (2010). Multimodality: A social semiotic approach to contemporary communication. London: Routledge.

Oller, J. W. (Ed.). (1993). Methods that work: Ideas for literacy and language teachers. Boston: Heinle \& Heinle. 